\title{
An Example Postclosure Risk Assessment Using the Potential Yucca Mountain Site
}
P. G. Doctor
A. M. Liebetrau
P. W. Eslinger
P. W. Reimus
D. M. Elwood
D. L. Strenge
D. W. Engel
J. E. Tanner
M. D. Freshley
A. E. Van Luik

June 1988 (date of work)

May 1992

Prepared for the U.S. Department of Energy under Contract DE-AC06-76RLO 1830

Pacific Northwest Laboratory

Operated for the U.S. Department of Energy

by Battelle Memorial Institute

\section{Battelle}




\title{
DISCLAIMER
}

This report was prepared as an account of work sponsored by an agency of the United States Government. Neither the United States Government nor any agency thereof, nor Battelle Memorial Institute, nor any of their employees, makes any warranty, expressed or implied, or assumes any legal liability or responsibility for the accuracy, completeness, or usefulness of any information, apparatus, product, or process disclosed, or represents that its use would not infringe privately owned rights. Reference herein to any specific commercial product, process, or service by trade name, trademark, manufacturer, or otherwise does not necessarily constitute or imply its endorsement, recommendation, or favoring by the United States Government or any agency thereof, or Battelle Memorial Institute. The views and opinions of authors expressed herein do not necessarily state or reflect those of the United States Government or any agency thereof.

\author{
PACIFIC NORTHWEST LABORATORY \\ operated by \\ BATTELLE MEMORIAL INSTITUTE \\ for the \\ UNITED STATES DEPARTMENT OF ENERGY \\ under Contract DE-ACO6-76RLO 1830
}

Printed in the United States of America

Availanie to DOE and DOE contractors from the

Office of Scientific and Technical Information, P.O. Box 62, Oak Ridge, TN 37831;

prices available from (615) 576-8401. FTS 626-8401.

Available to the public from the National Technical information Service, U.S. Department of Commerce, 5285 Port Royal Rd., Springfield, VA 22161. 
AN EXAMPLE POSTCLOSURE RISK ASSESSMENT USING

THE POTENTIAL YUCCA MOUNTAIN SITE
P. G. Doctor
A. M. Liebetrau
P. W. Eslinger
P. W. Reimus
D. M. Elwood
D. L. Strenge
D. W. Engel
J. E. Tanner
M. D. Freshley
A. E. Van Luik

June 1988 (date of work)

May 1992

Prepared for

the U.S. Department of Energy

under Contract DE-AC06-76RLO 1830

Pacific Northwest Laboratory

Richland, Washington 99352 


\section{PREFACE}

The risk analysi.s described in this document was performed for the U.S. Department of Energy's (DOE) Office of Civilian Radioactive Waste Management (OCRWM) over a 2-year time period ending in June 1988. The objective of Pacific Northwest Laboratory's (PNL) task was to demonstrate an integrated, though preliminary, modeling approach for estimating the postclosure risk associated with a geologic repository for the disposal of high-level nuclear waste. The modeling study used published characterization data for the proposed candidate site at Yucca Mountain, Nevada, along with existing models and computer codes available at that time. Some of the site data and conceptual models reported in the Site Characterization Plan published in December 1988, however, were not yet available at the time that PNL conducted the modeling studies.

The final report describing PNL's study was subsequently reviewed by OCRWM and its contractors, with the comment period extending to August 1989. At that time, DOE decided, based on the reviewers' concerns, not to proceed with comment resolution and pubiication of the document. Even though PNL's study was conducted as a demonstration of performance assessment methodology, reviewers were concerned that the results would be perceived as an actual risk assessment for the Yucca Mountain site at a time when most detailed site characterization studies had not even been initiated.

In April 1991, OCRWM requested PNL to continue publication of the document, after addressing the review comments, but without performing significant new calculations. This report provides not only a citable reference for work completed in 1988, but documentation for some of the early performance assessment studies that contribute to OCRWM's eventual approach to the risk analyses needed for the license application. New models have been developed, more site data have been collected, and new risk calculations have been initiated since this work was completed. The results contained here should be interpreted as only a demonstration of an initial stage of study for determining the risk of the proposed repository, rather than a definitive statement of risk based on comprehensive models and the most recent data. 


\section{EXECUTIVE SUMMARY}

This report was prepared by Pacific Northwest Laboratory (PNL) for the Office of Civilian Radioactive Waste Management, (OCRWM) of the U.S. Department of Energy (DOE). The study was undertaken to estimate the postclosure risk, in terms of population health effects, of a high-level nuclear waste repository at the proposed site at Yucca Mountain, Nevada.

Information on the public risk is needed to site, design, license, and operate a repository system. A literature study conducted by PNL and Brookhaven National Laboratory in Fiscal Year (FY) 1986 concluded that published information was not sufficient to develop a comprehensive estimate of population risk from the proposed repository system. The Risk Characterization Program was initiated by OCRWM in FY 1987 to develop preliminary risk estimates prior to the collection of detailed information during site characterization activities. Estimates of the postclosure risks were developed by the Performance Assessment Scientific Support Program at PNL.

The objective of the Postclosure Risks Task was to develop a technically consistent estimate of the risk, in terms of human population health effects, of a repository system at the proposed site at Yucca Mountain. The risk estimates for the repository system were developed using the latest (as of 1988) published data and technically consistent models and assumptions.

The risk estimates cover a time span of 1 million years following repository closure. Representative disruptive and intrusive events were selected and evaluated in addition to expected conditions. The estimates were generated assuming spent fuel as the waste form, and included a 11 important radionuclides from an inventory, half-life, and dose perspective. A variety of modeling assumptions and data values are incorporated into a sensitivity analysis that identified important modeling parameters.

Estimates of the number of adverse health effects caused by locating a repository at Yucca Mountain range from 36 to 181 over 1 million years. These health effects are in addition to approximately 33,600 health effects (or a risk of 0.03 health effects per year) expected from the background radiation count. The estimate of additional health effects includes the 
effect of a postulated magmatic event and climate change scenarios. Thus, the repository would account for a 0.1 to $1.0 \%$ increase in health effects over background. These estimates are very sensitive to the ground-water recharge rate through the repositary horizon, the waste form dissolution rate, and the population size. 


\section{ACKNOWLEDGMENTS}

The authors thank the numerous reviewers from the U.S. Department of Energy's (DOE) Office of Civilian Radioactive Waste Management (OCRWM) and its contractors who provided extensive review comments and helpful suggestions that improved the quality of this report. The authors also thank R. C. Arthur, C. K. Hastings, C. T. Kincaid, and J. K. Soldat at Pacific Northwest Laboratory (PNL), who provided technical reviews of the report. The authors are especially grateful to J. M. Gephart, who was responsible for editorial review and management of revisions and production of the final revised document. Thanks also go to G. M. Owen and the PNL editorial and text processing staff who assisted with the production and revisions of the document over its extended history. This study was supported by DOE under Contract DE-AC06-76RLO 1830. PNL is operated by Battelle Memorial Institute for DOE. 


\section{CONTENTS}

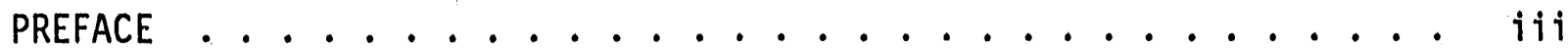

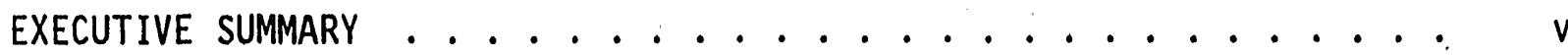

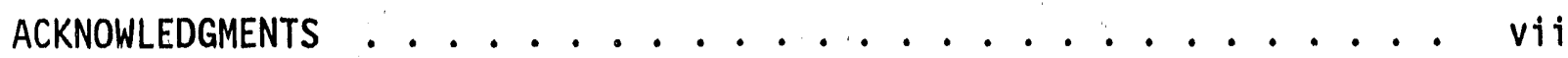

1.0 INTRODUCTION. . . . . . . . . . . . . . . 1.1

1.1 OBJECTIVE AND SCOPE OF THE RISK CHARACTERIZATION PROGRAM . • 1.3

1.2 OBJECTIVE AND SCOPE OF THE POSTCLOSURE RISKS TASK $\ldots \ldots$

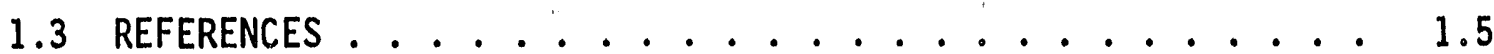

2.0 SELECTION OF DISRUPTIVE/INTRUSIVE SCENARIOS . . . . . . 2.1

2.1 STATUS OF SCENARIO DEFINITION AND SCREENING WORK . . . . 2.1

2.2 LiteratuRE REVIEW . . . . . . . . . . . . . 2.3

2.2.1 U.S. Department of Energy-Related Work . . . . . 2.3

2.2.2 U.S. Nuclear Regulatory Commission-Related Work . . 2.9

2.2.3 U.S. Environmental Protection Agency-Related Work . . 2.13

2.2.4 International Risk Assessments . . . . . . . 2.16

2.3 SCENARIO SELECTION FOR THE PACIFIC NORTHWEST LABORATORY

POSTCLOSURE RISK ASSESSMENT . . . . . . . . . . 2.20

2.3.1 Expected Conditions ............ 2.20

2.3.2 Climate Change ............. 2.21

2.3.3 Extrusive Magmatic Event . . . . . . . . 2.22

2.4 REFERENCES . . . . . . . . . . . . . . . 2.23

3.0 GEOHYDROLOGIC MODELING OF PRESENT-CASE CONDITIONS AT THE YUCCA

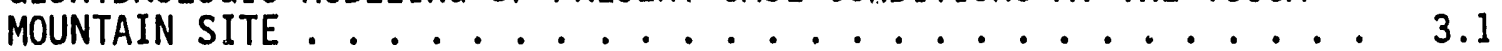

3.1 THE UNSATURATED ZONE AT YUCCA MOUNTAIN . . . . . . . 3.1

3.1.1 Description of the Unsaturated Zone at Yucca Mountain 3.1

3.1 .2 Conceptual Model Development . . . . . . . . 3.8

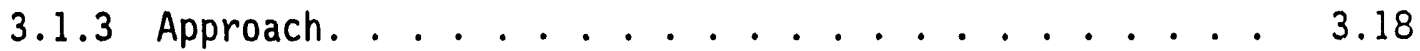


3.1 .4 Input Data . . . . . . . . . . 3.22

3.1 .5 Results . . . . . . . . . . . . . 3.35

3.2 THE SATURATED ZONE AT YUCCA MOUNTAin . . . . . . . 3.35

3.2.1 Conceptualization and Assumptions of the Hydrologic Model............... 3.39

3.2.2 Ground-Water Flow Modeling .......... 3.42

3.2.3 Discussion of Hydrologic Modeling and Travel Time

Results............... 3.64

3.3 REFERENCES . . . . . . . . . . . . . . . . 3.78

4.0 ENGINEERED BARRIERS RELEASE . . . . . . . . . . . 4.1

4.1 CONTAINMENT MODELING . . . . . . . . . . . 4.2

4.2 RELEASE MODELING . . . . . . . . . . . 4.3

4.2.1 Release Modeling for Unsaturated Media . . . . 4 4.3

4.2.2 Release Modeling for Saturated Media ...... 4.13

4.3 WASTE PACKAGE ENVIRONMENT . . . . . . . . . 4.15

4.3.1 Thermal Model ............. 4.16

4.3.2 Geochemical Model . . . . . . . . . . . 4.17

4.3.3 Hydrologic Model ............. 4. 4.20

4.4 INPUTS FOR SOURCE-TERM CALCULATIONS . . . . . . 4.21

4.4.1 Containment Failure Time Distributions . . . . . 4.21

4.4 .2 Radionuclide Data . . . . . . . . . . 4.22

4.4 .3 Spent Fuet Data . . . . . . . . . . 4.22

4.4 .4 Repository Data . . . . . . . . . . 4.24

4.5 REFERENCES . . . . . . . . . . . . . . . 4.28

5.0 FAR-FIELD GROUND-WATER-BASED TRANSPORT . . . . . . . . 5.1

5.1 CONCEPTUAL AND MATHEMATICAL MODEL $\ldots \ldots \ldots . \ldots . \ldots . \ldots$

5.2 MODEL IMPLEMENTATION . . . . . . . . . . 5.7 
5.3 INPUT DATA AND REPRESENTATIVE TRANSPORT RESULTS $\ldots \ldots . . \quad 5.9$

5.3 .1 Hydrologic Data . . . . . . . . . . 5.9

5.3.2 Retardation Data ............ . 5.10

5.3 .3 Decay Chains . . . . . . . . . . . 5.12

5.3.4 Radionuclide Source Term . . . . . . . . . 5.16

5.4 REFERENCES . . . . . . . . . . . . . . . . 5.17

6.0 DOSE MODELING FOR GROUND-WATER-BASED TRANSPORT . . . . . . 6.1

6.1 PATHWAY CONCENTRATION MODELS . . . . . . . . 6.2

6.1.1 Soil Concentration from Air Deposition . . . . 6 6.3

6.1.2 Leaf Concentration from Air Deposition ..... . 6.4

6.1.3 Concentration in Edible Plant Parts from $\ldots .5$

6.1.4 Concentration in the Soil from Irrigation Deposition .............. 6.5

6.1 .5 Leaf Concentration from Irrigation . . . . . 6.6

6.1.6 Total Uptake for Plants and Animals . . . . . 6.6

6.1.7 Total Uptake for Aquatic Foods. . . . . . . . 6.7

6.1 .8 Concentration in Sediment .......... 6.7

6.1 .9 Special Concentration Model for ${ }^{14} \mathrm{C} \ldots \ldots . . .6 .7$

6.2 PATHWAY DOSE MODELS . . . . . . . . . . . 6.8

6.2.1 Dose from Air Submersion . . . . . . . 6.8

6.2.2 Dose from Terrestrial Pathways . . . . . . . 6.9

6.2.3 Dose from Aquatic Pathways .......... 6.10

6.2.4 External Doses from Contaminated Materials . . . . 6.10

6.3 COMPUTATION OF LIFETIME EFFECTIVE DOSE EQUIVALENT . . . . 6.11

6.4 SOURCE TERMS AND DATA . . . . . . . . . . . 6.12

6.4 .1 Irrigation Water Source Term ......... 6.12 
6.4 .2 Population Data . . . . . . . . . 6.13

6.4 .3 Food Pathways Data . . . . . . . . . 6 6.13

6.4 .4 Dose Model Factors . . . . . . . . . . 6.13

6.4.5 Radionuclide Source Term . . . . . . . . . 6.14

6.5 DOSE ESTIMATES . . . . . . . . . . . . . 6.15

6.6 REFERENCES ...................... 6.17

7.0 DISRUPTIVE OR INTRUSIVE EVENTS . . . . . . . . . . . 7.1

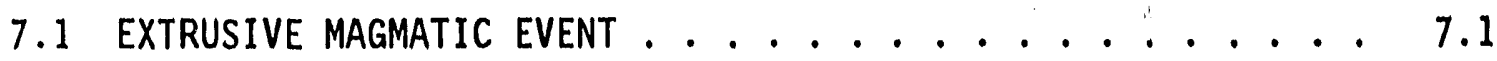

7.2 Climate change ........................ 7.3

7.3 GAS-PHASE ${ }^{14} \mathrm{C}$ RELEASE MODELING . . . . . . . . . 7.9

7.4 REFERENCES .......................... 7.10

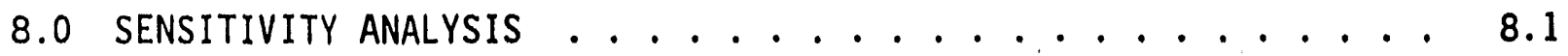

9.0 RISK ESTIMATES . . . . . . . . . . . . . . 9.1

APPENDIX A - MOISTURE RETENTION CHARACTERISTICS AND GENERAL HYDRAULIC CONDUCTIVITY DATA AND CORRESPONDING FITTED CURVES FOR

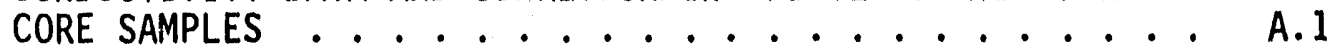

APPENDIX B - SOLUTION OF EQUATION 5.6 FOR AN ARBITRARY $\Phi(t) \ldots \ldots .1$

APPENDIX $C$ - BAND RELEASE ................ c.l

APPENDIX D - DOSE MODEL COEFFICIENTS . . . . . . . . . D. 1

APPENDIX E $-{ }^{14} \mathrm{C}$ TRAVEL TIME AT YUCCA MOUNTAIN . . . . . . . . E.1 


\section{FIGURES}

1.1 Location of Yucca Mountain Site in Southern Nevada . . . . . . 1.2

3.1 Geologic Map of Yucca Mountain . . . . . . . . . . . 3.2

3.2 Schematic Diagram of Hydrogeologic Units in the Unsaturated

Zone at Yucca Mountain............... 3.7

3.3 Idealized Hydraulic Conductivity Characteristic Curve for

Composite Continuum ................ 3.11

3.4 Boreholes Located in Yucca Mountain . . . . . . . . . . 3.13

3.5 Hydrogeologic Profile of Borehole USW G-1 . . . . . . . . 3.24

3.6 Hydrogeologic Profile of Borehole USW G-3 . . . . . . . . 3.25

3.7 Hydrogeologic Profile of Borehole USW G-4 . . . . . . . . . 3.26

3.8 Generalized Geology of the Yucca Mountain Study Area . . . . . 3.37

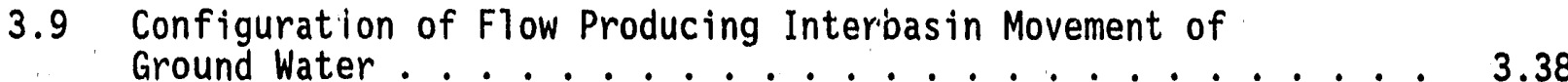

3.10 Schematic Representation of the Nevada Test Site Conceptual

Model ..................... 3.40

3.11 Schematic Representation of the Stream Tubes Used in the

Travel-Time Analyses................ 3.43

3.12 Location of the Near-Field Model . . . . . . . . . . . 3.45

3.13 Location of Study Area for the Regional or Far-Field

3.14 Contours of Hydraulic Heads Obtained from the U.S.

Geological Survey Interpretation............. 3.47

3.15 Preliminary Composite Potentiometric-Surface Map

of the Saturated Zone, Yucca Mountain . . . . . . . . . . . 3.49

3.16 Contoured Transmissivity Map for Baseline Potentiometric

Surface ..................... 3.52

3.17 Transmissivity Zonation Pattern for the Study Area . . . . . . 3.53

3.18 Correlation Between Porosity and Hydraulic Conductivity for

3.19 Location of the U.S. Geological Survey Subregional Model . . . 3.58 
3.20 U.S. Geological Survey-Interpreted Hydraulic Head Distribution for the Regional Model ................ 3.60

3.21 Model-Predicted Hydraulic Heads for Steady-State Confined Contitions .....................

3.22 Map of Kriging Error or Estimation Effort for the Regional Modei ..........................

3.23 Hydraulic Head Distribution of the Calibrated Regional Model with Stream Tubes Originating Near Well J-12 for the Far-Field Analysis

3.24 Transmissivity Distribution for the Calibrated Regional Model...........................

3.25 Modei Zcne Numbers, Parameter Groupings, Mode1 Boundary Fluxes and Transmissivities--U.S. Geological Survey Mode1 . . . . .

3.26 Location of Hydraulic Head Measurements for the U.S. Geological Survey and Pacific Northwest Laboratory Hydrologic Models . .

3.2T Kriged Potentiometric Surface Using Data from the U.S. Geological Survey Hydrologic Model .................

3.28 Map of Kriging Error for the Hydraulic Head Data from the U.S. Geological Survey Model ................

3.29 Stream Tubes Showing Direction of Ground-Water Flow from the Vicinity of Well $\mathrm{J}-12$ to Discharge Locations at Lathrop Wells and Alkali Flat, Using the Kriged Potentiometric Surface and a Constant Alluvial Porosity of Hydraulic Conductivity . . . .

3.30 Sensitivity of Calculated Transmissivity Near Yucca Mountain to Changes in Flux Boundary Conditions at Jackass Flats, Rock Valley, Ash Meadows, Western Amargosa Desert., Furnace Creek Ranch, and Frankl in Lake Playa ..... . . . . . . . . . . . .

4.1 Fractional Release Rates from Spent Fuel as a Function of Flow Rate at 1000 Years .. .. . . . . . . . . 4.12

4.2 Waste Packaye Container and Repository Average Temperatures for the Reference Nevada Nuclear Waste Storage Investigation Design

6.1 Individual Doses for the Base Case Summed Over Separate 10,000-Year Intervals.

7.1 Cumulative Doses Over 1 Million Years for a Single Individual for Different Ground-Water Recharge Rates 


\section{TABLES}

2.1 Potentially Significant Scenarios Evaluated by U.S. Department of Energy Expert Panel .................. 2.6

2.2 Scenarios Analyzed for Hypothetical Repositories in Basalt, Bedded Salt, and Tuff ................ 2.12

3.1 Hydrogeologic Units Correlated with Rock-Stratigraphic Units . . 3.6

3.2 Representative Samples for the Hydrogeologic Units . . . . . 3.23

3.3 Estimated Moisture Retention Characteristics . . . . . . . 3.31

3.4 Estimated Unsaturated Hydraulic Conductivity Parameters . . . . 3.31

3.5 Thickness and Predicted Travel Times for Different Vertical Profiles from the Base of the Disturbed Zone to the Water

Table at Yucca Mountain .............. 3.36

3.6 Hydraulic Head Data Used to Interpret Potentiometric Surface in Figure 3.14 ................... 3...48

3.7 Ground Water Levels, Yucca Mountain Area . . . . . . . . . 3.50

3.8 Estimates of Mean and Standard Deviation of Log Transmissivity for Each Zone . . . . . . . . . . . . . . . . .

3.9 Estimates of Mean and Standard Deviation of Effective

Porosity for Each Zone ....................

3.10 Hydrologic Information Used in Each of the Seven Cases for Which Uncertainty in Ground-Water Travel Time with the Local-Scale Model Was Calculated . . . . . . . . . . .

3.11 Sample Means, Standard Deviations, Coefficient of Variations, and Medians for Ground-Water Travel Times Based on Hydraulic

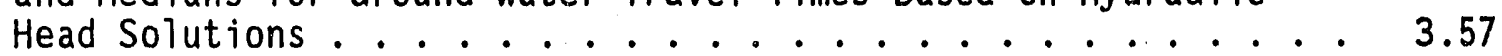

3.12 Revised Travel Time Statistics Based on Updated Saturated Thickness ................... . 3.57

3.13 Stream Tube Characteristics . . . . . . . . . . . . 3.57

3.14 Travel Times for the Far-Field Analysis Based on the Regional Model

3.15 Summary of Hydraulic Head Data in the U.S. Geological Survey Model Used in the Kriging Analysis............. 
3.16 Trave1 Times and Distances Traveled to Discharge Locations from the Vicinity uf $\mathrm{J}-12$ to Discharge Locations Lathrop

3.17 Comparison of Discharges in the Amargosa Desert: U.S. Geological

Survey Versus Pacific Northwest Laboratory Mode1 . . . . . . 3.77

4.1 Summary of AREST Code Logic for Release Rate Expressions . . . 4.9

4.2 Parameters Used in the Release Rate Analysis . . . . . . . 4.11

4.3 Assumed Reference Composition of Repository Ground Water . . . . 4.19

4.4 Radionuclide Inventory in Reference Pressurized Water Reactor Spent Fuel........................

4.5 Distribution of Key Radionuclides Used for Reference Pressurized Water Reactor Spent Fuel .................

4.6 Design Parameters for Nevada Nuclear Waste Storage Investigation Release Calculations .................

4.7 Radionuclide Parameters for Nevada Nuc' ?ar Waste Storage Investigation Release Calculations .............

5.1 Predicted Travel Times for Different Vertical

Profiles Using $0.5 \mathrm{~mm} / \mathrm{yr}$ Recharge ............ 5.5

5.2 Retardation Factors for the Transport Mde 1 . . . . . . . 5.11

5.3 Data and We11 Configurations for Mass Transport

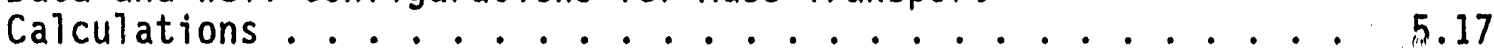

6.1 Organ Weighting Factors for the Effective Dose Equivalent . . 6.12

6.2 Terrestrial and Aquatic Pathway Data for an Average

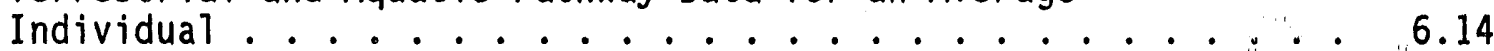

7.1 Total Activity Released in Curies from Volcanism Scenario . . . 7.2

7.2 Initial Dose Rates from Volcanism Scenario . . . . . . . . 7.3

7.3 Health Effect Incidence Rates by Organ from Volcanism Scenario . 7.4

7.4 Health Effects from Volcanism Scenario: Airborne Releases . . 7.4

7.5 Health Effects from Volcanism Scenario: Non-Airborne Releases.................... . 7.4

7.6 Health Effects from Volcanism Scenario: All Releases . . . . 7.5 
7.7 Predicted Travel Times for Different Vertical Profiles

Using $0.55 \mathrm{~mm} / \mathrm{yr}$ Recharge ............ 7.6

7.8 Thickness and Predicted Travel Times for Different Vertical

Profiles Using $0.63 \mathrm{~mm} / \mathrm{yr}$ Recharge . . . . . .... 7.6

7.9 Thickness and Predicted Travel Times for Different Vertical

Pripfiles Using $0.75 \mathrm{~mm} / \mathrm{yr}$ Recharge . . . . . . . . 7.7

8.1 Inv:ntory of Radionuclides Reaching Alkali Flat in 1 Million

Years for Different Release Assumptions ......... 8.4

8.2 Cumulative Effective Dose Equivalent as a Function of

Individual Organs for a Single Lifetime Using the Congruent

Waste Form Release Assumption ........... 8.4

8.3 Cumulative Effective Dose Equivalent as a Function of

Individual Organs for a Single Lifetime Using the Incongruent

Waste Form Release Assumption ..............

8.5 


\subsection{INTRODUCTION}

The U.S. Department of Energy's (DOE's) Office of Civilian Radioactive Waste Management (OCRWM) is developing a system for permanent disposal of spent nuclear fuel, commercial and defense-related high-level nuclear waste, and other waste that may be designated for geologic disposal by the U.S. Nuclear Regulatory Commission (NRC). The system will consist of one or more geologic repositories, a monitored retrievable storage (MRS) facility, and a transportation system to move the wastes from the waste generators to the storage and disposal facilities.

Information on the public and occupational risks produced by the waste management system is needed to site, design, license, and operate the system. A study was performed in Fiscal Year (FY) 1986 by Pacific Northwest Laboratory (PNL) (a) and Brookhaven National Laboratory (BNL). This study reviewed previous work that assessed the risks in the waste management system and used this information to develop preliminary estimates of the risks in the system. The major conclusion of this study was that published information was not sufficient to develop a comprehensive and technicaliy consistent estimate of all of the potentially important risks produced by the waste management system. Previous work did not address many potentially important risk categories and was based on a wide variety of methods, data, system designs, and key assumptions.

The OCRWM is planning a number of major risk and safety studies during the design, development, and licensing process for the waste management system. Many of these studies will be based on the detailed information being developed in the site characterization activities at the candidate repository site at Yucca Mountain, within the Nevada Test Site (NTS) in southern Nevada (Figure 1.1). Several years will be required to develop this information and perform these risk studies. Preliminary risk information is needed in the near term to help guide programmatic and design decisions that must be made before the more detailed risk studies are completed.

(a) Pacific Northwest Laboratory is operated by Battelle Memorial Institute for the U.S. Department of Energy. 


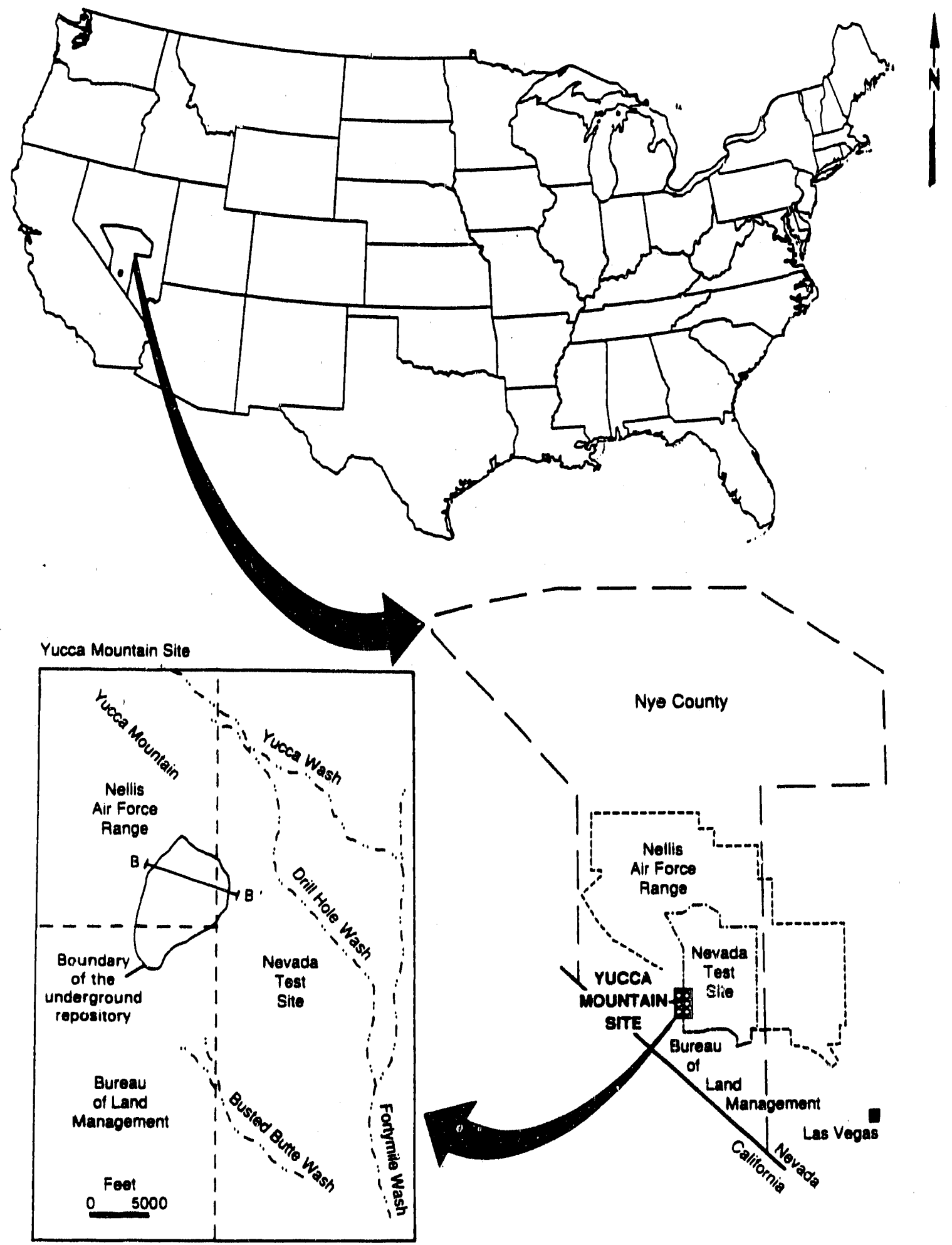

FIGURE 1.1. Location of Yucca Mountain Site in Southern Nevada 
The Risk Characterization Program was initiated by OCRWM in FY 1987 to develop this preliminary risk information. All major risk categories are being addressed: construction, operations (including transportation), decommissioning, retrieval, and postclosure. Methodologies for estimating postclosure risks are being developed by the Performance Assessment Scientific Support (PASS) Program at PNL using data and assumptions that are consistent with the other risk estimates being developed in the Risk Characterization Program. This document presents the results of a demonstration of an integrated, although preliminary modeling approach for estimating postclosure risks.

\subsection{OBJECTIVE AND SCOPE OF THE RISK CHARACTERIZATION PROGRAM}

The objective of the Risk Characterization Program was to use the best available methods, data, and system information to develop technically consistent estimates of the risks associated with storing, handling, transporting, and disposing of spent fuel and other wastes that will require disposal in geologic repositories. The scope of this study does not include development of new risk assessment codes or techniques.

The study scope is comprehensive so that the results can be used to meet a broad range of needs with in OCRWM for information on the risks in the waste management system. All potentially important risks will be estimated from a11 major system options and facility locations under active consideration by DOE. The study will address all waste categories designated for geologic disposal in the Mission Plan (DOE 1985). Spent fuel will be emphasized. Both preclosure and postclosure repository risks will be estimated. Risks will be analyzed for both the authorized and improved performance (MRS) configurations of the waste management system. The Yucca Mountain, Nevada, candidate repository site selected for site characterization will be studied along with an MRS facility and the transportation operations necessary to move the wastes through the syitem. Radiological and nonradiological health risks to both the public and facility workers will be estimated. Risks from both accidents and routine operations will be addressed. All phases of system development and operation will be analyzed including construction, operations, decommissioning, and possible retrieval operations at the repository. 


\subsection{OBJECTIVE AND SCOPE OF THE POSTCLOSURE RISKS TASK}

The objective of the Postclosure Risks Task is to demonstrate an integrated modeling approach to provide preliminary estimates of the risk, in terms of human health effects, of the postclosure repository system such as that at the proposed repository site at Yucca Mountain, Nevada. The time span covered by the calculation was initially 100,000 years after repository closure. Because the base-case risks were negligible in the first 100,000 years, the time span of the study was extended to 1 million years. Performance of the repository system is evaluated under expected conditions and selected disruptive and intrusive events. Spent fuel was assumed to be the waste form because even though the mix of waste forms for the repository has not been decided, spent fuel will be the predominant. waste form; also spent fuel provides a conservative estimate of radionuclide releases. All important radionuclides--in terms of inventory, half-life, chain decay, health effects, and U.S. Environmental Protection Agency (EPA) release limits (EPA 1985)--are evaluated. Although site characterization is an ongoing activity, published information was the source of the site data for the analyses. A sensitivity analysis was done to identify the components of the system that have the greatest effect on the risk estimates. The calculational time scale for postclosure risks, upwards of 100,000 years, as compared with only tens of years for the preclosure and transportation risks, makes it difficult to meaningfully combine postclosure risk estimates with preclosure risk estimates in the development of an integrated total system risk estimate.

The evaluation results of the scenarios and the list of disruptive and intrusive events included in the risk assessment is presented in Section 2.0. The hydrologic modeling results, which are needed to model the expected conditions, are presented in Section 3.0. Models for the release of radionuclides from the engineered barriers are presented in Section 4.0, along with release estimates for a variety of conditions. Far-field mass transport issues and results are presented in Section 5.0. Dose models for groundwater-based contamination are presented in Section 6.0. Analysis of selected 
disruptive scenarios is presented in Section 7.0. Sensitivity analys is results are presented in Section 8.0. Postclosure risk estimates are discussed in Section 9.0 .

\subsection{REFERENCES}

U.S. Department of Energy (DOE). 1985. Mission Pla,l for the Civilian Radioactive Waste Management Program. DOE/RW-005, Office of Civitian Radioactive Waste Management, Washington, D.C.

U.S. Environmental Protection Agency (EPA). 1985. "Environmental Radiation Protection Standards for Management and Disposal of Spent Nuclear Fuel, High-Level and Transuranic Radioactive Wastes." Title 40, Code of Federal Regulations, Part 191, Final Rule. 


\subsection{SELECTION OF DISRUPTIVE/INTRUSIVE SCENARIOS}

This section reports PNL's task to define a set of representative scenarios for use in a preliminary postclosure risk evaluation. Recent postclosure risk assessment literature and the Environmental Assessment (EA) (DOE 1986c) for the Yucca Mountain site are examined for the treatment of potential disruptive or intrusive event scenarios. Information from the review is used to select scenarios for evaluation.

\subsection{STATUS OF SCENARIO DEFINITION AND SCREENING WORK}

There are three major approaches currently used to identify scenarios for analysis: simulation, event trees, and expert judgment. Koplik, Kaplan, and Ross (1982) and Ross (1986) describe these concepts and review published works on them through 1985. The event-tree method for identifying scenarios has been demonstrated by Hunter (1983) and Hunter, Barr, and Bingham (1983). As Ross observed, most risk-assessment work to date has used the expertjudgment method for selecting scenarios because the event-tree method produces extremely large numbers of scenarios and scenario combinations. Simulation methods may be used to screen scenarios selected for consideration by another method, such as demonstrated by Petrie et a1. (1981), but these methods also have seen limited applications because of the lack of field data required to mathematically evaluate alternative scenarios.

Identification and evaluation of scenarios for the purpose of calculation of risk is a twofold problem. First, the specific evolution of site characteristics must be identified, and then the probability of the particular evolution of characteristics must be specified. Scenario impacts can be functions of frequency, timing, and severity. Even for a specific disruptive event, it is impossible to separately evaluate the impacts of all possible severities, times of occurrence, and frequencies of occurrence. Representative scenarios must therefore be identified so that a manageable number of severities, occurrences, and frequencies that credibly bound reasonable risks can be evaluated. As the literature survey will show, some progress has been made in identifying classes of site characteristics that 
must be examined. However, the problem of assigning probabilities to release scenarios remains largely unsolved at this time.

Hunter, Mann, and Cranwell (1985) cited a number of publications that include examples of unstated assumed probabilities, stated assumed probabilities, probabilities calculated using sophisticated mathematics and uncertain or poor data, probabilities based on geologic considerations and arguments, and probabilities based on combinations of these approaches. The purpose of the review was to make the point that no consensus exists on how to go about assigning probabilities to events with a low likelihood of uccurring.

Hunter, Mann, and Cranwell (1985) stated that they were working on the problem of assigning probabilities to scenarios on behalf of the NRC. This is of particular interest because Sandia National Laboratories (SNL) has been addressing this problem for the NRC since the late 1970s (Cranwell et al. 1982a,b). The problem is not amenable to easy or rapid solution. The purpose of the work by SNL was to evaluate the EPA standard and demonstrate a methodology for showing compliance with that standard (Pepping, Chu, and Siegel 1983a,b; Pepping et a1. 1983c; Siegel and Chu 1983). [See Ortiz and Wahi (1983) or Ortiz et al. (1984) for a more complete description and overview of this work.] This work demonstrated applications of a risk assessment methodology to hypothetical systems in basalt, bedded salt, and tuff. of interest is the conclusion by these authors that they have demonstrated a method of assessing compliance with the EPA standard "which can take into account the uncertainty of scenario frequencies. The more difficult problem of assigning realistic ranges and distributions to the scenario frequencies remains to be addressed" (Ortiz et a1. 1984). Although these authors agreed that this problem "is one of the most difficult areas in assessing compliance with the EPA standard," they are nevertheless confident that reasonable approaches have either been developed or are being developed.

Internationaliy, the prospects for the formulation of a defensible methodology for assigning probability distributions to release scenarios have fared similariy. Despite a 1980 Nuclear Energy Agency (NEA) workshop on the subject (NEA 1981), the recommendation was again made in 1985 that the NEA have a workshop or form an expert group to address methodology development for radionuclide release scenario identification and screening, and the 
assignment of probabilities and probability distributions to release scenarios (NEA 1986). The subject continues to challenge the repository risk/ performance assessment community, and some experts are pessimistic about the prospects of doing credible, technically defensible work in this area of assigning probability distributions to release scenarios, as required to show compliance with the EPA standard (Kocher et al. 1985, for example).

Finally, Ross (1986) came to a conclusion similar to that stated above, acknowledging that: "Whatever technique is used to identify scenarios, severe difficulties are encountered in assigning numerical probabilities to them."

\subsection{LITERATURE REVIEW}

A number of published preliminary performance analyses have included low-probability events. One of the earlier analyses was reported in the final environmental impact statement for high-level waste disposal (DOE 1980). A more recent analysis is reported in the EPA's background information document supporting the finat EPA standard (EPA 1985b).

\subsubsection{U.S. Department of Energy-Related Work}

\section{Generic Environmental Impact Statement}

In 1980, DOE published postclosure performance risk analyses using worst-case scenario evaluations intended to bound risks that could be expected from a repository (DOE 1980). The use of very low-probability/ high-consequence postulated events resulted in initial risk estimates sufficiently low to allow deep underground emplacement of high-level radioactive waste to be pursued as the preferred permanent disposal option (NWPA 1982).

The final generic environmental impact statement (GEIS) for the management of commercial radioactive waste contained a generic postclosure risk assessment (DOE 1980). The scope of the pastclosure risk assessment work reported in the GEIS was consistent with the need for a bounding estimate of postclosure risks from the geologic disposal activity. The scope was limited to an evaluation of the consequences of a worst-case scenario for a generic repository. The scenario consequence calculations were generic in the sense that host-rock properties were not taken into account. 
At the time the GEIS was done, different rock types being considered were basalt or granite, shale, and salt. Different inventories were assumed for each rock type, but the differences in the risks stemming from the differences in assumed inventory amounted only to a factor of two, which is not relevant in terms of the order-of-magnitude estimates being made in the GEIS.

Some highly unlikely scenarios, such as repository breach by a meteorite strike, and the solution mining of salt were treated in the GEIS. The meteor strike scenario is now considered too unlikely to be a significant contributor to risk (DOE 1985a; EPA 1986b). Some of the other scenarios evaluated in the GEIS were drilling that results in part of the contents of a waste canister being brought to the surface, and faulting that results in three possible consequence scenarios: 1) surface-water contamination by flow thro:c' a sma71 stream, 2) surface-water contamination by ground-water flow, and 3) coritaminated ground water reaching a well.

Even where probability estimates were assumed for initiating events in the GEIS, they were not considered defensible estimates by many reviewers. This is 17 lustrated by the controversy between the DOE and EPA over the probability of faulting that is documented in the footnotes of the GEIS postclosure risk assessments. The GEIS illustrates that the purpose for which a risk analysis is done determines the uses to which the results can legitinately be put.

An objection to performing preliminary estimates of postclosure repository risks stems from the lack of site-specific data needed for disruptive/ intrusive event consequence analyses. For example, DOE Office of Geologic Repositories (OGR) Project Environmental Assessments (DOE 1986a,b,c) for the three sites initially approved for characterization each reiterate the need for more work to describe credible ranges for scenario probabilities. The key to obtaining more realistic estimates of risk lies in obtaining realistic estimates of intrusive and disruptive event scenario likelihoods and consequences. 


\section{AEGIS Technology Demonstration}

From 1979 through 1981, the Assessment of Effectiveness of Geologic Isolation systems (AEGIS) Program at PNL was involved in creating a geologic simulation model (GSM), and in demonstraiing its use on a hypothetical basalt repository site in the Columbia Plateau (Petrie et a1. 1981; Dove et a1. 1982). As part of this modeling effort, a comprehensive set of disruptive and intrusive event scenarios was described and the effects of the scenarios on the geologic disposal system were quantified into interrelated submodels. The program demonstrated an application of the simulation method for evaluating consequences of scenarios given probabilities of occurrence of many system parameters. However, scenario selection for the GSM was based on a literature review and evaluation documented by Stottlemyre et al. (1980). Thus, the AEGIS Program no longer provides state-of-the-art information or methodologies to aid in the selection of scenarios and the assignment of occurrence probabilities.

\section{Environmental Assessment-Related Studies}

To aid the selection of sites to be characterized, an expert panel convened by DOE made a qualitative assessment of the degree to which repository performance will likely be affected by disruptive/intrusive events (DOE 1986d). This qualitative assessment included evaluations of the scenarios listed in Table 2.1. Of the intrusive/disruptive scenarios considered by this panel, only two to three scenarios are considered both credible and potentially significant for a repository in basalt, bedded salt, or tuff. The expected case scenario and the chance that site characterization will fail to reveal some unexpected features that will influence releases apply to all sites, of course. The expert panel also assigned some probability ranges and consequence ranges to these scenarios, but, like the probability assignments used by the EPA (1985b), this work was not meant to be used as a basis for anything but scoping preliminary risk estimates. The panel's work may be useful, however, as a discussion of current thought and a compilation of current knowledge concerning scenarios and their likelihoods and consequences. 
IABLE 2.1. Potentially Significant Scenarios Evaluated by U.S. Depariment of Energy Expert Panel (DOE 1986d)

\section{Scenario Description}

1. Nominal case (expected conditions)

2. Unexpected features in the site system

3. Repository-induced hostrock dissolution

4. Advance of a dissolution front

5. Movement of a large fault near but not inside the repository

6. Movement of a large fault inside the repository

7. Movement of a small fault near but not inside the repository

8. Movement of a small fault inside the repository

9. Movement along a large fault at least $5 \mathrm{~km}$ from the repository

10a. Extrusive magmatic event within 500 years after closure

10b. Extrusive magmatic event 500 to 10,000 years after closure

11. Intrusive magmatic event

12. Large-scale exploratory drilling

13. Small-scale exploratory drilling

14. Incomplete sealing of the shafts and the repository
Potential

$\frac{\text { Credibility or Significance }}{\text { Basalt }}$

$c(a)$

C

c

C

C

c

$\mathrm{NC}(\mathrm{b})$

NC

NC.

c

c.

NC

NC

NC

NA (c)

NC

NC

NA

NA

NA

NA

NA

NC

NA

NA

NA

NA

NC

NC

c

$N C$

NC

C

NC

NC

NC

NC

C

NC

NA

NA

NA

C

C

NA

(a) $C=$ scenario credible.

(b) $N C=$ scenario not credible.

(c) $N A=$ scenario would have insignificant release effect. 


\section{Detailed Analysis of the Environmental Assessment}

The information presented in this section was taken from volumes I and II of the Yucca Mountain EA (DOE 1986c). Because the EA cites and references the documents upon which it is based and because no primary research results are reported, no references other than the EA are provided here. The EA addresses the 10 CFR Part 960 "General Guidelines for the Recommendation of Sites for the Nuclear Waste Repositories" (DOE 1984). Subsections of the EA address individual guidelines and, in so doing, present material germane to the evaluation of scenarios.

Material given in greater detail in the EA is paraphrased and summarized. Relevant sections of the $E A$ are identified by $E A$ soction numbers in brackets. For example, [6.3.1.4] is the section entitled "Climatic changes (10 CFR 960.4-2-4)."

Climate Change. [6.3.1.4.2] Pluvial conditions have occurred and will cccur again in this area. These conditions presumably result in increased recharge and surface hydrologic features associated with raised water tables. However, the increases in recharge and water table rises plausible for Yucca Mountain are not expected to affect ground-water travel times [6.4.2.5.1], assuming matrix flow and barring fracture flow.

Preliminary paleoclimate evaluations and hydrological characterization of the Yucca Mountain area suggests that the climate change scenario should be included in considerations of risk.

Faulting. [3.2.3] Yucca Mountain lies in an area of low seismicity relative to seismic belts to the west and north. Geologic evidence suggests that the Yucca Mountain area has been relatively stable for 11 million years. Surface faulting in response to nearby nuclear weapons testing has been observed, suggesting susceptibility to faulting. Historical earthquake evidence is considered inadequate for judging maximum earthquake potentials because large earthquakes may be followed by aftershocks for a century and by relatively quiet periods of one or more thousands of years before recurring.

[6.3.1.7.5] The expectation is that movement will occur along existing faults in fractured rock, and therefore large fracture zones will be avoided in locating the repository. In addition, in the highly unlikely event that a 
canister or a small number of canisters are ruptured by movement along a fault through the repository, the lack of flowing water in the repository, combined with the small fraction of canisters that could possibly be destroyed by such an event would not result in massive waste form disso:ution. Ground-water transport times from the repository to the water table that are calculated in multiple 10,000-year intervals also ensure no significant effects from faulting in the repository. It appears that, although somewhat likely, faulting does not have the potential for causing significant risk increases at Yucca Mountain.

Magmatic Event. [6.3.1.7.3] Calculations performed for the Yucca Mountain site suggest a probability between $3.3 \times 10^{-10} / \mathrm{yr}$ and $4.7 \times 10^{-8} / \mathrm{yr}$ for 10,000 years for the occurrence of basaltic volcanism. The possibility of volcanism, in the form of basaltic eruptions, is suggested by basaltic eruptions during the Quaternary Period to the west and south of Yucca Mountain [6.3.1.7.4]. Basaltic eruptions occurred periodically in the crater Flat area west and south of Yucca Mountain during the Quaternary Period [6.3.1.7.4]. The assumption is made that Quaternary history is predictive of future events [6.3.1.7.2]. Consequences for the repository involve the physical transport of waste to the surface [6.3.1.7.1].

The probability of volcanism appears small. However, assuming that waste would be physically entrained and deposited on the surface, or perhaps dispersed into the atmosphere with fine-grained ash, the volcanic scenario should be addressed in a semi-quantitative fashion.

Human Intrusion Potential. [3.2.4.1] There is no evidence for geothermal, uranium, hydrocarbon, oil shale, or coal resources at Yucca Mountain. Althougin there is a high heat flow in the site, there is no prospect for hot water at economically attractive depths, and nearby $(20 \mathrm{~km})$ uranium occurrences are not considered attractive targets for development.

[3.2.4.2] Active silver and gold mining nearby $(20 \mathrm{~km})$, and lead and copper mining to the northwest of Yucca Mountain seem to have no bearing on the tuff site's resource potential. Yucca Mountain is not considered to have any potential for metal resource development. 
[3.2.4.3] Sand and gravel are ubiquitous, and are found at Yucca Mountain. Although clays, ceramic silica, zeolites, alunite, fluorite, and construction aggregates are extracted nearby, Yucca Mountain has none of these resources in commercially significant quantities.

[3.3.3] Ground-water resources in the Yucca Mountain subsurface drainage are being tapped by wells, largely domestic. Maximum populations supportable by Amargosa Desert ground water are estimated at less tian 20,000. It would appear that the aquifer that flows from beyond Yucca Mountain under the mountain and toward Death Valley will continue to be used for human activities in the future. A human intrusion scenario seems unlikely for the repository, as long as the intrusion is motivated by a desire to find resources other than the repository content itself.

Shaft Seal Failure. [2.1.4] The objective of the sealing activity is to use sealing materials that offer isolation properties at least equivalent to that offered by the host rock. In an unsaturated, fractured, and porous medium, it should not be difficult to seal shafts with a medium of roughly equivalent properties to those of the host rock. It is difficult to postulate a scenario in which a sealed shaft at Yucca Mountain could become a preferential pathway for radionuclide transport when net flux of ground water appears to be downward.

\subsubsection{U.S. Nuclear Regulatory Commission-Related Work}

The NRC recently published its proposed amendments (NRC 1986) to its final rule on the disposal of high-level radioactive waste and spent nuclear fuel (NRC 1983). In these proposed amendments, which serve to conform the NRC rule to the final EPA standard, there is a discussion of the NRC's intent concerning the assignment of probabilities to scenarios (processes and events) resulting in releases to the accessible environment:

The Commission will require an extensive and thorough investigation of relevant processes and events, but will require analyses of the probability and/or consequence of each only to the extent necessary to determine its contribution to the overall probability distribution...Generally, categories of processes and events that can be shown to have a likelihood of less than one chance in 10,000 over 10,000 years, along with categories of processes and events that otherwise can be shown not to change the remaining probability distribution of cumulative release significantly, need not receive further analysis. 
Based on this statement, the likelihood of a significant-release occurrence needs to be described in terms of a probability distribution. According to the NRC (1986), conservative bounding calculations may be performed when no consensus can, be reached on this probability distribution. The approach of using bounding calculations may mean assigning a scenario probability at, or near, unity and including the process or event in the consequence probability distribution. This approach of assigning a unit probability to a scenario has been used in some of the preliminary risk assessments done to date.

Modeling results based on assuming a probability of one for scenarios of unknown likelihood are scoping or worst-case analyses. They address only release consequences given the occurrence of certain postulated, but unlikely, events and processes. Calculation of an overall repository risk estimate requires combining the consequences of many scenarios. The procedure for the combination of consequences makes use of the probability of occurrence of different scenarios. Assigning a probability of one to a. scenario requires the inconsistent modeling assumption that only one scenario is of interest.

The most comprehensive recent risk assessment work is probably that done by SNL in 1983, which included results of simplified repository performance analyses that addressed the EPA standard's cumulative release limits (EPA 1985a). The three reports that describe these simplified analyses for hypothetical basalt, salt, and tuff repositories, respectively, are by Pepping, Chu, and Siegel (1983a,b) and Siegel and Chu (1983).

The probiem presented by the general inability to specify probabilities for scenarios is reflected in these three SNL studies of hypothetical repository performance. For the basalt site it is suggested that uncertainty in scenario probabilities may be addressed through an assumed probability distribution for each scenario (Pepping, Chu, and Siegel 1983a). Study of the likelihood of exploratory drilling at Yucca Mountain is recommended to aid in the determination of the safety of that location as a repository site (Siegel and Chu 1983). Finally, the hypothetical salt repository evaluation 
(Pepping, Chu, and Siegel 1983b) concludes that a practical difficulty in addressing the EPA standard is the inability to assign meaningful probabilities to scenarios.

Table 2.2 summarizes the scenarios evaluated by Ortiz and Wahi (1983). The judgments in Table 2.2 agree with, those in Table 2.1. The one exception is the magmatic event in Table 2.1, thought to be credible for Yucca Mountain, that was not analyzed by Ortiz and Wahi (1983). Thus, it appears that for all intents, the DOE expert panel came to the same conclusions regarding the credibility of disruptive/intrusive scenarios for the three firstrepository sites as the group at SNL did in their evaluations for the NRC.

Pepping, Chu, and Siegel (1983i) discuss three possible sources of information for the assignment of probabilities for scenarios: 1) If a process can be shown to be stochastic in nature, an analyst may be able to assign a probability based on observations of that process, e.g., Donath and Cranwel1 (1981) attempted to use this approach for faulting by analysis of data describing existing fault densities and stress states; 2) hictorical data may be useful for extrapolation into the future, particularly with respect to exploratory drilling; and 3 ) in the absence of the detailed understanding or the appropriate records necessary for either of the above sources, expert judgment must be relied on. The Delphi method was cited as one way, among many, to formalize expert judgment. No example was given, but the Basalt Waste Isolation Project has used the Delphi method in its preliminary attempt to address scenario selection in its EA (Davis et al. 1983; Roberds, Plum, and Visca 1984; DOE 1986a). Pepping, Chu, and Siegel (1983a) stressed the implicit need for expert judgment in evaluating either stochastic observations or historical data.

For the hypothetical repository in tuff (Siegel and Chu 1983), the selected scenarios represent different ways in which the changes or the unknowns in the site's properties could affect radionuclide releases. Each scenario was modeled as an anticipated event and was evaluated separately. There was no way to assign comparative values to the likelihood of sorption, leach-rate-limited or solubility-limited dissolution processes, or 
TABLE 2.2. Scenarios Analyzed for Hypothetical Repositories in Basalt, Bedded Salt, and Tuff (Ortiz and Wahi 1983)

\begin{tabular}{|c|c|c|c|}
\hline Host Medium & Basalt & Bedded Salt & Tuff \\
\hline Scenario 1 & $\begin{array}{l}\text { Routine release with } \\
\text { no disruption. }\end{array}$ & $\begin{array}{l}U \text {-tube formed by, a } \\
\text { failed shaft seal } \\
\text { and one or more } \\
\text { boreholes; water } \\
\text { originates from and } \\
\text { returns to primary } \\
\text { aquifer. }\end{array}$ & $\begin{array}{l}\text { No retardation in } \\
\text { any fractured } \\
\text { layers or (Case B) } \\
\text { rock matrix diffu- } \\
\text { sion in fractured } \\
\text { layers. }\end{array}$ \\
\hline Scenario 2 & $\begin{array}{l}\text { Fractures in dense } \\
\text { basalt. }\end{array}$ & $\begin{array}{l}\text { U-tube formed by two } \\
\text { or more boreholes; } \\
\text { water originates and } \\
\text { returns to primary } \\
\text { aquifer. }\end{array}$ & $\begin{array}{l}\text { Rock matrix diffu- } \\
\text { sion and vertical } \\
\text { gradient unaffected } \\
\text { by thermal pulse: } \\
\text { leach-limited or } \\
\text { (Case B) mixing-cell } \\
\text { source models. }\end{array}$ \\
\hline Scenario 3 & $\begin{array}{l}\text { Borehole connection } \\
\text { to upper aquifer; } \\
\text { mixing cell source } \\
\text { model. }\end{array}$ & $\begin{array}{l}\text { U-tube formed by } \\
\text { failed shaft seal } \\
\text { and one or more } \\
\text { boreholes; water } \\
\text { originates from and } \\
\text { returns to secondary } \\
\text { aquifer. }\end{array}$ & $\begin{array}{l}\text { Retardation in some } \\
\text { fractured layers due } \\
\text { to zeolites. }\end{array}$ \\
\hline Scenario 4 & $\begin{array}{l}\text { Borehole connection } \\
\text { to upper aquifer; } \\
\text { leach limited; } \\
10^{-4} \text { to } 10^{-7} \text { per } \\
\text { year. }\end{array}$ & $\begin{array}{l}\text { U-tube formed by two } \\
\text { or more boreholes; } \\
\text { water originates and } \\
\text { returns to secondary } \\
\text { aquifer. }\end{array}$ & $\begin{array}{l}\text { Retardation in por- } \\
\text { ous vitric or } \\
\text { devitrified tuff in } \\
\text { some fractured } \\
\text { layers. }\end{array}$ \\
\hline Scenario 5 & $\begin{array}{l}\text { Borehole connection } \\
\text { to upper aquifer; } \\
\text { leach limited; } \\
10^{-5} \text { to } 10^{-7} \text { per } \\
\text { year. }\end{array}$ & $\begin{array}{l}\text { Canister direct hit; } \\
\text { rapid and direct } \\
\text { movement of radio- } \\
\text { nuclides to surface. }\end{array}$ & $\begin{array}{l}\text { Same as Scenario } 1 \\
\text { and } 1 \mathrm{~B} \text {, but with a } \\
91.4-\mathrm{m}(300-\mathrm{ft}) \\
\text { rise in the water } \\
\text { table. }\end{array}$ \\
\hline Scenario 6 & (None.) & $\begin{array}{l}\text { Brine pocket } \\
\text { penetration. }\end{array}$ & $\begin{array}{l}\text { No retardation in } \\
\text { any fractured } \\
\text { layers, accessible } \\
\text { environment } 12.9 \mathrm{~km} \\
\text { (8 mi) away. }\end{array}$ \\
\hline
\end{tabular}


other processes. Therefore, the report on tuff by Siegel and Chu (1983) did not address the assignment of probabilities to scenarios.

In terms of evaluating scenarios, however, Pepping et al. (1983) evaluated a salt repository with regard to both the EPA cumulative release standard and the health-effects consequences. The objective of the study was to perform a preliminary total system risk assessment, including intrusive and disruptive events, to demonstrate the use of existing analytical tools in showing compliance with the EPA standard. The EPA standard was in draft form when the Pepping et al. work was performed.

Uncertainty and sensitivity were addressed by Pepping et a1. (1983) through parameter variation exercises. The methodology was found to be most sensitive to gross features such as onset of release, rate of release, and inventory. The simple source-term model was, therefore, an important determinant of the nature of the results. Output scatter was relatable to the ranges assumed for the input parameters. Onset of release, on the other hand, was a function of the timing of the events that initiated the intrusive/disruptive scenario.

The Pepping et al. (1983) study results have been questioned in terms of the realism of the system description, the scenarios analyzed, and the applicability of the models used. These questions were partly addressed in a study done for the office of Nuclear Waste Isolation (INTERA 1985) in which the two scenarios with the highest modeled consequences were re-analyzed.

Significantly lower consequences were predicted in the INTERA (1985) study, which illustrates the importance not only of including significant scenarios in a risk analysis, but also of selecting realistic system and scenario characteristics that are defensible. As these studies indicate, risk assessment is an iterative process that will continue to evolve as sitespecific data become avallable from a site characterization program.

\subsubsection{U.S. Environmental Protection Agency-Related Work}

In the generic risk assessment by Smith et a1. (1982), which helped the EPA formulate its 40 CFR Part 191 standard, a number of scenarios were considered: drilling, faulting, breccia pipes (salt), volcanoes, and meteorite strikes. In the final environmental impact statement by DOE (1980), a 
worst-case scenario of a meteorite strike that breached the repository was also evaluated. The meteorite strike scenarto has since been eliminated as needing consideration by the EPA's 40 CFR Part 191 (EPA 1985a,b), which puts a limit on the scenarios that need to be considered in addressing the EPA standard. Scenarios that need not be considered include those that have a probability of less than 1 in 10,000 of occurring over 10,000 years and those for which there is a reasonable expectation that the remaining probability distribution of cumulative releases would not be significantly changed by their omission. These criteria are identical to those proposed by the NRC (1986), as cited above, and were qualitatively applied in the DOE (1986d) effort that created Table 2.1.

The EPA and its contractors have done a number of risk assessments in support of the development of the 40 CFR Part 191 (EPA 1985a), specifically, to help define the EPA standard's quantitative limits on 10,000-year cumulative radionuclide releases into the accessible environment. These risk assessments are described by Smith et a1. (1982) and in EPA (1985b).

The final repository performance standard developed by EPA (1985a) is based on the acceptability of a cumulative release to the accessible environment resulting in 1000 health effects over 10,000 years from a 100,000 metric-ton of heavy metal (MTHM) repository. This particular level of acceptable risk was based on risk assessments of uranium ore bodies (Williams 1980). These studies estimated the health effects produced from the uranium ore. The final standard was within the range of the results reported in these studies. The standard was set at a level that would result in public consequences at or below the level that could have been expected had the uranium never been mined (EPA 1985a).

The 1982 EPA risk assessments (Smith et a1. 1982) attempted to bound risks for hypothetical repositories in basalt, granite, bedded salt, domed salt, and shale. Although the properties of these rock types were used to an extent, the purpose was to provide insight into the generic standard that was being developed for application to any repository in any rock type. No effort was made, therefore, to simulate the actual locations DOE was considering as candidates for repositories. 
In the supporting documents published by EPA (Smith et al. 1982; Smith, Fowler, and Goldin 1982), the population risks from the undisturbed generic repositories were based on estimates of radionuclide releases through an aquifer into a river. The use of ground water as a direct water supply was not considered, and a generic river was assumed for each generic site. Irrtgation with contaminated river water and human intrusion scenarios brought radionuclides to the soll surface. Resuspension of radionuclides deposited on land surfaces was considered in the consequence calculations. Pathways in which the river and air sources deposited materials in the oceans were also examined. All of these sources of radionuclides were then analyzed for dose contributions through applicable food chains.

In 1985, EPA reported revised estimates of risks from generic repositories in basalt, bedded salt, tuff, and granite. These revised risk estimates contained results of parameter varlation studies. These results (EPA 1985b) underscored the importance of improved models for pathway and dose analyses. The very low-probability meteorite and volcano scenarlos were also not included because their risk contributions were negligible. These judgments are compatible with the judgments made by the DOE (1986d) as shown in Table 2.1.

In terms of uncertainties, both EPA risk analyses (Smith et al. 1982; EPA 1985b) 1isted the use of generic assumptions, estimated parameters, and simplified models as significant sources of uncertainty. Both analyses contained results of parameter variation studies. The EPA (1985b) parameter variation results underscored the importance of the assumed waste-form "leach rate" in the modeling and that host-rock permeability was generally more important to the determination of risk than were reasonable variations in retardation and solubility numbers. Whether or not there was fracture flow rather than just matrix flow in unsaturated tuff was found to be a very important consideration.

The EPA (1985b) study evaluated human intrusion for the basalt, bedded salt, and tuff repositories. Human intrusion consequences were highest for the bedded salt repository, lower for the basalt repository, and near negligible for the tuff repository. Considering the conservatism of these analyses, this is in essential agreement with the judgment of DOE (1986d). 
Human intrusion into the Yucca Mountain site for the purpose of locating natural resources is considered highly unlikely. In the case of deliberate intrusion, it seems reasonable to assume that a future generation deliberately excavating the rock (presumably to extract the radioactive material) will also be sufficiently skilled to cope with the hazards. This judgment parallels that of the Swedish (SKBF 1983), SWiss (NAGRA 1985), and Canadian (Wuschke et a1. 1981) programs.

\subsubsection{International Risk Assessments}

Internationally, the prospects for the formulation of a defensible methodology for assigning probability distributions to release scenarlos have fared no better than in the United States. Selected international risk assessments are revfewed in this section.

\section{Canadian Risk Assessment for a Generic Crystalline Repository}

The most recent Canadian risk assessment was reported by Wuschke et al. (1985). The report describes the methods being developed and presents pre1 iminary results. This is the second safety assessment for the Canadian program. The first, a very preliminary and conservative assessment, was pub7 ished by Wuschke et a1. in 1981 .

The purpose of Wuschke et a1. (1985) was to evaluate the performance assessment methodology and to provide information for the design and planning of a deep geologic repository. Ultimately, these assessments are to be used to predict the impact of the disposal system on the human environment.

The Canadian safety assessment is iimited to a preliminary determination of the maximum annual dose equivalent to an individual. Collective dose may be addressed in subsequent studies. The individual of interest is representative of a population living its entire life in the area where radionuclides reach the ground surface.

The basis for the Canadian performance calculations consists of a number of detailed considerations evaluated in their system model SYVAC (SYstems Variabllity Analysis Code). SYVAC is a stochastic systern model composed of three main modular submodels: vault, geosphere, and biosphere. In the more recent work, an improved version of SYVAC called SYVAC2-C is used to generate 
a probabilistic estimate of aoses to the maximally exposed individual from a repository containing CANDU spent fue1.

The blosphere modeling assumed a number of pathways. Well, lake, and agricultural land exposure scenartos were considered assuming present-day conditions. Doses were calculated for a reference group of individuals who have eaten plant, animal, and aquatic foods that are exposed to contaminated ground or surface waters, and have drunk contaminated ground or surface waters. No disruptive events were considered in the analyses.

Parameter values were input as distributions and stochastically sampled for each calculation. Each realization was called i scenario, which meant a possible variation of the expected case. The results of the assessment indicated 1) there were no consequences for tens of thousands of years after disposal; 2) out of 1000 scenarlos analyzed using a Monte Carlo parameter selection method to define each case, only $7 \%$ resulted in doses greater than $1.8 \mathrm{mrem} / \mathrm{yr}$ ( $1 \%$ of background dose); 3) ${ }^{129}$ I was the predominant dose contributor (It was the only radionuclide that produced an annual dose greater than $0.1 \mathrm{mrem} / \mathrm{yr}$ in any scenario.); 4) the geosphere was the most important and effective barrier; 5) the highest doses resulted from using a contaminated well as the source of household water (Again, 129 I was the largest contributor to dose; the second largest was ${ }^{99} \mathrm{Tc}$. The only other source of importance was the ingestion of terrestrial plants. This source ranked second if a well was the household water source, and first if the lake was the household water source.); and 6) all doses greater than $30 \mathrm{mrem} / \mathrm{yr}$ were given by the well scenario. About $95 \%$ of the lake scenario results were below $1 \%$ of background.

The Canadian safety assessment work did not evaluate disruptive or intrusive event scenarlos. However, it lllustrates that uncertainty or even a known, but large, distribution in pararieter values is important in calculating expected risks to maximally exposed individuals. The importance of the assumed biosphere pathway scenario even for the expected repository performance case is also well illustrated. 
The Canadian risk assessment does not address disruptive events except to state that ice age glactation is quitg likely, and could disrupt the surface and geosphere flow systems. Glaclal advance and retreat could also stress the vault through regional subsidence and rebound. The problems related to the inclusion of disruptive and intrusive scenarios and their consequences in a risk assessment have not been explicitly addressed, however, limiting the utility of this work for the present PNL study.

\section{Swedish Risk Assessments for a Generic Crystall ine Repository}

Of interest are the series of safety assessments by the Swedish Nuclear Fuel Supply Company, Division KBS, which were done to evaluate the concept of high.level waste disposal in stable crystalline rock formations. The latest of these safety assessments is known as the KBS-3 report (SKBF 1983), which reviews and recalculates the KBS-3 work carried out by SKI, the Swedish nuclear power inspectorate (Andersson, Kjellbert, and Forsberg 1984). The SKI recalculation is, in essence, a regulatory review of the KBS-3 work.

The purpose of the KBS-3 safety assessments is to show that the concept of deep geologic disposal is safe, thus addressing a regulatory requirement of the Swedish government.

The scope of the postclosure assessments includes the expected performance of the total disposal system in terms of release rates and doses to individuals. The basis for the KBS-3 assessment, according to its reviewers (Andersson, KJellbert, and Forsburg 1984; NAGRA 1985), consists of a number of conservative assumptions and overestimates of doses. As pointed out by Andersson, KJellbert, and Forsberg (1984), however, there is much uncertainty in the current knowledge of some very basic aspects, such as the hydrology, of the system described in KBS-3, and therefore the conservatism seems warranted.

The KBS-3 safety assessment (SKBF 1983) has been favorably reviewed in detail by the U.S. National Academy of Sciences and by the SKI, the Swedish nuclear regulatory authority. In the SKI calculations done by Andersson, Kjellbert, and Forsberg (1984), the KBS-3 case was redone using slightly different, somewhat more conservative, values for some parameters. 
The inclusion or exclusion of phenomena such as matrix diffusion in a risk assessment for a fractured host-rock repository is of great interest to the U.S. program. The KBS-3 work also quantitatively addressed some unlikely events and conditions, including early waste package containment fallure, oxidizing rather than reducing conditions at depth, and the potential effects of colloids and complexants in the ground water. Events that could cause substantial changes in geology, hydrology, or geochemistry over the next million years were discounted through qualitative arguments, however. Thus, the lack of quantitative assessments of intrusive or disruptive event scenarios in the preliminary work performed to date limits the utility of this swedish work for the present PNL study.

\section{Swiss Risk Assessment for a Generic Crystalline Repository}

The Swiss National Cooperative for the Storage of Radioactive Waste (NAGRA) has published the results of its safety assessment for a hypothetical repository in crystalline rock in Switzerland. The English language summary of their report (NAGRA 1985) was consulted for this review.

The NAGRA safety studies address a governmental requirement to show that the population will not be exposed to unreasonable risks from the final disposal of radioactive wastes. The continued operation of Swiss nuclear power plants depends on the demonstration of a permanent, safe disposal method for all categories of radioactive waste (NAGRA 1985).

The scope of the NAGRA safety studies is very similar to the scope of the Swedish safety analysis: an evaluation of disposal system safety using a deterministic modeling approach and realistic, yet conservative, parameter values describing a generic crystalline rock site. The endpoint is a dose rate (mrem/yr) that represents the total dose equivalent integrated over 50 years following radionuclide intake.

This risk assessment is of interest because it purports to be a realistic assessment of expected repository performance. There was no quantitative inclusion of intrusive or disruptive event scenarios, and this limits the utility of this Swiss work for the present PNL study. A qualitative discussion of likely intrusive and disruptive event consequences was included, however, in which the reasons were given for expecting low or 
inconsequential risk effects for the particular type of generic northern Switzerland deep crystalline rock repository location modeled.

\subsection{SCENARIO SELECTION FOR THE PACIFIC NORTHWEST LABORATORY POSTCLOSURE RISK ASSESSMENT}

The literature reviewed included work performed on behalf of the DOE, the EPA, the NRC, and selected international programs. With the exception of climate change scenarios, none of the work evaluated was in any significant way out of harmony with the selections of significant by the DOE expert panel (DOE 1986d," Therefore, the scenarios listed in Table 2.1 are representative of previous work. Even though there are longer iists in the literature, e.g., IAEA (1983), the list is as comprehensive as or more comprehensive than any provided by the other risk assessments cited.

A qualitative estimate of the range of unexpected conditions, based on generic considerations, was made by the DOE expert panel (DOE 1986d).

However, these conditions cannot be quantitatively considered until specific data have provided further support for their plausibility. If identified, they will become part of the base case. No unexpected conditions will be addressed in the PNL study.

As a result of the literature review, however, it became apparent that the time span of interest in the risk assessment determined, to an extent, whether a given scenario was credible. Hence, the Table 2.1 scenarios were evaluated and modified as necessary to furnish a representative sample of those considered to be important in terms of the PNL risk assessment time span of interest, which exceeds 100,000 years. Review of the literature and consideration of the time span difference between the DOE (1986d) effort and the PNL risk task resulted in the following three scenarios being chosen for evaluation of postclosure risks: 1) expected conditions, 2) climate change, and 3 ) extrusive magmatic event. A more detailed rationale for inclusion of these scenarios is given subsequently.

\subsubsection{Expected Conditions}

The nominal (base case) scenario defines the stored waste, the repository, and its geohydrologic setting at the time of closure. Data are 
lacking for the development of models to fully describe the geohydrologic setting, and thus, this scenario. This scenario considers the existing site characteristics and conditions and deals with the expected effects caused by the emplacement of the waste, the release of radionuclides from the engineered barrier system, and transport through the natural barriers away from the repository.

The present site hydrologic system properties are not yet fully characterized and will not be until further site-specific data are collected. Until these data are available, the conceptual model of the geologic and hydrologic setting will be based on more regional-scale and preliminary data of the type contained in the $E A$.

Thus, the base case uses the baseline data existing under present conditions, with the repository and waste in place, and considers undisturbed repository conditions beyond the time of waste package failure.

\subsubsection{Climate Change}

The DOE expert panel included climate change in its description of the expected case. Although climate changes are likely to occur, especially over a 100,000-year period, the magnitude and effects of these changes are not at a11 certain. Changes may include flowpath geometry and discharge point location, for example, which may result in changes in the conceptual model and its mathematical description. On the other hand, changes may only include minor, temporary perturbations to the far-field flow system.

Because of these uncertainties, addressing climate change as part of the expected case seems problematic in that it suggests that whatever is done to model the expected case adequately addresses climate change. This may or may not be the case, depending on the magnitude and duration of the climate change. Thus, for the PNL risk assessment task, climate change is considered separately from the expected case.

Climate changes can be reasonabiy expected to occur over the 100,000-year period after closure. Various authors have posiculated worldwide changes over tens of thousands of years that could lead to cooler conditions and a trend toward enlargement of glaciers and/or reestablishment of continental ice sheets in North America. It is generally accepted that the 
extent of ice cover from renewed glaciation within the next 100,000 years will probably be confined to the areas that were covered by ice during the Pleistocene. Because the Yucca Mountain site was not covered by ice during the Pleistocene, it is believed unlikely that it will be covered during any renewed continental glaciation during the next 100,000 years, and direct loading effects are not considered. The possibility of a higher world mean temperature from increased atmospheric carbon dioxide is not considered.

A change to a more pluvial climate in the future would cause changes in both infiltration and recharge volumes. Yucca Mountain is topographically high with respect to the washes and drainageways surrounding it, and with the water table 200 to $300 \mathrm{~m}$ below the proposed repository level, increased precipitation is not likely to raise the saturated zone boundary this distance. However, as precipitation increases, some increase in recharge would occur from direct precipitation over the surface of the repository. The water table beneath the repository would rise some amount, and the travel times through the unsaturated and saturated zones would decrease. The effects of the increased precipitation through the approximately $300 \mathrm{~m}$ of material above the repository need to be investigated. The saturated zone would rise toward the surface in the closed basins of the area, perhaps forming lakes, and the ground-water discharge zones would move upward along the topographic slope of the land surface where the discharge zones intersected it. The resulting shorter flow-path lengths and increase in gradients would affect travel times. Estimates of ground-water travel times obtained for a range of increased recharge rates indicate that travel times will be within acceptable ranges for higher recharge rates, i.e., travel times would still greatly exceed regulatory limits of 1000 and 10,000 years.

\subsubsection{Extrusive Magmatic Event}

The extrusive magmetic scenario was postulated as magma rising from an underlying source through the earth's crust as a thin, elongated dike, which intersects a fraction of the waste packages and transports the waste to the land surface with the magma. The possibility of a Strombolian type explosive eruption that could entrain waste within an eruptive cloud of ash/gas may also be considered as an alternative scenario. According to the DOE expert panel, this scenario is possible but unlikely at the Yucca Mountain site. 
The annual probability cited for volcanic disruption within the approximately $10-\mathrm{km}^{2}$ repository was estimated to be $2.9 \times 10^{-8} / \mathrm{yr}$. The scenario was judged to have a probability of $5 \times 10^{-8}$ of occurring during the next 500 years, with a range of $5 \times 10^{-6}$ to $10^{-10}$ over 500 years. The same event occurring between 500 and 10,000 years was estimated to have a probability of $10^{-6}$ with a range of $10^{-4}$ to $10^{-10}$.

Yucca Mountain is within an active tectonic area: faults bound the repository; the site lies adjacent to seismically active areas; and there is evidence of Quaternary volcanism within the geologic setting. Based on the age range and distribution of cinder cones in Crater Flat, just west of the site, the DOE expert panel decided that volcanism is only barely credible at the Yucca Mountain site (DOE 1986d). The age range suggests that there may be a probability of greater than 1 in 10,000 of an extrusive magmatic event over the next 10,000 years. This scenario is considered credible and is therefore evaluated in the PNL risk assessment.

\subsection{REFERENCES}

Andersson, K., N. A. Kjellbert, and B. Forsberg. 1984. Radionuclide Migration Calculations with Respect to the KBS-3-Concept. Technical Report SKI 84:1, Swedish Nuclear Power Inspectorate (SKI), Stockholm, Sweden.

Cranwe11, R. M., R. V. Guzowski, J. E. Campbe11, and N. R. Ortiz. 1982a. Risk Methodology for Geologic Disposal of Radioactive Waste: Scenario Selection Procedure. NUREG/CR-1667, prepared by Sandia National Laboratories for the U.S. Nuclear Regulatory Commission, Washington, D.C.

Cranwel1, R. M., J. E. Campbe11, J. C. Helton, R. L. Iman, D. E. Longsine, N. R. Ortiz, G. E. Runkle, and M. J. Shortencarier. 1982b. Risk Methodology for Geologic Disposal of Radioactive Waste: Final Report. NUREG/CR-2452, prepared by Sandia National Laboratories for the U.S. Nuclear Regulatory Commission, Washington, D.C.

Davis, J. D., A. K. Runchar, N. A. Baumann, and 0. L. Ervin. 1983. Delphi Analysis of Radionuclide Release Scenarios for a Nuclear Waste Repository at the Hanford Site, Washington State. RHO-BW-ST-42P, Rockwell Hanford Operations, Richland, Washington.

DOE. See U.S. Department of Energy.

Donath, F. A., and R. M. Cranwe11. 1981. "Probabilistic Treatment of Faulting in Geologic Media." In Mechanical Behavior of Crustal Rocks: The Handin Volume, pp. 231-241. Geophysical Monographs No. 24, American Geophysical Society, Washington, D.C. 
Dove, F. H., C. R. Cole, M. G. Foley, F. W. Bond, R. E. Brown, W. J. Deutsch, M. D. Freshley, S. K. Gupta, P. J. Gutknecht, W. L. Kuhn, J. W. Lindberg, W. A. Rice, R. Schalla, J. F. Washburn, and J. T. Zellmer. 1982. AEGIS Technology Demonstration for a Nuclear Waste Repository in Basalt. PNL-3632, Pacific Northwest Laboratory, Richland, Washington.

Hunter, R. L. 1983. Preliminary Scenarios for the Release of Radioactive Waste from a Hypothetical Repository in Basalt of the Columbia Plateau. NUREG/CR.3353, prepared by Sandia National Laboratories for the U.S. Nuclear Regulatory Commission, Washington, D.C.

Hunter, R. L., G. E. Barr, and F. W. Bingham. 1983. Scenarios for Consequence Assessments of Radioactive-Waste Repositories at Yucca Mountain. Nevada Test Site. SAND82-1227, Sandia National Laboratories, Albuquerque, New Mexico.

Hunter, R. L., C. J. Mann, and R. M. Cranwell. 1985. Determining Probabilities of Geologic Events and Processes. SAND85-0024C, Sandia Nationa 7 Laboratories, Albuquerque, New Mexico.

INTERA Technologies, Inc. 1985. Preliminary Analysis of Scenarios for Potential Human Interference for Repositories in Three Salt Formations. BMI/ONWI-553, INTERA Technologies, Inc, prepared for the Office of Nuclear Waste Isolation, Battelle Memorial Institute, Columbus, Ohio.

International Atomic Energy Agency (IAEA). 1983. Concepts and Examples of Safety Analys is for Radioactive Waste Repositories in Continental Geological Formations. Safety Series, No. 58, Vienna.

Kocher, D. C., E. D. Smith, G. D. O'Kelley, and A. L. Sjoreen. 1985. "A Perspective on Demonstrating Compliance With Standards for Disposal of High-Level Radioactive Wastes." Radioactive Waste Management and the Nuclear Fuel cycle 6:1-18.

Koplik, C. M., M. F. Kaplan, and B. Ross. 1982. "The Safety of Repositories for Highly Radioactive Wastes." Rev. Modern Phys. 54:269-310.

NAGRA. 1985. Project Gewahr 1985. Nuclear Waste Management in Switzerland: Feasibility Studies and Safety Analyses. Project Report NGB 85-09 (English Condensed Version of Project Reports 85-01 through 85-08). NAGRA, National Cooperative for the Storage of Radioactive Waste, Baden, Switzerland.

Nuclear Energy Agency (NEA). 1981. Proceedings of the Workshop on Radionuclide Release Scenarios for Geologic Repositories, Paris, 8-12 September 1980. Nuclear Energy Agency, Organization for Economic Cooperation and Development, Paris. 
Nuclear Energy Agency (NEA). 1986. Proceedings of the NEA Workshop on System Performance Assessments for Radioactive Waste Disposal, Paris, 22-24 October 1985. Nuclear Energy Agency, Organization for Economic Cooperation and Development, Paris.

"Nuclear Waste Policy Act of 1982" (NWPA). Public Law 97-425. U.S. Code, Tit7e 42, Sec. 10101-10226 (January 7, 1983).

NRC. See U.S. Nuclear Regulatory Commission.

Ortiz, N. R., and K. K. Wahi. 1983. Executive Summary. Vol. 1 of Technical Assistance for Regulatory Development: Review and Evaluation of the Draft EPA Standard 40 CFR 191 for Disposal of High-Level Waste. NUREG/CR-3235, prepared by Sandia National Laboratories for the U.S. Nuclear Regulatory Commission, Washington, D.C.

Ortiz, N. R., K. K. Wahi, M. S. Y. Chu, and M. D. Siegel. 1984. "Review and Evaluation of the Draft EPA Standard (40 CFR 191)." In Waste Management '84, Vol. 1, pp. 401-410. University of Arizona, Tucson, Arizona.

Pepping, R. E., M. S. Y. Chu, and M. D. Siegel. 1983a. A Simplified Analysis of a Hypothetical Repository in a Basalt Formation. Vol. 2 of Technical Assistance For Regulatory Development: Review and Evaluation of the Draft EPA Standard 40 CFR 191 for Disposal of High-Level Waste. NUREG/CR-3235, prepared by Sandia National Laboratories for the U.S. Nuclear Regulatory Commission, Washington, D.C.

Pepping, R. E., M. S. Y. Chu, and M. D. Siegel. 1983b. A Simplified Analysis of a Hypothetical Repository in a Salt Formation. Vol. 4 of Technical Assistance for Requlatory Development: Review and Evaluation of the Draft EPA Standard 40 CFR 191 for Disposal of High-Level Waste. NUREG/CR-3235, prepared by Sandia National Laboratories for the U.S. Nuclear Regulatory Commission, Washington, D.C.

Pepping, R. E., M. S. Y. Chu, K. K. Wahi, and N. R. Ortiz. 1983. Risk-Analys is Methodology for Spent-Fuel Repositories in Bedded Salt. NUREG/CR-2402, prepared by Sandia National Laboratories for the U.S. Nuclear Regulatory Commission, Washington, D.C.

Petrie, G. M., J. T. Zellmer, J. W. Lindberg, and M. G. Foley. 1981. Geologic Simulation Model for a Hypothetical Site in the Columbia Plateau. PNL-3542, Pacific Northwest Laboratory, Richland, Washington.

Roberds, W. J., R. J. Plum, and P. J. Visca. 1984. Proposed Methodology for Completion of Scenario Analys is for the Basalt Waste Isolation Project. RHO-BW-CR-147 P, Rockwel1 Hanford Operations, Richland, Washington.

Ross, B. 1986. "Scenarios in Performance Assessment of High-Level Waste Repositories." Radioactive Waste Management and the Nuclear Fuel Cycle $7(1): 47-61$. 
Siegel, M. D., and M.S.Y. Chu. 1983. A Simplified Analys is of a Hypothetical Repository in a Tuff Formation. Vol. 3. of Technical Assistance for Regulatory Development: Review and Evaluation of the Draft EPA Standard 40 CFR 191 for Disposal of High-Level Waste, NUREG/CR-3235, prepared by Sandia National Laboratories for the U.S. Nuclear Regulatory Commission, Washington, D.C.

Swedish Nuclear Fuel Supply Company (SKBF). 1983. Safety. Vol. IV of Einal Storage of Spent Nuclear Fuel - KBS 3. Division KBS (Karnbrans-lesakerhet), Stockholm, Sweden.

Smith, C. B., D. J. Egan, Jr., W. A. Williams, J. M. Gruhlke, C-Y. Hung, and B. L. Serini. 1982. Population Risks From Disposal of High-Level Radioactive Wastes in Geologic Repositories. EPA 520/3-80-006 Draft Report, U.S. Environmental Protection Agency, Washington, D.C.

Smith, J. M., T. W. Fowler, and A. S. Goldin. 1982. Environmental Pathway Models for Estimating Population Risks from Disposal of High-Level

Radioactive Wastes in Geologic Repositories. EPA 520/5-80-002 Draft Report, U.S. Environmental Protection Agency, Washington, D.C.

Stottlemyre, J. A., R. W. Wallace, G. L. Benson, and J. T. Zellmer. 1980. Perspectives on the Geological and Hydrological Aspects of Long-Term Release Scenario Analyses. PNL-2928, Pacific Northwest Laboratory, Richland, Washington.

U.S. Department of Energy (DOE). 1980. Final Environmental Impact Statement. Management of Commercially Generated Radioactive Waste. DOE/EIS-0046F, Vol. I of 3, U.S. Department of Energy, Office of Nuclear Waste Management, Washington, D.C.

U.S. Department of Energy (DOE). 1984. "U.S. Department of Energy, 10 CFR Part 960, Nuclear Waste Policy Act of 1982; Recommendation of Sites for Nuclear Waste Repositories." Final Siting Guideline. 49 Fed. Reg. 47714-47770 (December 6, 1984).

U.S. Department of Energy (DOE). 1986a. Environmental Assessment, Reference Repository Location, Hanford Site, Washinaton. DOE/RW-0070, Vols. 1 and 2, U.S. Department of Energy, Office of Civilian Radioactive Waste Management, Washington, D.C.

U.S. Department of Energy (DOE). 1986b. Environmental Assessment, Deaf Smith County Site, Texas. DOE/RW-0069, Vols. 1 and 2, U.S. Department of Energy, Office of CiviTian Radioactive Waste Management, Washington, D.C.

U.S. Department of Energy (DOE). 1986c. Environmental Assessment, Yucca Mountain Site, Nevada Research and Development Area, Nevada. DOE/RW-0073, Vols. 1 and 2, U.S. Department of Energy, Office of Civilian Radioactive Waste Management, Washington, D.C. 
U.S. Department of Energy (DOE). 1986d. A Mult lattribute Ut 1 lity Analys is of Sites Nominated for Characterization for the First Radioactive-Waste Repository - A Decision-Alding Methodology. DOE/RW-0074, Chapter 3 and Appendixes B, C and D. U.S. Department of Energy, Office of Civilitan Radioactive Waste Management, Washington, D.C.

U.S. Environmental Protection Agency (EPA). 1985a. "Environmental Protection Agency, 40 CFR Part 191, Environmental Standards for the Management and Disposal of Spent Nuclear Fuel, High-Level and Transuranic Radioactive Wastes." 50 Fed. Reg. 38066-38089 (September 19, 1985), Final Rule.

U.S. Environmental Protection Agency (EPA). 1985b. High-Level and Iransuranic Radioactive Wastes. Background Information Document for Final Rule. EPA 520/1-85-023, U.S. Environmental Protection Agency, Washington, D.C.

U.S. Nuclear Regulatory Commission (NRC). 1983. "U.S. Nuclear Regulatory Commission, 10 CFR Part 60, Disposal of High-Level Radioactive Waste in Geologic Repositories - Technical Criterta." 48 Fed. Reg. 28194-28229 (June 20, 1983).

U.S. Nuclear Regulatory Commission (NRC). 1986. "U.S. Nuclear Regulatory Commission, 10 CFR Part 60, Disposal of High-Level Radioactive Waste in Geologic Repositories; Conforming Amendments." (Proposed Rule) 51 Fed. Reg. 22288-22301 (June 19, 1986).

Williams, W. A. 1980. Population Risks From Uranium Ore Bodies. EPA 520/3-80-009. Office of Radiation Programs, U.S. Environmental Protection Agency, Washington, D.C.

Wuschke, D. M., K. K. Mehta, K. W. Dormuth, T. Andres, G. R. Sherman, E. L. J. Rosinger, B. W. Goodwin, J. A. K. Reid, and R. B. Lyon. 1981. Post-Closure Assessment. Volume 3 of Environmental and Safety Assessment Studies for Nuclear Fuel Waste Management. TR-127-3, Atomic Energy of Canada Ltd., Whiteshell Nuclear Research Establishment, Pinawa, Manitoba.

Wuschke, D. M., P. A. Gillespie, K. K. Mehta, W. F. Heinrich, D. M. LeNeveu, V. M. Guvanesen, G. R. Sherman, D. C. Donahue, B. W. Goodwin, T. H. Andres, and R. B. Lyon. 1985. Second Interim Assessment of the Canadian Concept for Nuclear Fuel Waste Disposal. Post-Closure Assessment. AECL-8373-4, Atomic Energy of Canada, Ltd., Whiteshell Nuclear Research Establishment, Pinawa, Manitoba. 


\subsection{GEOHYDROLOGIC MODELING OF PRESENT-CASE CONDITIONS \\ AT THE YUCCA MOUNTAIN SITE}

\subsection{IHE UNSATURATED 7.ONE AT YUCCA MOUNTAIN}

\subsubsection{Description of the Unsaturated Zone at Yucca Mountain}

\section{Physical Setting}

The Yucca Mountain site is located within a broad desert region known as the Great Basin (DOE 1986). The Great Basin is characterized by predominantly linear mountain ranges and valleys. The basins and intervening mountain ranges of the Great Basin strongly influence the climate, vegetation, and surface drainage of local areas. Most precipitation falls in the cooler mountainous terrain, whereas the lower basins are warmer and drier. The annual precipitation at the NTS is less than $15 \mathrm{~cm}$. The higher mountain ranges generally support contferous forests, while the basins and lower mountain ranges such as Yucca Mountain (Figure 3.1) are covered with sparse desert vegetation. Few streams or rivers flow out of the region.

\section{Physical Characteristics}

Yucca Mountain is a prominent group of north-trending, fault-block ridges that extend southward from Beatty wash on the northwest to U.S. Highway 95 in the Amargosa Desert. The terrain at Yucca Mountain is controlled by high-angle normal faults and eastward-tilting volcanic rocks. Slopes are steep $\left(15^{\circ}\right.$ to $\left.30^{\circ}\right)$ along the western side of Yucca Mountain and along some of the valleys that cut into the more gently sloping $\left(5^{\circ}\right.$ to $\left.10^{\circ}\right)$ eastern side of the mountain.

The climate at the Yucca Mountain site varies with elevation. Lower elevations at Yucca Mountain are typical of southwestern desert regions, with hot summers, mild winters, and 1 imited amounts of precipitation. Higher elevations experience less severe summer temperatures and greater, but still 1 imited amounts of precipitation. The temperature at Yucca Mountain fluctuates between wide limits under predominantly clear skies and low relative humidity. Summer temperatures in excess of $38^{\circ} \mathrm{C}$ are common, as are winter temperatures below $0^{\circ} \mathrm{C}$. 


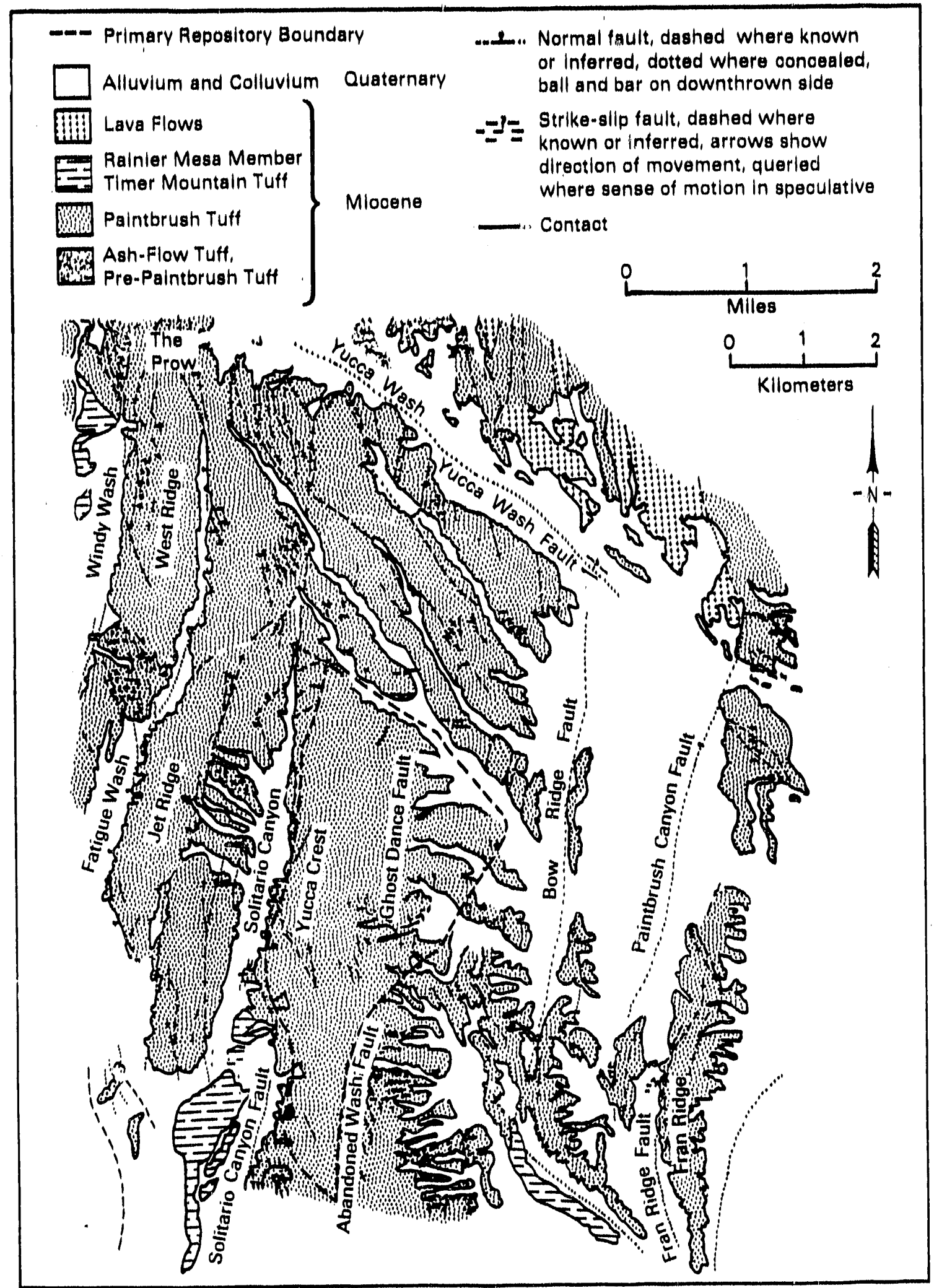

FIGURE 3.1. Geologic Map of Yucca Mountain. Approximate outline of primary repository area indicated by dashed line (modified from DOE 1988) 


\section{Yucca Mountain Geology}

The reglonal stratigraphy of the area around Yucca Mountain is characterized by four major rock groups (DOE 1986). The first and oldest of these groups, the Precambrian, crystalline rocks, is not exposed in the vicinity of Yucca Mountain, but is expected to be present at depth. The second group, consisting of Upper Precambrian and Paleozoic sedimentary rocks, is present at the surface about $15 \mathrm{~km}$ east of Yucca Mountain. These sedimentary rocks, primarlly carbonates, are present in the saturated zone beneath Yucca Mountain.

The third major group, consisting of Tertiary volcanic rocks, occurs at Yucca Mountain in at least the upper $2000 \mathrm{~m}$ of the stratigraphic section. These volcanic rocks are present above the water table at Yucca Mountain and consist primarily of rhyolitic ash-flow tuffs, with smaller amounts of dacitic lava flows and flow breccias, and minor amounts of tuffaceous sedimentary rocks and air-fall tuffs. These tuffs, where welded, are fractured. The fourth group consists of uppermost Tertiary and Quaternary alluvium and unsorted debris-flow deposits in channels that are cut into the uppermost layers of volcanic rocks at Yucca Mountain.

The group of Tertiary volcanic rocks in the unsaturated zone consists of four major stratigraphic units. The uppermost and youngest unit is the Timber Mountain Tuff, underlain by the Paintbrush Tuff, the tuffaceous beds of the Calico Hills, and the Crater Flat Tuff. Older tuffs exist below the water table and the Crater Flat Tuff at Yucca Mountain. The total thickness of these older tuffs is not known. The volcanic tuffs at Yucca Mountain originated from calderas near the mountain. The most prominent, Timber Mountain Caldera, was the source for the Timber Mountain Tuff.

The Timber Mountain Tuff occurs at only a few locations at Yucca Mountain. The Timber Mountain Tuff is a moderately welded, devitrified tuff that grades downward into a nonwelded vitric, tuff at the base.

The Paintbrush Tuff consists of four members. From youngest to oldest, the subunits of the Paintbrush Tuff are the Tiva Canyon Member, the Yucca Mountain Member, the Pah Canyon Member, and the Topopah Spring Member. The Tiva Canyon Member forms the caprock for Yucca Mountain and has a moderately 
to densely welded, devitriffed central portion, underlatn by a less densely welded vitric zone. The thickness of the Tiva Canyon Member at Yucca Mountain ranges from 0 to more than $50 \mathrm{~m}$. The Yucca Mountain Member is a simple cooling unit with nonwelded to partially welded zones, and ranges in thickness from 0 to $36 \mathrm{~m}$. The Pah Canyon Member is a simple ash-flow cooling unit with nonwelded to partially welded zones at Yucca Mountain, and ranges in thickness from 11 to $83 \mathrm{~m}$. The Topopah Spring Member, which contains the horizon being considered as the potential host rock for the repository, is about $350 \mathrm{~m}$ thick at Yucca Mountain. The Topopah Spring Member is a compound-cooling unit consisting of four distinct zones from top to bottom: a nonwelded to densely welded, generally vitric tuff; a moderately to densely welded, devitrified tuff that accounts for most of the total thickness of the member; a basal vitrophyre; and a vitric tuff grading downward from welded to nonwelded. The densely welded portions of the Paintbrush Tuff are highty fractured.

The tuffaceous beds of Calico Hills is an informal name for tuffaceous rocks that may have originated from a currently obscured volcano near the north end of the Calico Hills, east of Yucca Mountain. The unit ranges in thickness from 90 to $150 \mathrm{~m}$ at Yucca Mountain and consists primarity of nonweided ash-flow tuffs, numerous thin tuffaceous sedimentary beds, and minor air-fall tuffs. In the northern and eastern portions of Yucca Mountain, the unit is typically zeolitic, having undergone a low-temperature, low-pressure alteration to zeolite minerals. In the southern and western portions of the mountain, the Calico Hills unit has not been altered to zeolite minerals and is predominantiy vitric.

The Crater Flat Tuff, beneath the tuffaceous beds of Calico Hills, consists of three members. The uppermost subunit, the Prow Pass Member, ranges from $130 \mathrm{~m}$ to $180 \mathrm{~m}$ thick at Yucca Mountain and consists mostly of partially to moderately welded tuff. Some bedded, reworked, and densely welded materials occur in its central part, and zeolitic ash-fall tuffs occur at its base. The Bullfrog Member ranges in thickness from 100 to $160 \mathrm{~m}$ and consists predominantly of partialiy to moderately welded ash-flow tuffs with 
isolated, thin, densely welded layers. The Tram Member ranges from 150 to $330 \mathrm{~m}$ thick and consists of densely welded ash-flow tuffs, some of which are devitriffed and zeolitic.

The hydrogeologic units defined in DOE (1988) for Yucca Mountain are listed in Table 3.1. These units are also correlated with rock-stratigraphic units in Table 3.1. The tuffs have been organized into functional units that minimize the thermal, mechanical, and hydrologic property variability within each unit (K1avetter and Peters 1986).

The structural development of southern Nevada and southeastern Californita has been long and complex. Crustal extension and associated volcanism, basin and range style faulting, and alluvial filling of intervening valleys during Cenozoic time have obscured the relationship of older, regional structural features. Structural features at Yucca Mountain include local faults related to caldera collapse and longer faults related to basin and range deformation. Rock strata in the primary area for the proposed repository at Yucca Mountain (Figure 3.2) are gentiy tilted to the east at about $5^{\circ}$ to $8^{\circ}$ and are offset by several north-trending high-angle faults, down-dropped chiefly to the west, that created several large, north-trending structural blocks.

The depth to the regional water table within the boundary of the proposed primary repository area at Yucca Mountain ranges from about 500 to 750 $m$ (DOE 1986). Within the primary repository area, the local water table slopes to the southeast, from an elevation of $800 \mathrm{~m}$ to as $10 \mathrm{w}$ as $730 \mathrm{~m}$ above mean sea level. The water table ranges from 200 to $400 \mathrm{~m}$ below the proposed repository horizon.

Most of the annual precipitation, approximately $150 \mathrm{~mm}(5.9 \mathrm{in}$.$) , that$ falls at Yucca Mountain is returned to the atmosphere by evapotranspiration (DOE 1986). A small portion of the precipitation that falls on Yucca Mountain is thought to percolate through the unsaturated zone at an estimated average rate of $0.5 \mathrm{~mm} / \mathrm{yr}$ or less (Montazer and Wilson 1984). However, the actual rate, although not currently known, is probably episodic and uneven $1 y$ distributed over the surface of Yucca Mountain. 
IABLE 3.1. Hydrogeologic Units Correlated with Rock-Stratigraphic Units

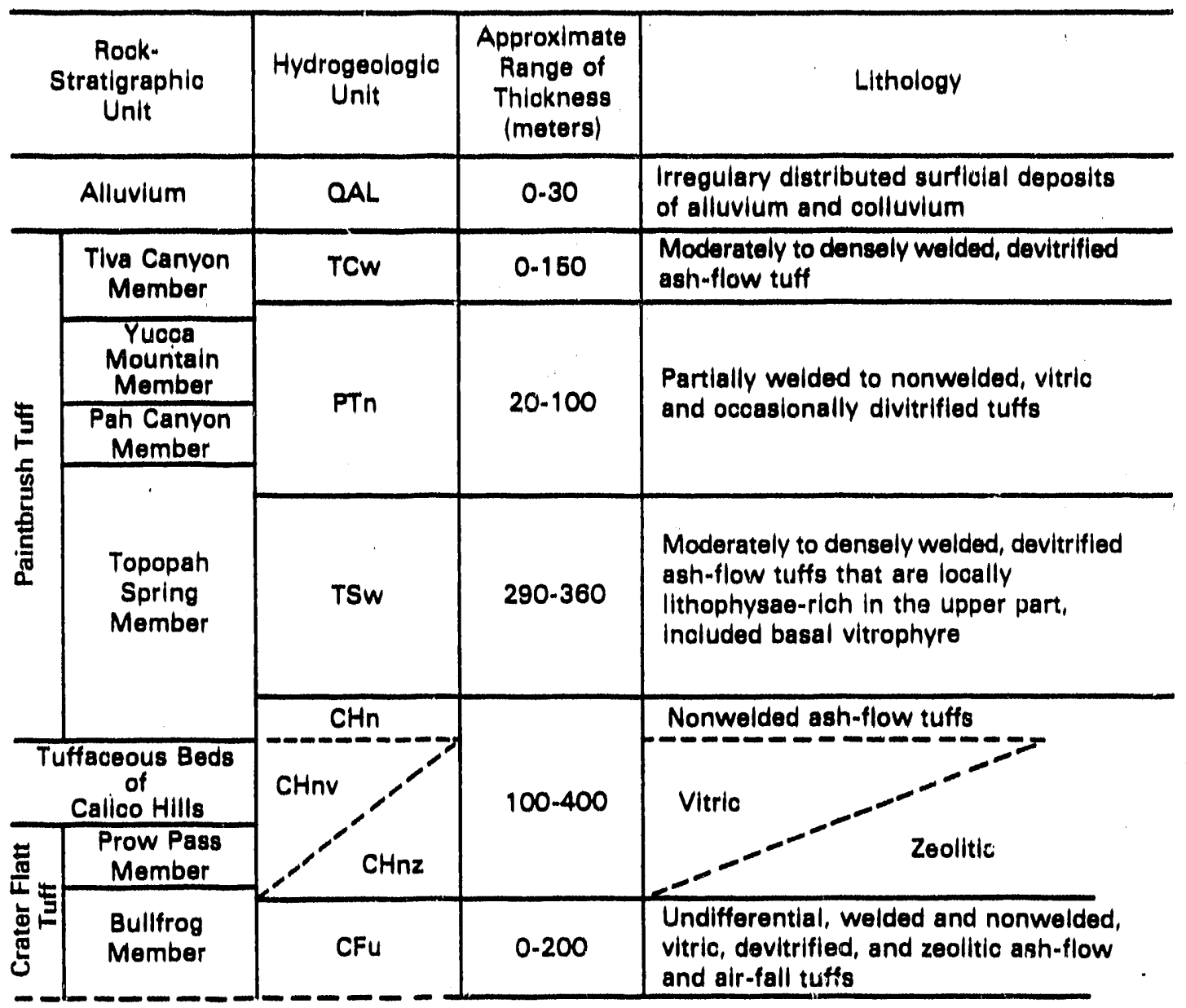

The moisture content of the layered volcanic tuffs in the unsaturated zone at Yucca Mountain generally increases with depth, but can vary both within and between stratifications (Jacobson, Freshley, and Dove 1985; Peters, Gauthier, and Dudley 1986). Reported saturations, which represent the ratio of moisture content to porosity of the tuff matrix, range from 34 to $96 \%$ (DOE 1988). Several wells have been instrumented in the unsaturated zone at Yucca Mountain and are being monitored for matric potentials. The results of this monitoring are preliminary in nature. The matrix porosity of the volcanic tuffs in Yucca Mountain varies between 10 and $44 \%$. The tuffs typically exhibit low saturated matrix hydraulic conductivities, ranging in order of magnitude from $10^{-7}$ to $10^{-12} \mathrm{~m} / \mathrm{s}$ (Klavetter and Peters 1986). 


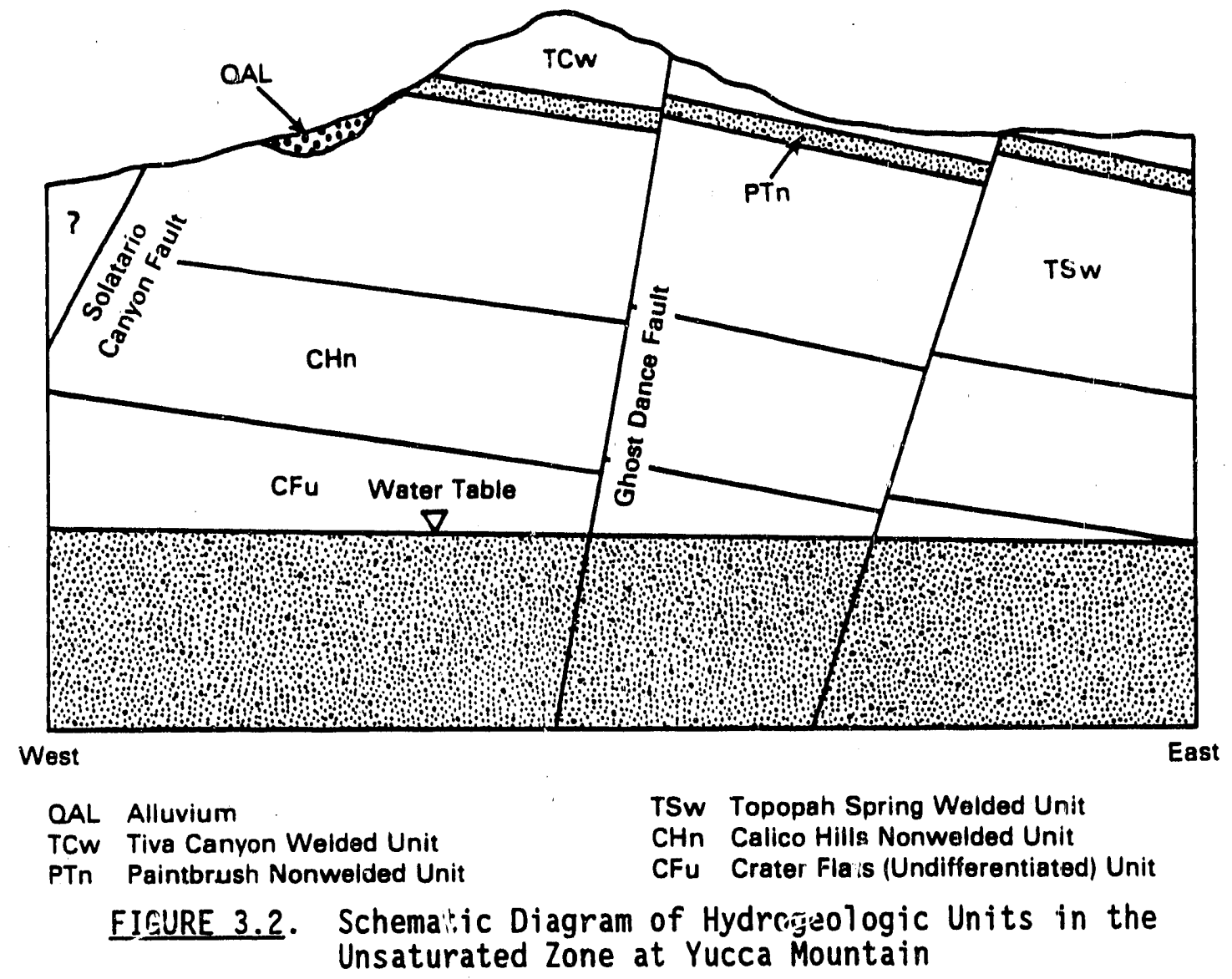

The source of moisture in the unsaturated zone at Yucca Mountain is net infiltration of precipitation. Net infiltration refers to the quantity of water that enters the unsaturated zone beyond the root zone of plants where it is available for evapotranspiration. Temporal variations of net infiltration are expected to be attenuated with depth in the uppermost few tens of meters in the unsaturated zone at Yucca Mountain (DOE 1988). Slow temporal variation of the moisture flux at any horizon is expected to occur only in response to long-term climatic changes. Net infiltracion and recharge at Yucca Mountain also varies spatially, depending on elevation, hydrogeologic properties, and flow processes within the unsaturated zone. Methods for determining natural and artificial infiltration rates have been outlined in DOE (1988).

The physics of moisture movement in the thick, unsaturated fractured tuffs of Yucca Mountain is complex, and only preliminary conceptual models are available (Montazer and Wilson 1984; Wang and Narasimhan 1985; Klavetter and Peters 1986; DOE (1988). The preliminary conceptual models are derived 
from preliminary data, from principles of unsaturated flow, and from 1 iterature. Adequate data are presently lacking to test the conceptual models of unsaturated flow at Yucca Mountain. Little direct information on matric potential and the recharge rate in Yucca Mountain is currently available.

\subsubsection{Conceptual Model Development}

The conceptual model of the unsaturated zone at Yucca Mountain is summarized in DOE (1988). The hydrogeologic framework for the conceptual model consists of the eastward-tilted Yucca Mountain block bounded on the west and east by high angle normal faults. The eastward-dipping hydrogeologic units consist of welded and nonwelded volcanic tuffs with contrasting hydraulic properties. The upper hydrologic boundary of Yucca Mountain is the land surface where flux occurs as net infiltration across the boundary from precipitation. The lower hydrologic boundary is the water table.

Steady-state moisture flow conditions are assumed for all but a thin interval of the unsaturated zone near the 1 and surface. In this interval, temporal variations of infiltration are assumed to be attenuated within several tens of meters.

The qualitative features of the conceptual model of the unsaturated zone at Yucca Mountain are summarized beiow (Montazar and Wilson 1984; al so DOE 1988). These features are described in order from the land surface downward to the water table. Most of these features are not currently supported by direct measurements or direct data, but the SCP for Yucca Mountain addresses the appropriate measurements.

Moisture is assumed to enter the unsaturated zone as net infiltration below the plant-root zone. This moisture movement may occur primarily as liquid-water flow in the fractures of the Tiva Canyon welded tuff. Subsequent uptake by capillary forces into the matrix of the Tiva Canyon and the unwelded Paintbrush Tuff units is assumed to attenuate the fracture flow before the Topopah Spring welded unit is reached.

Lateral movement of water is possible in the Tiva Canyon welded tuff at the contact with the underlying nonwelded portion of the Paintbrush Tuff. 
This lateral movement may occur as a result of 1) efficient fracturedominated flow in the Tiva Canyon welded unit at high recharge rates, and 2) capillary barrier effects that may prevent water from moving into the Paintbrush Tuff nonwelded unit with its relatively higher saturated hydraulic conductivities.

Both vertical and lateral water movement may be possible in the relatively high-conductivity matrix of the nonwelded Paintbrush Tuff. Lateral flow in the nonwelded Paintbrush Tuff may occur as a result of intrinsic anisotropy of this unit and the low matrix hydrautic conductivity of the underlying Topopah Spring welded unit.

Moisture movement in the Topopah Spring welded unit is assumed to be essentially vertical. Flow is assumed to occur in the matrix at a flux less than $0.5 \mathrm{~mm} / \mathrm{yr}$ (approximately the average saturated hydraulic conductivity of the Topopah Spring unit) and in the fractures at fluxes greater than that. Lateral flow may be possible in the Topopah Spring welded tuff at the contact with the underlying nonwelded $\mathrm{Calico} \mathrm{Hills}$ unit. The conditions under which this is possible depend on the magnitude of the flux through the Topopah Spring welded tuff and whether the underlying Calico Hills Tuff is the lowconductivity zeolitic facies or the relatively higher-conductivity vitric facies.

Moisture movement in both the vitric and zeolitic Calico Hills unit is assumed to be predominantly vertically downward through the matrix, continuing directly to the water table or into the Crater Flat undifferentiated tuffs. This is based on the following assumptions: 1) steady-state flow conditions, 2) spatially uniform flux at the contact between the Topopah Spring-Calico Hills units, 3 ) and no impacts from horizontal bedding in the Calico Hills unit.

Other features at Yucca Mountain influence moisture movement in the unsaturated zone. The vertically oriented normal faults and their associated fractures may behave as pathways for vertical flow, but may also impede lateral movement of water. Moisture movement within the deep unsaturated zone at Yucca Mountain is postulated to be occurring under conditions that are essentially steady state. 
The hydrologic conditions within the unsaturated zone at Yucca Mountain remain poorly known, although as described DOE (1988), considerable data on these conditions will be collected from planned boreholes and the exploratory shaft. The pathway by which water and contaminants move from the proposed repository in the unsaturated zone at Yucca Mountain to the water table depends on the flow mechanisms in the welded Topopah Spring unit and in the Calico Hills unit. These flow mechanisms depend on the hydraulic properties and fluxes in those units. Preliminary data from existing wells completed, and saturation measurements indicate an ambient matric potential of about -0.3 megapascals (approximately $-31 \mathrm{~m}$ pressure head) in the repository horizon of the Topopah Spring welded tuff DOE (1988).

$\mathrm{K}$ lavetter and Peters (1986) report that a dual-porosity, porous-medium equivalent representation may be a satisfactory representation of the unsaturated fractured tuffs at Yucca Mountain. They state that the dependence of relative hydraulic conductivity on water potential for an unsaturated fractured-rock system under the composite continuum approach might appear as in Figure 3.3. Plans to test the adequacy of this hypothesis on a large scale are described in DOE (1988).

The natural geothermal gradient within the unsaturated zone at Yucca Mountain creates the potential for upward movement of moisture as water vapor. According to DOE (1988), this potential is greatest in the welded Topopah Spring unit where the vapor movement is likely to occur within the partially saturated fractures. Although only by considering movement in the rock matrix, Ross (1984) concludes that upward movement of water vapor in deep unsaturated zones only becomes important at recharge rates less than $0.3 \mathrm{~mm} / \mathrm{yr}$. Movement of water vapor in the Topopah Springs unit may become more important under postclosure conditions in the repository when the waste canisters are heating the host rock, as was demonstrated in heating experiments described by Rasmussen and Evans (1987). In their conceptual model and experiments, a "liquid-vapor countercurrent flow system" exists, with water-vapor flow away from the repository and liquid-water return flow. 


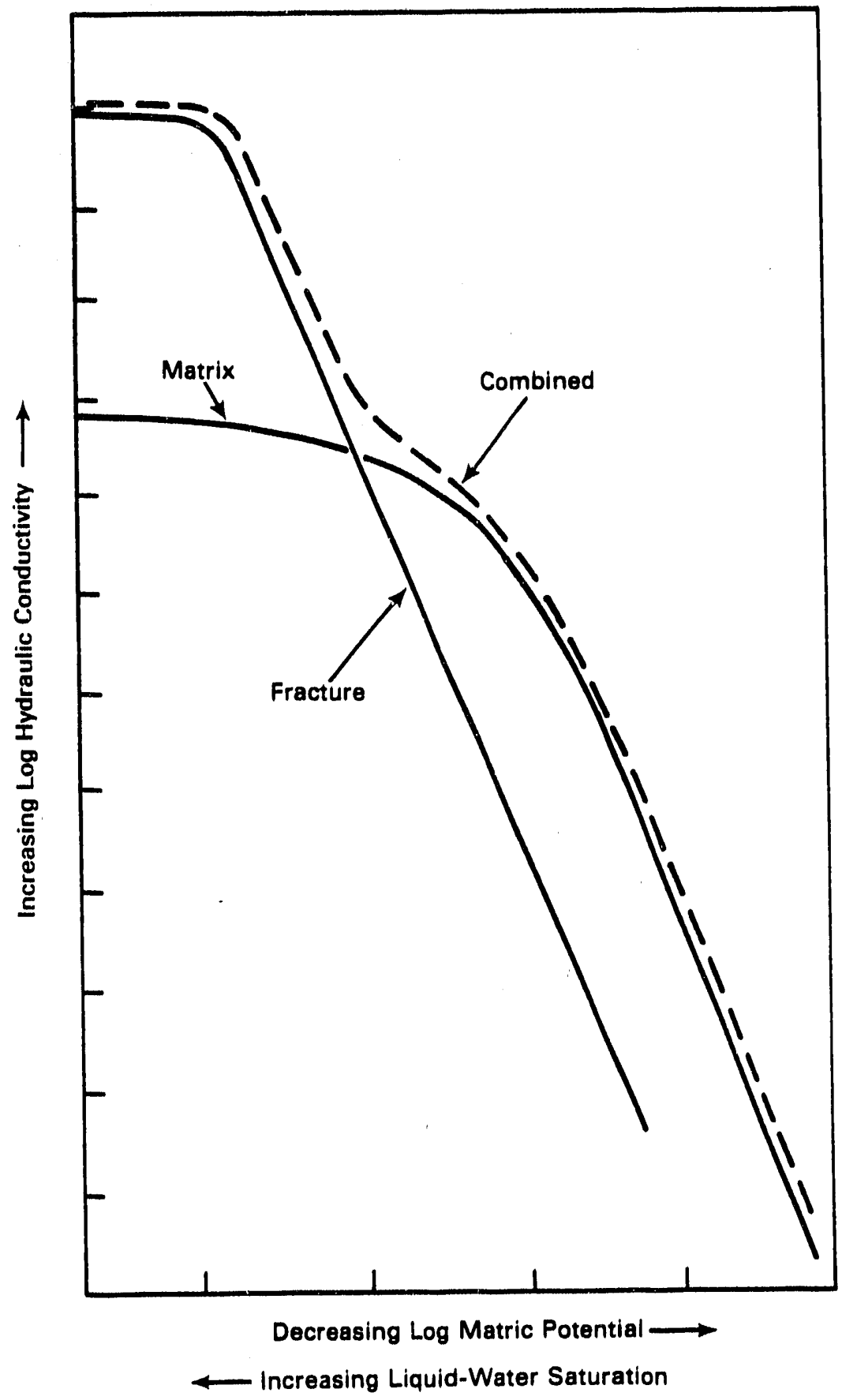

FIGURE 3.3. Idealized Hydraulic Conductivity Characteristic Curve for Composite Continuum (from Montazer and Wilson 1984) 


\section{Conceptual Hydrologic Model of the Unsaturated Zone}

This section describes the conceptual hydrologic model of the unsaturated zone underlying Yucca Mountain, as was used in the risk assessment. This conceptual model is the basis of the numerical model described in Section 3.1.3. The unsaturated zone hydrologic modeling effort focused on that portion of the subsurface that lies between the lower surface of the proposed repository and the water table.

Given the relatively low water flow rate (Wang and Narasimhan 1985), lateral flow of water in Yucca Mountain was not evaluated in the risk assessment. (The flow rate is discussed further below.) The unsaturated zone underlying the proposed repository was treated as a collection of distinct, noninteracting, one-dimensional, vertically oriented columins of porous material, bounded below by the water table. Each of the columns corresponds to a borehole that penetrates the unsaturated zone and for which a physical description of the geologic materials is available. The boreholes are labeled USW G-1, USW G-4, and USW G-3 in Figure 3.4. In addition, cores were obtained during the drilling of two boreholes, USW GU-3 and USW G-4, and these cores have been tested in the laboratory to determine their material hydrologic properties (see Section 3.1.3). Note that boreholes USW G-3 and USW GU-3 are at approximately the same location. Water flow through each column was simulated, and the corresponding travel times for water moving from the repository to the water table were calculated.

By taking this approach, we can partially account for horizontal variations in 1) the depth to water table, 2) the elevations of hydrogeologic unit boundaries, and 3) hydrogeologic unit thicknesses. A disadvantage of this approach, however, is that it ignores horizontal interactions between the flow fields within the various columns; for instance, lateral flow induced by sloping contacts between hydrogeologic units and heterogeneities present within each layer. Thus the effects of the three-dimensional character of the actual flow field on the water travel times are not well represented.

Percolating water is assumed to cross the lower boundary of the proposed repository and to move predominantiy downward at a low rate (net liquid flux 


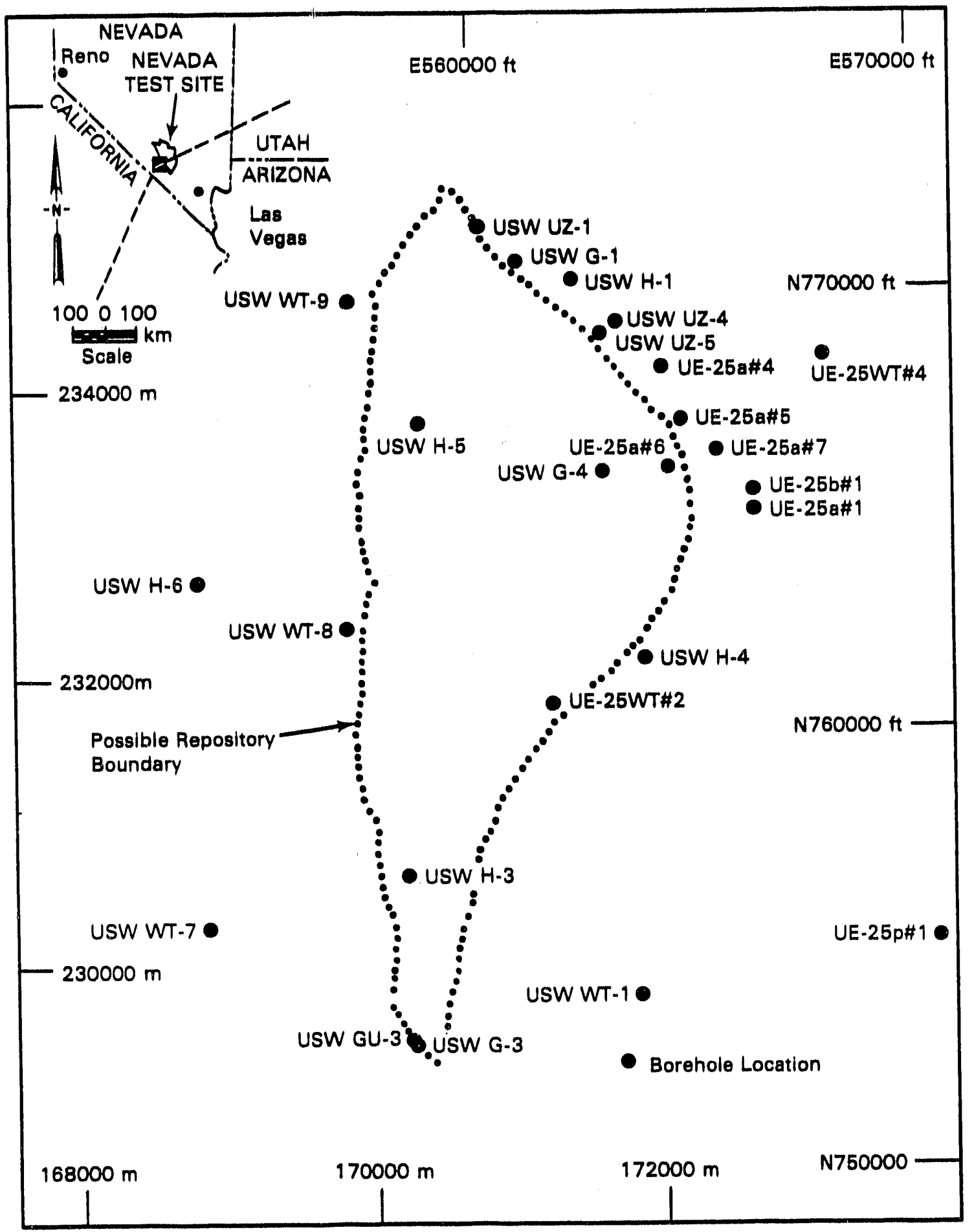

FIGURE 3.4. Boreholes Located in Yucca Mountain 
of $0.5 \mathrm{~mm} / \mathrm{yr}$ or less). This assumption is partfally supported by observations of moisture content in the Topopah Spring unit. Assuming that the liquid flux is low, it is likely that the existing molsture conditions within Yucca Mountain represent the effects of long-term climatic changes that may have occurred in the past.

There are two physical-conceptual approaches commonly taken today for modeling fluid flow through fractured, nonporous rocks: 1) the equivalent porous medium approach (also called continuum approach), and 2) the discrete fracture network approach. A third approach, the composite porous-medium approach described conceptually by Montazer and Wilson (1984), has been developed as part of the Yucca Mountain Site Characterization Project.

In the equivalent porous medium approach, it is assumed that the fractured medium can be represented by a continuum so that the standard equations governing flow in porous continua are applicable. The, hydraulic characteristics of the equivalent porous medium are assumed to depend on the statistical characteristics of the individual fractures within the region, in a manner that is not yet fully understood. Thus, this type of model implicitly accounts for the effects of fractures on the water flow field. In using the equivalent porous medium approach, one assumes that a representative elementary volume (REV) (Bear 1979) exists for the fractured medium. In practice, it may be very difficult to determine the size of an REV that exists for a given fractured rock. In spite of this difficulty, the method is sometimes favored over the discrete approach because of its simplicity.

Discrete fracture network models explicitly account for the effects of individual fractures within the model region. This approach typically involves generating a multidimensional network of individual fractures with idealized geometries, and then simulating fluid flow through the network. Construction of the fracture network requires information on the locations and geometries of individual fractures within the model region. The fracture network approach has the advantage over the equivalent porous medium approach in that it does not require the existence of a REV. In practice, however, it may be very difficult to obtain the necessary input data on fracture locations and geometries. 
For materials in which the pore space is made up of both fractures and matrix pores, such as the fractured, porous tuffs in the unsaturated zone at Yucca Mountain, approaches to modeling the flow are more complex than described above. Some possible physical-conceptual approaches for modeling subsurface flow through such materials are 1) porous medium--ignoring fractures, 2) fractured medium--ignoring matrix pores, 3) equivalent porous medium, 4) dual-porosity system with fractures treated as discrete network, and 5) duat-porosity system with fractures treated as equivalent porous medium.

In the porous medium approach, the existence of fractures is ignored and all of the permeating fluid is assumed to flow through the nonfracture pores in the rock. This may be a useful approximation for modeling flow under conditions in which the effects of the fractures are negligible. For instance, in some unsaturated fractured porous rocks the fractures may behave as cap. $\$ 17$ ary barriers to flow except when the rock is almost fully saturated. If the fractures are verticaliy oriented and the flow is predominantly downward, then this approach may be acceptable. This was, in fact, the approach taken for the present study.

In the fractured medium approach, the nonfracture pores in the rock are assumed to contribute a negligible amount of mobility to the permeating fluids. Hence only the fractures are accounted for when modeling advective transport. The fractures can be modeled as either a discrete network or as a continuum. This approach is likely to be useful for describing flow through certain fractured, low-permeability rocks, under fully saturated conditions.

In the equivalent porous medium approach the fractured, porous rock system is treated as an equivalent porous continuum much the same way that a fractured, nonporous rock is treated when using the equivalent porous medium approach. The same considerations that are important in modeling fliow through fractured, nonporous rock using the continuum approach are ri? levant here, except that in this case, the hydraulic properties of the rock are determined by the properties of the porous rock matrix as well as the characteristics of the fractures. In using this approach one assumes that an REV exists for the fractured, porous rock mass. 
In the dual-porosity approach, the pore space within the rock matrix and that within the fractures are treated as if each were the pore space in a distinct medium. The combined flow system is then described by specifying the flow fleld in each of the two media and to the hydrologic interaction of the two media (for example, leakage from the porous rock matrix into the fractures and vice versa). The medium corresponding to the fractures can be treated etther as a discrete fracture network or, if an REV can be defined for the fracture medium, as a continuum (equivalent porous medium). An important drawback to this approach is that the interaction of the two media is rarely understood and hence may be difficult if not impossible to quantify.

When both media of a partially saturated, fracture-matrix, dual-porosity system can be treated as continila, one can further simplify the mathematical description of the system by making additional assumptions about the degree of interaction between the two flow fields to obtain a composite continuum description such as that given in Klavetter and Peters (1986). In this case, the resulting conceptualization is similar to, and may even be considered a special case of, the equivalent porous medium approach. As is true of the equivalent porous medium approach, this method requires that an appropriate REV exist for the porous, fractured rock.

Continuum approaches to describing fluid flow through the fractures, including the composite continuum formulation by Klavetter and Peters (1986), were eliminated from consideration in this study because the few available data from the site are insufficient to establish the existence of a representative elementary volume, or to reliably estimate its hydraulic characteristics, should an REV exist. Until more hydraulic data from the site are obtained and analyzed, and the continuum approaches critically examined in light of such data, these approaches should only be used as conceptual aids rather than predictive tools.

Construction of a realistic discrete fracture network unsaturated flow model to describe fluid flow through the fractures was considered impractical for three reasons. First, the information required as input is such that a model is not now and most likely never will be available. This information 
would be derived from field data on the locations and geometries of individual fractures within the model region. Second, even if the necessary information were available, this modeling approach is considered to be impractical from a computational standpoint. Binnall et a1. (1987) state: "For practical applications, the complexity introduced by this second posstbility [a fractured rock that cannot be treated as an equivalent porous medium] is beyond the ability of modern day fracture mapping techniques and computing capabilities." Third and perhaps most important, even in cases where the necessary data are avaliable, it is not clear whether current discrete fracture network models, properly represent the physics of fracture flow. Neuman (1987) claims: "...there is growing laboratory and fleld evidence that the manner in which such models [discrete fracture network mode1s] translate data about fracture geometry into hydraulic and transport properties of the rock is open to serious questions." Neuman was apparently referring to saturated, fractured rock systems. For the more complex partially saturated fractured rock systems, it would seem that his claim is, if anything, an understatement.

Pore fluids within the unsaturated zone generally contain two phases, liquid and gas. Here the term "pore fluids" denotes any fluids residing either in the pores of the rock matrix or in the fractures. Moisture can exist as vapor in the gas phase, and liquid water is expected to make up the main portion of the liquid phase. Bulk advective transport of each phase can occur in response to net gravitational and pressure gradient forces. Additionaliy, in the presence of vapor pressure or thermal gradients, water vapor can be transported by molecular diffusion in the gas phase.

Diffusion of vapor may be a non-negligible source of moisture transport locally (Ross 1984), but its contribution to the net transport of moisture from the disturbed zone to the accessible environment is not currently known. A comprehensive assessment of the relative importance of vapor transport to the net moisture transport beneath Yucca Mountain would require a two-phase description of flow under nonisothermal conditions. The hydrologic model used in this study focused on 1iquid-phase transport only, under isothermal conditions. 


\section{1 .3 Approach}

\section{Model Selection}

Several numerical codes exist to solve problems of unsaturated flow (Oster 1982). Most of these codes have been developed to simulate molsture movement under varlably saturated conditions in unconsolidated sediments over relatively short periods of time. Considering unsaturated flow in consoitdated rock over longer time perlods has only recently become of interest (Lappala 1982).

The long time periods involved with disposal of high-level nuclear waste in the unsaturated zone at Yucca Mountain make solving the unsaturated problem with conventional unsaturated flow codes difficult. Therefore, for this demonstration of a risk assessment methodology, a simple analytical solution was selected to avoid large computational costs. Other models can be included in the future.

\section{Model Description}

A one-dimensional, steady-state analytical solution for unsaturated flow implemented by Jacobson, Freshley, and Dove (1985) was used to determine travel times through the unsaturated zone at Yucca Mountain. The analytical solution, which determines the distribution of pressure head over a vertical profile, was derived by integrating Richards' (1931) extension of Darcy's law, in part, over a one-dimensional profile. Thus, it is an analytical solution that was evaluated numerically. Gardner (1958) solved the integral with simple algebraic expressions for the material properties. In the application by Jacobson, Freshley, and Dove (1985), the equation was evaluated numerically to allow more flexibility in the algebraic expressions for describing material properties. Travel time for water was based on the distribution of hydraulic head defined by the analytical solution.

For this risk assessment, water flow through the unsaturated zone at Yucca Mountain was treated as one dimensional and was assumed to be at steady state. Water flow is defined as steady state when the magnitude and direction of the flow velocity are constant with time at any point in a flow field (Freeze and Cherry 1979). An analytical solution for steady-state, one-dimensional downward flow of water through the unsaturated zone was 
obtained by integrating Darcy's law over a vertical profile. The analytical solution over an incremental distance $\Delta z$ is

$$
\Delta z=\int_{i-1}^{\psi_{i}} \frac{d \psi}{q / K_{i}(\psi)-1}
$$

where $\Delta z_{f}=$ the distance between the $f$ and $1-1$ points

$\psi_{f}=$ pressure head at the ith point

$q=$ the steady-state recharge rate

$K_{f}(\psi)=$ a representative unsaturated hydraulic conductivity over $\Delta z_{f}$.

In the analytical solution, the molsture flux q moving through the unsaturated zone is input, as are the hydraulic properties for the materials in the profile. A harmonic mean hydraulic conductivity is used to represent $K_{f}(\psi)$ between two points in the proftle. Solution of Equation (3.1) yields the distribution of pressure head over the profile. Equation (3.1) is derived and integrated in an appendix in Jacobson, Freshley, and Dove (1985).

In deriving the one-dimensional, steady-state analytical solution for unsaturated flow [Equation (3.1)], a number of assumptions ware made: that water flow is steady state, the hydraulic gradient is vertically downward, water table conditions exist at the lower boundary, and the upper boundary condition is constant flux.

Travel time over the incremental distance $\Delta z_{i}$ is obtained by the following equation:

$$
\Delta t_{i}=\frac{\left(\Delta z_{i}\right)^{2} \theta_{i}^{*}}{k_{i}^{*} \Delta h_{i}}
$$

where $\Delta t_{j}=$ the incremental travel time over $\Delta z_{j}$

$\Theta_{i}^{*}=$ an effective moisture content over $\Delta z_{i}$

$\mathrm{K}_{f}{ }^{*}=\mathrm{a}$ harmonic mean of the hydraulic conductivity over $\Delta z_{j}$

$\Delta h_{i}=$ the change in hydrautic head over $\Delta z_{j}$. 
Hydraulic head $h$ is the sum of pressure head and elevation head $z$. The effective moisture content is the product of saturation $S$ and effective porosity $n_{e}$. Moisture content is an expression for the volume of water to volume of soll or rock, and saturation is the ratio of volume of water to volume of volds in the soll or rock. Effective porosity considers only those pore spaces through which flow can occur (Bear 1979).

Equations (3.1) and (3.2) are evaluated numerically by computer programs at discrete points over the vertical profile.

Moisture retention characteristics, or characteristic curves, describe the change in molsture content with change in pressure head in unsaturated media. The molsture retention characteristics, which are used to determine motsture contents from pressure heads, represent a statistical least squares fit of measured data with Haverkamp's formula (Haverkamp et a1. 1977; McKeon et a1. 1983), which is

$$
\theta(\psi)=\frac{\alpha\left(\theta_{s}-\theta_{r}\right)}{\alpha+(\ln |\psi|)^{\beta}}+\theta_{r}
$$

where $\Theta=$ the volumetric moisture content at a given pressure head $\psi$

$$
\begin{aligned}
& \Theta_{S}=\text { the moisture content at saturation } \\
& \Theta_{r}=\text { the residual moisture content }
\end{aligned}
$$

$\alpha$ and $\beta=$ empirical constants derived from fitting the data.

Haverkamp's relationship for moisture retention characteristics was selected because it fits the data we11, and it allows verification of the travel-time equation with a fully analytical solution (Jacobson, Frashley, and Dove 1985). Other relationships will not permit verification with fully analytical solutions.

Unsaturated hydraulic conductivities $K(\psi)$ are generated from the shape of the moisture-retention characteristics with a method developed by Mualem (1976). Curves to represent the unsaturated hydrauitic conductivity relationships were obtained from Haverkamp's formula (McKeon et a1. 1983): 


$$
K(\psi)=K_{S} \frac{A}{A+|\psi|^{B}}
$$

where $K_{S} i s$ the saturated hydraulic conductivity, and $A$ and $B$ are empirical coefficients used to fit the unsaturated hydraulic conductivity values.

\section{Numerical Implementation.}

In Jacobson, Freshley, and Dove (1985), the numerical evaluation of the analytical solution was verified with a fully analytical solution. The function in Equation (3.4) was evaluated for a simple form for $K(\psi)$ where $B=2$. The pressure head solutions for the numerically evaluated and the fully analytic solutions were nearly identical. At an input flux of $0.20 \mathrm{~cm} / \mathrm{yr}$, the difference between the total travel times predicted for both of the solutions was $0.02 \%$.

The expression derived from integration of Equation (3.1) is evaluated numerically over a one-dimensional grid, beginning at a lower water table boundary and solving the problem upward (Jacobson, Freshley, and Dove 1985). The solution is done iteratively, with specific criteria for when a solution at a grid point is achieved. The grid spacing can be made finer close to boundaries between hydrostratigraphic units to accommodate differences in hydrautic properties between the materials.

The solution is analytic except for iterating to obtain $K_{j}$ and $K^{*}$. In the code, the spatial variation of hydraulic head is extrapolated from previous node points to obtain an initial guess for iterating toward a solution. Empirical functions are used to describe the moisture-retention characteristics $\Theta(\psi)$ and unsaturated hydraulic conductivity $K(\psi)$. The functions are statistically fit to measured moisture retention and generated hydraulic conductivity data to obtain the expressions used in modeling. Because the one-dimensional profiles through Yucca Mountain are layered horizontaliy, a harmonic mean hydraulic conductivity is used (Jacobson, Freshley, and Dove 1985). The volumetric moisture content $\Theta$ is saturation multiplied by the porosity. 


\section{Profile Description}

Profiles for estimating travel times through the unsaturated zone at Yucca Mountain are based on existing boreholes that extend to the water table. The location of these wells, USW G-1, USW G-3, and USW G-4, are illustrated in Figure 3.4. Multiple profiles, distributed in the conceptual repository boundary outlined in Figure 3.4, allow some of the variations in layering and material properties at Yucca Mountain to be evaluated. Existing wells were used to develop the profiles because geologic logs are provided for each borehole.

The thicknesses of the units for the profiles and the samples used to represent the hydraulic properties of each unit are listed in Table 3.2. The hydraulic properties of the samples and their selection are described in Section 3.1.4. The spacing betweer node points in the profiles was $0.5 \mathrm{~m}$, with spacing reduced to $0.05 \mathrm{~m}$ at contacts between the hydrogeologic units. This finer spacing was required to obtain a solution at points in the profiles where hydraulic properties change abruptly, such as at interfaces between materials.

\subsubsection{Input Data}

Various types of information are required to implement the numerical approach discussed above. These include information on the geometry of the model region, the material hydrologic properties, and the boundary conditions. This section describes how data from various sources, primarily the draft SCP, were used to obtain the necessary information.

\section{Geometry}

As described above, the modeling approach is one dimensional. That is, the geometry of the model region corresponds to a vertically oriented line segment or profile. Construction of this profile requires knowledge of the depths to the upper and lower boundaries of the model region.

It was assumed that the model region can be divided into a finite number of rolatively homogeneous subregions or layers, the material in each of which constitutes a hydrogeologic unit. Under this assumption, the complete specification of hydrologic property values for the entire model region requires 
TABLE 3.2. Representative Samples for the Hydrogeologic Units

\begin{tabular}{|c|c|c|c|c|}
\hline & Representative & Thi & kness (r & n) \\
\hline Hydrogeologic Unit & Sample ${ }^{(a)}$ & USW-GI & SW-GE! & JSW-G4 \\
\hline Topopah Springs Welded & $4-6 B$ & 48 & 7 & 82 \\
\hline $\begin{array}{l}\text { Basal Vitrophyre of } \\
\text { Topopah Springs }\end{array}$ & G4 -8A & 25 & 68 & 15 \\
\hline $\begin{array}{l}\text { Calico Hills Nonwelded } \\
\text { (vitric) }\end{array}$ & GU3-12B & 114 & NP & 130 \\
\hline $\begin{array}{l}\text { Calico Hills Nonwelded } \\
\text { (zeolitic) }\end{array}$ & G4-11B & $N P(a)$ & 45 & NP \\
\hline Prow Pass Nonwelded & GU3-18A & $24^{(b)}$ & $275^{(b)}$ & NP \\
\hline
\end{tabular}

(a) NP denotes not present.

(b) Thickness is to water table.

knowledge of 1) the locations of the various layers, and 2) the values of the hydrologic properties corresponding to each hydrogeologic unit. Thus, it is useful to include in the profile the following information:

- depth to, or elevation of, the upper boundary of the model region

- depths to, or elevations of, the interfaces between the various hydrogeologic units present within the model region

- depth to, or elevation of, the lower boundary of the model region.

To account for the horizontal spatial variation of these elevations over the model region, several hydrogeologic profiles were considered. These profiles correspond to boreholes USW G-1, USW G-3, and USW G-4 (see Figure 3.4). The relevant depth or elevation data for these profiles can be found in Fernandez and Freshley (1984) and DOE (1988). Figures 3.5, 3.6, and 3.7 show the various profiles schematically.

The upper boundary of the model region was chosen to coincide with the estimated lower boundary of the proposed repository; effects of the disturbed zone below the repository were not included. Information on the location of the proposed repository was obtained from DOE (1988). This approach was 
Borehole: USW G-1

Elevation
(meters)

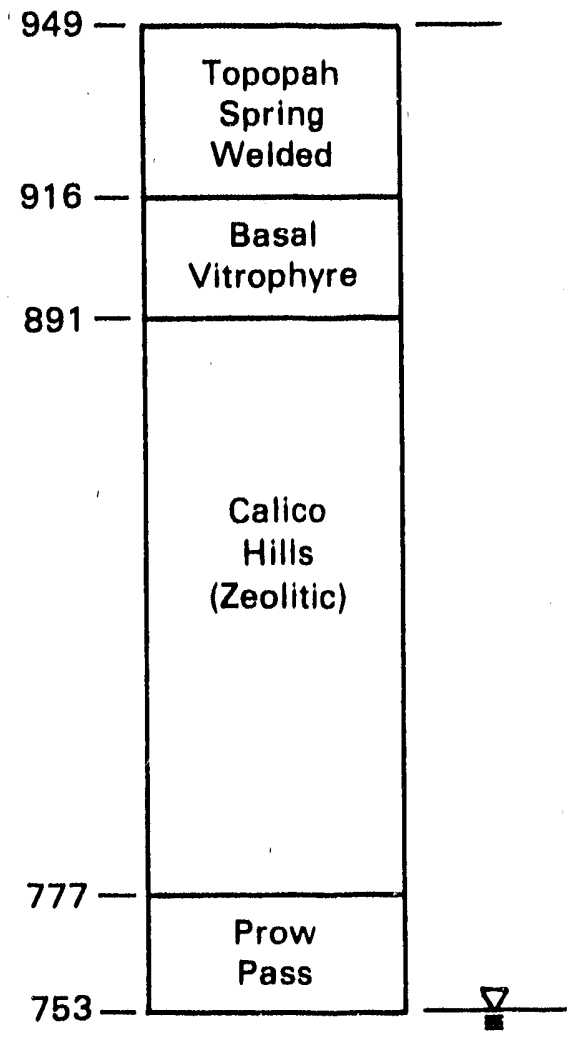

FIGURE 3.5. Hydrogeologic Profile of Borehole USW G-?

taken because it does not require specification of the disturbed zone boundaries, which are currently unknown. The resulting estimates of ground-water travel time may be considered slightly optimistic (high, noncunservative) in the following sense. Because the assumed flow paths originate at the lower boundary of the hypothetical repository, they are slightly longer than those originating at the disturbed zone boundary. The difference in length is equal to the thickness of that portion of the disturbed zone underlying the repository. Hence, the calculated travel times are greater than those of flow paths beginning at the disturbed zone boundary. In spite of this, it is not clear whether the resulting ground-water travel-time estimates are optimistic or pessimistic per se, because other simplifications in the analysis complicate interpretation. For instance, the detailed effects of the 
Borehole: USW G-3

\section{Elevation}

(meters)

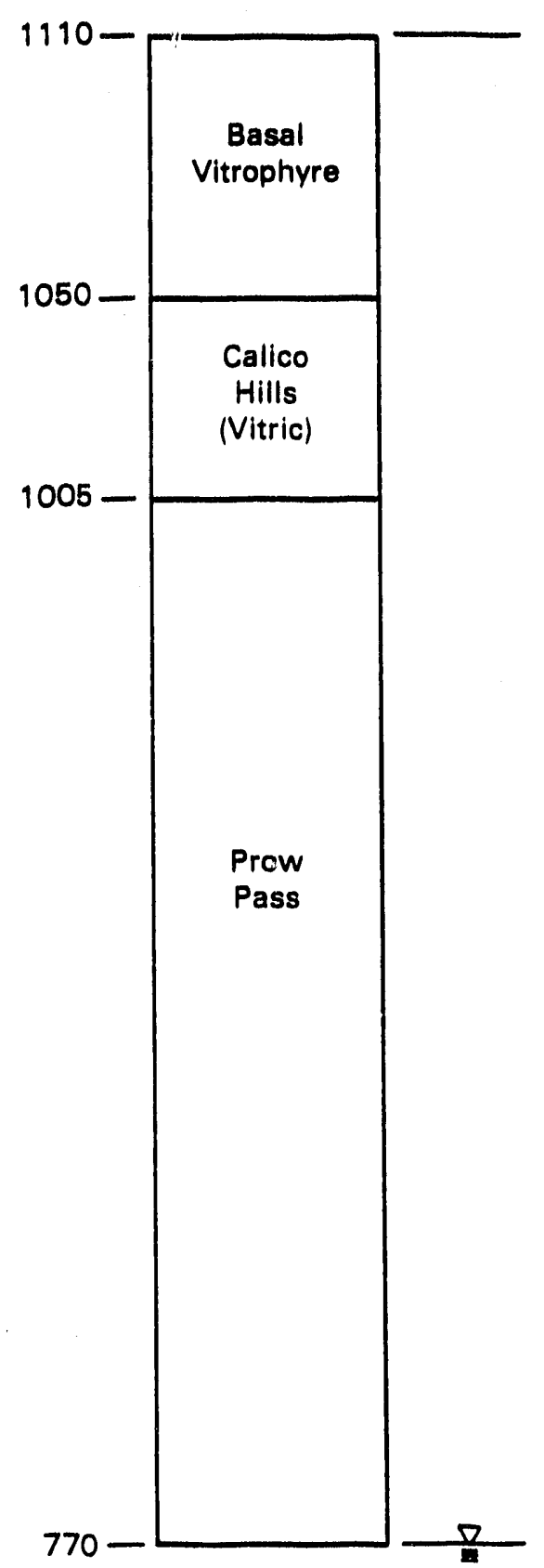

FIGURE 3.6. Hydrogeologic Profile of Borehole USW G-3 
Borehole: USW G-4

Elevation

(meters)

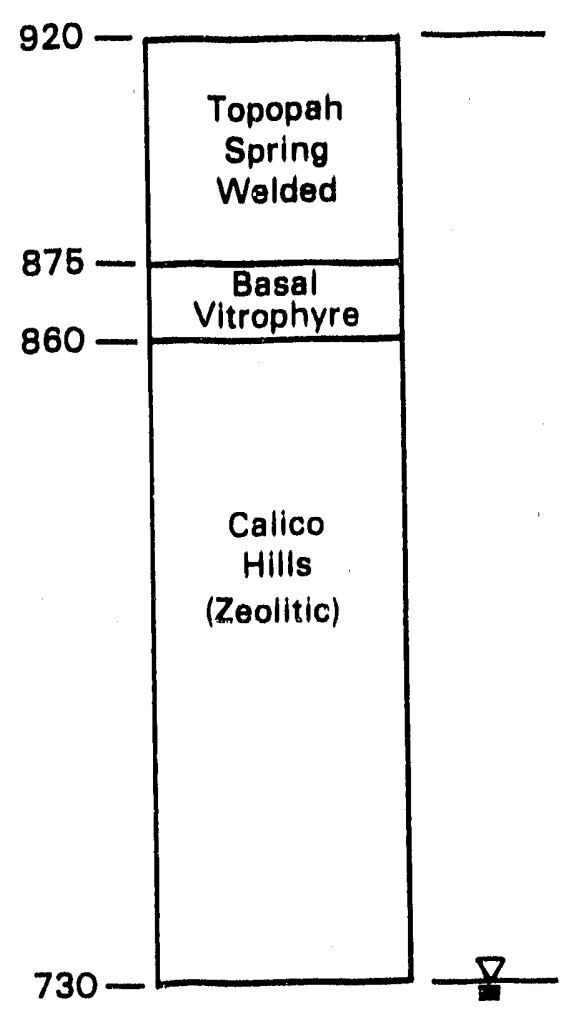

FIGURE 3.7. Hydrogeologic Profile of Borehole USW G-4

disturbed zone on the ground-water flow field are not we 11 understood and have not been considered in the simulations. These effects may include changes in fluid temperature, rock temperature, vapor pressure, capillary liquid pressure, porosity, permeability, moisture retention characteristics, fluid densities, fluid viscosities, and the spatial gradients of these quantities, as well as changes in liquid and gaseous moisture fluxes.

No unique method exists for determining what choice of hydrogeologic units is most appropriate to represent the materials within the model region. Thus the determination is made subjectively, based on the interpretation of available hydrologic, geophysical, and geologic information, and 
consideration of the intended use of the representation. For this study the hydrogeologic units used by Peters et a1. (1984) were used to represent the model region.

The vertical positions of the interfaces separating the various hydrogeologic units in the profiles were chosen to be consistent with those reported by Peters et a1. (1984). These elevation data for the three boreholes listed previously are from DOE (1988) and Fernandez and Freshley (1984).

The lower boundary of the model region was taken to be the water table. Depth to water table data reported in DOE (1988) was used to establish the position of this lower boundary in the various profiles.

\section{Material Hydrologic Properties}

The conceptualization of the site presented earlier essentially requires that only matrix hydrologic properties be input to the numerical hydrologic model. For hydrologic modeling, it is assumed that the material within any given hydrogeologic unit the material is homogeneous (i.e., the hydrologic properties do not vary with the vertical coordinate). Thus for simulations to be conducted, one set of hydrologic properties for each hydrogeologic unit must be specified as input to the numerical model (flow code). These hydrologic "properties" are in fact constitutive relationships, but for convenience are simply referred to as "properties." The relationships of interest here are the following:

- volumetric liquid moisture content versus capillary liquid pressure relationship (moisture retention relationship)

- hydraulic conductivity versus capillary liquid pressure relationship (unsaturated hydrautic conductivity relationship)

- effective porosity versus volumetric liquid water content relationship (effective porosity relationship).

In principle, each of these relationships can be fully expressed by specifying an appropriate family of curves or functions and the values of all of the parameters that enter into the functional form. The family of functions is generally expressed as an equation in which certain physical characteristics (e.g., capillary liquid pressure, hydraulic conductivity) are 
considered as variables, and others (e.g., porosity, hydraulic conductivity at saturation) are considered to be constants (physical parameters). Other constants, which are sometimes referred to as "fitting parameters, " may be present in the equation as we11. These other constants, along with the physical parameters discussed above, determine the form or shape of the curve. Unlike the physical parameters, however, the fitting parameters usually cannot be determined by a single experiment. Nor is it usually possible to predict the values of the fitting parameters directly from knowledge of the physical parameters alone.

For each hydrologic property relationship, one physical characteristic or "property" is the dependent variable, while other physical characteristics are the independent variables. For instance, in the equation describing the effective porosity-moisture content relationship, effective porosity is considered the dependent variable, while volumetric liquid-water content is the independent variable.

In general, the physical, parameters and fitting parameters that enter into the hydrologic property constitutive relationships can be considered functions of spatial coordinates; that is, the constitutive relationships are themselves dependent on location. For example, the pore spaces in the tuffs may change with time as a result of mineral precipitation or dissolution. As the volume and geometry of the pore spaces are modified, the material's moisture retention, hydraulic conductivity, and effective porosity relationships all may change. In some cases, as an approximation, the time dependence is ignored because the time span of interest is extremely short compared with the time scale of the property fluctuations. Similarly, if the spatial variability of parameters is small compared with the length scales of the model region, it may be possible to ignore this spatial variability.

For this study, temporal variability in hydrologic property constitutive relationships was ignored; that is, it was assumed that the constitutive relationships do not change with time. Little is known about this aspect of the materials' behavior.

Spatial variability of material hydrologic properties was considered, albeit in a limited way. As discussed earlier, some of the gross horizontal variations were explicitly accounted for by considering various profiles. 
The thicknesses of the hydrogeologic units within each profile, and the total thickness, vary from one profile to another. The gross vertical variations were accounted for by dividing each vertical profile into distinct hydrogeologic units, each of which was assigned material hydrologic properties as if it were spatially uniform. Spatial variation within any given hydrogeologic unit, however, was not explicitly accounted for.

The general forms (equations) assumed for the various constitutive relationships were determined by analysis of experimental data and the use of theoretical relationships. For each of the three properties (i.e., moisture retention, hydrautic conductivity, and effective porosity) the same equation was used to represent the corresponding constitutive relationship in all of the hydrogeologic units.

For this analysis, Equation (3.3) (Haverkamp et a1. 1977) describes the assumed functional relationship between volumetric liquid-water content and capillary liquid pressure of an unsaturated material. This form was used for two reasons. First, the curves appear to fit the experimental moisture retention data from Yucca Mountain we11. Second, other authors have found this expression to be useful for describing the experimentally derived moisture retention curves of most naturaliy occurring porous materials.

Estimates of the three fitting parameters $\left(\alpha, \beta\right.$, and $\left.\Theta_{\gamma}\right)$ were obtained for individual samples by fitting Haverkamp-type curves to corresponding experimental water retention (drainage) data. For a given sample these data consist of a collection of pairs of volumetric liquid-water content versus capillary suction head (suction head is negative pressure head) values. Typically, the moisture retention data for each sample contain experimentally determined suction head values ranging from 0 to 8000 or $9000 \mathrm{~m}$ (see Peters et al. 1984). Similarly, for each individual sample the experimentally determined value of the moisture content at a pressure head of zero was used as an estimate of $\theta_{S}$ for that sample. The fitting was accomplished by using a computer program that uses a least-squares algorithm (McKeon et a1. 1983) to fit the curve to experimental moisture retention data.

Experimental moisture retention data corresponding to samples obtained from cores in boreholes USW G-4 and USW GU-3 were available when the moisture 
retention curves were fitted. Note that borehole USW GU-3 is at approximately the same location as borehole USW G-3, for which a profile was constructed. The retention data are reported in Peters et a1. (1984). When Peters et a1. reported their results, they referred to individual samples as "subsamples." For estimating material hydrologic properties, the experimental data corresponding to each such subsample were treated in this study as though they correspond to a distinct, individual sample.

Graphs of the experimental moisture retention curves and the corresponding fitted curves for selected material samples can be found in Appen$\operatorname{dix} A$. The parameter estimates for the moisture retention curves for all of the hydrogeologic units are summarized in Table 3.3.

Peters et a1. (1984) found molsture-retention data for Yucca Mountain to be adequately fit by the van Genuchten representation. Therefore, more than one relationship fits the empirical moisture-retention data for Yucca Mountain.

The unsaturated hydrautic conductivity curves for the various hydrogeologic units were assumed to be of the form of the Haverkamp et al. (1977) equation [Equation (3.4)]. The saturated hydraulic conductivity is considered to be a physical constant and is routinely determined by field or laboratory experiment. This particular form was used because the numerical flow code has been verified against a quasi-analytical solution using this form, and because there is little, if any, evidence to indicate that any other form is more suitable.

Unlike the moisture retention curves, few experimental hydraulic conductivity data are available on the hydrogeologic units underlying the Yucca Mountain site. Peters et a1. (1984) report the results of laboratory experiments performed to determine the saturated hydraulic conductivities of samples obtained from cores in boreholes USW G-4 and USW GU-3. The samples include those tested for the water retention characteristics (discussed above). Only those samples that had been tested for both moisture retention and saturated hydraulic conductivity were considered for this analysis. (Table 3.4). 
IABLE 3.3. Estimated Moisture Retention Characteristics

\begin{tabular}{|c|c|c|c|c|}
\hline Hydrogeologic Unit & Sample & $\alpha^{(a)}$ & $\beta^{(a)}$ & $\theta_{r}$ \\
\hline Topopah Springs Welded & $G 4-6 B$ & $6.64 \times 10^{4}$ & 1.78 & $7.27 \times 10^{-3}$ \\
\hline $\begin{array}{l}\text { Basal Vitrophyre of } \\
\text { Topopah Springs }\end{array}$ & $G 4-8 A$ & $5.55 \times 10^{2}$ & 1.04 & $9.53 \times 10^{-3}$ \\
\hline $\begin{array}{l}\text { Calico Hills Nonwelded } \\
\text { (vitric) }\end{array}$ & GU3.12B & $6.64 \times 10^{7}$ & 4.23 & $2.42 \times 10^{-2}$ \\
\hline $\begin{array}{l}\text { Calico Hills Nonwelded } \\
\text { (zeolitic) }\end{array}$ & G4-11B & $2.54 \times 10^{3}$ & 1.18 & $5.40 \times 10^{-2}$ \\
\hline row Pass Nonwelded & GU3 $-18 \mathrm{~A}$ & $5.59 \times 10^{6}$ & 4.47 & $2.04 \times 10^{-2}$ \\
\hline
\end{tabular}

(a) Assumes capt17ary liquid pressure head measured in meters.

TABLE 3.4. Estimated Unsaturated Hydraulic Conductivity Parameters

\begin{tabular}{|c|c|c|c|c|}
\hline Hydrogeologic Unit & Sample & $A^{(a)}$ & $\underline{B(a)}$ & $K_{s}(b)$ \\
\hline Topopah Springs Welded & $G 4-6 B$ & $1.88 \times 10^{10}$ & 4.63 & $1.64 \times 10^{-6}$ \\
\hline $\begin{array}{l}\text { Basal Vitrophyre of } \\
\text { Topopah Springs }\end{array}$ & $G 4-8 A$ & $1.89 \times 10^{2}$ & 2.46 & $3.89 \times 10^{-5}$ \\
\hline $\begin{array}{l}\text { Calico Hills Nonwelded } \\
\text { (vitric) }\end{array}$ & GU3-12B & $4.10 \times 10^{16}$ & 9.63 & $2.72 \times 10^{-4}$ \\
\hline $\begin{array}{l}\text { Calico Hills Nonwelded } \\
\text { (zeolitic) }\end{array}$ & G4-11B & $4.50 \times 10^{4}$ & 2.86 & $1.73 \times 10^{-6}$ \\
\hline Prow Pass Nonwelded & GU3-18A & $1.24 \times 10^{10}$ & 1.0 & $11.12 \times 10^{-4}$ \\
\hline
\end{tabular}

(a) Assumes capillary liquid pressure head measured in meters.

(b) In meters per day.

As far as the authors are aware, no published data are available on the unsaturated hydraulic conductivities of any of the units underlying Yucca Mountain. Therefore, the unsaturated hydraulic conductivity curves were estimated indirectiy. The estimation procedure was as follows. First a theoretical relationship between the moisture retention curve and the 
unsaturated hydraulic conductivity curve was used to generate unsaturated hydraulic conductivity versus capillary liquid pressure head "data". Then a theoretical unsaturated hydraulic conductivity curve was fit to these data.

The theoretical relationship between unsaturated hydraulic conductivity and the moisture retention curve is that developed by Mualem (1976). In this equation, $K(S)$ denotes hydraultc conductivity as a function of $S$, the effective saturation: $K_{s}$ denotes hydraultc conductivity at full saturation; $\psi(S)$ denotes Tiquid caplliary pressure head as a function of the effective saturation and is analogous to the inverse of the moisture retention relationship. Volumetric liquid-water content, residual water content, and water content at full saturation are represented as $\theta, \theta_{r}$, and $\theta_{s}$, respectively. For each hydrogeologic unit considered, $\psi(S)$ was assumed to be equal to the inverse of the corresponding fitted molsture retention equation for that unit [see Equation (3.3)].

The unsaturated hydraulic conductivity curve for each hydrogeologic unit was assumed to be of the form given in Equation (3.4). For each hydrogeologic unit, this equation was fit to the corresponding unsaturated hydraulic conductivity data that were generated, thus giving an estimate of the fitting parameters $A$ and $B$. The fitting procedure used a least-squares algorithm (Mckeon et a1. 1983). Graphs of the unsaturated hydraulic conductivity values that were generated and the corresponding fitted curves are shown in Appendix $A$. The resulting parameter estimates for the hydraulic conductivity relationship for all of the hydrogeologic units are summarized in Table 3.4 where $n_{e}$ is the effective porosity, $q$ is the specific discharge, and $V$ is the average linear velocity (seepage velocity) of the permeating fluid. The effective porosity can be thought of as the ratio of the cross-sectional area of the pore space contributing to the mobility of the fluid to the bulk cross-sectional area of the medium. Both of these cross-sectional areas are considered to be measured in a plane orthogonal to the mean flow direction. Thus, under fully saturated conditions, the effective porosity generally is 


$$
K(S)=K_{S} S^{1 / 2}\left[\int_{0}^{S} \frac{d S}{\psi} / \int_{0}^{1} \frac{d S}{\psi}\right]^{2}
$$

where

$$
s(\theta)=\frac{\theta-\theta_{r}}{\theta_{s}-\theta_{r}}
$$

The effective (kinematic) porosity with respect to the flow through a porous medium is defined as (Bear 1979)

$$
n_{e}=q / V
$$

presumed to be less than or equal to, but never greater than, the porosity of the medium. similariy, in unsaturated porous materials, the effective porosity is expected to be bounded above by the volumetric liquid-water content because only that portion of the vold space that is occupied by the flutd contributes to its mobility.

In the present analysis, the effective porosity of an unsaturated medium is assumed to be equal to the medium's volumetric liquid-water content

$$
n_{\theta}(\theta)=\theta
$$

where $n_{e}(\Theta)$ denotes effective porosity as a function of volumetric 1 lquidwater content. This simplistic approach assumes that 211 of the saturated pore space contributes to fluid mobility. Actually some of the saturated pore space may consist of 1) nonconnected, isolated cavities within the rock, 2) pores that are part of the interconnected pore space but are not interconnected by fluid, and 3) pores that, although interconnected by fluid, behave as dead-ends relative to the microscopic flow paths. With respect to advection, these pores contribute nothing to the mobility of the permeating fluid. Pores that exist as isolated cavities in the rock are not normally 
detected during most laboratory porosimetry experiments because these experiments are usually destgned to measured the relative volume of the interconnected pores only. Thus, the tsolated pores can usually be tgnored. Those saturated pores that exist within the interconnected pore space $(2$ and 3 above), however, may be detected during porosity measurements and, hence, are a potential source of bias in estimating effective porosity. Therefore, this approach could lead to overestimating the effective porosity and consequently overestimating the ground-water travel time.

One sample from each hydrogeologic unit was selected as a representative sample for that unit. The sample was selected by comparing the inferred hydrologic properties of the various samples from the same unit, and choosing the sample whose properties appeared to be closest to the "average" values for that unit. The inferred hydrologic properties of this sample are assumed to be representative of the entire unit. Neglecting possible measurement and interpretation errors, this method ensures that for each hydrogeologic unit, the corresponding hydrologic property estimates constitute a realistic combination of property values. The comparisons focused on 1) hydraulic conductivity at full saturation, 2) the shape of the fitted moisture retention curve, and 3) the volumetric liquid-water content at full saturation. Table 3.2 shows the sample whose properties were determined to be most representative of each hydrologic unit.

\section{Boundary Conditions}

Because the modeling approach is one-dimensional, boundary conditions are only required for the endpoints of each vertical profile. The upper boundary of the model region, which corresponds to the assumed lower boundary of the proposed repository, was treated as a prescribed flux (Neumann or second type) boundary with the flux specified as the vertical percolation rate. The lower boundary of the region, which corresponds to the water table, was treated as a prescribed head (Dirichlet or first type) boundary with the head specified as the elevation. 


\section{1 .5 Results}

Three vertical profiles were simulated for conditions of $0.5 \mathrm{~mm} / \mathrm{yr}$ average recharge. The vertical profiles were simulated at wells USW G-1, USW G-3, and USW G-4, as summarized in Section 3.1.4.

The average pressure head of $-31 \mathrm{~m}$ in the matrix of the Topopah Spring welded unit (DOE 1988) compares favorably with the average pressure head in the same unit calculated with the analytical solution using a recharge rate of $0.5 \mathrm{~mm} / \mathrm{yr}$. Assuming the measured comparison demonstrates that the model predictions are reasonable. However, at these pressure heads in the Topopah spring unit, the predicted saturations are greater than $95 \%$. The measured saturations for the Topopah Spring unit reported by Montazer and Wilson (1984) average about 65\%. Additional site characterization data, including moisture retention characteristics of cores from other boreholes and parameters used to estimate recharge through Yucca Mountain, are needed to resolve this and other discrepancies.

The travel times predicted for the three vertical profiles are summarized in Table 3.5. These predicted travel times are within the range of travel times predicted by Peters, Gauthier, and Dudley (1986), but are larger than those predicted by Sinnock, Lin, and Tierney (1986). Travel time increases with length of the profile. As indicated in Table 3.5, the largest proportions of the travel times in the profiles occur in the nonwelded vitric and zeolitic tuffs.

\subsection{THE SATURATED ZONE AT YUCCA MOUNTAIN}

The study are for the analysis of regional travel times through the saturated zone of Yucca Mountain is shown in Figure 3.8. This figure shows the major geologic features and rock types in the NTS, which is part of the basin and range physiographic province. Several researcher. have investigated the geology and hydrology of the NTS: Eakin (1966), Eakin et al. (1951), Eakin and Moore (1964), Eakin and Winograd (1965), Grove et al. (1969), Hunt and Robinson (1960), Loeltz (1960), Maxey (1968), Maxey and Mifflin (1966), Miller (1977), Pistrang and Kunkel (1964), Walker and Eakin (1963), Winograd (1962, 1981), Winograd and Friedman (1972), and Winograd and 
TABLE 3.5. Thickness and Predicted Travel Times for Different Vertical Profiles from the Base of the Disturbed 7one to the Water Table at Yucca Mountain

\begin{tabular}{|c|c|c|c|c|c|c|}
\hline Hydrogeologic Unit & $\begin{array}{l}\text { USh } \\
\text { Thickness } \\
\begin{array}{c}\text { (m) } \\
\end{array}\end{array}$ & $\begin{array}{l}\frac{1-G l}{\text { Travel }} \\
\text { Time } \\
(y r) \\
\end{array}$ & $\begin{array}{l}\text { USW } \\
\text { Thickness } \\
\begin{array}{c}(\mathrm{m}) \\
\end{array}\end{array}$ & $\begin{array}{l}\frac{d-G 3}{\text { Travel }} \\
\text { Time } \\
\text { (yr) }\end{array}$ & $\begin{array}{l}\text { USW } \\
\text { Thickniess } \\
\begin{array}{l}\text { (m) } \\
\end{array}\end{array}$ & $\begin{array}{l}\frac{G 4}{\text { Travel }} \\
\text { Time } \\
(y r) \\
\end{array}$ \\
\hline $\begin{array}{l}\text { Topopah Spring } \\
\text { Welded }\end{array}$ & 48 & 8,580 & 7 & 1,149 & 82 & 14,652 \\
\hline $\begin{array}{l}\text { Basal Vitrophyre of } \\
\text { Topopah Spring }\end{array}$ & 25 & 3,811 & 68 & 10,798 & 15 & 2,308 \\
\hline $\begin{array}{l}\text { Calico Hills Non- } \\
\text { welded (zeolitic) }\end{array}$ & 114 & 67,420 & & & 130 & 77,476 \\
\hline $\begin{array}{l}\text { Calico Hills Non- } \\
\text { welded (vitric) }\end{array}$ & & & 45 & 23,384 & & \\
\hline Prow Pass Nonwelded & $24^{(a)}$ & $\underline{13,257}$ & $\underline{275}^{(a)}$ & 70,404 & - & \\
\hline Total & 211 & 93,068 & 395 & 105,735 & 227 & 94,436 \\
\hline
\end{tabular}

(a) Thickness is to the water table.

Thordarson (1975). These studies were used to formulate the hydrological conceptualization of the study area.

It is generally believed that there are two ground-water flow systems in the study area, a regional and a local flow system. The regional flow system encompasses several topographic basins where interbasin flow is common. The regional flow paths are relatively long compared to flow paths of "local" ground-water flow systems that are generally confined to one topographic or ground-water basin.

Freeze and Witherspoon (1966, 1967) "theoretically studied" regional ground-water flow systems and found that large discharges can occur at depth if a zone of relatively high permeability exists (Figure 3.9). They determined the following general characteristics of regional flow systems: 


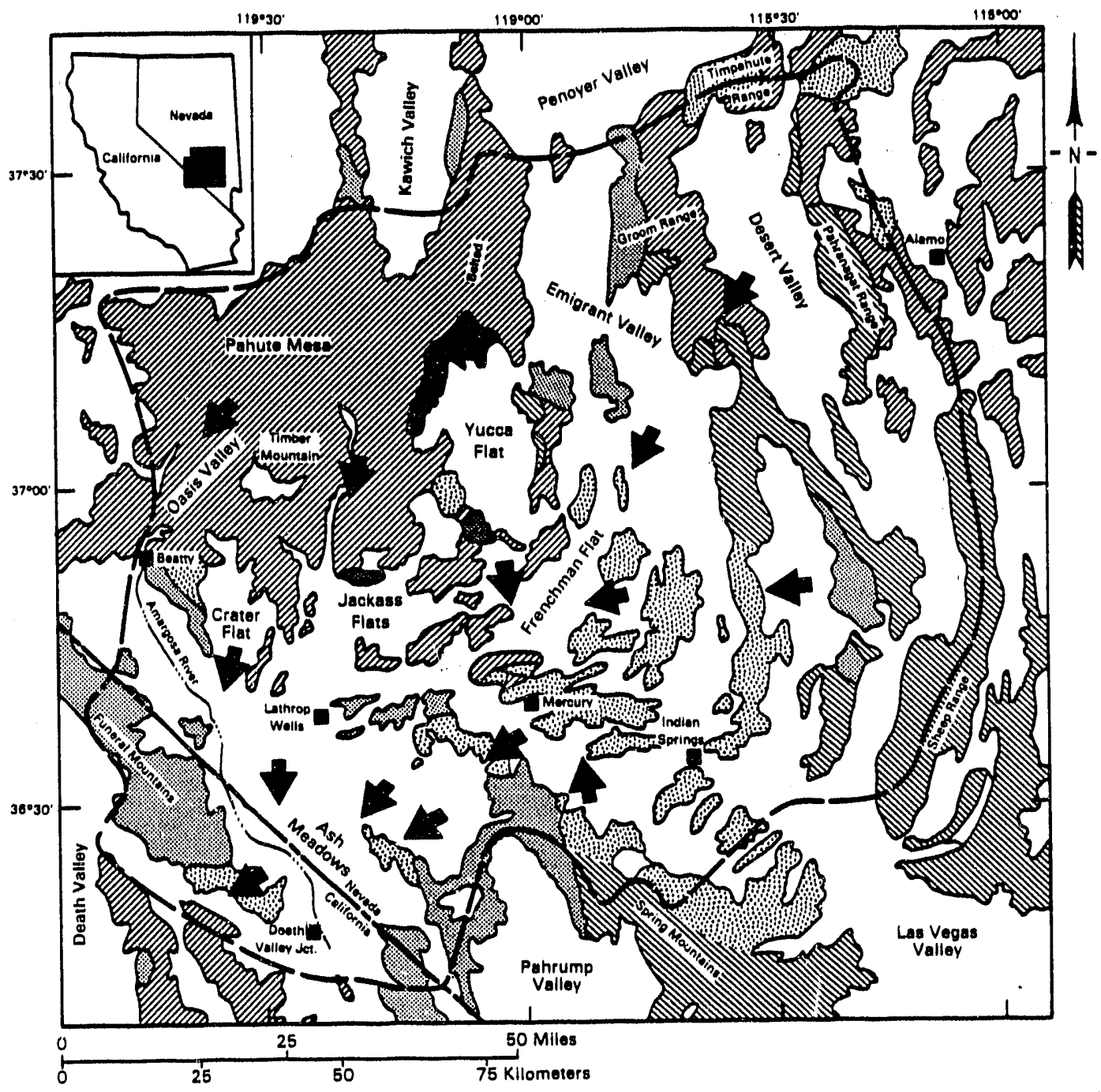

Explanation

Quaternary
Alluvium, lake beds, and minor
volcanic rocks
Tertiary
TIIIIS Tuff, rhyolite, and associated
volcanic rocks
Mesozoic (Minor .. not shown)
Paleozoic
andifferentiated upper elastic aquitard,

\begin{tabular}{l} 
Upper elastic aquitard \\
Lower carbonate aquifer \\
Paleozoic (Cambrian) - Precambrian \\
Lower elastic aquitard \\
Symbols \\
\hline $\begin{array}{l}\text { Contact } \\
\text { Thrust fault } \\
\text { Approximate boundary of USGS } \\
\text { Approximate direction of } \\
\text { ground-water flow }\end{array}$
\end{tabular}

FIGURE 3.8. Generalized Geology of the Yucca Mountain Study Area 

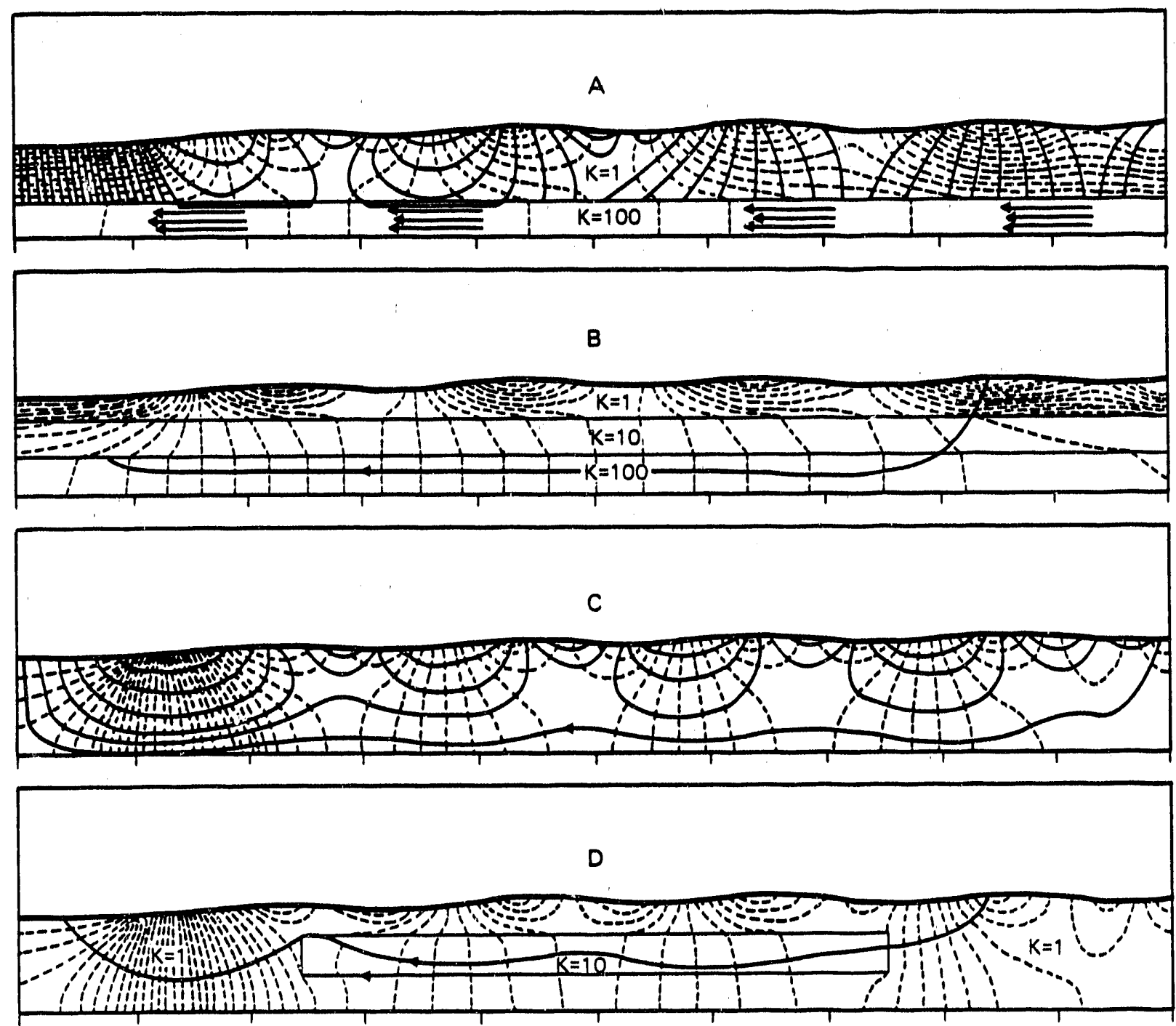

$A$ and $B$ - Situation of interbasin flow produced by greater relative permeability at depth and relief.

C - Situation of interbasin flow produced by relief alone, in uniform permeability media.

D - Situation of interbasin flow created by lense of permability material.

— Flow line

- Equipotential line

$K$ - Relative hydraulic conductivity

FIGURE 3.9. Configuration of Flow Producing Interbasin Movement of Ground Water (modified after Freeze and Witherspoon 1967) 
1) ground-water discharge tends to be concentrated in major valleys; 2) recharge areas are larger than discharge areas; 3) local ground-water flow systems are superimposed on a regional flow system in a hummocky terrain; 4) buried aquifers direct flow toward the principal discharge areas, have little or no effect on the subbasins, and produce artesian conditions; and 5) geologic structures can distribute, recharge, and discharge independent of the water table configuration.

All five of the preceding conditions exist in the study area. In the Basin and Range physiographic province, local flow systems sit in a hummocklike fashion in the numerous intermontane valleys and basins (see Figure 3.9).

These systems constitute the valley-fill aquifer and are composed of an alluvial material. Underlying these local systems is a massive interbasin or regional flow system composed of highly fractured carbonate rock that is an avenue of flow beneath the local systems. The regional system is confined in the deepest portions of the valleys and unconfined beneath the mountain ridges.

\subsubsection{Conceptualization and Assumptions of the Hydrologic Model}

A conceptual flow model of the saturated flow system was developed both by PNL (Rice 1984) and the U.S. Geological Survey (USGS) (Wadde11 1982). The conceptual model of the regional hydrologic system used in this study is shown in Figure 3.10.

Recharge occurs in mountainous areas at higher elevations where more precipitation occurs and evaporation is less. Water directly recharges the lower carbonate aquifer where it is exposed in mountainous areas, and recharge moves downward through the alluvium and volcanic tuffs to recharge the carbonate aquifer.

The highly permeable sequence of carbonate rock, termed the carbonate aquifer by Winograd and Thordarson (1975), is primarily responsible for interbasin or regional ground-water flow beneath the NiS. Ground water then moves laterally toward discharge areas that are located in the valleys; discharge occurs through springs, evapotranspiration, and pumping. The schematic representation of the conceptual model in Figure 3.10 illustrates 


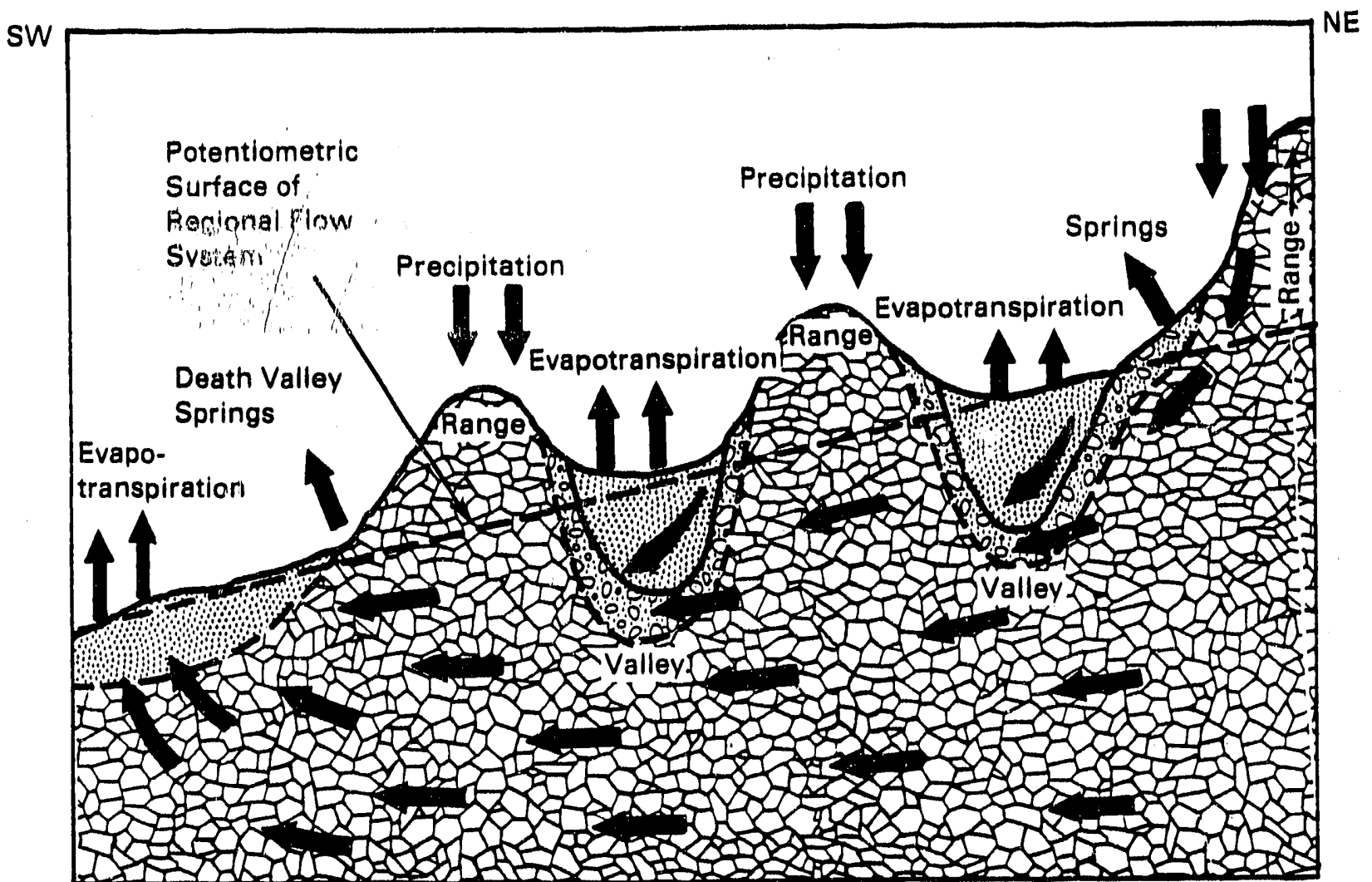

Generalized section across NTS regional model

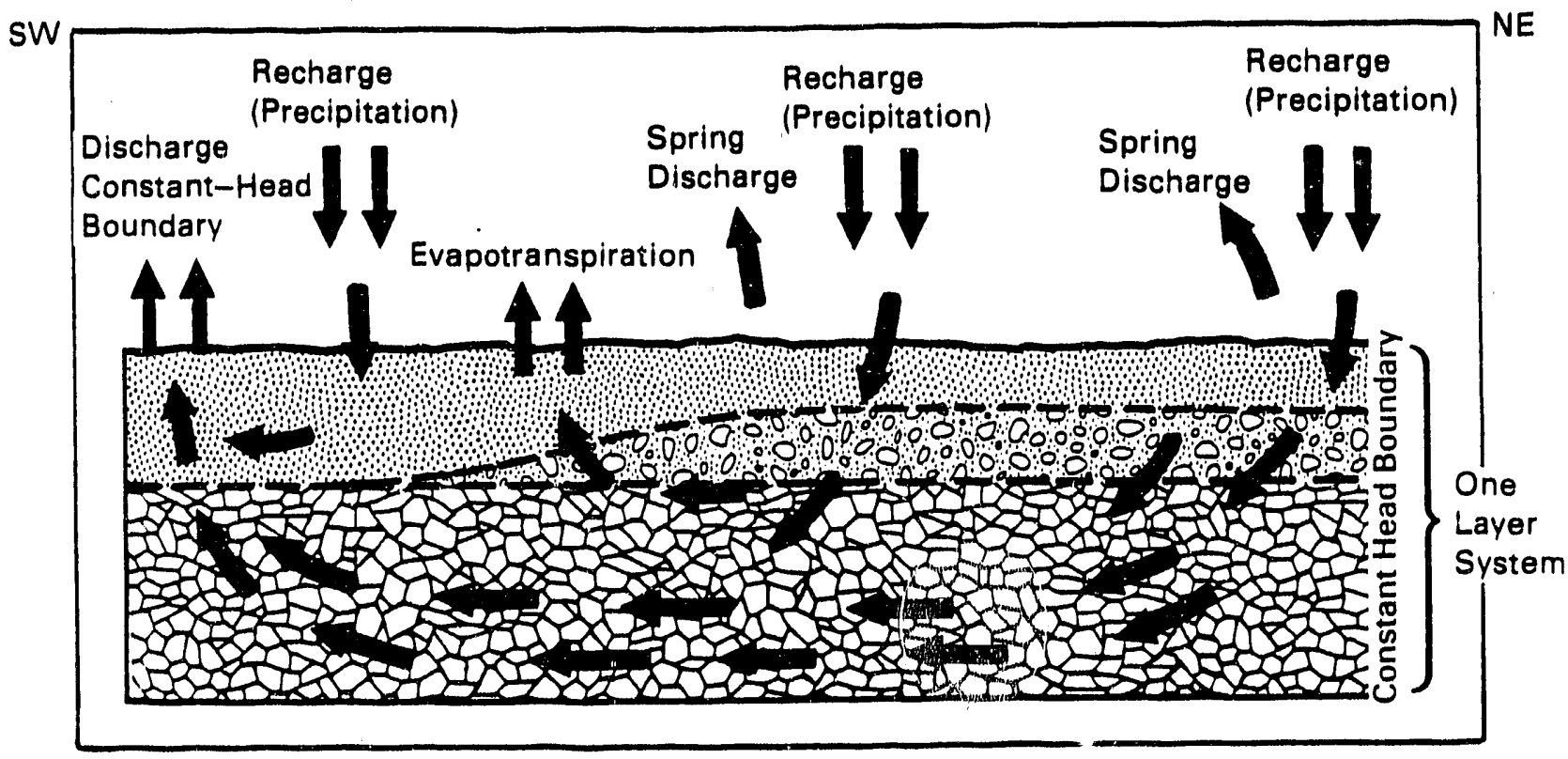

Idealized ground-water flow of NTS conceptual model

13 Valley-Fill

Volcanic Rock
(Tuff)

Eg Carbonate Rock

FIGURE 3.10. Schematic Representation of the Nevada Test Site Conceptual Model 
the multilayered flow system composed of the alluvial, volcanic, and carbonate aquifers as one unit. At a particular location, the most transmissive hydrostratigraphic unit(s) are simulated. The direction of regional groundwater flow is indicated in Figure 3.8. Ground water from Yucca Mountain generally flows south and then southwest to the Furnace Creek Wash area of Death Valley. Primary rock types over this flow path are volcanic tuffs in the vicinity of Yucca Mountain, alluvium south of Yucca Mountain, and carbonates in the vicinity of Furnace Creek Wash.

\section{Conceptual Model Assumptions}

A number of simplifying assumptions about the hydrogeology of the study area were made to facilitate implementation of a numerical model.

- Regional ground-water flow is assumed to be strictly horizontal. Evidence exists for both upward and downward flow. Although no data are available on vertical head distributions in most areas, geometric considerations suggest that flow beneath recharge areas is downward, and flow beneath discharge areas is upward (see Figures 3.9 and 3.10). Flow beneath Pahute Mesa north of Yucca Mountain, where hydraulic gradients are steep, provides evidence of downward flow [Blankennagel and Weir (1973) and Oberlander (1979)]. Flow at Alkali Flat, a major discharge area, provides evidence of upward flow. Consequently, with the exception of recharge and discharge areas, the horizontal flow assumption is reasonable.

- Hydrologic parameters (transmissivity, rates of recharge and discharge) do not change with time, and the current distribution of hydraulic head is assumed to represent steady-state conditions. The steady-state ass'mption is known to be violated by several processes. For example, in areas where pumping has been intense (Ash Meadows, Pahrump Valley and Sand Spring Valley), short-term chaiges in water level have occurred. These changes have been we11 documented and appear to be small compared with the range of heads throughout the study area.

- The aquifers are assumed to be isotropic with respect to transmissivity, although few porous media are isotropic (Freeze and Cherry 1979). The effects of applying this assumption are 1) transmissivity calculated or used in the model represents transmissivity in the direction of flow and 2) calculations of fluxes and flow directions will contain errors because, unless transiated by a transmissivity or hydraulic conductivity tensor, the flow occurs perpendicular to the hydraulic head contours. Recent analyses by the USGS (Czarnecki and Waddel1 1984) incorporating an anisotropic ratio in the transmissivity of western Jackass Flats resulted in slightly greater travel times and greater error variances. However, greater uncertainty in other parameters will more significantly affect travel-time calculations. 
- Travel-time calculations are based on the concept that hydraulic conductivity and porosity are correlated. Empirical evidence for boreholes within Yucca Mountain shows this to be true. Brace et al. (1982) discussed the relationship between porosity and permeability for flow through fractures and porous media. They conclude that hydraulic conductivity and porosity are correlated for a given geologic material.

\subsubsection{Ground-Water Flow Modeling}

Ground-water flow modeling for estimation of travel times presented in this study is based primarily on two previous hydrologic model analyses of the NTS: a local-scale or near-field flow and sensitivity/uncertainty travel-time analysis reported by Jacobson, Freshley, and Dove (1985) and a regional hydrologic analysis by Rice (1984).

Both the local and regional systems were modeled conceptually as a onelayer flow system combining valley-fill (alluvium), volcanic (tuff), and carbonate aquifers in a single unit. Total ground-water travel time from Yucca Mountain to Furnace Creek Wash is the sum of the local and regional estimates of cravel time.

The analysis of ground-water flow was conducted in two phases: a nearor local-scale model was used to analyze ground-water flow and travel time between Yucca Mountain and well J-12 (discussed in Section 3.2.3) and a far-field regional model was used to predict ground-water flow and travel time between we $11 \mathrm{~J}-12$ and the Furnace Creek Wash (discussed in Section 3.2.4). Stream tubes used in analysis of ground-water travel time between Yucca Mountain and Furnace Creek Wash are schematically illustrated in Figure 3.11. These stream tubes originate between USW-HI and USW-H3 at the reference repository location of Yucca Mountain, and spatialiy bound the one-dimensiorial unsaturated travel-time analyses at borehole USW-H4.

Ground-water flow modeling reported in Rice (1984) (Figure 3.11) predicted ground water-discharges at Furnace Creek Wash. Alkali Flat is considered by the USGS in their modeling activities to be the discharge area for ground water originating beneath Yucca Mountain. Section 3.2.5 of this report addresses and compares flow and travel-time interpretations by the USGS to the modeling results presented here.

The first phase (or local-scale model) is based on a near-field model reported by Thompson, Dove, and Krupka (1984) and subsequently used by 


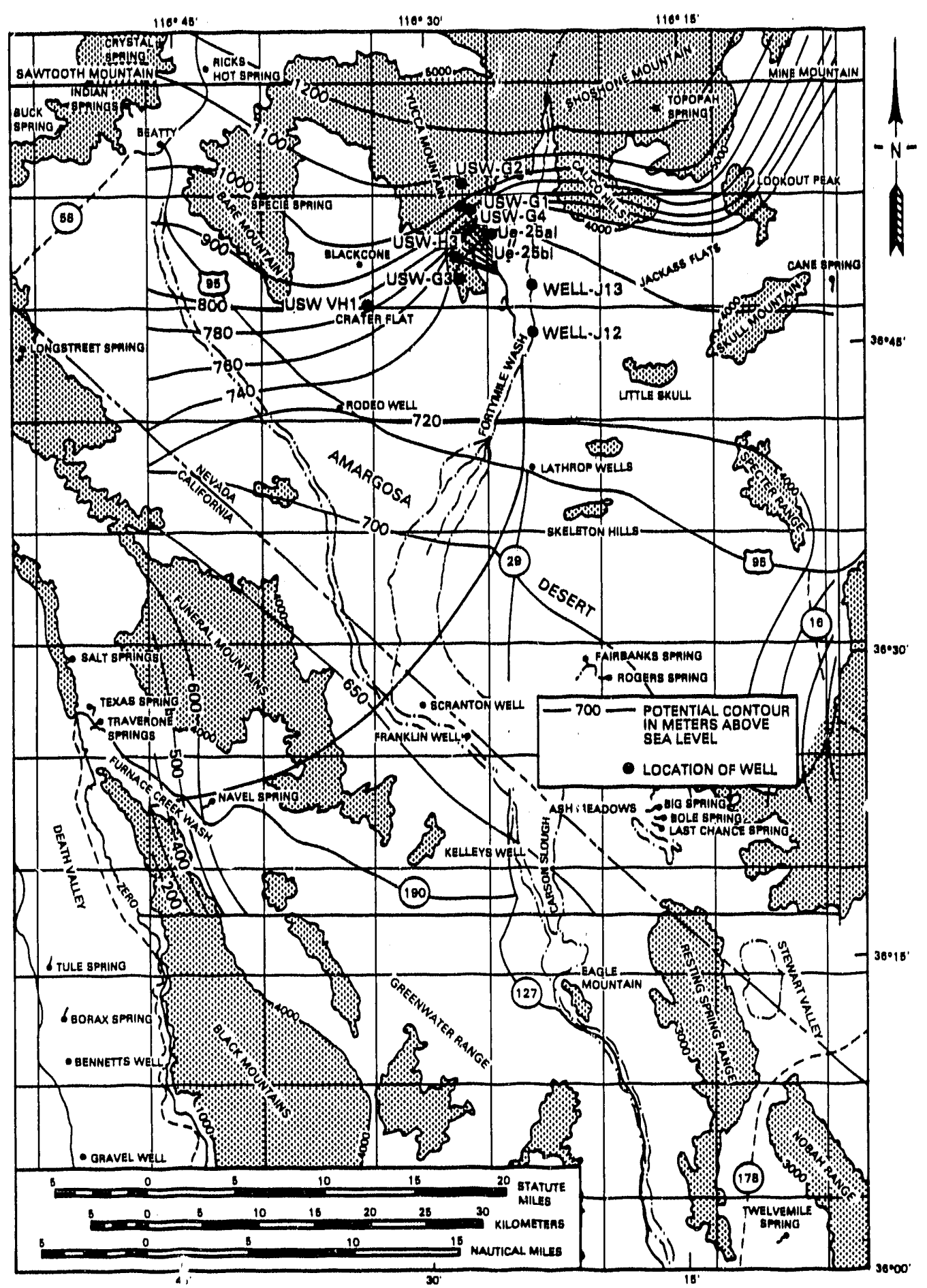

FIGURE 3.11. Schematic Representation of the Stream Tubes Used in the Travel-Time Analyses 
Jacobson, Freshley, and Dove (1985) for travel-time sensitivity analyses. The results from the latter study will be used for the near-field traveltime calculation based on the flow path between Yucca Mountain and well J-12. The study area of the near-field model is shown in Figure 3.12.

The second phase of the analysis is based on the regional calibrated hydrologic model of the NTS by Rice (1984). The study area for the regional model is shown in Figure 3.13. The regional model is used in a far-field analysis to calculate travel times from borehole J-12 to Furnace Creek Wash.

\section{Local-Scale Modeling}

The boundaries of the local-scale flow model that 1 le between $116^{\circ} 40^{\prime}$ and $116^{\circ} 11^{\prime}$ west longitude and $36^{\circ} 40^{\prime}$ and $37^{\circ} 00^{\prime}$ north latitude, are shown in Figure 3.12. The finite-difference grid is represented by 75 columns and 47 rows. Discretization of the local flow field is relatively dense at $0.8 \mathrm{~km}$. Equipotentials shown in Figures 3.11 and 3.14 are digitized from hand-contoured maps and from data that the USGS (Czarnecki and Wadde11 1984) obtained in 1982. These data are Tisted in Table 3.6. Robinson (1986) pub1 ished a more recent water table map (Figure 3.15 ) from water table measurements that were collected in 1983 . The 1983 water table elevations are 1isted in Table 3.7. Differences in 1982 and 1983 measurements are presented for comparison.

Depth to the water table at Yucca Mountain ranges between 300 and $750 \mathrm{~m}$. Observations of the smal1 fluctuations in head occurring between 1982 and 1983 can be related to measuring precision and on-going drilling activities in the area. Available data indicate that seasonal variations in water levels are a fraction of a meter. The 1982 hydraulic head data are used as the baseline potentiometric surface because no long-term trends are available.

Measured hydraulic heads used to construct the saturated-zone potentiometric map (Figures 3.11 and 3.14 ) are mostly composite heads, mensuring a wide portion of the aquifer and reflecting heads in the zones of higher transmissivity. The hydraulic head gradient is low in western jackass Flats (Fortymile Wash) and the Amargosa Desert and high in the region north of Yucca Mountain. If vertical movement of water is not considered, it can be 


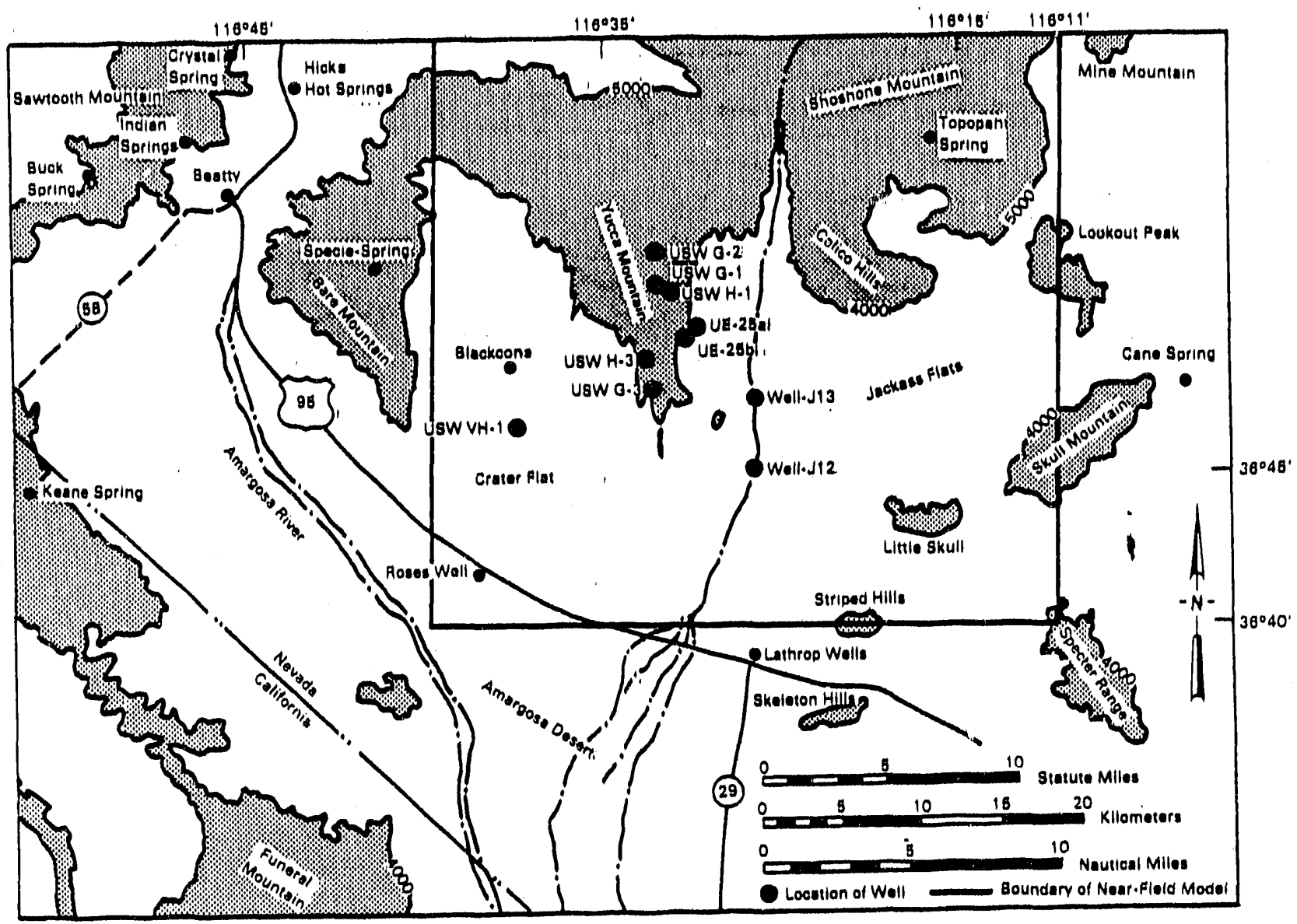

EIGURE 3.12. Location of the Near-Field Model

assumed that high transmissivities are reflected by low gradient and low transmissivities characterized by steep gradients. With this assumption, a trial-and-error technique based on the 1982 potentiometric surface was implemented to calculate a transmissivity distribution for the hydrologic model. This transmissivity distribution is shown in Figure 3.16.

No real recharge was assumed over the modeled region. This is a valid assumption, given that the regional analysis (Rice 1984) shows less than $0.254 \mathrm{~cm}$ of recharge at higher elevations in the Pahute Mesa area, north of Yucca Mountain. Less than $0.254 \mathrm{~cm}$ of recharge will not significantly change the boundary conditions of the near-field model.

Constant hydraulic heads were imposed at all boundaries of the flow model based on the digitized version of the 1982 USGS-interpreted hydraulic 


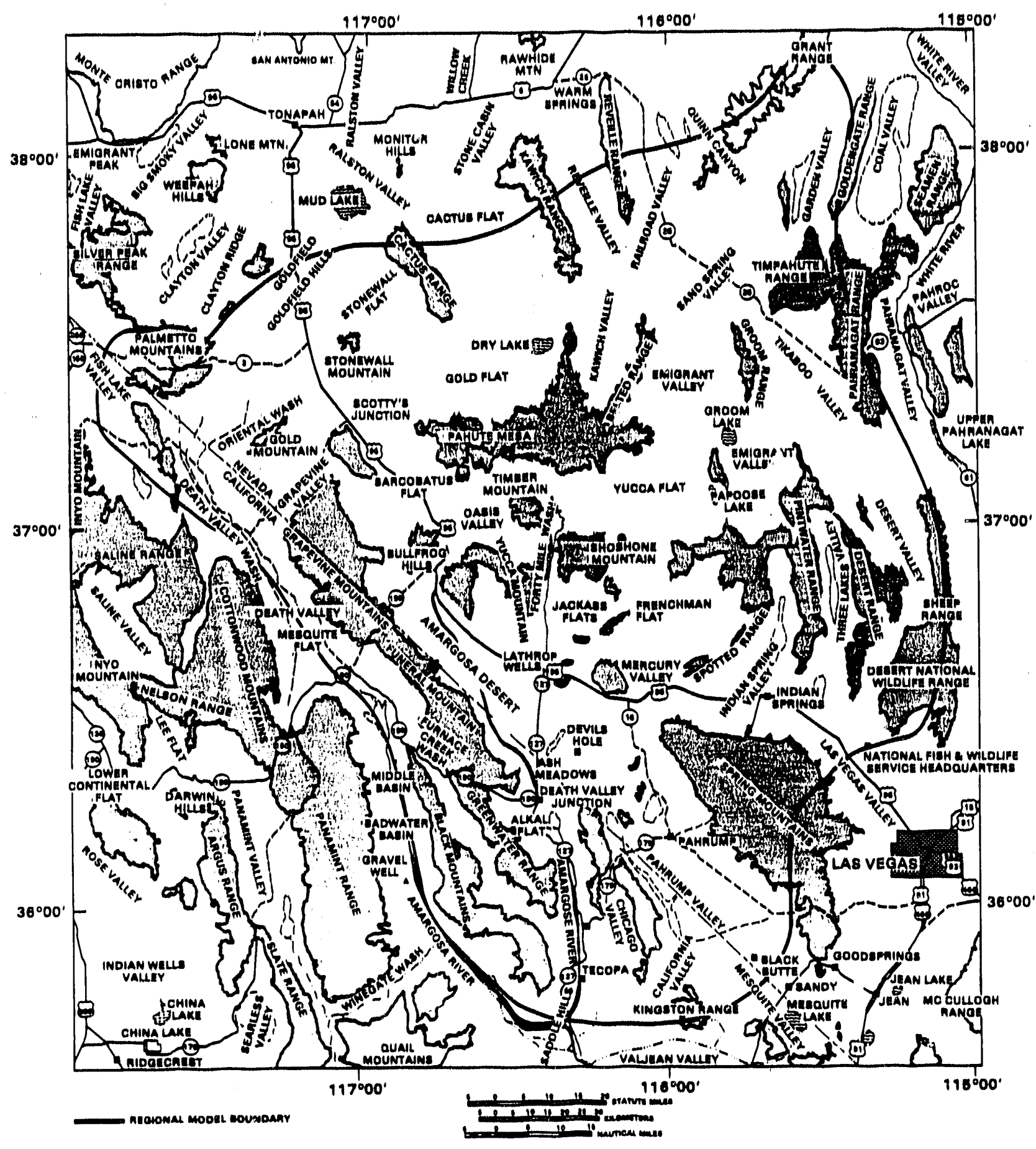

FIGURE 3.13. Location of Study Area for the Regional or Far-Field Analysis 


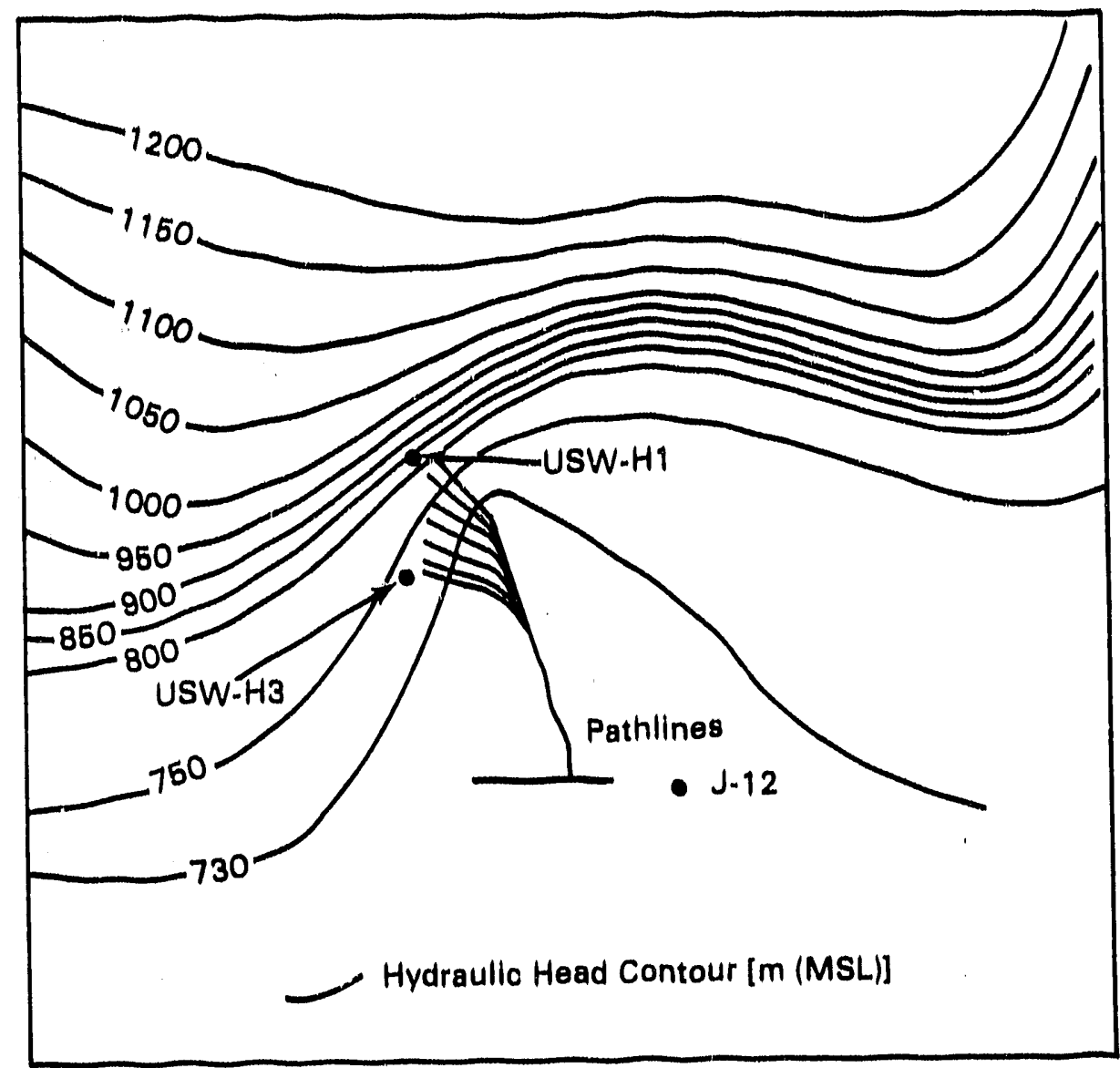

EIGURE 3.14. Contours of Hydraultc Heads Obtained from the U.S. Geological Survey Interpretation

head surface shown in Figure 3.14. Given these boundary conditions and the estimated transmissivity distribution, the model was used to estimate the hydraulic heads. Calibration of the flow model was considered unnecessary because the transmissivity surface was derived from the potentiometric surface and should theoretically match the hydraulic head data.

\section{Local Scale Travel-Time Analysts}

The near-field or local-scale analysis of travel time is based on the hydrologic model described above. Using this model, Jacobson, Freshley, and Dove (1985) conducted several uncertainty analyses for travel time based on conditioned Monte Carlo techniques. The stream tubes used in the 10cal travel-time analyses are shown in Figure 3.14. As mentioned previousiy, 
IABLE 3,6. Hydraultic Head Data(a) Used to Interpret Potentiometric Surface in Figure 3.14 from USGS (1982)

\begin{tabular}{|c|c|c|}
\hline $\begin{array}{l}\text { Hydraul ic } \\
\text { Head } \\
\text { Value (m) }\end{array}$ & $\begin{array}{l}\text { Measurement } \\
\text { Error (m) }\end{array}$ & We!l Name \\
\hline $\begin{array}{r}729.5 \\
729.4 \\
748.7 \\
1030.8 \\
785.2 \\
729.8 \\
770.9 \\
728.4 \\
729.4\end{array}$ & $\begin{array}{l} \pm 0.2 \\
\pm 0.2 \\
\pm 0.2 \\
\pm 8.9 \\
N / D(b) \\
\pm 2.0 \\
\pm 0.2 \\
\pm 2.0 \\
N / D\end{array}$ & $\begin{array}{l}\text { UE-25a1 } \\
\text { UE-25b1 } \\
\text { USW-G1 } \\
\text { USW-G2 } \\
\text { USW-G3 } \\
\text { USW-HI } \\
\text { USW-VHI } \\
\text { We11 J-13 } \\
\text { USW-H3 }\end{array}$ \\
\hline
\end{tabular}

(a) Writiten communication from USGS Denver office to PNL, March 31, 1982.

(b) $N / D=$ No data avallable.

streamlines for the local scale model originate between wells $\mathrm{H}-1$ and $\mathrm{H}-3$ of Yucca Mountain and terminate in the vicinity of well $\mathrm{J}-12$.

These streamlines traverse several transmissivity zones material types. A zonation pattern reflecting the transmissivity distribution is presented in Figure 3.17. Table 3.8 lists the mean and standard deviation of the computed transmissivities for each zone.

Figure 3.18 presents the correlation of porosity values with hydraulic conductivity measurements from boreholes GU-3 and G-4 at Yucca Mountain. This correlation of porosity values was used to establish the porosity values 1isted in Table 3.9 .

The various cases considered in the uncertainty analyses by Jacobson, Freshley, and Dove (1985) vary with respect to whether transmissivity and porosity distributions employed are deterministic or random and whether solution hydraulic heads or digitized potentiai contours are used. The seven cases considered by Jacobson, Freshley, and Dove (1985) are summarized in Table 3.10. Five of these cases $(2,3,5,6$, and 7$)$ are based on hydraulic 


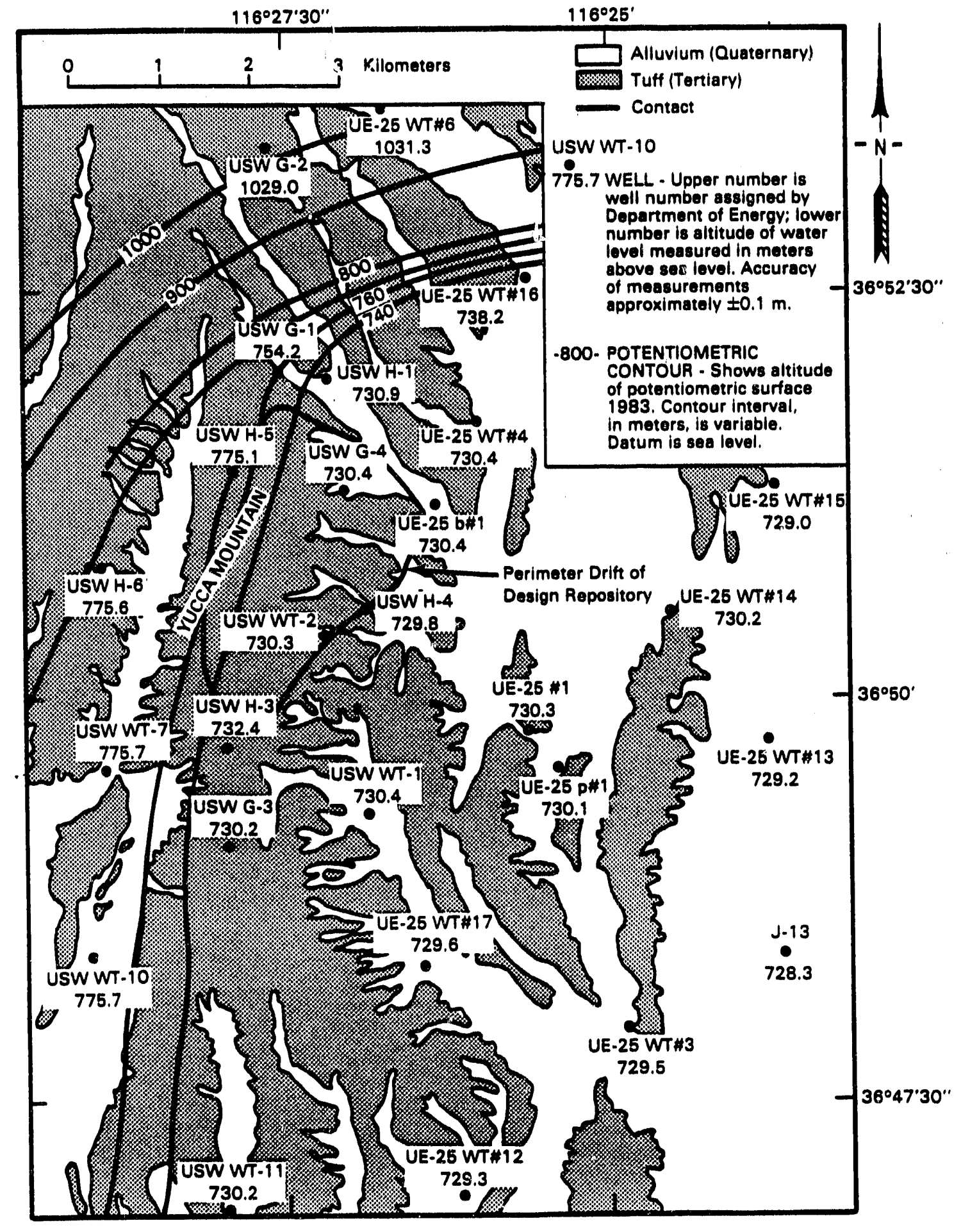

FIGURE 3.15. Preliminary Composite Potentiometric-Surface Map of the Saturated Zone, Yucca Mountain (modified from Robinson 1984) 
TABLE 3.7. Ground-Water Leve1s, Yucca Mountain Area (1982 data modified from Robinson 1984)

\begin{tabular}{|c|c|c|c|c|c|c|c|c|c|}
\hline \multirow{3}{*}{$\begin{array}{l}\text { Hole(a) or } \\
\text { Noll Number }\end{array}$} & \multirow{2}{*}{\multicolumn{2}{|c|}{$\begin{array}{c}\text { Location (b) } \\
\text { (feot) }\end{array}$}} & \multirow{3}{*}{$\begin{array}{l}\text { Dato(c) } \\
\text { Measured }\end{array}$} & \multirow{3}{*}{$\begin{array}{l}\text { Coologic (d) } \\
\text { Unit }\end{array}$} & \multicolumn{5}{|c|}{ Water Lovol (Corrected) } \\
\hline & & & & & \multirow{2}{*}{$\begin{array}{l}\text { Interval (0) } \\
\text { (noters) }\end{array}$} & \multirow{2}{*}{$\begin{array}{l}\text { Depth ( } f \text { ) } \\
\text { of Wator } \\
\text { (eotors) } \\
\end{array}$} & \multirow{2}{*}{$\begin{array}{l}1983 \text { Data } \\
\text { Altitude(g) } \\
\text { (notors) }\end{array}$} & \multirow{2}{*}{$\begin{array}{l}1982 \text { Data } \\
\text { Altitude } \\
\text { (moters) }\end{array}$} & \multirow{2}{*}{$\begin{array}{l}\text { Difforence } \\
\text { (moters) } \\
2983 \text { Data- } \\
1982 \text { Data }\end{array}$} \\
\hline & North & Enst & & & & & & & \\
\hline UE 25b \& 2 & 765,243 & 568,418 & $\begin{array}{l}12 / 03 / 83 \\
68 / 01 / 83 \\
08 / 81 / 83\end{array}$ & $\begin{array}{l}\text { Th/TIr } \\
\text { Th/Tet } \\
\text { Tet/TIr }\end{array}$ & $\begin{array}{l}\text { Conposito } \\
471 \quad 1,199 \\
1,199 \quad 1,220\end{array}$ & $\begin{array}{l}470.8 \\
470.3 \\
472.2\end{array}$ & $\begin{array}{l}730.9 \\
736.4 \\
728.5\end{array}$ & 729.4 & 1.0 \\
\hline UE $25 c \$ 1$ & 757,605 & 569,889 & $11 / 97 / 83$ & Tpt/Tct & Conposite & 469.3 & 739.3 & & \\
\hline UE 25p 11 & 758,171 & 571,485 & $\begin{array}{l}92 / / 83 \\
11 / 07 / 83\end{array}$ & $\begin{array}{l}\text { Th/Tcp } \\
P_{2} / P_{2}\end{array}$ & $\begin{array}{rr}383 & 598 \\
1,297 & 1,895\end{array}$ & $\begin{array}{l}383.9 \\
304.7\end{array}$ & $\begin{array}{l}738.1 \\
748.4\end{array}$ & & \\
\hline USW G 1 & 770,500 & 581,068 & $13 / 23 / 82$ & Tep/Tof & Conposito & 571.7 & 754.2 & 748.7 & 5.5 \\
\hline USW 02 & 778,824 & 569,684 & $69 / 17 / 82$ & Tpt/Tof & Composite & 524.9 & $\cdot 1,029.0$ & $1,030.8$ & 1.8 \\
\hline USW G 3 & 752,780 & 558,483 & $11 / 38 / 83$ & Tcb/Tof & Conposite & 750.3 & 730.2 & & \\
\hline usw 04 & 765,807 & 563,1882 & $64 / 27 / 83$ & - Tep/Tet & Composite & 530.1 & 730.4 & & \\
\hline USW II \& & 770,254 & 682,388 & $\begin{array}{l}02 / 25 / 82 \\
11 / 61 / 83 \\
11 / 91 / 83 \\
11 / 01 / 83 \\
11 / 61 / 83\end{array}$ & $\begin{array}{l}\text { Tep/Tof } \\
\text { Tep/Tep } \\
\text { Teb/Teb } \\
\text { Tet/Tet } \\
\text { Tof/Tof }\end{array}$ & \begin{tabular}{rr}
\multicolumn{2}{c}{ Composito } \\
572 & 673 \\
716 & 785 \\
1,097 & 1,123 \\
1,783 & 1,814
\end{tabular} & $\begin{array}{l}572.1 \\
572.4 \\
572.4 \\
571.7 \\
518.2\end{array}$ & $\begin{array}{l}739.9 \\
739.7 \\
739.7 \\
731.4 \\
784.9\end{array}$ & 729.8 & -1.1 \\
\hline USW II 3 & 756,542 & 658,452 & $\begin{array}{l}11 / 19 / 82 \\
11 / 83 / 83 \\
11 / 03 / 83\end{array}$ & $\begin{array}{l}\text { Teb/TIr } \\
\text { Teb/TIr } \\
\text { TIr/TIr }\end{array}$ & $\begin{array}{cc}\text { Conposito } \\
751 & 1,100 \\
1,190 & 1,210\end{array}$ & $\begin{array}{l}570.8 \\
750.8 \\
729.6\end{array}$ & $\begin{array}{l}732.4 \\
732.4 \\
34.0\end{array}$ & 729.4 & 3.8 \\
\hline USW II 4 & $\begin{array}{c}781,643 \\
.\end{array}$ & 583,911 & $\begin{array}{l}12 / 30 / 82 \\
60 / 16 / 83 \\
66 / 16 / 83\end{array}$ & $\begin{array}{l}\text { Tep/TIr } \\
\text { Tep/TIr } \\
\text { TIr/TIr }\end{array}$ & $\begin{array}{cc}\text { Composite } \\
518 & 1,181 \\
1,181 & 1,210\end{array}$ & $\begin{array}{l}518.7 \\
518.2 \\
518.1\end{array}$ & $\begin{array}{l}729.8 \\
739.3 \\
739.4\end{array}$ & & \\
\hline USW II 5 & 786,634 & 558,989 & $\begin{array}{l}12 / 22 / 83 \\
11 / 87 / 83 \\
11 / 97 / 83\end{array}$ & $\begin{array}{l}T c b / T I \\
T c b / T I \\
T I / T I\end{array}$ & $\begin{array}{ll}\text { Composite } \\
794 & 1,091 \\
1,891 & 1,210\end{array}$ & $\begin{array}{l}704.2 \\
793.8 \\
703.8\end{array}$ & $\begin{array}{l}774.7 \\
775.1 \\
775.1\end{array}$ & & \\
\hline USW II 6 & 783,299 & 554,075 & $\begin{array}{l}12 / 15 / 82 \\
16 / 24 / 83 \\
10 / 24 / 83\end{array}$ & $\begin{array}{l}\text { Tep/TIr } \\
\text { Tcp/Tcb } \\
\text { Tct/TIr }\end{array}$ & $\begin{array}{cc}\text { Conposito } \\
520 & 1,187 \\
1,187 & 1,226\end{array}$ & $\begin{array}{l}520.6 \\
526.1 \\
524.7\end{array}$ & $\begin{array}{l}775.1 \\
775.8 \\
777.8\end{array}$ & & \\
\hline USW VTII & 753,941 & 563,739 & $10 / 31 / 83$ & $T h / T c b$ & Couposite & 471.0 & 730.4 & & \\
\hline uSW wt/2 & 781,061 & 561,924 & $11 / 01 / 83$ & Tep/Tep & Composito & 871.0 & 730.3 & & \\
\hline UE $25 N T \$ 3$ & 746,095 & 573,384 & $10 / 31 / 63$ & Tcb/Tab & Composite & 300.5 & 729.5 & & \\
\hline UE 25 WT/4 & 768,512 & 588,540 & $11 / 01 / 83$ & Th/Th & Conposite & 438.8 & 730.4 & & \\
\hline UE 25 mT/6 & 780,576 & 687,524 & $10 / 31 / 83$ & $T h / T h$ & Composite & 283.8 & $1,031.3$ & & \\
\hline USW WTY7 & 755,570 & 583,891 & $18 / 24 / 03$ & Tpt/Tep & Composite & 421.2 & 775.7 & & \\
\hline USW WTI10 & 748,771 & 553,302 & $10 / 24 / 83$ & Tpt/Tpt & Conposite & 347.7 & 775.7 & & \\
\hline USW WTIII & 739,070 & 558,377 & $10 / 24 / 83$ & $T p t / T h$ & Conposite & 383.9 & 730.2 & & \\
\hline UE 25 WT/12 & 739,726 & 567,011 & $10 / 31 / 83$ & Tpt/Th & Conposito & 345.4 & 729.4 & & \\
\hline LE 25 พT/13 & 756,884 & 578,843 & $10 / 31 / 83$ & $T p t / T p t$ & Conposite & 383.3 & 729.2 & & \\
\hline
\end{tabular}


TABLE 3.7. (contd)

\begin{tabular}{|c|c|c|c|c|c|c|c|c|c|}
\hline \multirow{3}{*}{$\begin{array}{l}\text { Hola }(\mathbf{a}) \text { or } \\
\text { veli Number }\end{array}$} & \multirow{2}{*}{\multicolumn{2}{|c|}{$\begin{array}{c}\text { Location(b) } \\
\text { (foot) }\end{array}$}} & \multirow{3}{*}{$\begin{array}{l}\text { Dato(c) } \\
\text { Hesesured }\end{array}$} & \multirow{3}{*}{$\begin{array}{c}\text { Coologic(d) } \\
\text { Unit }\end{array}$} & & & & & \\
\hline & & & & & Int & $\begin{array}{l}\text { Depth(f) } \\
\text { of Votar }\end{array}$ & $\begin{array}{l}1983 \text { Data } \\
\text { Altitude }(g)\end{array}$ & $\begin{array}{l}1982 \text { Dats } \\
\text { Altituda }\end{array}$ & $\begin{array}{l}\text { Difforence } \\
\text { (notors) } \\
1083 \text { Data- }\end{array}$ \\
\hline & North & Est & & & (uoters) & (wotora) & (neters) & (eotors) & 1082 Data \\
\hline UE $25 \mathrm{NT/14}$ & 781,851 & 575,210 & $11 / 07 / 83$ & $T p t / T h$ & Conposito & 340.2 & 730.2 & & \\
\hline UE $25 \mathrm{~T} / 15$ & 780,116 & 579,800 & 12/01/00 & $T p t / T p t$ & Couposite & 364.2 & 729.0 & & \\
\hline UE 25 IT/16 & 774,429 & 578,395 & $12 / 01 / 83$ & $T h / T h$ & Conposite & 472.7 & 738.2 & & \\
\hline VE 25 IT/17 & 748,420 & 566,212 & $12 / 87 / 60$ & Tep/Tep & Conposito & 394.8 & 729.1 & & \\
\hline Woll J 11 & 741,988 & 611,764 & $03 / 22 / 73$ & $--/ T p t$ & Couposite & 317.4 & 732.8 & & \\
\hline Woll J 12 & 733,860 & 581,011 & $12 / 05 / 83$ & $T p t / T p t$ & Composito & 228.2 & 727.3 & 727.3 & 1.0 \\
\hline Voll \& 13 & 749,200 & 579,051 & $10 / 31 / 83$ & $T p t / T I P$ & Conposito & 283.2 & 728.1 & 728.4 & -8.3 \\
\hline USW VII 1 & 743,356 & 633,628 & $12 / 12 / 81$ & $Q_{2} / T c b$ & Composito & 184.2 & 779.3 & 778.9 & 8.4 \\
\hline USW VII 2 & 748,320 & 528,284 & $04 / 23 / 83$ & $Q_{a} / \mathrm{Tcb}$ & Conposito & 184.0 & 020.4 & & \\
\hline
\end{tabular}

(a) Hole or wall nuaber: Dasignation aseigned by U.S. Dapartaent of Enoray.

(b) Lecation: Mevada State Coordinate Syatee Control Zone.

(c) Date messured: Dato of a mater-lovel aessurcasent.

(d) Coologic unit: Shallowest geologic unit reprosented by the wtor lovol/deepeat geol zyic unit ropresented by the water level. Qa = alluviun; Tpt = Topopah Spring Hobor of Paintbruch Tuff; Th = Luffaceous beds of Calico Hilla; Tep = Prow Paes Leaber of Crater Flat Tuff; Teb - Bulleroo Member of Crater Flat Tuff; Tet = Trae Unaber of Crater Flat Tuff; TI = Lava; Tir = Lithic Rides Tuff; Tof = oldor flows and tuffa; $z$ Paloozoic rocke.

(e) Interval: Depth intorval of the hole represented by the wator-lovel sessuraent. Composito lovels represent aixed hydraulic hasds of the ontire interval botwen the water table or lower end of the casing and the botton of the hole. Whare a epecific interval ie indicated, the zone ma ieolated using a single packer inatalled to datarmine hydraulic hoad differences above and bolow the packer.

(f) Dopth to weter: Dapth baeed on direct saseuresents of wator levele using down hole wireline equipaent, adjuated for depth correction, there available. Aceuracy of seasurcaente approximately 1.1a. Dapth in USW VH 2 eatimated fron goophysical loos.

(g) Altitude: Computed altitude of water levol above cos-lovel, based on land surface sltitude and mesaured depth to water (corrected).

head solutions and are described in more detail at the bottom of Table 3.10. These cases were considered for estimating travel time as a part of this risk assessment.

For each case, 100 realizations of transmissivity and solution hydraulic heads were generated. Streaml ines were generated from Yucca Mountain to well J-12 and travel times were computed for each realization. Porosity values used were either deterministic (constant over the domain or spatially larying for each zone) or were randomly generated but correlated with hydraulic conductivity (see Table 3.10). 


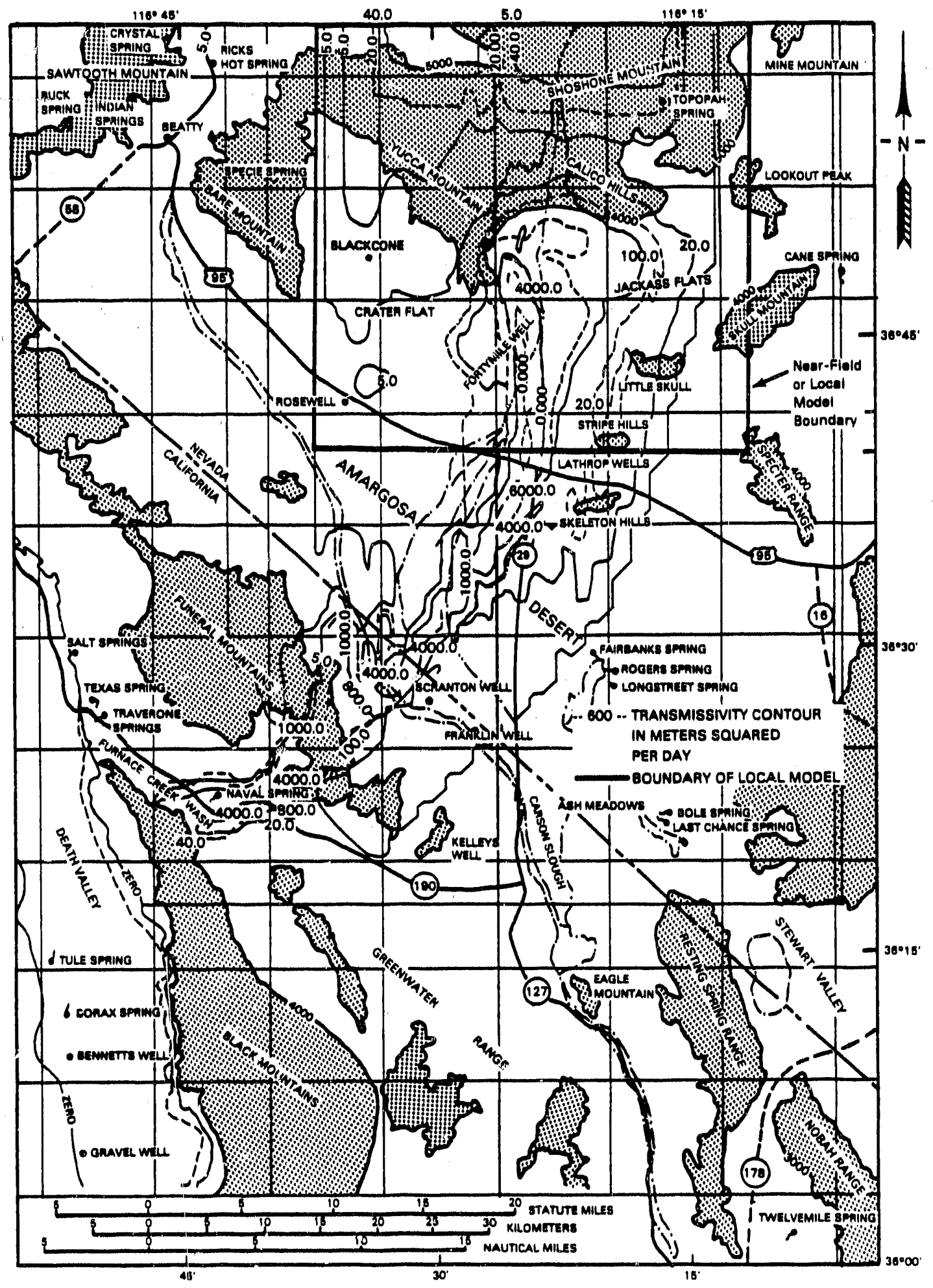

FIGURE 3.16. Contoured Transmissivity Map for Baseline Potentiometric Surface 


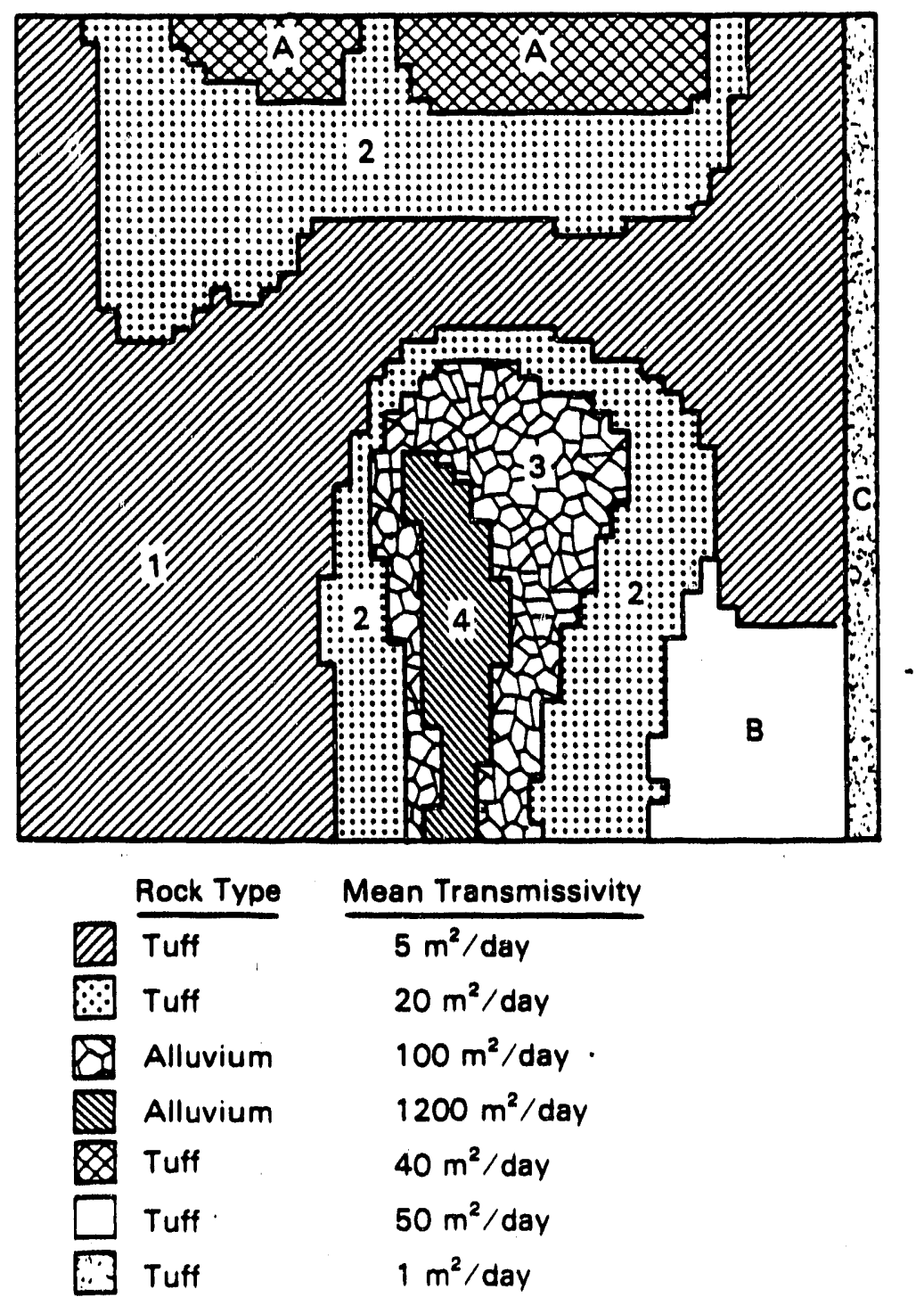

FIGURE 3.17. Transmissivity Zonation Pattern for the Study Area

Table 3.11 lists both the mean and standard deviations of travel times from wells $\mathrm{H}-1$ and $\mathrm{H}-3$ of Yucca Mountain to well J-12. For the cases based on hydraulic head solutions (cases $2,3,5,6,7$ ), relatively little difference in mean travel time (between 840 and 1090 years) was found. It should be emphasized that the results listed in Table 3.11 are based on a constant saturated thickness value of $81 \mathrm{~m}$.

A more recent saturated thickness, $749 \mathrm{~m}$, is reported by the USGS (see Lahoud, Lobmeyer, and Whitfield 1984, p. 42) at well UE-25b 1. This value of 
TABLE 3.8. Estimates of Mean and Standard Deviation of Log Transmissivity for Each Zone

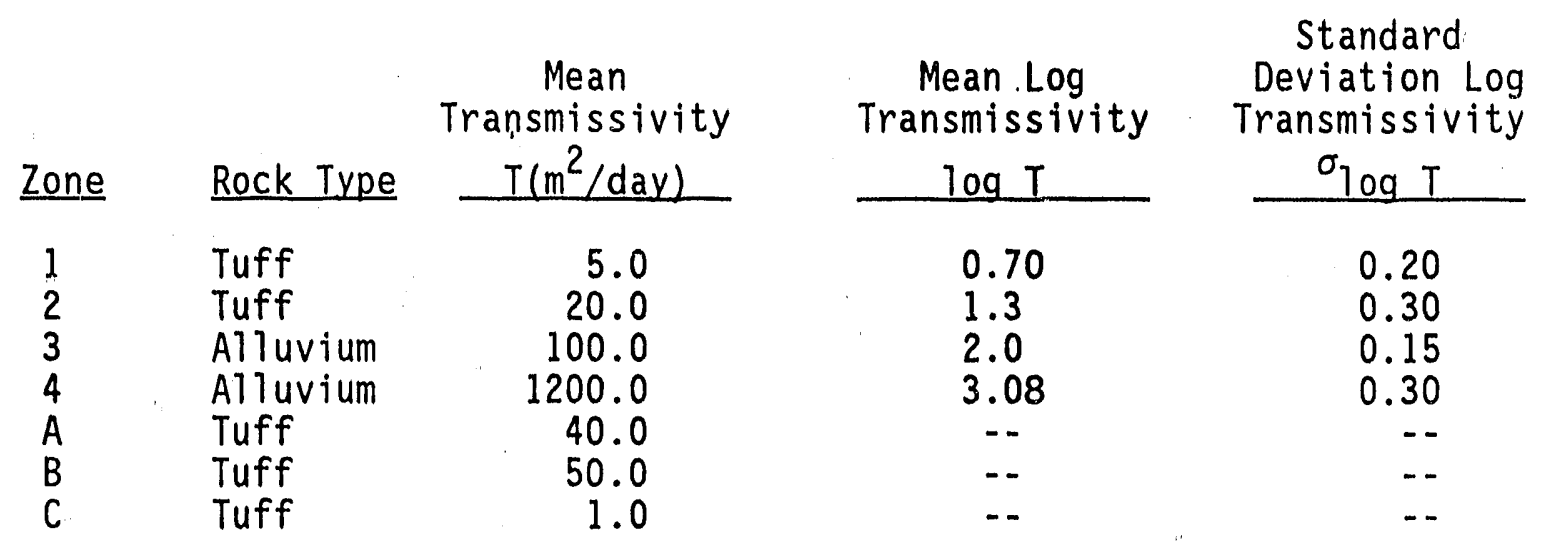

saturated thickness is consistent with other hydrologic modeling of the NTS (Waddell 1982; Czarnecki and Waddell 1984), where saturated thicknesses ofthe tuffs and alluvium are reported between 500 and $1000 \mathrm{~m}$ (Benson et al. 1983). When our travel-time calculations were updated to reflect the $749 \mathrm{~m}$ measured ai well UE-25b 1, travel times lengthened by a factor of 9.246 . Table 3.12 lists these revised travel times. Stream tube characteristics needed for scenario calculations are listed in Table 3.13.

\section{Comparison of Local-Scale Ground-Water Travel Times with Previous} Calculations

Previous travel-time calculations have been performed by the USGS using the flow model developed by Czarnecki and Waddell (1984). The location of the USGS subregion hydrologic model is shown in Figure 3.19. A flow path of $11.96 \mathrm{~km}$ was selected as one possible route by which radionuclides might move downgradient from the repository site. Saturated thicknesses were assumed to be between 500 and $1000 \mathrm{~m}$; this assumption is based on pump tests that indicate the extent of the permeable zone at Yucca Mountain (Benson et al. 1983). Primary porosities were assumed to range between 0.001 (fracture porosity) and 0.01 (matrix porosity). Travel times for the extremes of these ranges $(n=0.001, b=500 \mathrm{~m}$, and $n=0.01, b=1000 \mathrm{~m})$ are 86 and 17,313 years, respectively.

The flow path length used in our analys is varies between 9.5 and $12.6 \mathrm{~km}$ (Table 3.13 ) and the length of the flow path used by the USGS is 


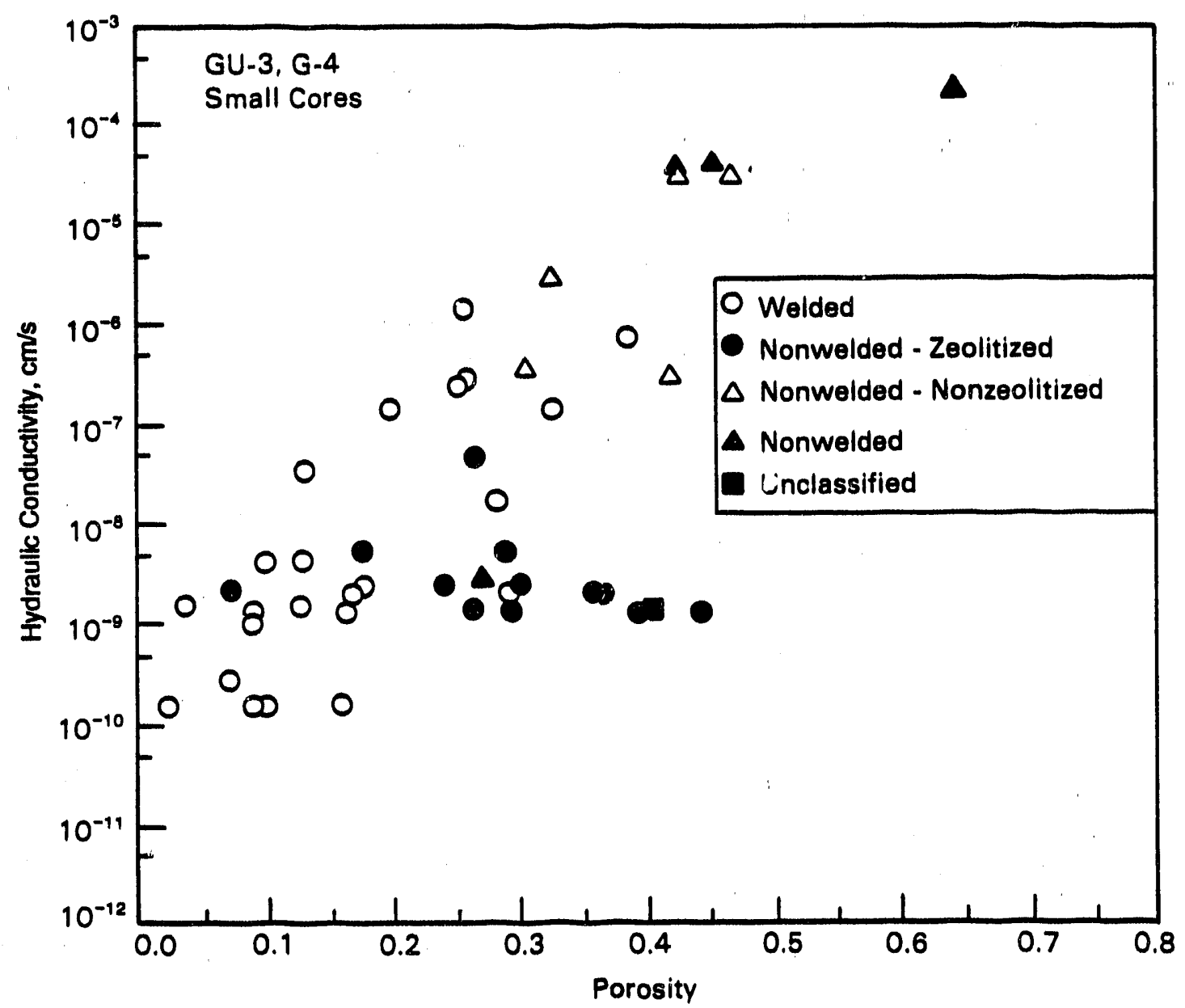

FIGURE 3.18. Correlation Between Porosity and Hydraulic Conductivity for Small Cores USW GU-3 and USW GU-4 (from Peters et al. 1984)

IABLE 3.9. Estimates of Mean and Standard Deviation of Effective Porosity for Each Zone

\begin{tabular}{|c|c|c|c|}
\hline Zone & $\begin{array}{c}\text { Mean } \\
\text { Transmissivity } \\
\left(m^{2} / \text { day }\right) \\
\end{array}$ & $\begin{array}{l}\text { Mean } \\
\text { Effective } \\
\text { Porosity }\end{array}$ & $\begin{array}{l}\text { Standard } \\
\text { Deviation } \\
\text { Effective } \\
\text { Porosity } \\
\end{array}$ \\
\hline $\begin{array}{l}1 \\
2 \\
3 \\
4\end{array}$ & $\begin{array}{r}5 \\
20 \\
100 \\
1,200\end{array}$ & $\begin{array}{l}0.10 \\
0.15 \\
0.20 \\
0.32\end{array}$ & $\begin{array}{l}0.02 \\
0.03 \\
0.04 \\
0.04\end{array}$ \\
\hline
\end{tabular}



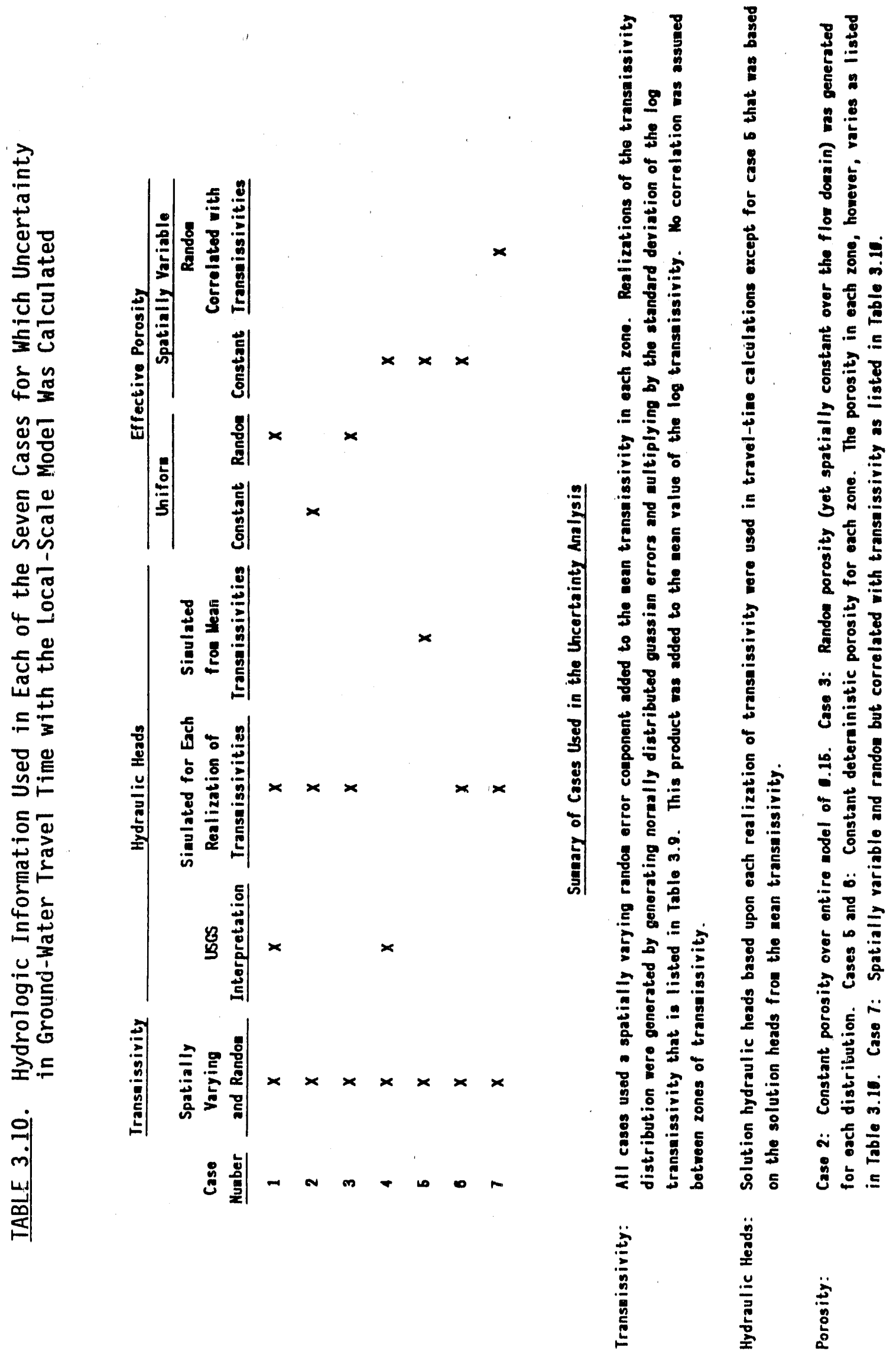
TABLE 3.11. Sample Means, Standard Deviations, Coefficient of Variations and Medians for Ground-Water Travel Times Based on Hydraulic Head Solutions (saturated thickness $=81 \mathrm{~m}$ )

\begin{tabular}{|c|c|c|c|c|}
\hline Case & $\begin{array}{c}\text { Sample } \\
\text { Mean (yr) }\end{array}$ & $\begin{array}{l}\text { Median } \\
(\forall r)\end{array}$ & $\begin{array}{c}\text { Standard } \\
\text { Deviation (yr) }\end{array}$ & $\begin{array}{l}\text { Coefficient } \\
\text { of Variation } \\
\end{array}$ \\
\hline $\begin{array}{l}2 \\
3\end{array}$ & $\begin{array}{r}840 \\
920 \\
1090 \\
1070 \\
1090\end{array}$ & $\begin{array}{r}820 \\
890 \\
990 \\
1030 \\
1060\end{array}$ & $\begin{array}{l}280 \\
460 \\
390 \\
360 \\
340\end{array}$ & $\begin{array}{l}0.29 \\
0.50 \\
0.36 \\
0.34 \\
0.31\end{array}$ \\
\hline
\end{tabular}

TABLE 3.12. Revised Travel Time Statistics Based on Updated Saturated Thickness (saturated thickness $=749 \mathrm{~m}$ )

\begin{tabular}{|c|c|c|c|}
\hline Case & $\begin{array}{c}\text { Sample } \\
\text { Mean (yr) }\end{array}$ & $\begin{array}{l}\text { Median } \\
(y r)\end{array}$ & $\begin{array}{c}\text { Standard } \\
\text { Deviation (yr) }\end{array}$ \\
\hline 5 & $\begin{array}{r}7,767 \\
8,507 \\
10,079 \\
9,894 \\
10,079\end{array}$ & $\begin{array}{l}7,582 \\
8,229 \\
9,154 \\
9,523 \\
9,801\end{array}$ & $\begin{array}{l}2,589 \\
4,253 \\
3,606 \\
3,328 \\
3,143\end{array}$ \\
\hline
\end{tabular}

TABLE 3.13. Stream Tube Characteristics

\begin{tabular}{|c|c|c|}
\hline $\begin{array}{c}\text { Stream } \\
\text { Tube } \\
\text { Number }\end{array}$ & $\begin{array}{c}\text { Distance } \\
\text { to Well } \\
\mathrm{J}-12(\mathrm{~km})\end{array}$ & $\begin{array}{l}\text { Distance } \\
\text { to Furnace } \\
\text { Creek (km) }\end{array}$ \\
\hline $\begin{array}{l}1 \\
2 \\
3 \\
4 \\
5 \\
6\end{array}$ & $\begin{array}{r}9.47 \\
9.95 \\
10.44 \\
11.13 \\
11.84 \\
12.57\end{array}$ & $\begin{array}{l}67.83 \\
08.31 \\
68.81 \\
69.33 \\
70.03 \\
70.75\end{array}$ \\
\hline
\end{tabular}

$12.0 \mathrm{~km}$. Multiplying the USGS travel time, which was estimated with $10 \%$ porosity, by a factor of 0.749 (to reflect a saturated thickness value of $749 \mathrm{~m}$ rather than $1000 \mathrm{~m}$ ) reduces the travel time to 12,967 years. This travel time is consistent with our estimates of 7,767 to 10,079 years. 


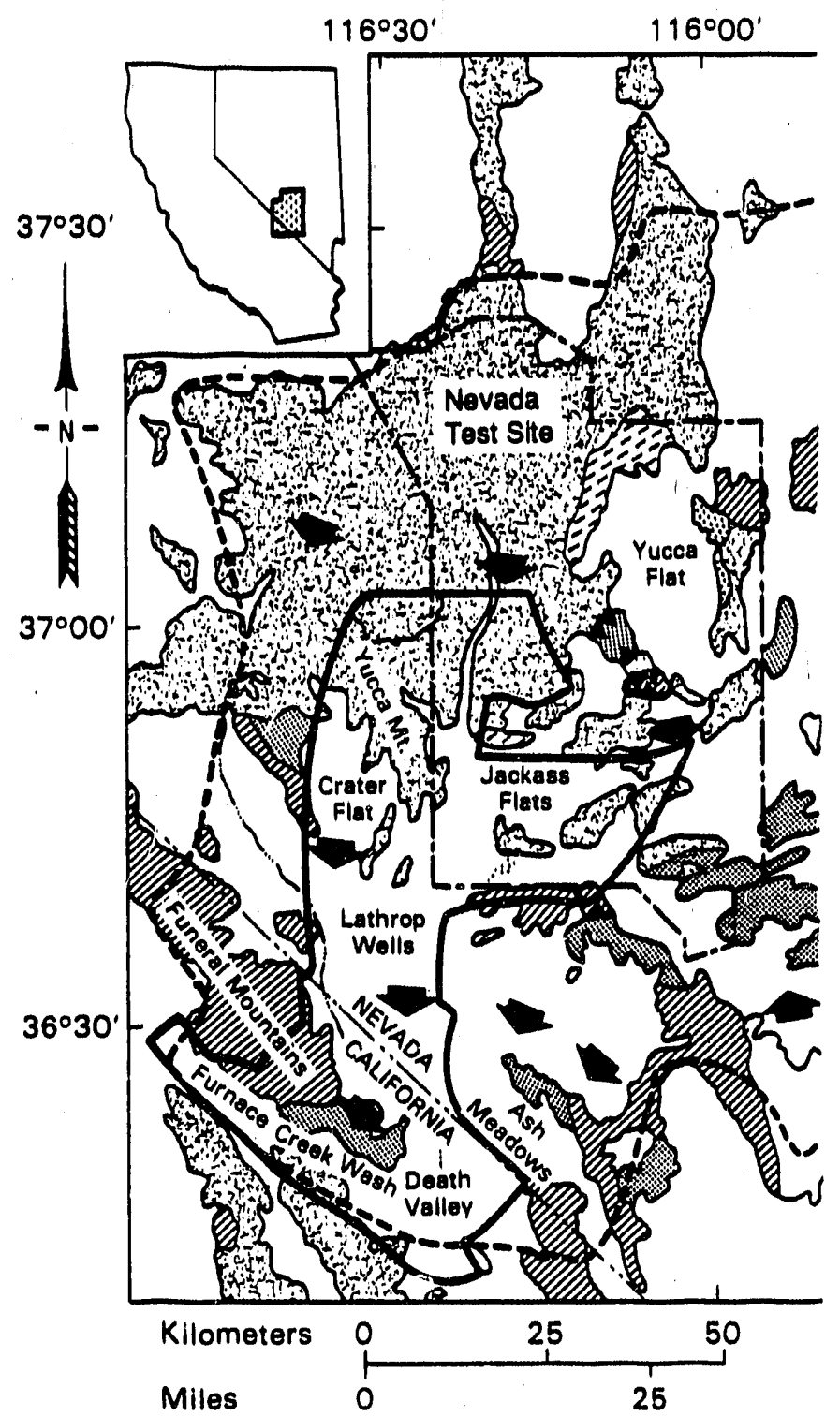

\section{EXPLANATION \\ QUATERNARY}

Alluvium, lake beds,

and minor volcanic rooks

TERTIARY

Tuff, rhyolite, and associated volcanic rocks

\section{MESOZOIC (Minor-not shown)}

PALEOZOIC

Undifferentiated upper classic aquitard, and lower and upper carbonate aquifers

EYe] Upper classic aquitard Lower carbonate aquifer

PALEOZOIC (CAMBRIAN) and PRECAMBRIAN

YIIIA Lower classic aquitard

\section{SYMBOLS}

_ Contact

Trust fault with sawteeth on upper plate

- . Regional model boundary (Waddell 1982) (approximate boundary of ground-water system)

USGS model boundary

- Approximate direction of ground-water flow

FIGURE 3.19. Location of the U.S. Geological Survey Subregional Model

\section{Description of the Regional-Scale Hydrologic Model}

Description of the regional-scale analysis for travel time is based on a regional scale model by Rice (1984). The study area for the regional analysis is shown in Figure 3.13. The extent of the study area is larger than the area covered by the USGS regional hydrologic model (see figure 3.8). Therefore, regional flow and transport analyses by the USGS are compared with the regional-scale model by Rice (1984). 
The study area considered in the regional hydrologic model of Rice (1984) shown in Figure 3.13 is located between $114^{\circ} 59^{\prime}$ and $117^{\circ} 54^{\prime}$ west longtude and $35^{\circ} 34^{\prime}$ and $38^{\circ} 19^{\prime}$ north. latitude. The finite difference node spacing of the model is $3.81 \mathrm{~km}$. The boundaries of the hydrologic model shown in Figure 3.13 were established along topographic highs: on the north, the Palmetto Mountains and the Catus, Kawich, Reveille and Grant Ranges; on the east, the Paranagat Range, Sheep Range, and Spring Mountain; and on the south, the Kingston Range and Saddle Hills. Death Valley, a topographic low, defined the western boundary, while the recharging boundaries on the north and east were prescribed at those shown on a water table elevation map provided by the Denver office of the USGS (Figure 3.20).

The uncertainty in the USGS-interpreted hydraulic head distribution was estimated by comparing the hand-contoured distribution shown in Figure 3.20 with water table measurements at well locations. The average and root-meansquared error differences between the USGS-interpreted distribution and well data are 23.7 and $34.3 \mathrm{~m}$, respectively.

The hydraulic head data shown in Figure 3.20 were kriged with a zeroorder drift generalized covariance function, $K[\mathrm{~h}]=0.0 \delta-1.5459[\mathrm{~h}]$. The kriged distribution is shown in Figure 3.20. The kriging or estimation error is the standard deviation of each estimated point and is contoured in Figure 3.21. The uncertainty in the hydraulic head map is approximately 30 to $50 \mathrm{~m}$ at the major discharging areas, Furnace Creek Wash and Ash Meadows. This amount of error in the hydraulic head distribution contributes to hydraulic gradient errors and could affect the direction and velocity of ground-water flow.

\section{Regional Travel-Time Analysis}

The regional travel-time analysis is based on results from the regional hydrologic model. Travel times were calculated for ten stream tubes shown in Figure 3.22. These stream tubes start at well J-12 and terminate at the Furnace Creek Wash area of Death Valley. The calibrated transmissivity distribution for the hydrologic model (Figure 3.23 ) is used to calculate travel times. 


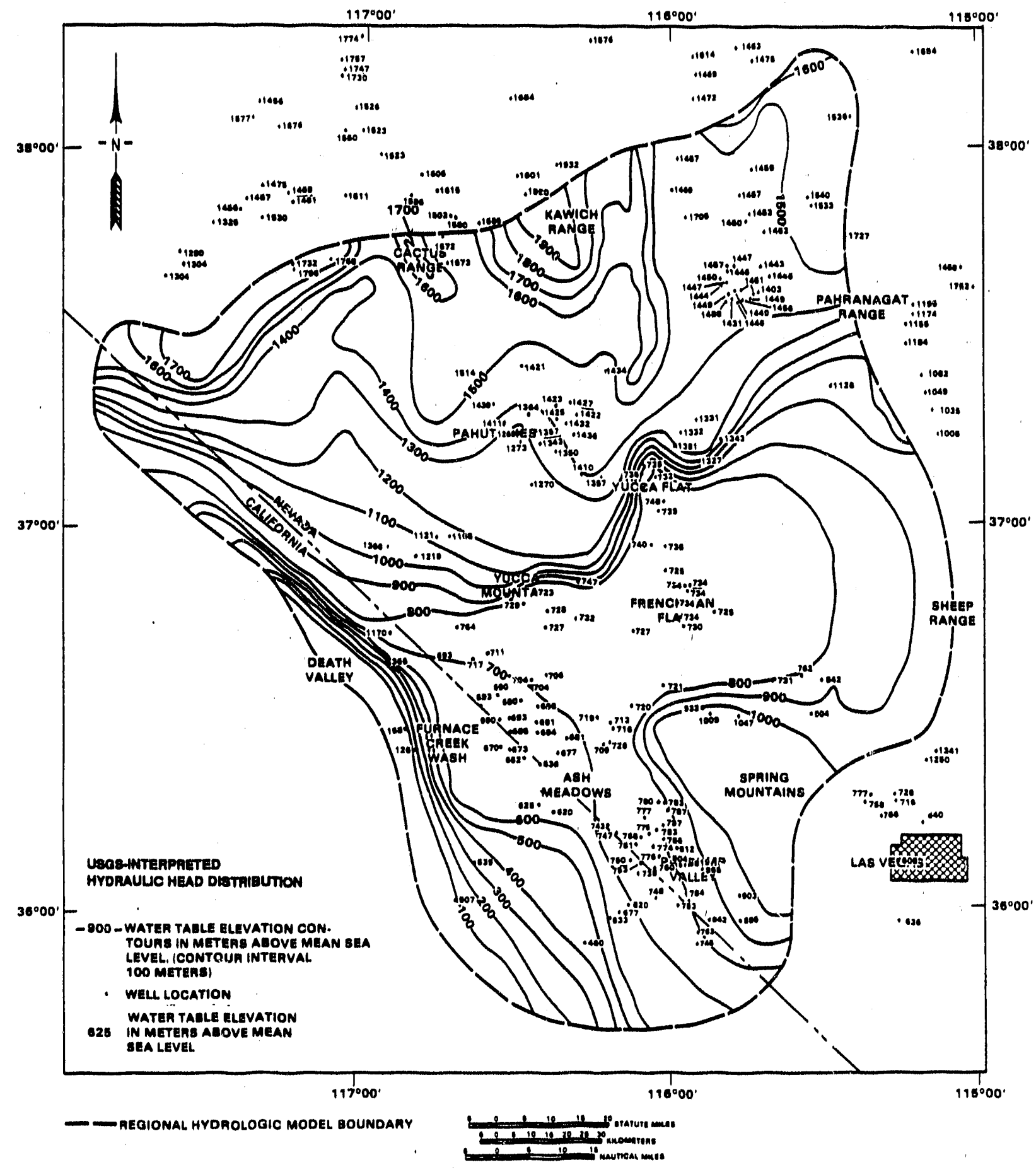

FIGURE 3.20. U.S. Geological Survey-Interpreted Hydraulic Head Distribution for the Regional Model (hydraulic heads in meters above mean sea level) 


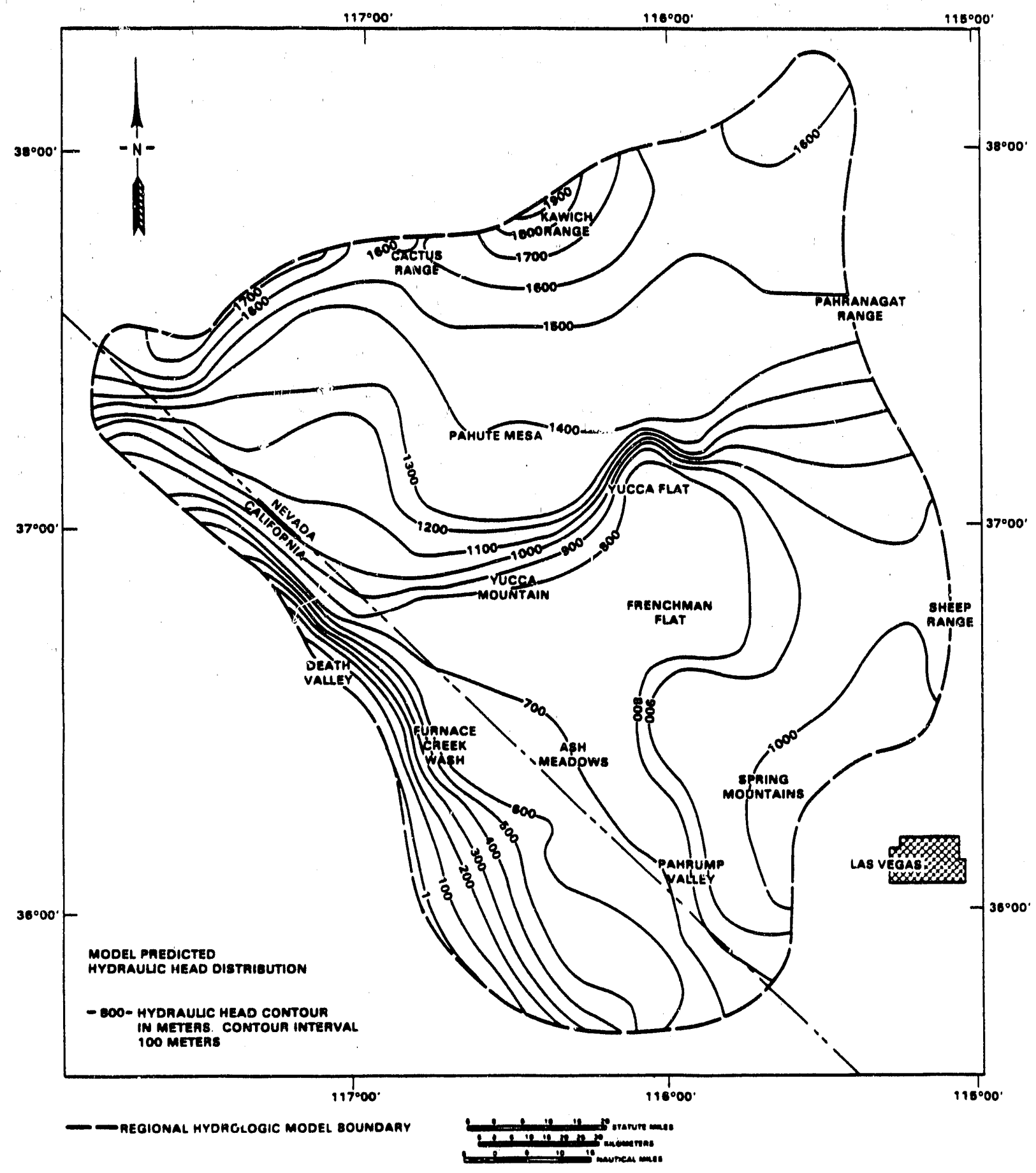

FIGURE 3.21. Mode7-Predicted Hydraulic Heads for Steady-State Confined Conditions (hydraulic heads in meters above mean sea level) 


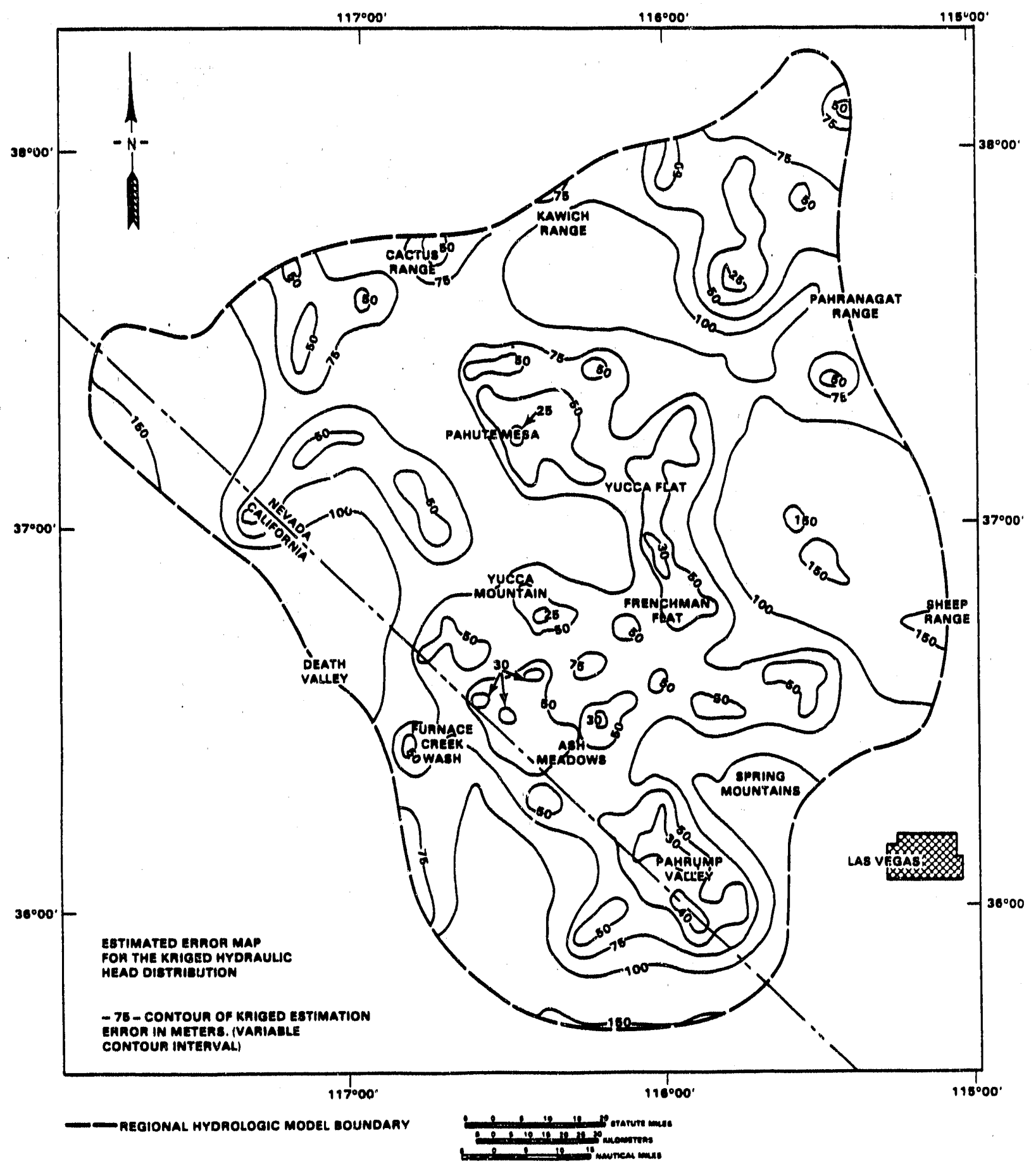

FIGi'RE 3.22. Map of Kriging Error or Estimation Effort for the Regional Mode1 (contours in meters of error) 


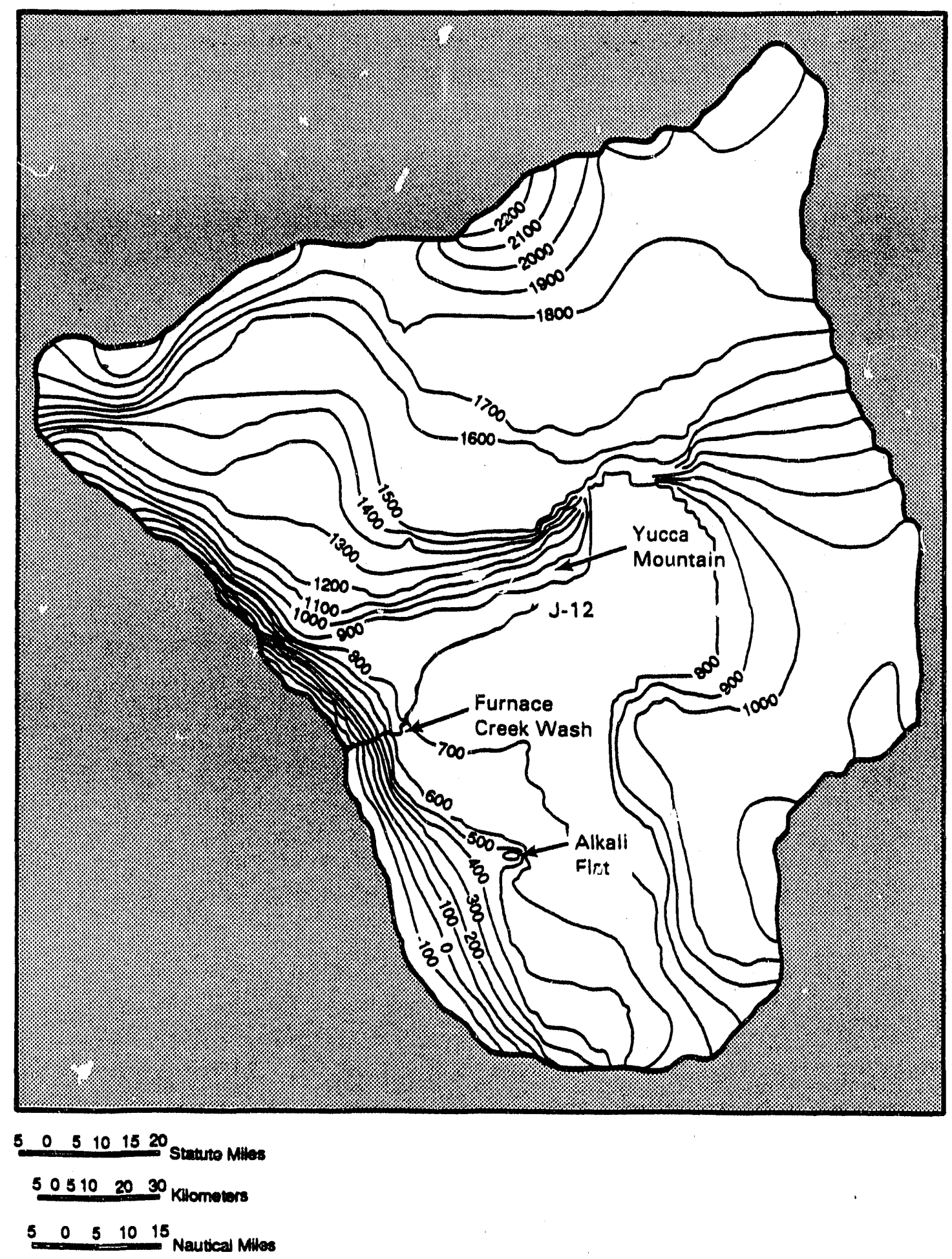

FIGURE 3.23. Hydraulic Head Distribution of the Calibrated Regional Model with Stream Tubes Originating Near Well J-12 for the Far-Field Analysis 
The transmissivity in the model of Rice (1984) changes as the stream tubes intersect alluvium and carbonate rock along the flow path. Transmissivities range between 1000 and $5000 \mathrm{~m}^{2} /$ day for the alluvium and 100 to $500 \mathrm{~m}^{2} /$ day for the lower carbonate unit near Furnace Creek Wash. Similar transmissivities (Figure 3.24) were estimated by calibration of the USGS hydrologic modei (Czarnecki and Waddell 1984). The latter model uses a transmissivity value for alluvium of $1336 \mathrm{~m}^{2} /$ day, while carbonate rock at Furnace Creek Wash is assigned a value of 119 to $128 \mathrm{~m}^{2} /$ day (Czarnecki and Waddell 1984). These values are consistent with the transmissivity values reported by Winograd and Thordarson (1975).

For the regional travel-time calculations, a saturated thickness of the combined transmissive units of $1000 \mathrm{~m}$ was used. This saturated thickness is consistent with hydrologic modeling by the USGS (Waddell 1982; Czarnecki and Waddell 1984) and with values reported bj' Winograd and Thordarson (1975). A value for effective porosity of 0.2 is used for carbonate rock. This is. slightly higher than the primary and effective porosity of 0.04 to 0.12 and $0-0.1$ reported by Winograd and Thordarson (1975). Alluvial porosities are based on correlated transmissivities and porosities of 0.20 and 0.32 listed in Table 3.9. Alluvial porosities reported by Freeze and Cherry (1979) of 0.25 to 0.50 are consistent with the latter values.

Preliminary ground-water travel times between well J-12 and Furnace Creek Wash, as well as the lengths of stream tubes and average of these parameters, are 1isted in Table 3.14. These travel times are consistent with predictions by the USGS (Czarnecki and Waddell 1984).

\subsubsection{Discussion of Hydrologic Modeling and Travel-Time Results}

The hydrologic analyses by Jacobson, Freshley, and Dove (1985) and Rice (1984) are based on hydrologic parameters and hydraulic data collected before 1983. More recent measurements and parameter estimates were analyzed to determine their effect on travel-time estimates. In addition, the modeling results reported by the USGS (Czarnecki and Wadde11 1984) were evaluated to determine whether they differ significantly from those of Jacobsen, Freshley, and Dove (1985) and Rice (1984). 


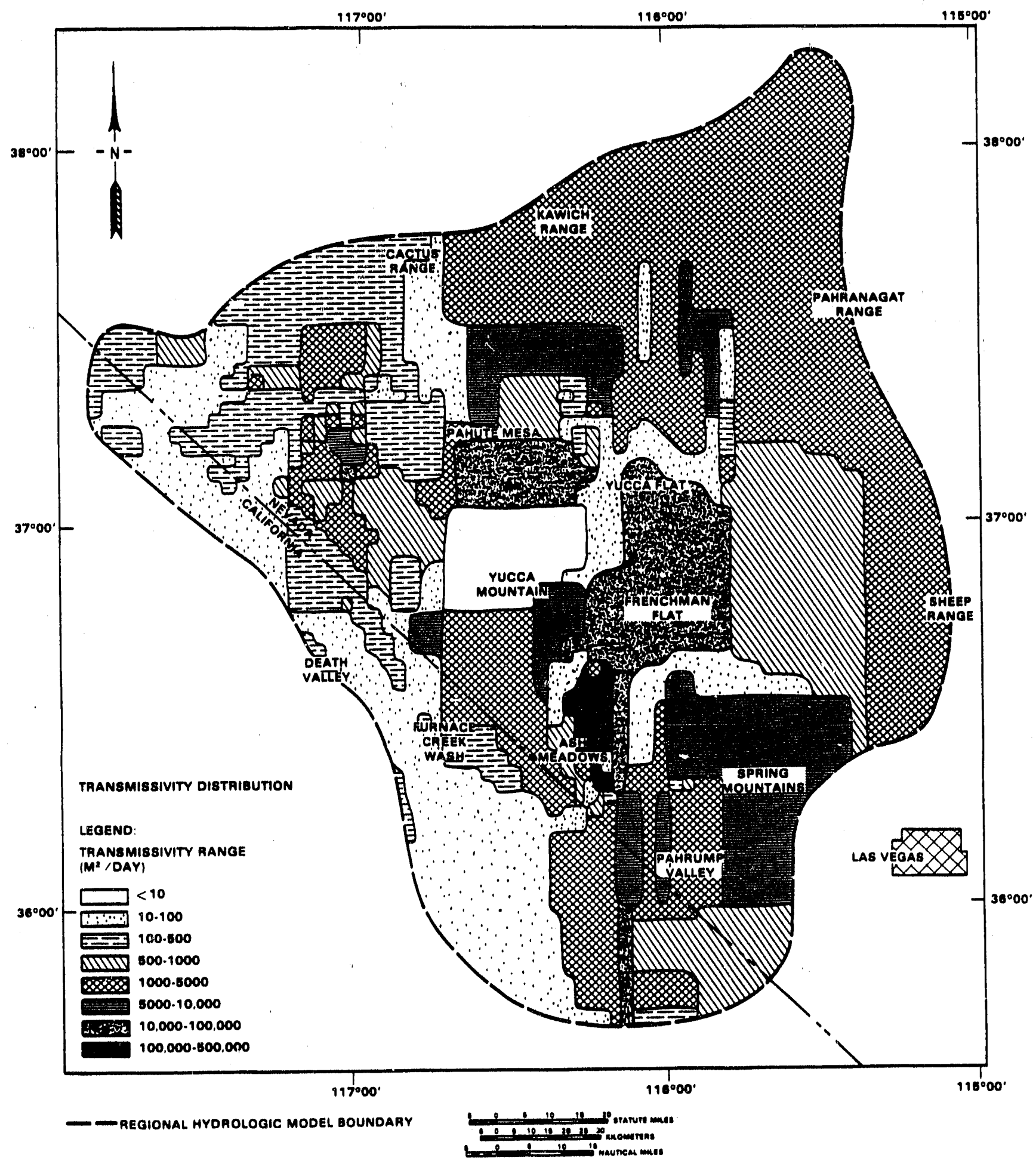

FIGURE 3.24. Transmissivity Distribution for the Calibrated Regional Model 
IABLE 3.14. Travel Times for the Far-Field Analysis Based on the Regional Model (Rice 1984) (porosity of 0.3 )

\begin{tabular}{|c|c|c|c|c|}
\hline & & $\begin{array}{r}\text { We } \\
38.00 \\
39.00\end{array}$ & $\begin{array}{l}12 \\
Y 1=37.00 \\
Y 2=37.00\end{array}$ & \\
\hline Number & $\begin{array}{l}X-\text { End } \\
\text { (NODE) }\end{array}$ & $\begin{array}{l}Y \text {-End } \\
\text { (NODE) }\end{array}$ & Time (yr) & Distance (m) \\
\hline $\begin{array}{r}1 \\
2 \\
3 \\
4 \\
5 \\
6 \\
7 \\
8 \\
9 \\
10 \\
11\end{array}$ & $\begin{array}{l}24.7 \\
24.8 \\
24.9 \\
24.7 \\
25.0 \\
24.9 \\
25.0 \\
24.8 \\
24.8 \\
24.7 \\
24.7\end{array}$ & $\begin{array}{l}26.8 \\
26.8 \\
27.0 \\
26.8 \\
27.0 \\
26.8 \\
26.8 \\
26.8 \\
26.8 \\
26.8 \\
26.8\end{array}$ & $\begin{array}{l}110,135.70 \\
105,507.95 \\
105,134.88 \\
105,553.88 \\
100,963.58 \\
103,753.59 \\
101,997.48 \\
104,442.55 \\
104,934.81 \\
102,038.73 \\
101,439.05\end{array}$ & $\begin{array}{l}69,723 \\
69,723 \\
69,723 \\
70,866 \\
69,723 \\
70,866 \\
70,866 \\
72,009 \\
72,009 \\
73,152 \\
73,152\end{array}$ \\
\hline
\end{tabular}

Earlier we considered differences when more recent data were available. For example, we have presented the potentiometric surface by Robinson (1984) in Figure 3.15 and listed the 1983 hydraulic head data in Table 3.7. Also, travel times were reported by Claassen (1985) and Czarnecki and Waddell (1984).

The major difference between the regional hydrologic analysis summarized here and that reported by the USGS is the areal extent and the boundary conditions set by each of the models. These differences result in a change in the major discharge boundary for the respective models. Rice (1984) assumes ground water from Yucca Mountain discharges at Furnace Creek Wash. The USGS established the major outflow boundary at Alkali Flat, which is at the southern boundary of the USGS hydrologic model. Therefore, in the USGS regional model almost all ground water exits at Alkali Flat.

Ground water does flow from Yucca Mountain to Alkali Flat in the PNL model if streamlines are started several nodes (approximately $8 \mathrm{~km}$ ) east of Yucca Mountain. The kriging and root-mean-squared error in the vicinity of 
the Amargosa Desert is on the average of 30 to $50 \mathrm{~m}$ (see Figure 3.22). In the Amargosa Desert area, the potentiometric surface is relatively flat. Thus, even slight changes in elevation might change the direction of groundwater flow, making ground-water discharge at Alkali Flat possible.

The travel times for the regional-scale analysis range between 101,997 and 110,135 years (see Table 3.14), with an average travel time of 104,173 years. These results are based on porosity values of 0.3 for alluvium (valley-fill) and 0.2 for carbonate rock. In terms of velocity, these travel-times range from 0.69 to $0.633 \mathrm{~m} / \mathrm{yr}$. Several other investigators have estimated travel times and these are reported below.

Claassen (1985) estimated ground-water velocities at between 4 and $7 \mathrm{~m} / \mathrm{yr}$. This estimation is based on apparent ages of ground water from ${ }^{14} \mathrm{C}$ dating and the length of flow paths. Estimates of average velocities of $200 \mathrm{~m}$ to $20 \mathrm{~km} / \mathrm{yr}$ below Scepter Range represent upper limits of velocities for the carbonate aquifer. Claassen (1985) deduces a maximum velocity of $7 \mathrm{~m} / \mathrm{yr}$ for the region between the head of Fortymile Wash and the central Amargosa Desert.

The travel-time estimates made by the USGS based on hydrologic modeling by Wadde 11 (1982) and Czarnecki and Wadde 11 (1984) is 17,313 years for a flowpath length of $11.96 \mathrm{~km}$, an effective porosity of 0.1 , and a saturated thickness value of $1000 \mathrm{~m}$. If these figures are used, the average groundwater velocity is $0.6797 \mathrm{~m} / \mathrm{yr}$ and is consistent with the regional average ground-water velocity of the PNL model by Rice (1984) of $0.6827 \mathrm{~m} / \mathrm{yr}$. The latter value is also consistent with the near-field average velocity computed between Yucca Mountain and well J-12 of 1.082 to $1.403 \mathrm{~m} / \mathrm{yr}$.

The USGS hydrologic model by Czarnecki and Waddell (1984) has more hydraulic head data in the vicinity of Amargosa Desert and Alkali Flat than the PNL model. Figure 3.25 shows the well locations used in the USGS hydrologic model. The solid data points in Figure 3.25 are measurements common to the USGS and PNL hydrologic models.

The newer data from the USGS model shown in Figure 3.26 were kriged. (The hydraulic head data and well coordinates are listed in Table 3.15.) These data have a zero-order drift and a generalized covariance model of 


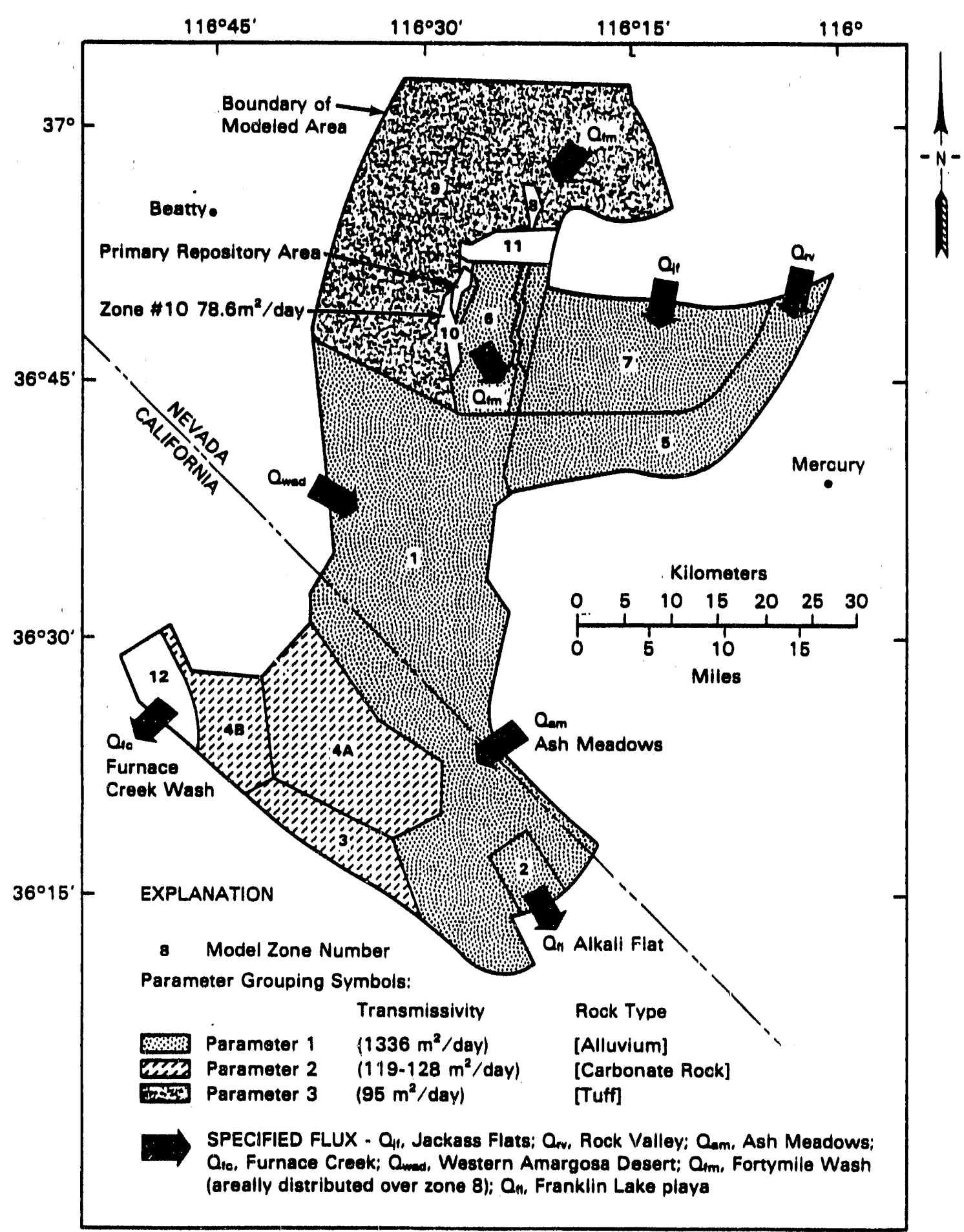

FIGURE 3.25. Model Zone Numbers, Parameter Groupings, Model Boundary Fluxes and Transmissivities--U.S. Geological Survey Model (Czarnecki and Wadde11 1984) 


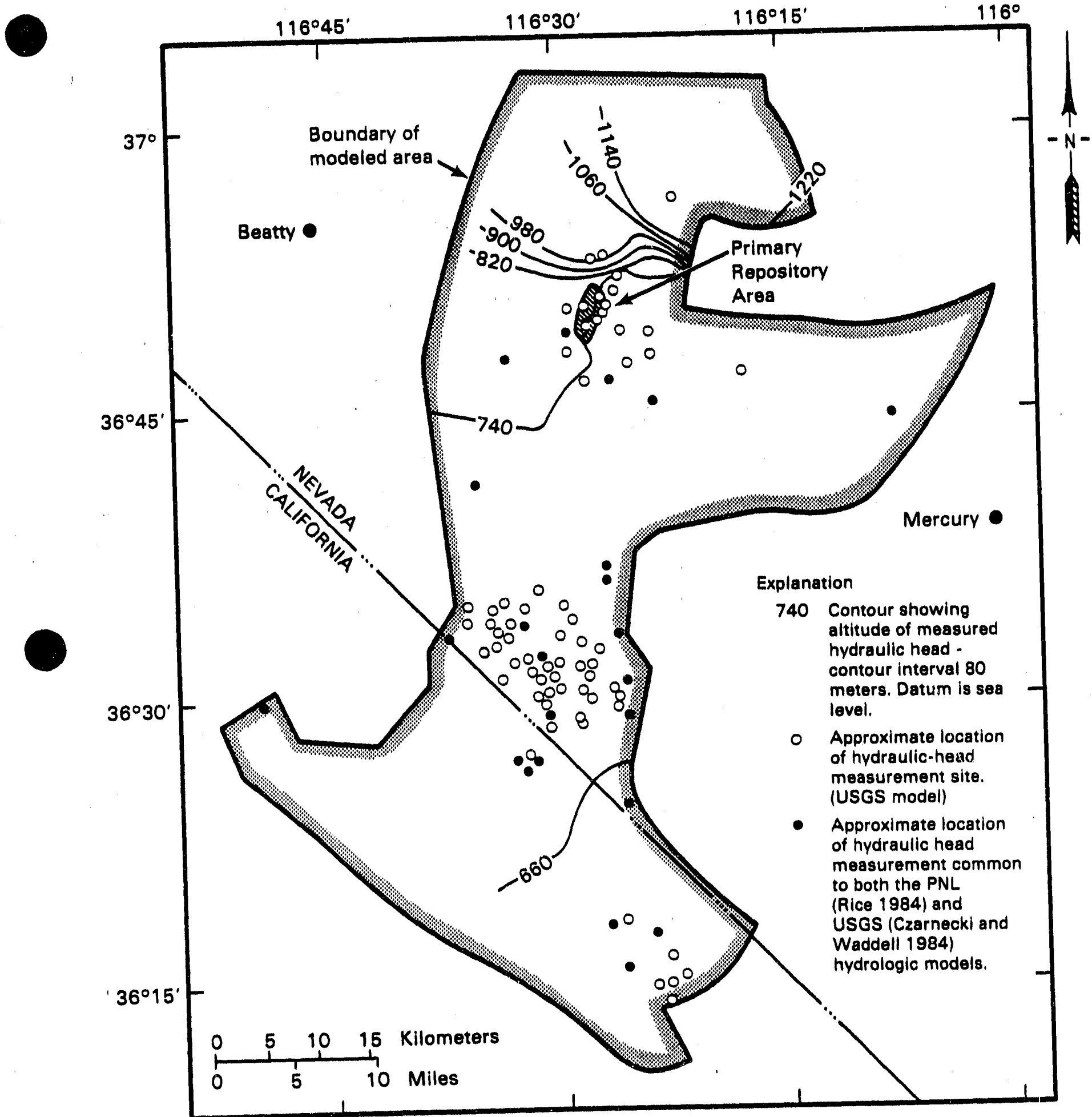

FIGURE 3.26. Location of Hydrautic Head Measurements for the U.S. Geological Survey and Pacific Northwest Laboratory Hydrologic Models 
IABLE 3.15. Summary of Hydraulic Head Data in the U.S, Geological Survey Model Used in the Kriging Analysis (a) (after Czarnecki and Waddell 1984)

\begin{tabular}{|c|c|c|c|}
\hline East (ft) & North $(\mathrm{ft})$ & $\begin{array}{l}\text { Hydraulic } \\
\text { Head } \\
\text { Above Sea } \\
\text { Level (m) }\end{array}$ & Source \\
\hline $\begin{array}{l}566,622.88 \\
535,238.38 \\
538,827.63 \\
571,002.75 \\
570,779.75\end{array}$ & $\begin{array}{l}566,969.63 \\
618,774.13 \\
615,145.50 \\
553,226.13 \\
568,570.63\end{array}$ & $\begin{array}{l}623 \\
671 \\
672 \\
618 \\
623\end{array}$ & $\begin{array}{l}5 \\
2 \\
3 \\
5 \\
5\end{array}$ \\
\hline $\begin{array}{l}540,274.50 \\
542,249.50 \\
580,103.88 \\
579,536.25 \\
530,622.25\end{array}$ & $\begin{array}{l}620,565.38 \\
618,528.00 \\
547,363.38 \\
563,961.13 \\
644,364.63\end{array}$ & $\begin{array}{l}674 \\
673 \\
608 \\
619 \\
691\end{array}$ & $\begin{array}{l}2 \\
1 \\
5 \\
5 \\
2\end{array}$ \\
\hline $\begin{array}{l}546,176.63 \\
584,683.88 \\
584,726.50 \\
584,270.50 \\
534,638.00\end{array}$ & $\begin{array}{l}629,023.38 \\
540,988.63 \\
548,747.88 \\
557,392.88 \\
650,014.25\end{array}$ & $\begin{array}{l}684 \\
607 \\
608 \\
615 \\
691\end{array}$ & $\begin{array}{l}3 \\
5 \\
5 \\
5 \\
1,2\end{array}$ \\
\hline $\begin{array}{l}541,681.88 \\
544,405.00 \\
546,140.63 \\
589,113.00 \\
570,179.25\end{array}$ & $\begin{array}{l}639,138.25 \\
636,211.75 \\
632,973.50 \\
550,998.50 \\
604,653.38\end{array}$ & $\begin{array}{l}689 \\
688 \\
688 \\
611 \\
644\end{array}$ & $\begin{array}{l}1 \\
2 \\
1 \\
5 \\
5\end{array}$ \\
\hline $\begin{array}{l}538,880.13 \\
540,454.88 \\
543,017.25 \\
545,950.25 \\
556,081.50\end{array}$ & $\begin{array}{l}651,231.38 \\
647,045.13 \\
643,626.50 \\
640,631.00 \\
630,713.00\end{array}$ & $\begin{array}{l}690 \\
689 \\
688 \\
688 \\
687\end{array}$ & $\begin{array}{l}1 \\
2 \\
1 \\
2 \\
1\end{array}$ \\
\hline $\begin{array}{l}555,317.13 \\
524,172.13 \\
528,561.88 \\
532,544.75 \\
543,122.25\end{array}$ & $\begin{array}{l}632,461.75 \\
653,213.13 \\
654,938.75 \\
657,514.25 \\
652,448.63\end{array}$ & $\begin{array}{l}686 \\
695 \\
697 \\
695 \\
690\end{array}$ & $\begin{array}{l}1 \\
2 \\
1 \\
2 \\
1\end{array}$ \\
\hline $\begin{array}{l}536,924.75 \\
544,802.00 \\
547,331.50 \\
550,176.00 \\
529,375.50\end{array}$ & $\begin{array}{l}661,484.00 \\
648,462.38 \\
645,135.63 \\
642,169.75 \\
659,745.25\end{array}$ & $\begin{array}{l}707 \\
689 \\
688 \\
688 \\
697\end{array}$ & $\begin{array}{l}1,2 \\
2 \\
2 \\
1 \\
2\end{array}$ \\
\hline
\end{tabular}


IABLE 3.15. (contd)

\begin{tabular}{|c|c|c|c|}
\hline East $(\mathrm{ft})$ & North (ft) & $\begin{array}{l}\text { Hydraulic } \\
\text { Head } \\
\text { Above Sea } \\
\text { Level (m) }\end{array}$ & Source \\
\hline $\begin{array}{l}533,489.63 \\
538,069.75 \\
549,129.38 \\
556,888.63 \\
558,824.38\end{array}$ & $\begin{array}{l}662,553.63 \\
667,219.00 \\
649,902.75 \\
640,916.50 \\
637,862.00\end{array}$ & $\begin{array}{l}702 \\
697 \\
690 \\
685 \\
679\end{array}$ & $\begin{array}{l}1,2 \\
5 \\
1 \\
1 \\
1\end{array}$ \\
\hline $\begin{array}{l}526,225.88 \\
548,256.75 \\
555,799.38 \\
558,388.00 \\
567,715.38\end{array}$ & $\begin{array}{l}662,307.50 \\
658,518.13 \\
648,308.25 \\
645,480.13 \\
636,470.88\end{array}$ & $\begin{array}{l}693 \\
692 \\
689 \\
689 \\
677\end{array}$ & $\begin{array}{l}2 \\
1 \\
2 \\
2 \\
1\end{array}$ \\
\hline $\begin{array}{l}567,843.38 \\
514,198.38 \\
519,444.44 \\
526,931.25 \\
531,006.13\end{array}$ & $\begin{array}{l}638,803.63 \\
657,734.00 \\
662,327.25 \\
667,215.75 \\
669,361.38\end{array}$ & $\begin{array}{l}677 \\
693 \\
693 \\
708 \\
696\end{array}$ & $\begin{array}{l}1 \\
2 \\
2 \\
1 \\
2\end{array}$ \\
\hline $\begin{array}{l}555,848.63 \\
543,118.88 \\
559,916.88 \\
566,550.75 \\
570,412.25\end{array}$ & $\begin{array}{l}656,100.25 \\
672,993.25 \\
650,007.63 \\
641,854.75 \\
633,675.63\end{array}$ & $\begin{array}{l}691 \\
699 \\
689 \\
690 \\
674\end{array}$ & $\begin{array}{l}3 \\
3 \\
2 \\
1 \\
2\end{array}$ \\
\hline $\begin{array}{l}519,769.25 \\
553,223.88 \\
550,041.50 \\
561,872.25 \\
570,057.88\end{array}$ & $\begin{array}{l}667,888.25 \\
663,997.13 \\
668,219.63 \\
654,453.25 \\
644,207.13\end{array}$ & $\begin{array}{l}695 \\
687 \\
699 \\
691 \\
678\end{array}$ & $\begin{array}{l}1,2 \\
2,2 \\
1,3 \\
1 \\
2\end{array}$ \\
\hline $\begin{array}{l}513,365.00 \\
568,571.75 \\
451,941.13 \\
563,296.13 \\
563,939.13\end{array}$ & $\begin{array}{l}667,251.75 \\
659,751.75 \\
640,378.38 \\
677,159.88 \\
681,129.75\end{array}$ & $\begin{array}{l}695 \\
699 \\
285 \\
704 \\
706\end{array}$ & $\begin{array}{l}3 \\
2 \\
5 \\
2 \\
1\end{array}$ \\
\hline $\begin{array}{l}522,042.88 \\
531,225.88 \\
556,951.00 \\
578,801.38 \\
551,294.75 \\
551,143.88\end{array}$ & $\begin{array}{l}706,805.63 \\
745,923.00 \\
739,607.38 \\
733,203.25 \\
748,439.50 \\
755,050.38\end{array}$ & $\begin{array}{l}711 \\
773 \\
731 \\
728 \\
776 \\
776\end{array}$ & $\begin{array}{l}5 \\
4 \\
4 \\
4 \\
4 \\
4\end{array}$ \\
\hline
\end{tabular}


TABLE 3.15. '(contd)

\begin{tabular}{lccc} 
East (ft) & North (ft) & $\begin{array}{c}\text { Hydraulic } \\
\text { Head } \\
\text { Above Sea } \\
\text { Level (m) }\end{array}$ & Source \\
\hline $564,559.25$ & $739,358.13$ & 729 & 4 \\
$555,517.25$ & $752,502.88$ & 730 & 4 \\
$577,367.63$ & $748,495.25$ & 728 & 4 \\
$570,359.75$ & $745,207.88$ & 729 & 4 \\
$551,721.25$ & $762,803.00$ & 779 & 4 \\
$556,068.38$ & $756,972.88$ & 732 & 4 \\
$607,118.25$ & $743,447.75$ & 733 & 4 \\
$558,975.25$ & $759,098.88$ & 730 & 4 \\
$576,973.88$ & $755,539.25$ & 729 & 4 \\
$555,924.00$ & $764,069.38$ & 775 & 4 \\
$561,593.38$ & $761,290.50$ & 731 & 4 \\
$558,965.38$ & $770,034.00$ & 754 & 4 \\
$567,682.63$ & $756,175.63$ & 730 & 4 \\
$563,168.13$ & $763,698.63$ & 730 & 4 \\
$560,888.00$ & $766,123.13$ & 730 & 4 \\
$561,183.25$ & $769,312.13$ & 730 & 4 \\
$558,361.75$ & $778,278.75$ & 1,029 & 4 \\
$657,512.00$ & $730,411.25$ & 732 & 4 \\
$565,963.38$ & $768,213.13$ & 730 & 4 \\
$566,380.13$ & $773,321.38$ & 738 & 4 \\
$562,679.25$ & $780,070.00$ & 1,029 & 4 \\
$584,139.25$ & $798,574.00$ & 1,187 & 4
\end{tabular}

(a) Coordinates based on Central Nevada Coordinate System.

Sources: 1) W. J. Oatfield (USGS, written and oral communication) (1983); 2) Walker and Eakin (1963); 3) Waddell (1982); 4) J. H. Robinson (USGS, written and oral communication) (1984); 5) J. B. Czarnecki (unpubitshed data) (1983) and (1984).

$K[h]=0.0 \delta-1020.0297[h]$. The kriged estimate of the potentiometric surface is shown in Figure 3.27. The kriged error map of hydraulic head is shown in Figure 3.28. Notice the kriging error is now 20 to $30 \mathrm{~m}$ in the Amargosa Desert; whereas previousiy, using the more 11 mited data set, the kriging was 30 to $50 \mathrm{~m}$ (see Figure 3.22). The steep hydraulic gradient in the northern portion of the region and the closed contours are likely artifacts of kriging. 


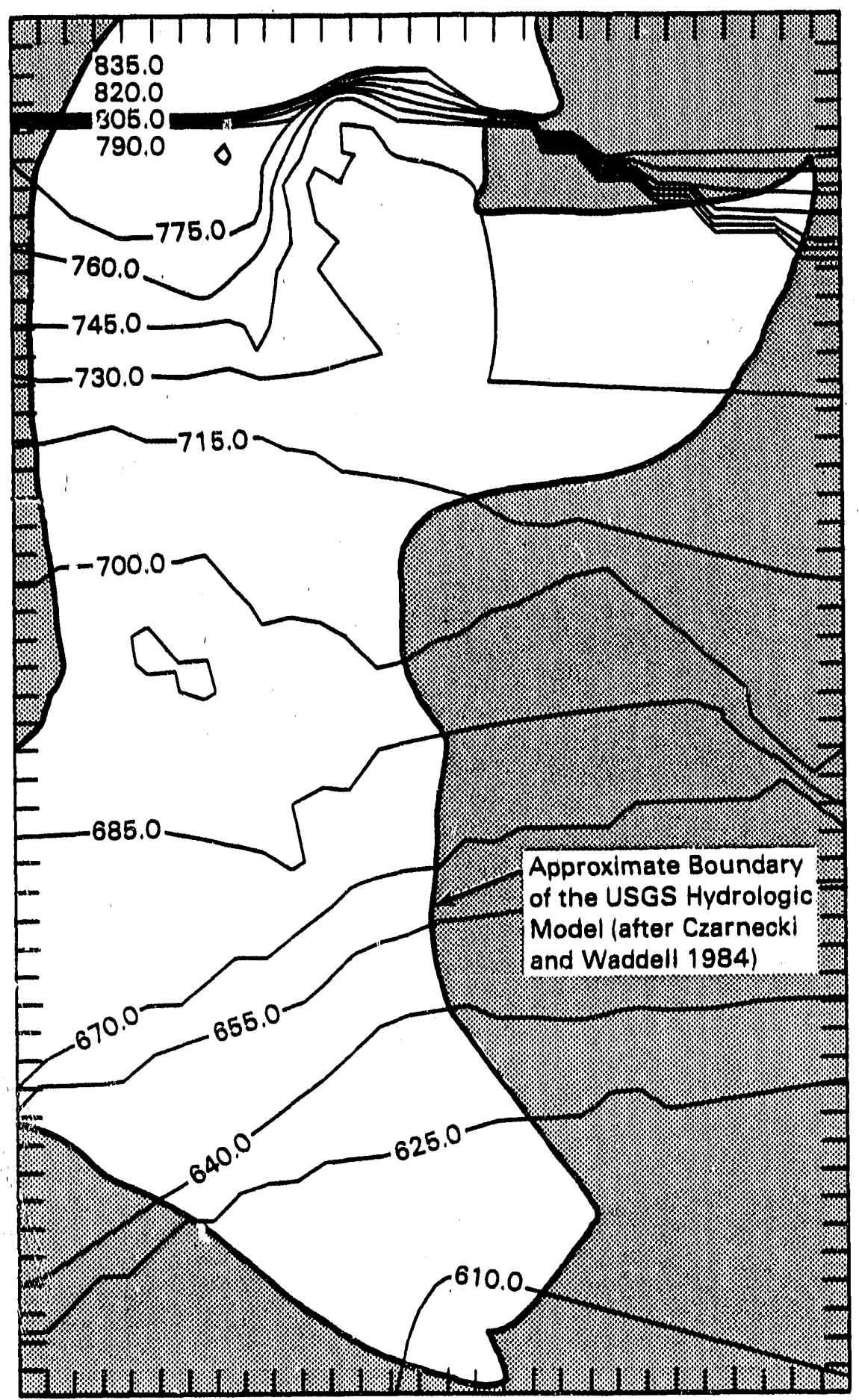

FIGURE 3.27. Kriged Potentiometric Surface Using Data from the U.S. Geological Survey Hydrologic Model (Czarnecki and Wadde 11 1984) 


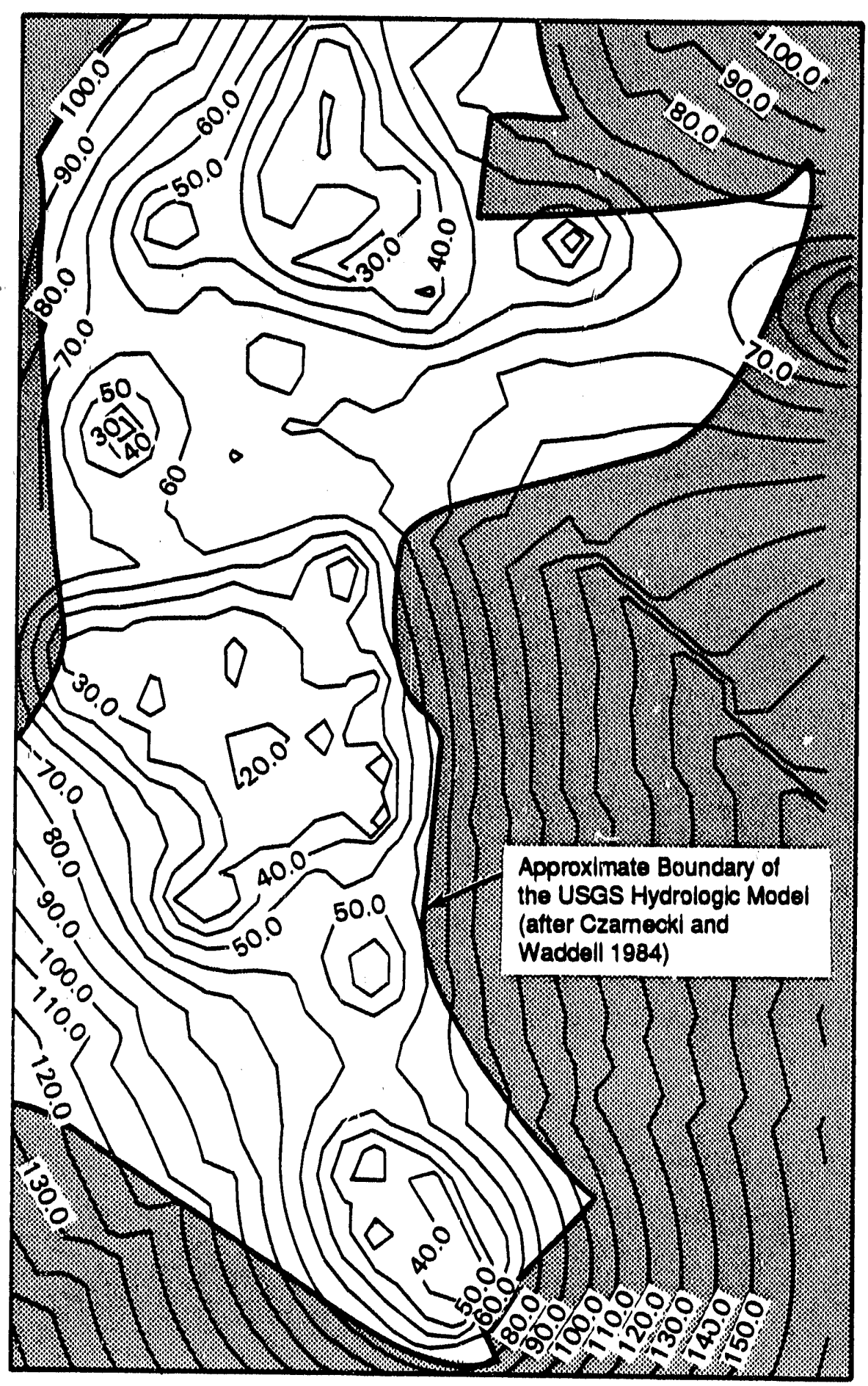

FIGURE 3.28. Map of Kriging Error for the Hydraulic Head Data from the U.S. Geological Survey Model (Czarnecki and Waddell 1984) 
Ground-water development in the valley-fill aquifer southwest of Lathrop Wells for the years 1962 to 1984 has produced a water level decline ranging between 0.427 and $8.35 \mathrm{~m}$. However, the shape of the kriged water table for 1984 is similar to the shape of the kriged water table for 1962 .

The ground-water flow paths are based on the kriged model results in Figure 3.26. In this representation of the regional mode1, the major discharge locations of ground water from Yucca Mountain, as indicated by the streamlines originating near well J-12 (see Figure 3.29), are Lathrop Wells and Alkali Flat. There appears to be a ground-water divide just east of $\mathrm{J}-12$. Streamlines that originate a few kilometers east of well $\mathrm{J}-12$ discharge to Alkali Flat. Ground water from well J-12 is predicted to discharge at Lathrop We 11.

Deterministic travel times were estimated for the stream tubes originating at well J-12 and discharging to Alkali Flat based on the kriged USGS model results (see Figure 3.29). The deterministic travel times are listed at the bottom of Table 3.16. The length of the streamlines to discharge area is also given in Table 3.17. These travel times are based on an alluvial porosity of 0.3 . Note the travel times to this discharge area range between 39,453 and 47,261 years, with average travel time of 44,343 years. Groundwater velocities average $1.4 \mathrm{~m} / \mathrm{yr}$.

Travel times to Lathrop We11s range between 14,012 and 17,420 years. The average ground-water velocity is $1.57 \mathrm{~m} /$ year. These velocities are the same order of magnitude as the ground-water velocitins previously computed for the regional analyses of 0.61 to $0.67 \mathrm{~m} /$ year.

The discharge quantities predicted with the PNL and USGS models were al so compared. Discharge estimates at Alkali Flat and the Amargosa Desert. significantly influence the shape of the potentiometric surface and, consequently, the discharge location. The discharges for losses by evapotranspiration at Alkali Flat (as well as spring discharges in the Amargosa Desert) for the two hydrologic models are listed in Table 3.17. Estimates of discharge by evapotranspiration may be in error by as much as $30 \%$ (Rice 1984), but they also establish the boundary conditions of the two models. The regional extent and the southern boundary condition of the model significantly affect flow behavior of the USGS model because the major flux by 


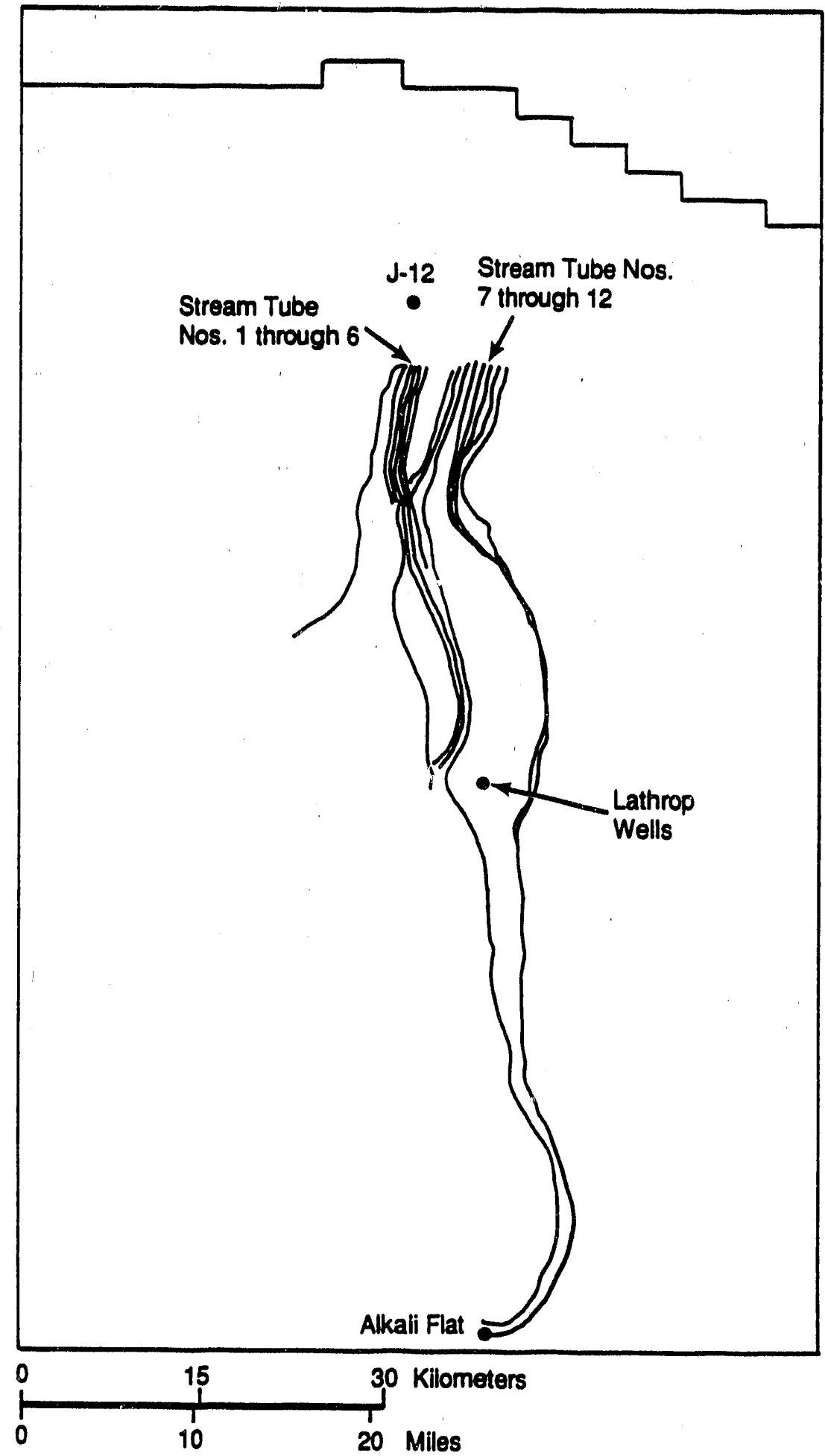

FIGURE 3.29. Stream Tubes Showing Direction of Ground-Water Flow from the Vicinity of Well J-12 to Discharge Locations at Lathrop Wells and Alkali Flat, Using the Kriged Potentiometric Surface and a Constant Alluvial Porosity of Hydraulic Conductivity 
TABLE 3.16. Trave1 Times and Distances Traveled to Discharge Locations from the Vicinity of J-12 to Discharge Locations Lathrop Well and Alkali Flat (porosity $=0.3$ )

\begin{tabular}{|c|c|c|}
\hline $\begin{array}{l}\text { Stream } \\
\text { Line } \\
\text { Number } \\
\end{array}$ & $\begin{array}{c}\text { Trave1 } \\
\text { Time (yr) } \\
\end{array}$ & $\begin{array}{l}\text { Distance } \\
\text { (m) }\end{array}$ \\
\hline $\begin{array}{l}1 \\
2 \\
3 \\
4 \\
5 \\
6\end{array}$ & $\begin{array}{l}16,368.94 \\
17,420.50 \\
14,512.40 \\
14,547.52 \\
14,458.21 \\
14,012.88 \\
\end{array}$ & $\begin{array}{l}18,346 \\
25,588 \\
24,623 \\
25,106 \\
25,106 \\
25,106 \\
\end{array}$ \\
\hline Average & 15,219 & 23,979 \\
\hline
\end{tabular}

\section{Destination: Alkali Flat}

\section{Stream}

Line

Number

\begin{tabular}{l} 
Trave1 \\
Time (yr) \\
\hline
\end{tabular}

Distance

7

7
8
9

$39,453.95$

$45,976.86$

$47,261.25$

$45,596.59$

$40,863.75$

$\underline{46,914.73}$

(m)

11

12

44,343

60,833

62,282

62,282

62,282

61,799

$\underline{62,282}$

Average

$$
44,343 \quad 61,960
$$

TABLE 3.17. Comparison of Discharges in the Amargosa Desert: U.S. Geological Suryey Versus Pacific Northwest Laboratory Model ( $\mathrm{m}^{3} /$ day)

\begin{tabular}{|c|c|c|}
\hline \multirow[b]{2}{*}{$\begin{array}{l}\text { Evapotranspiration } \\
\text { Spring Discharge } \\
\text { Underflow } \\
\text { Total }\end{array}$} & \multicolumn{2}{|c|}{ Amargosa Desert } \\
\hline & $\begin{array}{r}83,940 \\
60,210 \\
1,824 \\
145,974\end{array}$ & $\begin{array}{c}45,140 \\
136,860 \\
\text { (not computed) } \\
183,000\end{array}$ \\
\hline & \multicolumn{2}{|c|}{$\frac{\text { Alkali Flat }}{\text { USGS }}$} \\
\hline vapotranspiration & 35,580 & 35,640 \\
\hline
\end{tabular}


evapotranspiration in the model is at Alkali Flat. In the USGS model, this forces regional flow to exit from this discharge location. The PNL model, on the other hand, extends south to Pahrump Valley and east to Death Valley. The regional extent of the model allows for alternate ground-water flow routes around Alkali Flat; underflow to Pahrump Valley is also allowed.

The flux by evapotranspiration in the USGS hydrologic model is reported by Czarnecki and Wadde 11 (1984) as $35,580 \mathrm{~m}^{3} /$ day. This is consistent w:th the PNL hydrologic model transpiration flux at this location of $35,640 \mathrm{~m}^{3} /$ day.

Czarnecki and Wadde11 (1984) computed the sensitivity of transmissivity estimates at various model locations to the discharge flux at Alkali Flat. By varying the flux at Alkali Flat, they found a one-to-one correspondence or 7 inear dependence of the transmissivity of the Amargosa Desert with the change in flux at Alkali Flat. The sensitivity of the transmissivity at Yucca Mountain is shown in Figure 3.30. Increasing the flux by a factor of two at Alkali Flat (at Franklin Lake Playa), doubles the transmissivity at Yucca Mountain. The second greatest effect on Yucca Mountain transmissivity is the flux at Furnace Creek Ranch (see Figure 3.30).

\subsection{REFERENCES}

Bear, J. 1979. Hydraulics of Ground Water. McGraw-Hi1l, Inc., New York, New York.

Benson, L. V., J. H. Robison, R. K. Blankennagel, and A. E. Ogard. 1983. Chemical Composition of Ground Water and the Locations of Permeable Zones in the Yucca Mountain Area, Nevada. USGS-0FR-83-854, U.S. Geological Survey, Denver, Colorado.

Binnall, E. P., S. M. Benson, L. Tsao, H. A. Wollenberg, T. K. Tokunaga, and E. M. Didwa11. 1987. Critical Parameters for a High-Level Waste Repository Volume 2: Tuff. NUREG/CR-4161, U.S. Nuclear Regulatory Commission, Washington D.C.

Blankennagle, R. K., and J. E. Weir. 1973. "Geohydrology of the Eastern Part of Pahute Mesa, Nevada Test Site, Nye County, Nevada." In U.S.

Geological Survey Prof. Paper 712-B, pp. B.1-B.35., U.S. Government Printing Office, Washington, D.C.

Brace, W. F., M. D. Voegele, and H. R. Pratt. 1982. Porosity and Permeability and Their Relationship in Granite, Basalt, and Tuff. ONWI/82/E512-02900/TR-10, Office of Nuclear Waste Isolation, CoTumbus, Ohio. 


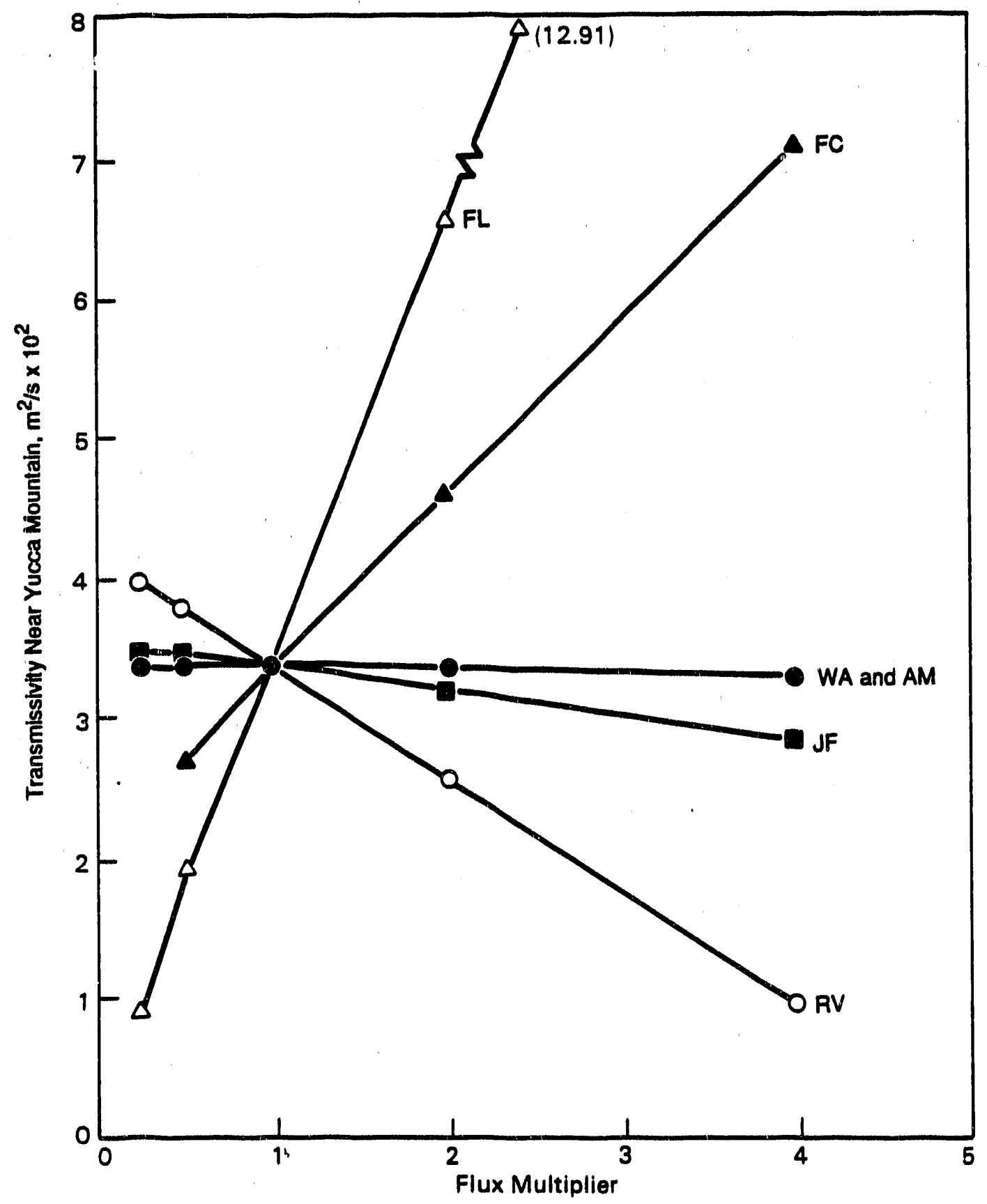

FIGURE 3.30. Sensitivity of Calculated Transmissivity Near Yucca Mountain to Changes in Flux Boundary Conditions at Jackass Flats (JF), Rock Valley (RC), Ash Meadows (AM), Western Amargosa Desert (WA), Furnace Creek Ranch (FC), and Frankl in Lake Playa (FL) (after Czarnecki and Waddell 1984) 
Claassen, H. C. 1985. "Sources and Mechanisms of Recharge for Ground Water in the West-Central Amargosa Desert, Nevada--A Geochemical Interpretation." In U.S. Geological Survey Professional Paper 712-F, U.S. Government Printing Office, Washington, D.C.

Czarnecki, J. B., and R. K. Wadde11. 1984. Finite-Element Simulation of Ground-Water Flow in the Vicinity of Yucca Mountain, Nevada-California. USGS-WRI-84-4349, Water Resources Investigations Report, U.S. Geological Survey, Denver, Colorado.

DOE. See U.S. Department of Energy.

Eakin, T. E. 1966. "A Regional Interbas in Ground water system in the White River Area, Southeastern Nevada." Water Resour. Res. 2(2):251-271.

Eakin, T. E., et a1. 1951. "Contributions to the Hydrology of Eastern Nevada." Nevada State Engineers, Water Resources Bullet in 12:171.

Eakin, T. E., and D. 0. Moore. 1964. "Uniformity of Discharge of Muddy River Springs Southeastern Nevada and Relation to Interbasin Movement of Ground Water." In U.S. Geological Survey Professional Paper 501-D, pp. D171-176. U.S. Government Printing Office, Washington, D.C.

Eakin, T. E., and I. J. Winograd. 1965. "Interbasin Movement of Ground Water in South-Central Nevada--Some Implications." In Geological Society of America Special Paper 82, p. 52.

Fernandez, J. A. and M. D. Freshley. 1984. Repository Sealing Concepts for the Nevada Nuclear Waste Storage Investigations Projects. SAND83-1778, Sandia National Laboratories, Albuquerque, New Mexico.

Freeze, R. A., and J. A. Cherry. 1979. Ground Water. Prentice-Hall Inc., Edgewood Cliffs, New Jersey.

Freeze, R. A., and P. A. Witherspoon. 1966. "Theoretical Analys is of Regional Ground-Water Flow; (1) Analytical and Numerical Solutions to the Mathematical Mode1." Water Resour. Res. 2(4):641-656.

Freeze, R. A., and P. A. Witherspoon. 1967. "Theoretical Analysis of Regional Ground-Water Flow; (2) Effect of Water-Table Configuration and Subsurface Permeability Variation." Water Resour. Res. 3(2):623-634.

Gardner, W. R. 1958. "Some Steady-State Solutions of the Unsaturated Moisture Flow Equation with Application to Evaporation from a Water Table." Soil Sci. Soc. Am. Proc. 85:228-232.

Grove, D. B., M. Rubin, B. B. Hanshaw, and W. A. Beetem. 1969. "Carbon-14 Dates of Ground Water from a Paleozoic Carbonate Aquifer, Southcentral Nevada." In U.S. Geological Survey Professional Paper 650-C, pp. C215-C218. U.S. Government Printing Office, Washington, D.C. 
Haverkamp, R., M. Vauclin, J. Touma, P. J. Wierenga, and G. Vachaud. 1977. "A Comparison of Numerical Simulation Models For One-Dimensional

Infiltration." Soil Sci. Soc. Am. J. 41:285-294.

Hunt, C. B., and T. W. Robinson. 1960. "Possible Interbasin Circulation of Ground Water in the Southern Part of the Great Basin." In U.S. Geological Survey Professional Paper 400-B, pp. B273-B274. U.S. Government Printing Office, Washington, D.C.

Jacobson, E. A., M. D. Freshley, and F. H. Dove. 1985. Investigations of Sensitivity and Uncertainty in Some Hydrologic Models of Yucca Mountain and Vicinity. SAND84-7212, Sandia National Laboratories, Albuquerque, New Mexico.

Klavetter, E. A., and R. R. Peters. 1986. Fluid Flow in a Fractured Rock Mass. SAND85-0855, Sandia National Laboratories, Albuquerque, New Mexico.

Lahoud, R. G., D. H. Lobmeyer and M. S. Whitfield, Jr. 1984. Geohydrology of Volcanic Tuff Penetrated by Test Well UE-25b 1, Yucca Mountain. Nye County, Nevada. USGS-WRI-84-4253, Water Resources Investigations Report, U.S. Geological Survey, Denver, Colorado.

Lappala, E. G. 1982. "Recent Developments in Modeling Variably Saturated Flow and Transport." In Symposium on Unsaturated Flow and Transport Modeling, Seattle, Washington, March 23-24, 1982. NUREG/CP-0030, U.S. Nuclear Regulatory Commission, Washington, D.C.

Loe 1tz, 0. J. 1960. "Source of Water Issuing from Springs in Ash Meadow Valley, Nye County, Nevada." Geol. Soc. of America Bull. 71:1917-1918 (Abstract).

Maxey, G. B. 1968. "Hydrogeology of Desert Basins." Ground Water (5) :10-22.

Maxey, G. B., and C. H. Jameson. 1948. Geology and Water Resources of Las Vegas, Pahrump, and Indian Snrings Valleys, Clark and Nye Counties, Nevada. Nevada State Engineer Water Resources BuTletin Number 5.

Maxey, G. B., and M. D. Mifflin. 1966. "Occurrence and Movement of Ground Water in Carbonate Rocks of Nevada." Nat1. Speleol. Soc. Bull. $28(3): 141-157$.

Mckeon, T. J., S. W. Tyler, D. W. Mayer, and A. E. Reisenauer. 1983. TRUSTII Utility Package: Partially Saturated So il Characterization, Grid Generation, and Advective Transport Analysis. NUREG/CR-3443, U.S. Nuclear Regulatory Commission, Washington, D.C.

Miller, G. A. 1977. "Appraisal of the Water Resources of Death Valiey, Cal ifornia-Nevada." In U.S. Geological Survey Open-File Report 77-728,

p. 67. U.S. Geological Survey, Washington, D.C. 
Montazer, P., and W. E. Wilson. 1984. Conceptual Hydrologic Model of Flow in the Unsaturated Zone, Yucca Mountain. Nevada. USGS-WRI-84-4345, Water-Resources Investigations Report, U.S. Geological Survey, Lakewood, Colorado.

Mualem, Y. 1976. "A New Model for Predicting the Hydraulic Conductivity of Unsaturated Porous Media." Water Resour. Res, 12(3):513-522.

Neuman, S. P. 1987. "Stochastic Continuum Representation of Fractured Rock Permeability as an Alternative to the REV and Fracture Network Concepts." In Proceedings of NATO Advanced Research Workshop on Advances in Analytical and Numerical Ground Water Flow and Quality Modeling, Lisbon, Portugal, June 2-6, 1987, and Proceedings of 28th U.S. Sympos tum on Rock Mechanics, Tucson, Arizona, June 29-JuTy 1, 1987.

Oberlander, P. L. 1979. Development of a Quasi Three-Dimensional GroundWater Model for a Portion of the Nevada Test Site. NV0-1253-14, Water Resources Center, Desert Research Institute, University of Nevada, Reno, Nevada.

Oster, C. A. 1982. Review of Ground-Water Flow and Transport Models in the Unsaturated Zone. NUREG/CR-2917 (PNL-4427), prepared by Pacific Northwest Laboratory for the U.S. Nuclear Regulatory Commission, Washington, D.C.

Peters, R. R., J. H. Gauthier, and A. L. Dudley. 1986. The Effect of Percolation Rate on Water-Travel Time in Deep. Partially Saturated Zones. SAND85-0854, Sandia National Laboratories, Albuquerque, New Mexico.

Peters, R. R., E. A. Klavetter, I. J. Hall, S. C. Blair, P. R. Heller, and G.W. Gee. 1984. Fracture and Matrix Hydrologic Characteristics of Tuffaceous Materials from Yucca Mountain, Nye County, Nevada. SAND84-1471, Sandia National Laboratories, Albuquerque, New Mexico.

Pistrang, M. A., and F. Kunkel. 1964. "A Brtef Geologic and Hydrologic Reconnaissance of the Furnace Creek Wash Area, Death Valley National Monument, Cal ifornia." In U.S. Geological Survey Water-Supply Paper 1779-Y, p. 35. U.S. Geological Survey, Washington, D.C.

Rasmussen, T. C., and D. D. Evans. 1987. Unsaturated Flow and Transport Through Fractured Rock Related to High-Level Waste Repositories, Final Report-Phase II. NUREG/CR-4566, U.S. Nuclear Regulatory Commission, Washington, D.C.

Rice, W. A. 1984. Preliminary Two-Dimensional Model of the Nevada Test Site and Vicinity. SAND83-7466, Sandia National Laboratories, Albuquerque, New Mexico.

Richards, L. A. 1931. "Capillary Conduction of Liquids in Porous Mediums." Physics $1: 318-333$. 
Robinson, J. H. 1984. Ground-Water Level Data and Preliminary

Potentiometric-Surface Maps, Yucca Mountain and Vicinity, Nye County, Nevada. USGS-WRI-84-4197, Water Resources Investigations Report, U.S. Geological Survey, Lakewood, Colorado.

Ross, B. 1984. "A Conceptual Model of Deep Unsaturated Zones With Negligible Recharge." Water Resour. Res. 20(11):1627-1629.

Sinnock, S., Y. T. Lin, and M. S. Tierney. 1986. Preliminary Estimates of Ground Water Travel Time and Radionuclide Transport at the Proposed Yucca Mountain Repository Site. SAND85-2701, Sandia National Laboratories, ATbuquerque, New Mexico.

Stewart, J. J., and J. E. Carlson. 1978. Geologic Map of Nevada. Scale 1:500,000, U.S. Geological Survey and Nevada Bureau of Mines and Geology, Carson City, Nevada.

Thompson, F. L., F. H. Dove, and K. M. Krupka. 1984. Preliminary Consequence Analysis for a Waste Repository at Yucca Mountain, Nevada. SAND-7475 and PNL-5103, Sandia National Laboratories, ATbuquerque, New Mexico.

U.S. Department of Energy (DOE). 1986. Environmental Assessment, Yucca Mountain Site, Nevada Research and Development Area, Nevada. D0E/RW-0073, U.S. Department of Energy, Office of Civitian Radioactive Waste Management, Washington, D.C.

U.S. Department of Energy (DOE). 1988. Consultative Site Characterization Plan, Yucca Mountain Site, Nevada Research and Development Area, Nevada. DOE/RW-0160, Office of Civilian Radioactive Waste Management, Washington, D.C.

Wadde11, R. K. 1982. Two-Dimenstonal, Steady-State Model of Ground-Water Flow, Nevada Test Site and Vicinity, Nevada-California. Water Resources Investigations Report 81-4085, U.S. Geological Survey, Denver, Colorado.

Walker, G. E., and T. E. Eakin. 1963. "Geology and Ground Water of Amargosa Desert, Nevada-California." In Nevada Department of Conservation and Natural Resources Reconnaissance Service Report 14, p. 45.

Wang, J.S.Y., and T. N. Narasimhan. 1985. Hydrologic Mechanisms Governing Fluid Flow in Partially Saturated, Fractured Porous Tuff at Yucca Mountain. SAND84-7202, Sandia National Laboratories, Albuquerque, New Mexico.

Winograd, I. J. 1962. "Interbasin Movement of Ground Water at the Nevada Test Site, Nevada." In U.S. Geological Survey Professional Paper 450-C, pp. C108-C11, U.S. Geological Survey, Washington, D.C.

Winograd, I. J., and I. Friedman. 1972. "Deuterium as a Tracer of Regional Ground-Water Flow, Southern Great Basin, Nevada and California." Geol. Soc. Am. Bu11. 83(12):3691-3708. 
Winograd, I. J., and W. Thordarson. 1975. "Hydrogeologic and Hydrochemical Framework South-Central Great Basin, Nevada-California, with Special Reference to the Nevada Test Site." In U.S. Geological Survey Professional Paper 712-C, p. 126. U.S. Geological Survey, Washington, D.C.

Winograd, I. J. 1981. "Radioactive Waste Disposal in Thick Unsaturated Zones." Science 212(4502):1457-1464.

Winograd, I. J., W. Thordarson, and R. A. Young. 1971. Hydrology of the Nevada Test Site and Vicinity, Southeastern Nevada. Open-File Report, U.S. Geological Survey, Denver, Colorado. 


\subsection{ENGINEERED BARRIERS RELEASE}

Estimation of radionuclide releases from the repository is the first step in mass transport modeling leading to evaluation of doses to an exposed population. Releases from the engineered barrier system (EBS) of the repository depend on factors such as thermal loading, ground-water chemistry and fluxes, waste container material, and waste form. The Analytical Repository Source Term (AREST) code (Liebetrau et al. 1987) is used as the source-term component in a suite of codes (AREST, DOTR, DITTY) used to evaluate the risk, in terms of integrated population doses, of the entire geologic repository system.

Conceptually, the AREST model conststs of three major components: the Engineered System Release (ESR) mode T, the Waste Package Containment (WPC) model, and the Waste Package Release (WPR) model. The implementing code is essentialiy an executive code designed to simulate the containment and release performance of individual waste packages under a wide range of environmental conditions, repository and waste package design configurations, and receipt scenarios. Currently, the code implicitly treats simulated waste packages independently; interactions among adjacent waste packages are not modeled. The WPC model simulates corrosion processes and degradation mechanisms that ultimately result in waste package containment fallure. The containment phase of the simulation is completed at the time physical containment is lost, and the possibility exists for release of radionuclides from the waste package. At the time of waste package containment fallure, the WPR model begins simulating the controlled release of radionuclides and their migration outward through the waste package barriers. Finally, the ESR model integrates (sums) the simulated releases from individual waste packages with respect to their failure-time distribution to provide an estimate of total repository release.

The simulation of waste package containment and release requires information about the environment in which these processes occur. The AREST code contains modules that use detalled, site-specific information about the physical and chemical environments of the waste package and the repository. In particular, the code incorporates modules that describe the thermal, 
geochemical, and hydrologic environments of the simulated waste package. The thermal module provides the near-field and container temperatures required by other components of the AREST code. The geochemical module provides the values of the variables that describe the ground-water composition in the vicinity of the waste package. In a saturated environment, the hydrologic module determines when, following emplacement and subsequent repository closure, resaturation occurs at the waste package surface. 'In an unsaturated environment, the hydrologic module determines when wetting of the waste package occurs.

A common feature of the waste package environmental modules is their use of information provided by "support" codes external to the AREST code. Instead of using simplified models and approximations in the AREST code, these modules use the output from detalled research/scientific codes whenever possible. The support codes perform site-specific calculations that are too time consuming to do during a simulation; output from the support codes is tabulated or otherwise preprocessed for input to the AREST code. The support-code strategy is used to maintain the computational efficiency of the AREST code without sacrificing modeling accuracy.

\subsection{CONTAINMENT MODELING}

Current strategies for demonstrating compliance with NRC performance criterla rely on metallic containers as the primary engineered barrier (NRC 1983, 1986; DOE 1986a). Because corrosion processes are expected to be the main degradation mechanisms for metallic containers, several mechanistic models of uniform and pitting corrosion, as well as empirical models derived from site-specific testing, have been included as modules in the AREST code (DOE 1986a; Sastre, Pescatore, and Sullivan 1986). All of the corrosion models are limited in applicability to certain material/environment combinations and, for this reason, the AREST code has been configured to accept arbitrary user-supplied containment fallure-time distributions.

With the use of an arbitrary user-supplied containment fallure-time distribution, no distinction is made between containment contributions from the container and the cladding. This modeling choice also ignores the 
possibility of significantly different containment semformance among potential repository and waste package designs.

\subsection{RELEASE MODELING}

The NRC has established quantitative performance objectives for the allowable release of radionuclides from an EBS (NRC 1983; DOE 1986a). Although the EBS has been defined by the NRC, there is uncertainty concerning the interpretation of this definition. To avoid confusion and to preserve technical conservatism, the AREST code was designed to assess release from the waste package (WP) subsystem of the EBS. Thus, release estimates from AREST can be used without modification as a source term for releases into the repository horizon.

Two approaches to radionuclide release modeling are incorporated into the AREST code: one for saturated media and one for unsaturated media. Release calculations for saturated media are based on diffusive mass transfer models. Both solubility-limited and inventory-limited diffusive mass transfer models are available (see section 4.2.2). For unsaturated media (assumed to be open to the aimosphere), radionuclide solubilities are generally greater than in saturated media, and transport pathways are likely to be convective rather than diffusive. A simple, but comprehensive, steady-state release model developed specifically for unsaturated media was recently incorporated into the AREST code. This model has not been previousiy described, so its derivation and a hypothetical application are presented in Section 4.2.1. Release modeling for saturated media is described in less detail in Section 4.2 .2 because the application of mass transfer theory to calculate releases for saturated media are extensively discussed el sewhere. (Chambré et al. 1985; Zavoshy, Chambré, and Pigford 1985; Kim, Chambré, and Pigford 1986; Apted, Liebetrau, and Engel 1987a).

\subsubsection{Release Modeling for Unsaturated Media}

In modeling the release of radionuclides from waste packages in unsaturated media, it is assumed that each radionuclide is released from the waste form matrix congruently at a rate given by the rate of forward matrix dissolution multiplied by the fractional inventory of the radionuclide in the matrix. If the release rate for a given radionuclide exceeds the rate of 
transport away from the waste package, then the radionuclide will reach its solubility limit at the waste form surface, and the overall release rate will be governed by the transport rate. The model distinguishes between diffusive and convective transport, with the release rate being set equal to the larger of these two rates for a given waste package. Inventory-limited release (e.g., spent fuel gap inventory) is assumed to be solubility/transport limited until the inventory is depleted.

The following three sections describe 1) the theoretical development and final form of a waste form matrix release model for unsaturated media, 2) the development and final form of an inventory-limited release model for unsaturated media, and 3) a simple demonstration of the waste form matrix release model applied to a spent fuel waste package in an unsaturated repository.

\section{Release of Radionuclides from the Waste Form Matrix}

A generalized mass balance for a radionuclide being released from the matrix of a waste form in contact with flowing ground water (assuming negligible diffusive pathways) is

$$
V d C_{j} / d t=z_{i}(t) R_{d} A-R_{p i}-k_{c i} C_{i}+Q(t)\left(C_{10}-C_{i}\right)
$$

where $V=$ control volume, $\mathrm{m}^{3}$

$$
t=\text { time, } y r
$$

$c_{i}=$ concentration of radionuclide $i, \mathrm{~g} / \mathrm{m}^{3}$

$c_{i 0}=\underset{\mathrm{g} / \mathrm{m}}{\text { congentration }}$.

$z_{i}(t)=$ mass fraction of radionuclide $i$ in waste form matrix

$R_{d}=$ forward rate of matrix dissolution, $g / m^{2}-y r$

$A=$ surface area of waste form in contact with water, $\mathrm{m}^{2}$

$R_{p f}=\underset{g / y r}{\text { rate }}$ of precipitation of radionuclide $i$ into alteration phases, 

$k_{c i}=\begin{aligned} & \text { first-order rate constant for the formation of colloids or other } \\ & \text { suspended matter containing radionuclide } i, \mathrm{~m}^{3} / \mathrm{yr}\end{aligned}$

$Q(t)=$ volumetric flow raţe of water through control volume in contact with waste form, $\mathrm{m}^{3} / \mathrm{yr}$.

In Equation (4.1), it is assumed that the release rate of each radionuclide from the matrix equals the forward rate of matrix dissolution multiplied by the mass fraction of the radionuclide in the matrix (i.e., congruent release). This assumption is implicit in the development of the release model.

The forward rate of matrix dissolution, $R_{d}$, could assume many possible functional forms, depanding on the waste form and the mechanism of dissolution in the environment of interest. To date, spent fuel dissolution experiments have not yielded results that support mechanistic model development, so a general expression for the rate of spent fuel matrix dissolution has been implemented in AREST:

$$
R_{d}=k_{+}\left([x]^{a}[y]^{b} \ldots\right)\left(1-c_{m} / c_{m}^{*}\right)
$$

where $k_{+}=$forward reaction rate constant, $g / m^{2}-y r\left(m^{3} / g\right)^{a+b+\ldots}$

$[x],[y]=$ activities of constituents $x$ and $y$ in rate $1 \mathrm{aw}, \mathrm{g} / \mathrm{m}^{3}$

$a, b=$ reaction order with respect to $x$ and $y$

$C_{m}=$ concentration of matrix constituent $m$ that controls matrix dissolution rate (assumed to be $\mathrm{UD}_{2}$ for spent fue 1 ), $\mathrm{g} / \mathrm{m}^{3}$

$C_{m}^{*}=$ arbitrary concentration of constituent $m$ at which the forward rate of dissolution becomes zero, $\mathrm{g} / \mathrm{m}^{3}$.

The functional form of Equation (4.2) implies that the dissolution reaction is reversible and that the backward reaction rate is first order with respect to constituent $\mathrm{m}$.

If the waste form is capable of equilibrating with the solution, then $C_{m}{ }^{*}$ in Equation (4.2) is set equal to $C_{s m}$, the saturation concentration of constituent $m$. In this case, the forward reaction will stop when $C_{m}=C_{s m}$, and the rate of precipitation of alteration phases for constituent $m\left[R_{p m}\right.$ in Equation (4.1)] will be zero because no alteration phases will form. 
If the waste form is not capable of equilibrating with the solution, then the dissolution reaction will not be completely reversible. In this case, $C_{m}^{*}$ in Equation (4.2) will be greater than $C_{s m}$, and the rate of matrix dissolution will remain non-zero even when the solution becomes saturated with respect to $m$ (i.e., $c_{m}=C_{s m}$ ). This situation is expected for both spent fuel and glass at the candidate Nevada repository site because the primary matrix consituents, $\mathrm{UO}_{2}$ and amorphous silica, respectively, are not thermodynamically stable in the unsaturated, oxidizing environment. If the concentration of $m$ has no effect on the forward dissolution rate, then $c_{m}{ }^{*}$ can be arbitrarily set to a very high value, forcing $C_{m} / C_{m}{ }^{*}$ to approach zero. In a closed system at steady-state with no colloid formation, the rate of precipitation of $m, R_{p m}$, must be equal to the rate of dissolution, $z_{m}(t) R_{d} A$, to satisfy the mass balance. Prior to saturation, however, $R_{p m}$ is assumed to be zero.

At steady state $\left(d c_{i} / d t=0\right)$, assuming that $c_{i 0}$ is equal to zero, Equation (4.1) becomes

$$
0=z_{i}(t) R_{d} A-R_{p i}-k_{c i} C_{i}-Q(t) C_{i}
$$

A steady-state mass balance on colloidal species yields

$$
0=k_{c i} C_{i}-Q(t) C_{c i}
$$

where $C_{c i}=$ concentration of radionuclide $i$ in colloidal form, $\mathrm{g} / \mathrm{m}^{3}$. Using Equation (4.4), we can rewrite Equation (4.3) as follows:

$$
0=z_{i}(t) R_{d} A-R_{p i}-Q(t)\left(C_{i}+C_{c i}\right)
$$

The release rate of radionuclide $i$ is equal to the last term of Equation (4.5), $Q(t)\left(C_{i}+C_{C i}\right)$. However, when $C_{i}<C_{s i}$ (the saturation concentration of $i)$, it is apparent from Equation (4.5) that the release rate will be equal to $z_{i}(t) R_{d} A\left(R_{p i}=0\right)$. Alternatively, when $C_{i}=C_{s i}$, the release rate will be equal to $Q(t)\left(C_{s i}+C_{c i}{ }^{*}\right)$, where $C_{c i}{ }^{*}$ is the concentration of radionuclide $i$ in colloidal form when $C_{i}=C_{s i}$ (a hypothetically measurable 
quantity). This analysis suggests a simple test to determine whether the release rate for a given radionuclide is controlled by the forward matrix dissolution rate or the convective transport rate:

'If $z_{j}(t) R_{d} A<Q(t)\left(C_{s j}+C_{c j}{ }^{*}\right)$, then the matrix dissolution rate controls release, and the release rate $=z_{j}(t) R_{d} A$.

If $z_{j}(t) R_{d} A>Q(t)\left(C_{s i}+C_{c i}{ }^{*}\right)$, then the convective transport rate controls release, and the release rate $=Q(t)\left(C_{s i}+C_{c i}{ }^{*}\right)$.

If the flow rate of ground water, $Q(t)$, is exceedingly low but the waste form is still in contact with a continuous diffusive pathway of water, diffusion could control the rate of radionuclide release from the waste package. To assess this possibility, an expression for steady-state diffusional release from a spherical waste form is used where it is assumed that the concentration of the diffusing constituent is zero at an infinite distance from the waste form (Chambré et a1. 1985):

$$
\text { Release Rate }=4 \pi D_{i} \in r_{0} C_{i 0}
$$

where $D_{i}=$ diffusion coefficient of radionuclide $i, m^{2} / \mathrm{yr}$

$$
\epsilon=\text { porosity }
$$

$r_{0}=$ effective radius of waste form, $m$

$c_{i 0}=$ concentration of radionuclide $i$ at waste form surface, $\mathrm{g} / \mathrm{m}^{3}$.

A spherical geometry is assumed because it results in higher, and therefore more conservative, release rates than planar or cylindrical geometries.

When colloidal species are present, Equation (4.6) must be modified to reflect the diffusion of colloidal species as well as dissolved species. Also, in unsaturated media, only a fraction of the waste form surface may actually be in contact with a diffusive water pathway. Equation (4.6) is therefore modified as follows:

$$
\text { Release Rate }=4 \pi \epsilon r_{0}\left(A_{d} / A_{t}\right)\left(D_{i} C_{i 0}+D_{c i} C_{c i 0}\right)
$$


where $A_{d}=$ area of waste form surface in contact with diffusive pathwav, $m^{2}$

$A_{t}=$ total surface area of waste form surface, $m^{2}$

$D_{c i}=\begin{aligned} & \text { effective diffusign coefficient for colloidal species containing } \\ & \text { radionuclide } i, \mathrm{~m}^{2} / \mathrm{yr}\end{aligned}$

$C_{\text {cio }}=\begin{aligned} & \text { concentration of radionuclide } i \text { in colloidal form at waste form } \\ & \text { surface, } \mathrm{g} / \mathrm{m}^{3}\end{aligned}$.

The right side of Equation (4.7) can be substituted for the term $Q(t)\left(C_{j}+C_{c j}\right)$ in Equation (4.5) to evaluate whether radionuclide release under conditions of low flow rate is controlled by the matrix dissolution rate or the diffusive transport rate. A test analogous to the test for convective transport is devised:

If $z_{j}(t) R_{d} A<4 \pi \epsilon r_{0}\left(A_{d} / A_{t}\right)\left(D_{i} C_{s j}+D_{c i} C_{c i}{ }^{*}\right)$, then the matrix dissolution rate controls release, and the release rate $=z_{j}(t) R_{d} A$.

If $z_{j}(t) R_{d} A>4 \pi \epsilon r_{0}\left(A_{d} / A_{t}\right)\left(D_{j} C_{s i}+D_{c i} C_{c i}{ }^{*}\right)$, then the diffusive mass transport rate controls release, and the release rate $=$ $4 \pi \epsilon r_{0}\left(A_{d} / A_{t}\right)\left(D_{j} C_{s i}+D_{c i} C_{c i}{ }^{*}\right)$.

If either of the above tests indicates that the matrix dissolution rate controls release, then this is the rate-controlling process. If both tests indicate that the matrix dissolution rate does not control the release rate, then the release rate will be controlled by either convection or diffusion. For cases in which there is a significant convective flow rate in a locally saturated section of the repository, it may be necessary to consider convective and diffusive release simultaneously as Chambré et al. (1988) have done. However, this situation is considered highly unlikely at the candidate Nevada repository site because water recharge rates are expected to be low and the geologic/hydrologic features at the site (e.g., fractures, environment open to the atmosphere) do not support saturated flow. Therefore, it is assumed that there is competition only between purely convective and purely diffusive mass transport. The following test is applied to determine which process controls release.

If $Q(t)\left(C_{s i}+C_{c i}{ }^{*}\right)>4 \pi \epsilon r_{0}\left(A_{d} / A_{t}\right)\left(D_{i} C_{s i}+D_{c i} C_{c i}{ }^{*}\right)$, then convective mass transport controls release, and the release rate $=Q(t)\left(C_{s i}+C_{C i}{ }^{*}\right)$. 
If $Q(t)\left(C_{s i}+C_{c j}{ }^{*}\right)<4 \pi \epsilon r_{0}\left(A_{d} / A_{t}\right)\left(D_{j} C_{s i}+D_{c i} C_{c j}{ }^{*}\right)$, then diffusive mass transport controls release, and the release rate $=4 \pi \epsilon r_{0}\left(A_{d} / A_{t}\right)$ $\left(D_{i} C_{s i}+D_{C i} C_{c i}{ }^{*}\right)$.

The above sequence of tests is applied in the AREST code for each radionuclide, at each time step, to determine which steady-state release rate expression should be used for a conservative estimate of radionuclide release rates. The possible situations and the expression used in the AREST code in each situation are summarized in Table 4.1. Except for diffusion-limited release at very early times and at locations close to the waste form surface, the steady-state release rates are conservative relative to transient release rates.

\section{Inventory-Limited Release of Radionuclides}

In spent fuel, a small percentage of certain radionuclides are not contained in the fuel matrix. These radionuclides accumulate in the gap or grain boundaries of the fuel during fuel irradiation (e.g., Cs and I) or as

TABLE 4.1. Summary of AREST Code Logic for Release Rate Expressions Relative Rates (a)

\begin{tabular}{|c|c|c|c|}
\hline \multicolumn{3}{|c|}{ 年 } & \multirow{2}{*}{$\begin{array}{l}\text { Mechanism } \\
\text { for Control }\end{array}$} \\
\hline$M$ & $c$ & $\underline{D}$ & \\
\hline 1 & 2 & 3 & Matrix Dissolution \\
\hline 1 & 3 & 2 & Matrix Dissolution \\
\hline 2 & 1 & 3 & Matrix Dissolution \\
\hline 2 & 3 & 1 & Matrix Dissolution \\
\hline 3 & 1 & 2 & Diffusion \\
\hline 3 & 2 & 1 & Convection \\
\hline (a) & $\begin{array}{l}C=c c \\
D=d \\
b=f \\
l=s\end{array}$ & $\begin{array}{l}x \text { di } \\
\text { ctio } \\
\text { sion } \\
\text { st } \\
\text { st }\end{array}$ & olution \\
\hline
\end{tabular}

Expression
$z_{j}(t) R_{d} A$
$z_{j}(t) R_{d} A$
$z_{j}(t) R_{d} A$
$z_{j}(t) R_{d} A$
$4 \pi \epsilon r_{0}\left(A_{d} / A_{t}\right)\left(D_{j} C_{s i}+D_{c i} C_{c i}{ }^{*}\right)$
$Q(t)\left(C_{s i}+C_{c i}{ }^{*}\right)$


crud on the outer surface of fuel cladding $\left(e . g .,{ }^{14} \mathrm{C}\right)$. In the AREST code, the volatile radionuclides (e.g., ${ }^{14} \mathrm{C}$ ) are assumed to be released instantly upon breaching of the containment.

The nonvolatile radionuclides that are not contained in the matrix generally have high solubilities, and they do not form colloids in oxidizing ground waters. In the AREST code, the nonmatrix release rate of these radionuclides is set equal to either $Q(t) C_{s i}$ or $4 \pi \epsilon r_{0}\left(A_{d} / A_{t}\right) D_{i} C_{s i}$, whichever is greater. The release rate remains at one of these two values until all of the nonmatrix inventory is depleted (hence the term "inventory-limited"), at which time the nonmatrix release rate is set equal to zero. Any further release must then come from the matrix.

\section{Application of Matrix Release Model}

To demonstrate the applicability of the steady-state matrix release model, a simple analysis was carried out to determine the fractional release rates of ${ }^{135} \mathrm{Cs},{ }^{238} \mathrm{U}$, and ${ }^{241} \mathrm{Am}$ as a function of flow rate from a 1060-year old PWR spent fuel waste package ( 1000 years after repository closure) in the candidate Nevada repository. ${ }^{135} \mathrm{Cs},{ }^{238} \mathrm{U}$, and ${ }^{241}$ Am were chosen because they represent radionuclides with high, intermediate, and low solubilities, respectively. Release of ${ }^{135} \mathrm{Cs}$ from the gap and grain boundaries was ignored. The parameters used in the analysis are listed in Table 4.2.

The forward matrix dissolution rate, $R_{d}$, was assumed to be constant, which is tantamount to setting parameters a, b ... in Equation (4.2) to zero, and parameter $C_{m}{ }^{*}$ to infinity. It was also assumed that there was no colloid formation; i.e., $k_{c i}, C_{c i}{ }^{*}=0$.

The calculated release rates of ${ }^{135} \mathrm{Cs},{ }^{238} \mathrm{U},{ }^{241} \mathrm{Am}$ as functions of water recharge rate at the candidate Nevada repository site are shown in Figure 4.1. Recharge rates were converted to flow rates by assuming that all water passing through the repository was distributed evenly among the waste packages and came in contact with the waste forms. An area per waste package of $411 \mathrm{~m}^{2} /$ package was assumed (DOE 1986a), which gives a flow rate per waste package of $0.411 \mathrm{~m}^{3} / \mathrm{yr}$ for every $\mathrm{mm} / \mathrm{yr}$ of recharge. The vertical line in Figure 4.1 corresponds to a recharge rate of $0.5 \mathrm{~mm} / \mathrm{yr}$, which is the expected value for the candidate Nevada repository (DOE 1986a). 
TABLE 4.2. Parameters Used in the Release Rate Analysis

\begin{tabular}{|c|c|c|}
\hline Parameter & Value & Reference $(s)$ \\
\hline$R_{d}$ & $10 \mathrm{~g} / \mathrm{m}^{2}-\mathrm{yr}$ & Average of values from (a), (b), (c) \\
\hline$A$ & $9.93 \mathrm{~m}^{2}$ & (d) \\
\hline$C_{s}(C s-135)$ & $810,000 \mathrm{~g} / \mathrm{m}^{3}$ & (d) \\
\hline$C_{S}(U-238)$ & $50 \mathrm{~g} / \mathrm{m}^{3}$ & (d) \\
\hline$C_{S}(A m-241)$ & $0.00145 \mathrm{~g} / \mathrm{m}^{3}$ & (d) \\
\hline$D_{j}$ (a11 species) & $0.03156 \mathrm{~m}^{2} / \mathrm{yr}$ & $\cdots$ \\
\hline$\epsilon$ & 0.1 & ... \\
\hline$r_{0}$ & $0.889 \mathrm{~m}$ & (d) \\
\hline$A_{d} / A_{t}$ & 0.1 & $\cdots$ \\
\hline${ }^{Z}$ Cs -135 & 0.000319 & (d) \\
\hline$z_{U-238}$ & 1.0 & $\cdots$ \\
\hline${ }^{z_{A m-241}}$ & 0.000113 & (d) \\
\hline
\end{tabular}

\footnotetext{
(a) Grandstaff (1976).

(b) Katayama and Bradley (1980).

(c) Thomas and Ti11 (1984).

(d) DOE (1986a).
}

The upper plateau in Figure 4.1 is the maximum release rate that can occur as a result of matrix dissolution (assuming congruent release). Experimental values for the matrix dissolution rate, $R_{d}$, vary widely (Grandstaff 1976; Katayama and Bradley 1980; Thomas and Till 1984). If defensible values for $R_{d}$ of less than about $3 \mathrm{~g} / \mathrm{m}^{2}$-yr used here (a conservative average), the computed fractional release rate would be less than the $1 \times 10^{-5} / \mathrm{yr}$ NRC 1 imit. The sloping portion of each curve is the region where release is controlled by convection (hence the flow rate dependence). The lower plateaus for ${ }^{238} \mathrm{U}$ and ${ }^{241} \mathrm{Am}$ are the release rates that occur as a result of steady-state diffusion. It should be noted that the release rate 


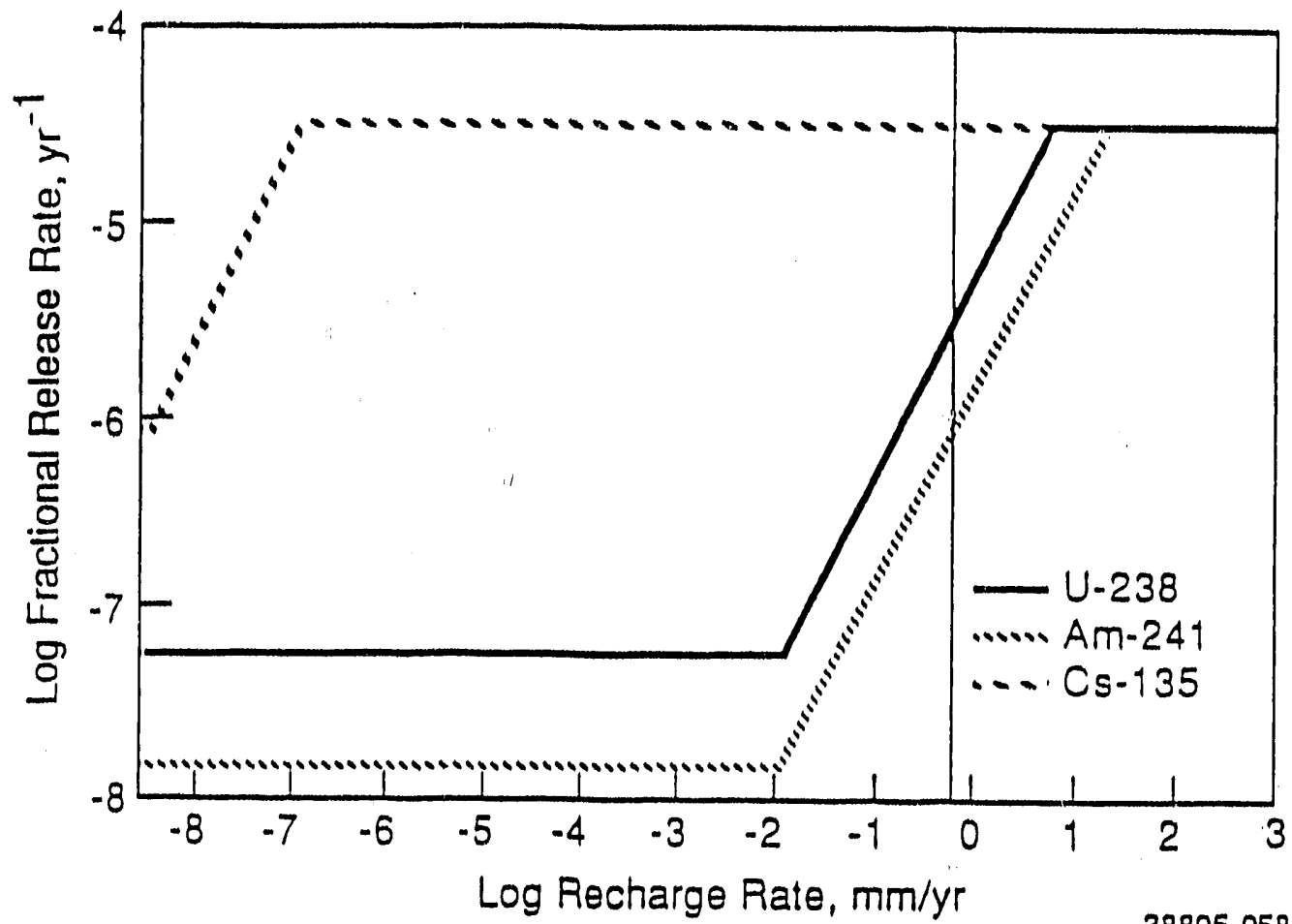

EIGURE 4.1. Fractional Release Rates from Spent Fuel as a Function of Flow Rate at 1000 Years

of ${ }^{135} \mathrm{Cs}$ can never be diffusion limited because the diffusion limited release rate of this radionuclide is several orders of magnitude greater than the rate of matrix dissolution. The sloping portion of the curve for ${ }^{135} \mathrm{Cs}$ will appear only when there is negligible contact between the waste form and diffusive water pathways. A lower plateau for ${ }^{135} \mathrm{Cs}$ will appear only when $A_{d}=$ $A<Q(t) C_{s i} / z_{j}(t) R_{d}$.

The results of the analysis indicate that the recharge rate in the candidate Nevada repository would have to be approximately one order of magnitude higher than expected before radionuclides with low to intermediate solubilities would be released at fractional rates greater than $1 \times 10^{-5} / \mathrm{yr}$ (assuming no colloid formation). Radionuclides with high solubilities, however, will be limited by the matrix dissolution rate over a wid? range of flow rates. For these radionuclides to have fractional release rates less than $1 \times 10^{-5} / \mathrm{yr}$, it will be necessary to demonstrate that the forward rate of matrix dissolution is less than 1 part in $10^{5}$ per year. Alternatively, it 
Wi11 be necessary to 1) show that flow rates or contact times are exceedingly low, 2) show that only a smal1 percentage of waste packages will come in contact with significant quantities of water, or 3) take credit for distributed container fatlures.

\subsubsection{Release Modeling for Saturated Media}

The National Academy of Sciences (NAS) has presented eviderice to support the assumption that diffusive transport is the expected mechanism for radionuclide migration within waste packages at candidate repository sites in saturated media (NAS 1983). This assumption is further supported by information in the environmental assessment reports produced for the two former candidate saturated repository sites. (DOE 1986b,c). On this basis, it is assumed in the AREST model that the transport of both stable and radioactive species from the waste package is diffusion-controlled at a saturated site.

\section{Solubility-Limited Release}

The AREST code implements equations that have beer derived with the aid of mass transfer theory to describe the time-dependent diffusive mass transport of radionuclides away from a waste package (Chambré et a1. 1985). Specifically, a mass transfer rate is calculated as a function of time and location within the waste package. The mass transfer equations are based on a model of waste package geometry that consists of three nested regions: an inner region that is assumed to be an impermeable spherical waste form with an area that is equal to the (inner) surface area of the actual cylindrical waste form container, a porous region surrounding the waste form that is either a tailored packing material or an equivalent barrier, and a porous host rock extending infinitely in all directions. Calculations for a prolate spheroid geometry, chosen to closely approximate the actual cylindrical geometry of a waste package, show that releases are nearly equal when waste form surface areas for the two geometries are set equal (Chambré et al. 1985). Note that this model ignores the potential void space that can result from incomplete filling of the waste package container with a particular waste form.

The mass transfer rate calculated for this "solubility-limited" model is a function of the following variables: 
- radionuclide concentrations at the waste form surface

- radioactive decay constants

- aqueous-phase diffusion coefficients

- radial dimensions of the waste form and thickness of packing

- nuclide retardation coefficients of packing and host rock

- porosity of packing and host rock.

In addition, the release rates can be scaled to account for the effect of the degree of hydrologic saturation and the 7 imited exposure of the spent fuel surface area (Pigford and Chambré 1986).

An initial boundary condition is imposed that fixes the concentration of each radionuclide at the waste form surface. These values can be solubilitylimited concentrations imposed by a discrete radionuclide-bearing solid (Chambré et a1. 1985). This assumption has been found to be realistic for glass and spent fuel under expected waste package conditions (Zavoshy, Chambré, and Pigford 1985; Apted, Liebetrau, and Enge1 1987a). In general, it is assumed that release is incongruent; i.e., it cannot be assumed that the surface concentrations for different radionuclides are all equal or otherwise related to each other, so the mass transfer rates will differ from one radionuclide to another.

It is possible, however, to model the congruent dissolution of the waste form. This forces the assumption that the instantaneous fractional release rates at the waste form surface are equal for all components. In this case, the surface concentrations for each radionuclide are related to the solubility of the primary constituent of the waste form matrix, the mass fraction of the radionuclide in the matrix, and a function related to the mass transfer rates of the specific radionuclide and the matrix components within the waste package.

\section{Inventory-Limited Release}

The AREST code implements mass transfer equations that have been derived to describe the release of highly soluble inventory-limited radionuclides from a waste package, such as those in the gap and grain boundaries of spent fuel (Kim, Chambré, and Pigford 1986). These equations are based on a planar 
geometry that includes a waste form, a water-fflled vold volume adjacent to the waste form, a porous layer of packing (or equivalent material), and the host rock. Dimensions of the barriers in this model are transformed from the actual cylindrical geometry of the waste package. The volume of the void is set equal to the difference in volumes of the cylindrical waste form container and the total volume of the enclosed waste form. The surface area is set equal to that of the cylindrical waste form container, and is identical to that used in the solubility-limited case.

It is assumed that the void volume fills with water instantaneously relative to the time scale of interest. A certain mass of the radionuclide is assumed to dissolve from the waste form at the same instant, so that an initial (non-zero) concentration of the radionuclide is present. The initial concentration of a soluble inventory-limited radionuclide is computed by dividing it.s mass by the volume of the water-filled void. Subsequent transport is assumed to be diffusion-controlled.

The inventory-limited mass transfer calculations depend on the following variables:

- initial concentrations of radionuclides in water-filled void space

- radioactive decay constants

- volume and outer surface area of the void space

- packing thickness

- diffusion coefficient

- radionuclide retardation coefficients for the packing and host rock

- porosity of the packing and host rock.

The inventory-limited release model takes account of decreasing mass flux from both radioactive decay of the source and depletion because of diffusion out of the region of fixed initial inventory.

\subsection{WASTE PACKAGE ENVIRONMENT}

The AREST code modules that provide site-specific information about the physical and chemical environments of the waste package and the repository 
are described here. In particular, modules that describe the thermal, geochemical, and hydrologic environments of the simulated waste package have been incorporated into the AREST code.

\subsubsection{Thermal Model}

Temperatures for simulated waste packages are calculated relative to the temperature-time proftle of a preselected reference case or design-basis waste package. The temperature of a simulated waste package is computed from a simulated initial temperature on the basis of the following assumption: at all times, the difference between the temperature of the simulated container and the ambient repository temperature is proportional to the difference between the temperature of the reference case waste package and the ambient repository temperature.

The reference-case waste package temperature history and the average ambient repository temperature history are obtained from waste package and repository-scale models using the ANSYS finite element code (Swanson Analysis systems, Inc. 1986). This code is a widely used general purpose finiteelement code with both structural and theimal capabilities. Three-dimensional models are used to estimate short-term (<1000 years) waste package scale temperatures. One-dimensional models are used to estimate the repository average temperature. The repository average temperatures and container temperatures become nearly equal after 1000 years, so repository average temperatures are used to est imate waste package temperatures at times greater than 1000 years (Altenhofen 1981). Waste package container temperature and repository average temperature histories for the reference Nevada Nuclear Waste Storage Investigations (NNWSI, now obsolete) design are shown in Figure 4.2. Temperature histories are tabulated for input to the AREST code thermal module.

The initial waste package temperatures are obtained by sampling from a distribution of initial waste package temperatures that is derived, in turn, from a distribution of initial waste package heat generation rates. The conversion of heat generation rates to initial waste package temperatures is site-specific and depends on the thermal properties of the host medium. The distribution of heat generation rates depends upon assumed spent fuel characteristics and repository receipt scenarios. This information is 


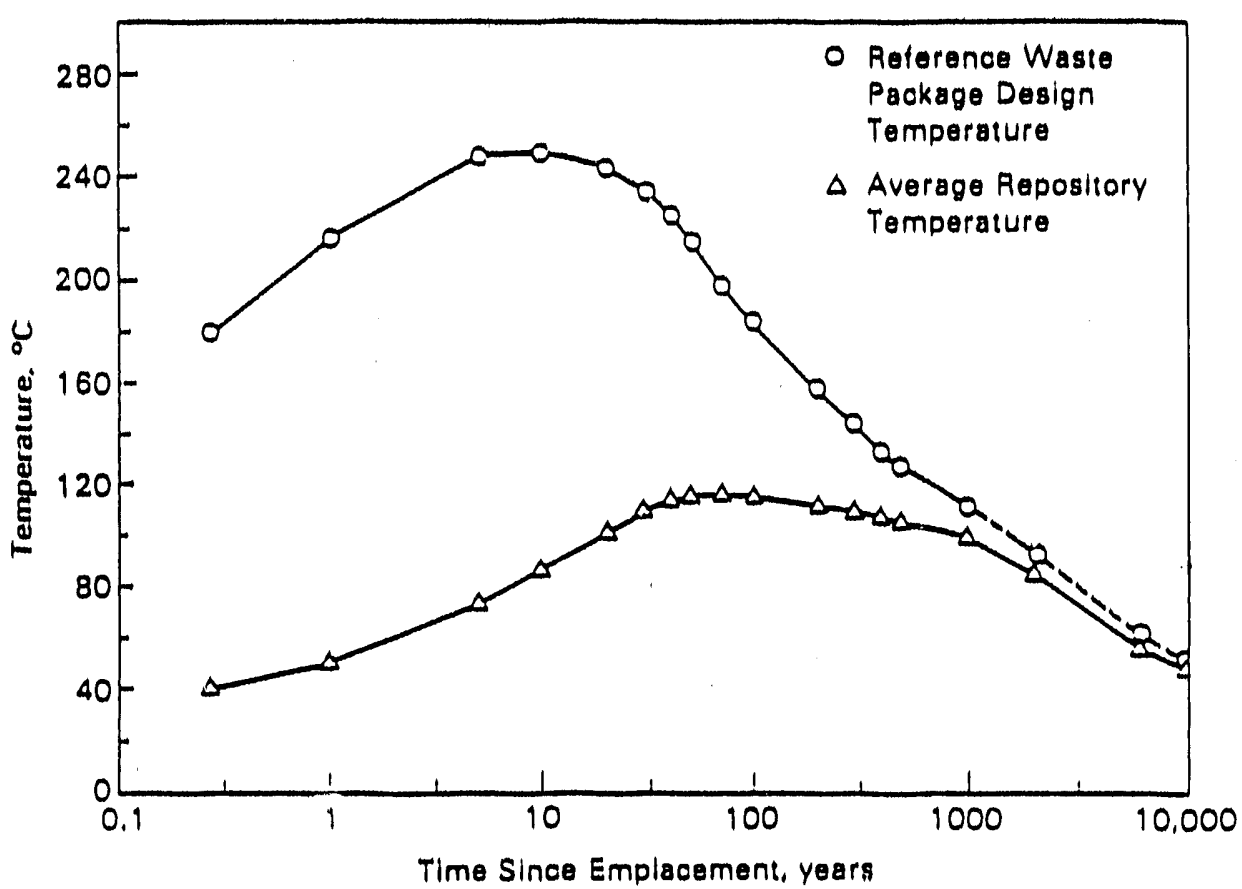

FIGURE 4.2. Waste Package Container and Repository Average Temperatures for the Reference Nevada Nuclear Waste Storage Investigations Design

currently provided by the support code WASTES II ind is based on the receipt scenarto described in the DOE Mission P7an for the OGR Program (DOE 1984a; Shay and Buxbaum 1986). The PNL spent fuel data base (Heeb, Libby, and Holter 1985) provides reactor-specific discharge information based on the 1984 EIA middle case nuclear growth projection to the WASTES II code, which keeps track of the age and exposure of each discharged batch of assemblies and calculates the heat generation rate of the spent fuel received at the repository. The reference-case spent fuel waste package is assumed to contain 10-year-old pressurized water reactor (PWR) spent fuel with an exposure of 33,000 MWd/MTU. Although the current emplacement schedule extends over a period of 25 years, simultaneous emplacement of waste package containers is assumed for modeling purposes.

\subsubsection{Geochemical Model}

The geochemical model provides input to the AREST code concerning the composition of ground water within the repository. The composition of ground water is determined by mass transfer reactions between the ground water and solids in the host rock, packing material, container, and waste form. These reactions are controlled by factors that include temperature, ground water

\subsection{7}


position, the solubility of solid phases in contact with the ground water, and the distribution of the aqueous mass among the various chemical species in solution. In addition, radiolysis may alter the ground-water composition in the waste package near-fleld. However, at present, the effects of radiolysis are not explicitiy modeled.

A simplifted conceptual model was used in the code EQ3NR (Wolery 1983) to derive the geochemical input to the AREST code. The composition of the ground water from well J-13 (Ogard and Kerrisk 1984) was taken as the reference composition (Table 4.3). Well $\mathrm{J}-13$ is located about $6 \mathrm{~km}$ from the proposed repository location.

Several assumptions were made in the conceptual model that affect the calculations. The assumptions are outlined briefly below, and an expanded discussion follows.

- The starting ground-water composition assumed was that reported for well $\mathrm{J}-13$.

- For a given set of chemical reactions in tuff, thermodynamic equilibrium was assumed, and kinetic constraints were not taken into account.

- A11 ground-water compositions were assumed not to change by reaction with the waste container and the spent fuel cladding.

- Sorption of radionuclides was not considered.

The first assumption essentially states that the ground-water composition is fixed by the rock at the horizon temperature because it has been in contact with the host rock for many years. Data from hydrothermal experiments with tuff (Oversby 1984) suggest that the composition of the ground water in contact with the rock does not change dramatically with increasing temperature.

Therefore, the well $\mathrm{J}-13$ ground-water composition represents a reasonable starting composition for input into the equilibrium speciation/ solubility code EQ3NR (Wolery 1983), which was used to generate ground-water compositions for a wide range of temperatures that are tabulated for use by the AREST code. The starting ground-water composition was speciated as a function of temperature and the total concentrations of the dissolved constituents were kept constant. For example, the total concentration for sulfur 


\section{TABLE 4.3. Assumed Reference Composition of Repository Ground Water}

\begin{tabular}{|c|c|}
\hline Constituent & Value \\
\hline $\mathrm{Na}^{+}$ & 48.4 \\
\hline $\mathrm{K}^{+}$ & 5.4 \\
\hline $\mathrm{Al}^{3+}$ & 0.11 \\
\hline $\mathrm{Ca}^{2+}$ & 14.7 \\
\hline $\mathrm{Mg}^{2+}$ & 2.1 \\
\hline $\mathrm{H}_{4} \mathrm{SiO}_{4}$ & 31.2 \\
\hline $\mathrm{Cl}^{-}$ & 7.1 \\
\hline $\mathrm{SO}_{4}^{-}$ & 18.4 \\
\hline$F^{-}$ & 2.6 \\
\hline $\mathrm{CO}_{3}-$ & 151.1 \\
\hline $\mathrm{NO}_{\overline{3}}$ & 8.5 \\
\hline PO3- & 2.7 \\
\hline $\mathrm{pH}$ & 7.2 \\
\hline
\end{tabular}

in the ground water remained constant, while the individual concentrations of $\mathrm{S}^{2-}, \mathrm{H}_{2} \mathrm{SO}_{4}$, etc. varied with temperature.

The second assumption concerns chemical reactions. Because the ground water will be moving very slowly, slifficient time should be available at any given spot in the waste package for the solution to reach equilibrium with its surroundings and for the dissolved constituents to be distributed according to the valious thermodynamic equilibria. Therefore, any kinetic considerations would be transient and would not contribute to the steadystate conditions.

The third assumption arises from the use of steel as the reference material for the waste containers. The containers will react with the incoming solution to form magnetite and/or hematite products and hydrogen gas. This set of reactions leads to a negligible change in the solution chemistry, most notably small changes in the $\mathrm{pH}$. This assumption might be unreasonable if different waste container materials were used or other corrosion products were produced that renove significant quantities of dissolved constituents from the solution. 
The fourth assumption states that sorption was not considered because 1) the current version of EQ3NR does not contain a sorption mode1, 2) existing sorption models do not appear to be adequate, and 3 ) sorption equilibration is generally established within minutes at $25^{\circ} \mathrm{C}$ (unless it is diffusion controlled). Sorption would lead to initially lower values of dissolved uranium and other radionuclides than those calculated from the dissolution of spent fuel, so ignoring sorption is viewed as conservative.

Several other potentiai reactions and processes were not considered. For example, water vaporization and subsequent mineral precipitation for early times after repository loading were not modeled, and reaction path calculations were not attempted. This is potentially a very important assumption. Under boiling/rewetting conditions it may be possible to concentrate constituents by several orders of magnitude, which can have very important impacts on corrosion rates, solubilities, and dissolution rates.

Although dissolved oxygen measurements have been made on samples of J-13 well water (Bish, Ogard, and Vaniman 1984; Tien et al. 1985), the Eh values are scattered $(+0.7 \mathrm{~V}$ to $+0.2 \mathrm{~V})$. These Eh values are consistent with the projection that the atmosphere in the repository will be about the same as that at the surface (l.indsay 1979). For expected redox conditions, the concentrations of elements in J-13 water, including uranium, are not very sensitive to changes in Eh. The dissolved oxygen levels appear to be limited to about $5.7 \mathrm{mg} / \mathrm{L}$ (Ogard and Kerrisk 1984). Because of the relatively high Eh of the water, the use of the uranium silicate soddyite [ $\left(\mathrm{UO}_{2}\right)_{2} \mathrm{SiO}_{4} \cdot 2 \mathrm{H}_{2} \mathrm{O}$ ] has been suggested as the uranium-bearing phase controlling the concentration of dissolved uranium, and was used in the AREST code as an upper limit for uranium concentration in the ground water (Liebetrau et al. 1987).

\subsubsection{Hydrologic Model}

Radionuclide release calculations for saturated media rely on the existence of interconnected pathways of water-filled pores in barrier materials. Thus, the degree of saturation, i.e., a field measure of the percent volume of voids (pores) that are filled with ground water, is an approximate correction factor for mass transfer calculations. The degree of saturation is supplied by the hydrologic model for various barrier material and host rock combinations. 
Closely related to the degree of saturation is the time of resaturation, i.e., the time to achieve resaturation at the waste package following its emplacement and subsequent repository closure. Resaturation is a complex phenomenon that may involve thermal conduction, ground-water boiling, fracture sealing, and other processes. Currently, the AREST code relies on simplified bounding calculations to determine the time of resaturation. Resaturation is assumed to occur when the temperature of the waste package drops below the boiling point of water.

For unsaturated media such as tuff, the quantity of interest is not the time to resaturation (which is physically impossible), but rather the time it takes for the waste package to cool to temperatures where liquid water can come in contact with the container surface. Therefore, hydrologic modeling is inherently linked to thermal modeling for unsaturated media (see Section 4.3.1).

\subsection{INPUTS FOR SOURCE-TERM CALCULATIONS}

The required iriputs for obtaining radionuclide release rates with the AREST code are described above and in greater detail in Sections 2.4 and 3.3 of Liebetrau et a1. (1987). The four basic input categories are

- containment-failure time distributions

- radionuclide data

- spent fuel data

- repository data.

For each category, the input values of variables used in this study are summarized in the following sections.

\subsubsection{Containment Failure Time Distributions}

Because 1) the final selection of waste container materials has not yet been made and the environment into which the containers will be placed has not yet been fully characterized, and 2) integrated dose calculations performed over times ranging from 50,000 to 1 million years are very insensitive to a shift in container failure times of less than 10,000 years, the failure time distribution selected for this report was not derived from simulations 
involving the WPC model of the AREST code. Instead, one of the five theoretical distributions used in a previous analysis of spent fuel was chosen (Apted, Liebetrau, and Engel 1987b): a normal (Gaussian) distribution with mean $\mu=1000$ years and standard deviation $\sigma=200$, with the lower tail truncated at 300 years.

\subsubsection{Radionuclide Data}

Immediately on discharge from a nuclear reactor, spent fuel contains more than 100 radionuclides. A screening analysis that considered radionuclide half-life and inventory led to selection of 21 key radionuclides for the risk analysis. The radionuclides to be considered in a source term for computing doses are identified in Table 4.4. Pressurized water reactor fuel has been selected for the assessments in this report. This selection is consistent with the DOE requirements in the generic requirements document (DOE 1984b), which specifies a characteristic 10-year-old, PWR fuel with 33,000 MWd/MTU burnup for the purposes of preliminary waste package designanalyses. The waste loading of this PWR fuel is $0.461 \mathrm{MTU} /$ assembly (DOE 1986c). The total 1000-year inventory for this fuel is equal to $1.08 \times 10^{6}$ $\mathrm{Ci} / 1000$ MTU.

\subsubsection{Spent Fuel Data}

The assessment of spent fuel as a waste form requires that certain relevant spent fuel characteristics be identified at the time of disposal. These include

- identification of component materials

- compositions of component materials

- dimensions of components

- radionuclide inventories of components

- temperatures and heat generation rates

- cladding integrity (optional).

Studies of spent fuel (Barner 1985) and the interaction of spent fuel with ground-water solutions (Johnson, Garisto, and Stroes-Gascoyne 1985; Wilson and Oversby 1985; Wilson 1985) indicate that release of radionuclides 
TABLE 4.4. Radionuclide Inventory in Reference

Pressurized Water Reactor Spent Fue1

\begin{tabular}{|c|c|c|c|}
\hline Radionuclide & $\begin{array}{c}1000-\text { Year } \\
\text { Inventory } \\
(\mathrm{Ci} / 1000 \text { MTU) } \\
\end{array}$ & $\begin{array}{c}\text { Half-Life } \\
\text { (yr) }\end{array}$ & $\begin{array}{l}\text { Specific } \\
\text { Activity } \\
(C i / g) \\
\end{array}$ \\
\hline${ }^{245} \mathrm{Cm}$ & $1.7 \mathrm{E}+02$ & $9.30 E+03$ & $1.57 \mathrm{E}-01$ \\
\hline${ }^{243} \mathrm{Am}$ & $1.3 E+04$ & $7.95 E+03$ & $1.85 \mathrm{E}-01$ \\
\hline${ }^{242} \mathrm{Am}$ & $1.1 \mathrm{E}+02$ & $1.52 E+02$ & $9.72 \mathrm{E}-00$ \\
\hline${ }^{241} 1_{A m}$ & $3.5 E+05$ & $4.58 \mathrm{E}+02$ & $3.24 E-00$ \\
\hline${ }^{242} \mathrm{Pu}$ & $1.6 \mathrm{E}+03$ & $3.79 E+05$ & $3.90 E-03$ \\
\hline${ }^{240} \mathrm{Pu}$ & $4.1 E+05$ & $6.58 E+03$ & $2.26 \mathrm{E}-01$ \\
\hline${ }^{239} \mathrm{Pu}$ & $2.8 E+05$ & $2.44 E+04$ & $6.13 E-02$ \\
\hline $238 \mathrm{U}$ & $3.2 E+02$ & $4.51 E+09$ & $3.33 \mathrm{E}-07$ \\
\hline${ }^{236} U$ & $2.3 E+02$ & $2.39 E+07$ & $6.34 E-05$ \\
\hline $235 \mathrm{U}$ & $1.6 \mathrm{E}+01$ & $7.10 E+08$ & $2.14 \mathrm{E}-06$ \\
\hline${ }^{234} U$ & $7.8 E+02$ & $2.47 E+05$ & $6.18 \mathrm{E}-03$ \\
\hline $233 \mathrm{U}$ & 2.1E+00 & $1.62 E+05$ & $9.47 \mathrm{E}-03$ \\
\hline${ }^{237} \mathrm{~Np}$ & $5.8 E+02$ & $2.14 E+06$ & $7.05 \mathrm{E}-04$ \\
\hline${ }^{226} \mathrm{Ra}$ & $1.5 E+00$ & $1.60 E+03$ & $9.88 \mathrm{E}-01$ \\
\hline${ }^{135} \mathrm{Cs}$ & $2.7 E+02$ & $3.00 E+06$ & 8.82E-04 \\
\hline${ }^{129} \mathrm{I}$ & $3.3 E+01$ & $1.59 \mathrm{E}+07$ & $1.74 \mathrm{E}-04$ \\
\hline${ }^{126} \mathrm{Sn}$ & $4.8 E+02$ & $1.00 E+05$ & $2.84 E-02$ \\
\hline${ }^{99} \mathrm{TC}$ & $1.3 E+04$ & $2.15 E+05$ & $1.70 \mathrm{E}-02$ \\
\hline${ }^{79} \mathrm{Se}$ & $4.0 E+02$ & $6.50 E+04$ & 6.97E-02 \\
\hline${ }^{14} \mathrm{C}$ & $6.9 \mathrm{E}+02$ & $5.73 E+03$ & $4.45 E+00$ \\
\hline${ }^{59} \mathrm{Ni}$ & $3.0 E+01$ & $8.00 E+04$ & 7.57E-02 \\
\hline
\end{tabular}

from spent fuel can be divided into four distinct components or radionuclide sources: the matrix of $\mathrm{UO}_{2}$ grains, the cladding, the gap between the fuel and cladding, and the boundaries between the $\mathrm{UO}_{2}$ grains. These sources can be distinguished on the basis of physical form, radionuclide inventory, and processes controlling release, as reviewed in Appendix $D$ of Liebetrau et a1. (1987).

Because radionuclide inventories and heat generation rates vary with time, their values must be specified or calculated for the post-emplacement 
period of a repository. Inventories for reference PWR fuel at 1000 years after permanent closure are identified in Table 4.4 for the key radionuclides (DOE 1986a). Table 4.5 presents the percentages of these radionuclides in the different sources within spent fuel based on the best available data (which is very limited). These inventories correspond to spent fuel 1060 years after reactor discharge, assuming a 60-year preclosure time period for repository construction and waste emplacement.

Radionuclide inventories in spent fuel rods vary because of radioactive decay, as well as differences in age and burnup. Inventory variations because of spent fuel type, age, and burnup have not been modeled. It is expected that fuels with lower burnup than the 33,000 MWd/MTU used as a reference in this report should perform better than the calculated values of this report. Higher burnup fuel is not significantly different in composition, with inventories higher by a factor of 3 or less (see Roddy et al. 1986).

The heat generation rate, which varies with time, is used in the AREST code to calculate the waste package temperature, as described in Appendix $B$ of Liebetrau et a1. (1987). The time dependence of temperature is judged to be of primary importance because other processes (corrosion, diffusion) and variables (solubility, ground-water composition) may be temperature dependent.

Appendix B of Liebetrau et a1. (1987) also describes how the heat generation rate distribution for disposed spent fuel used in this report is developed. The heat generation rate distribution is developed for both PWR and boiling water reactor (BWR) fuel, but PWR will constitute $65 \%$ of the fuel in the repository. As noted previously, PWR and BWR fuel with the same burnup and age have similar radionuclide inventories and can, therefore, be expected to have similar heat generation rates (Roddy et al. 1986).

\subsubsection{Repository Data}

This section contains the site-specific data used in the AREST code. The majority of these data come from the EA report for the candidate Nevada repository site (DOE 1986a). Unless otherwise stated, the assumptions and information used in this report are consistent with those of the EA or other project documents. 
IABLE 4.5. Distribution of Key Radionuclides Used for Reference Pressurized Water Reactor Spent Fuel (Percentage)

\begin{tabular}{|c|c|c|c|c|}
\hline Radionuclide & $\begin{array}{l}\mathrm{UO}_{2} \\
\text { Matrix }\end{array}$ & $\begin{array}{l}\text { Gap (t Grain } \\
\text { Boundary)(a) }\end{array}$ & Cladding & crud \\
\hline $238_{U}$ & 100 & -. & -. & $\cdots$ \\
\hline $236_{U}$ & 100 & -. & -. & -- \\
\hline $235 U$ & 100 & $\cdots$ & -- & $\cdots$ \\
\hline $234_{U}$ & 100 & -. & -. & .. \\
\hline $233 v$ & 100 & -- & -- & -. \\
\hline${ }^{243} \mathrm{Am}$ & 100 & $\cdots$ & -- & -. \\
\hline $242 \mathrm{Am}$ & 100 & -. & - & -- \\
\hline${ }^{241} \mathrm{Am}$ & 100 & -- & -. & -- \\
\hline${ }^{14} c$ (b) & 35 & 1 & 63 & 1 \\
\hline${ }^{245} \mathrm{~cm}$ & 100 & -- & -- & -- \\
\hline${ }^{135} \mathrm{Cs}$ & 98 & 2 & - & -- \\
\hline${ }^{129}{ }_{I}$ & 98 & 2 & -. & - \\
\hline${ }^{237} \mathrm{~Np}$ & 100 & -- & - & -- \\
\hline${ }^{239} \mathrm{Pu}$ & 100 & -. & -- & -- \\
\hline${ }^{240} \mathrm{Pu}$ & 100 & -. & -- & - \\
\hline${ }^{242} \mathrm{Pu}$ & 100 & -. & -. & -- \\
\hline${ }^{226} \mathrm{Ra}$ & 100 & - & - & - \\
\hline${ }^{79} \mathrm{Se}$ & 98 & 2 & -. & -- \\
\hline${ }^{99} \mathrm{TC}$ & 98 & 2 & - & - \\
\hline${ }^{126} \mathrm{Sn}$ & 100 & -- & - & - \\
\hline${ }^{59} \mathrm{Ni}$ & 100 & -- & -- & -- \\
\hline
\end{tabular}

(a) The $2 \%$ of total volatile fission products in the combined gap and grain boundary source is based on fission gas measurements of moderate burnup PWR fuel (Baker et al. 1987; Barner 1985) and experimental data on release in closed system tests (Oversby 1987).

(b) Based on data obtained by Van Konynenburg et a1. (1985).

Table 4.6 contains the information on the waste package design and dimensions presented in the candidate Nevada repository site EA (Apted, Liebetrau, and Engel 1987a). For the purposes of this report, it is 
TABLE 4.6. Design Parameters for Nevada Nuclear Waste Storage Investigations Release Calculations (after DOE 1986a)

Diffusion coefficient in steam $\left(D_{S}\right)=5.0 E-01 \mathrm{~cm}^{2} / \mathrm{s}$

Diffusion coefficient in water, $\left(D_{f}\right)=1.0 \mathrm{E}-05 \mathrm{~cm}^{2} / \mathrm{s}$

Outer edge of packing radius $\left(r_{1}\right)=8.8895 \mathrm{E}+01 \mathrm{~cm}$

Packing thickness $(b)=3.0 \mathrm{E}+00 \mathrm{~cm}$

Spherical waste form radius $\left(r_{1}-b\right)=8.5895 E+01 \mathrm{~cm}$

Radius of waste $\left(R_{0}\right)=8.8895 \mathrm{E}+01 \mathrm{~cm}$

Packing porosity $\left(\epsilon_{1}\right)=0.5$

Rock porosity $\left(\epsilon_{2}\right)=0.1$

Gap width $(a)=1.03 E+01 \mathrm{~cm}$

Gap surface area $\left(S_{v}\right)=9.2715 E+04 \mathrm{~cm}^{2}$

Gap volume $\left(V_{v}\right)=9.5701 E+05 \mathrm{~cm}^{3}$

PWR Assemb7 ies/Waste Package $=7$

Waste Loading $=3.2298 \mathrm{E}+00 \mathrm{MTU} /$ Waste Package

Bulk density of packing $\left(\sigma_{1}\right)=1.29 \mathrm{E}+00 \mathrm{~g} / \mathrm{cm}^{3}$

Bulk density of host rock $\left(\sigma_{2}\right)=2.33 \mathrm{E}+00 \mathrm{~g} / \mathrm{cm}^{3}$

Saturation $(\Phi)=60 \%$

conservatively assumed, based on other analyses for Yucca Mountain (Sadeghi 1990; Apted 1990), that the void region between the waste container and tuff host rock is filled with a matrix of crushed tuff with a $50 \%$ porosity. This table also shows the dimensions of the spherical waste package geometry used in the AREST code that were obtained from the dimensions presented. Reference values (DOE 1986a) of expected radionuclide solubilities and sorption coefficients for tuff are provided in Table 4.7 for key radionuclides. The NNWSI temperature history for a design basis waste package containing spent fuel and the repository average ambient temperature history are shown in Figure 4.2 for spent fuel expected at a first repository. 
IABLE 4.7. Radionuclide Parameters for Nevada Nuclear Waste Storage Investigations Release Calculations (after DOE 1986c)

\begin{tabular}{|c|c|c|c|c|c|c|}
\hline $\begin{array}{l}\text { Radio- } \\
\text { iuclide }\end{array}$ & $\begin{array}{l}\text { Inventory } \\
\text { (mg/pack) }\end{array}$ & $\begin{array}{l}\text { Solubtlity (a) } \\
\left(\mathrm{g} / \mathrm{m}^{3} \mathrm{~L}\right.\end{array}$ & $\begin{array}{l}K_{d}(P)(b) \\
(m L / g) \\
\end{array}$ & $\begin{array}{l}K_{d}(R)^{(b)} \\
(\mathrm{mL} / \mathrm{g})\end{array}$ & $K_{1}{ }^{(c)}$ & $\mathrm{K}_{2}{ }^{(\mathrm{c})}$ \\
\hline${ }^{38} \mathrm{U}$ & $3.10 E+09$ & $5.00 E+01$ & $1.80 E+00$ & $1.80 E+00$ & $5.64 E+00$ & $4.29 E+01$ \\
\hline $6_{U}$ & $1.17 E+07$ & $5.00 E+01$ & $1.80 E+00$ & $1.80 E+00$ & $5.64 E+00$ & $4.29 E+01$ \\
\hline${ }^{5} U$ & $2.41 E+07$ & $5.00 E+01$ & $1.80 E+00$ & $1.80 E+00$ & $5.64 E+00$ & $4.29 E+01$ \\
\hline${ }^{34} U$ & $4.08 E+05$ & $5.00 E+01$ & $1.80 E+00$ & $1.80 E+00$ & $5.64 E+00$ & $4.29 E+01$ \\
\hline $233 U$ & $7.16 E+02$ & $5.00 E+01$ & $1.80 E+00$ & $1.80 E+00$ & $5.64 E+00$ & $4.29 E+01$ \\
\hline${ }^{3} \mathrm{Am}$ & $2.27 E+05$ & $72 E-04$ & $1.20 E+03$ & $1.20 E+03$ & $3.10 E+03$ & $2.80 E+04$ \\
\hline & $3.66 E+01$ & $9.72 E-04$ & $1.20 E+03$ & $1.20 E+03$ & $3.10 E+03$ & $2.80 E+04$ \\
\hline Am & $3.49 E+05$ & $1.45 E-03$ & $1.20 E+03$ & $1.20 E+03$ & $3.10 E+03$ & $2.80 E+04$ \\
\hline & $5.01 E+02$ & 1. $40 E+00$ & $0.00 E+00$ & $0.00 E+00$ & $1.00 E+00$ & $1.00 E+00$ \\
\hline $\mathrm{Cm}$ & $3.50 E+03$ & $2.45 E-03$ & $1.20 E+03$ & $1.20 E+03$ & $3.10 E+03$ & $2.80 E+04$ \\
\hline & $9.89 E+05$ & $8.10 E+05$ & $2.90 E+02$ & $2.90 E+02$ & $7.49 E+02$ & $6.76 E+03$ \\
\hline${ }^{29} \mathrm{I}$ & $6.13 E+05$ & $7.74 E+05$ & $0.00 E+00$ & $0.00 E+00$ & $1.00 E+00$ & $1.00 E+00$ \\
\hline${ }^{237} \mathrm{~Np}$ & $2.69 E+06$ & $7.11 E+02$ & $7.00 E+00$ & $7.00 E+00$ & $1.91 E+01$ & $1.64 E+02$ \\
\hline${ }^{39} \mathrm{Pu}$ & $1.48 \mathrm{E}+07$ & $3.10 E-01$ & $6.40 E+01$ & $6.40 \mathrm{E}+01$ & $1.66 \mathrm{E}+02$ & $1.49 E+03$ \\
\hline${ }^{10} \mathrm{Pu}$ & $5.86 E+06$ & 1.20E-01 & $6.40 E+01$ & $6.40 E+01$ & $1.66 E+02$ & $1.49 \mathrm{E}+03$ \\
\hline & $1.33 E+06$ & $1.20 \mathrm{E}-01$ & $6.40 E+01$ & $6.40 E+01$ & $1.66 \mathrm{E}+02$ & $1.49 E+03$ \\
\hline${ }^{226} \mathrm{Ra}$ & $4.90 E+00$ & $2.26 \mathrm{E}-02$ & $1.50 E+03$ & $1.50 E+03$ & $3.87 E+03$ & $3.50 E+04$ \\
\hline & $1.86 \mathrm{E}+04$ & $5.50 E+05$ & $7.00 E+00$ & $7.00 \mathrm{E}+00$ & $1.91 E+01$ & $1.64 E+02$ \\
\hline & $2.47 E+06$ & $9.90 E+05$ & $3.00 \mathrm{E}-01$ & $3.00 E-01$ & $1.77 E+00$ & $7.99 E+00$ \\
\hline & $5.46 E+04$ & $1.26 \mathrm{E}-04$ & $1.00 E+02$ & $1.00 E+02$ & $2.59 E+02$ & $2.33 E+03$ \\
\hline & $1.28 \mathrm{E}+03$ & $4.60 E+01$ & $2.00 E-01$ & $2.00 \mathrm{E}-01$ & $1.52 E+00$ & $5.66 \mathrm{E}+00$ \\
\hline & $3.71 E+09$ & $4.60 E-05$ & $0.00 E+00$ & $0.00 E+00$ & $1.00 E+00$ & $1.00 E+00$ \\
\hline
\end{tabular}

(a) For elements with more than one long-lived isotope, an "isotopic solubility" is equal to the elemental solubility times the mass fraction of that particular isotope at 1000 years after emplacement.

(b) $F=$ Packing (or equivalent); $R=$ Host Rock; $K_{d}=$ Sorption Coefficient.

(c) $K_{1}=$ Packing Retardation Coefficient; $K_{2}=$ Host Rock Retardation Coefficient. 


\subsection{REFERENCES}

Altenhofen, M. K. 1981. Waste Package Heat-Transfer Analysis: Model Development and Temperature Estimates for Waste Packages in a Repos ttory Located in Basa7t. RHO-BWI-ST-18, Rockwell Hanford Operations, Richland Washington.

Apted, M. J., A. M. Liebetrau and D. W. Engel. 1987a. The Analytical Repository Source-Term (AREST) Model: Analys is of Spent Fuel as a Nuclear Waste Form. PNL-6347, Pacific Northwest Laboratory, Richland, Washington.

Apted, M. J., A. M. Liebetrau and D. W. Engel. 1987b. "Spent Fuel As a Waste Form: Analysis With AREST Performance Assessment Code." In Waste Management '87, Vo1. 2, pp. 545-554. University of Arizona, Tucson, Arizona.

Apted, M. J., W. J. O'Conne11, K. H. Lee, A. T. Macintyre, T.-S. Ueng, T. H. Pigford, and W. W.-L. Lee. 1990. Preliminary Calculations of Release Rates of Tc-99, I-129, Cs-135, and Np-237 from Spent Fuel in a Tuff Repository. WG2-5-90, Working Group Report (in progress).

Baker, D. A., W. J. Bailey, C. E. Beyer, F. C. Bold, and J. J. Tawil. 1987. Assessment of the Use of Extended Burnup Fuel in Light Water Power Reactors. PNL-6258, Pacific Northwest Laboratory, Richland, Washington.

Barner, J. 0. 1985. Characterization of LWR Spent Fuel MCC-Approved Testing Material - ATM-101. PNL-5109, Rev. 1, Pacific Northwest Laboratory, Richland, Washington.

Bish, D. L., A. E. Ogard, and D. T. Vaniman. 1984. "Mineralogy-Petrology and Ground Water Chemistry of Yucca Mountain Tuffs." In Scientific Basis for Nuclear Waste Management VII, ed. G. L. McVay, pp. 283-291. Elsevier, Amsterdam, Netherlands.

Chambré, P. L., T. H. Pigford, W. W.-L. Lee, J. Ahn, S. Kajiwara, C. L. Kim, H. Kimura, H. Lung, W. J. Willitams, and S. J. Zavoshy. 1985. Mass Transfer and Transport in a Geologic Environment. LBL-19430, Lawrence Berkeley Laboratory, Berkeley, California.

Chambré, P. L., C. H. Kang, W. W. -L. Lee, and T. H. Pigford. 1988. "The Role of Chemical Reaction in Waste-Form Performance." In Materials Research Society Symposium Proceedings, eds. M. J. Apted and R. E. Westerman, Materials Research Society, Pittsburgh.

DOE. See U.S. Department of Energy.

Grandstaff, D. E. 1976. "A Kinetic Study of the Dissolution of Uraninite," Econ. Geol. 71:1493.

Heeb, C. M., R. A. Libby, and G. M. Holter. 1985. Reactor-Specific Spent Fuel Discharge Projections: 1984 to 2020. PNL-5396, Pacific Northwest Laboratory, Richland, Washington. 
Johnson, L. H., N. C. Gartsto, and S. Stroes-Gascoyne. 1985. "Used-Fue1 Dissolution Studies in Canada." In Waste Management '85: Proceedings of the 1985 Symposium on Waste Management, ed. R. G. Post, Vol, 1, pp. 479-481. University of Arizona, Tucson, Arizona.

Katayama, Y. B. and D. J. Bradley. 1980. "Long-Term Leaching of Irradiated Spent Fuel." In Scientific Basis for Nuclear Waste Management, Vol. 2, ed. C. J. M. Northrup, Jr., pp. 323-334. Plenum Press, New York.

Kim, C. L., P. L. Chambré, and T. H. Pigford. 1986. Mass-Transfer-Limited Release of a Soluble Waste Species. LBL-20899, Lawrence Berkeley Laboratory, Berkeley, California.

Liebetrau, A. M., M. J. Apted, D. W. Engel, M. K. Altenhofen, C. R. Reid, C. F. Windisch, R. L. Erikson, and K. I. Johnson. 1987. The Analytical Repository Source-Term (AREST) Model: Description and Documentation. PNL-6346, Pacific Northwest Laboratory, Richland, Washington.

Lindsay, W. L. 1979. Chemical Equilibria in Soils. John Wiley and Sons, New York.

National Academy of Sciences. 1983. A Study of the I solation System for Geologic Disposal of Radioactive Wastes. National Academy Press, Washington, D.C.

NRC. See U.S. Nuclear Regulatory Commission.

Ogard, A. E., and J. F. Kerrisk. 1984. Ground Water Chemistry Along the Flow Path Between a Proposed Repository site and the Accessible Environment. LA-10188-MS, Los Alamos National Laboratory, Los Alamos, New Mexico.

Oversby, V. M. 1984. Reaction of the Topopah Spring Tuff with J-13 We11 Water at $90^{\circ} \mathrm{C}$ and $150^{\circ} \mathrm{C}$. UCRL-53552, Lawrence Livermore National Laboratory, Livermore, California.

Oversby, V. M. 1987. "Spent Fuel as a Waste Form: Data Needs to Allow Long-Term Performance Assessment Under Repository Disposal Conditions." In Sctentific Basis for Nuclear Waste Management, Vol. X, eds. J. K. Bates and W. B. Seefeldt, pp. 87-101. Materials Research Society, Pittsburgh, Pennsylvania.

Pigford, T. H., and P. L. Chambré. 1986. "Reliable Predictions of Waste Performance in a Geologic Repository." In High-Level Nuclear Waste Disposal, pp. 163-186. Battelle Press, Columbus, Ohio.

Roddy, J. W., H. C. Clairborne, R. C. Ashline, P. J. Johnson, and B. T. Rhyne. 1986. Physical and Decay Characteristics of Commerctal LWR Spent Fuel. ORNL/TM-9591/VI\&RI, Oak Ridge National Laboratory, Oak Ridge, Tennessee. 
Sadeght, M. M., W. W.-L. Lee, T. H. Pigford, and P. L. Chambré. 1990. "Diffusive Release of Radionuclides into Saturated and Unsaturated Tuff." Irans. Am. Nuc. Soc. 61:70.

Sastre, C., C. Pescatore, and T. Sullivan. 1986. Waste Package Reliability. NUREG/CR-4509, U.S. Nuclear Regulatory Commisston, Washington D.C.

Shay, M. R., and M. E. Buxbaum. 1986. Wastes II: Waste System Transportation and Economic Simulation--Version II. Users Guide. PNL-5714, Pacific Northwest Laboratory, Richland, Washington.

Swanson Analysis Systems, Inc. 1986. ANSYS-- Engineering Analysis System, Revision 4.2. Houston, Pennsylvania.

Thomas, G. F. and G. Till. 1984. "The Dissolution of Unirradiated $\mathrm{VO}_{2}$ Fuel Pellets Under Simulated Disposal Conditions." Nucl. Chem. Waste Manage. $2: 141$.

Tien, F.-L., C. D. Updegraff, K. K. Wahl, M. D. Siegel, and R. V. Guzowski. 1985. Repository Site Data Report for Unsaturated Tuff, Yucca Mountain, Nevada. NUREG/CR-4110 (SAND84-2668), prepared by Sandia National Laboratories for the U.S. Nuclear Regulatory Commission, Washington, D.C.

U.S. Department of Energy (DOE). 1986a. Environmental Assessment: Yucca Mountain Site, Nevada Research and Development Area, Nevada. DOE/RW-0073, Office of Civilian Radioactive Waste Management, Washington, D.C.

U.S. Department of Energy (DOE). 1986b. Environmental Assessment: Reference Repository Location. Hanford Site, Washington. DOE/RW-0070, Vol. 2 of 3, Office of Civilian Radioactive Waste Management, Washington, D.C.

U.S. Department of Energy (DOE). 1986c. Environmental Assessment: Deaf Smith County Site, Texas. DOE/RW-0069, Voi. 2 of 3, Office of Civilian Radioactive Waste Management, Washington, D.C.

U.S. Department of Energy (DOE). 1984a. Mission Plan for the Civilian Radioactive Waste Management Program. DOE/RW-005, Office of Civilian Radioactive Waste Management, Washington, D.C.

U.S. Department of Energy (DOE). 1984b. Generic Requirements for a Mined Geologic Disposal System. DOE/RW-005, Office of Civilian Waste Management, Washington, D.C.

U.S. Nuclear Regulatory Commission (NRC). 1983. Disposal of Nuclear Radioactive Waste in Geologic Repositories. Title 10, Code of Federal Regulations, Part 60, Vol. 46, No. 130, Final Rules, U.S. Nuclear Regulatory Commission, Washington, D.C.

U.S. Nuclear Regulatory Commission (NRC). 1986. Disposal of High-Level Radioactive Wastes in Geologic Repositories: Conforming Amendments. Federal Register, Vol. 51, 22288-22301. 
Van Konynenburg, R. C. Smlth, H. Culham, and C. Otto, Jr. 1985. "Behavtor of Carbon-14 in Waste Packages for Spent Fuel in a Repository in Tuff."

In Scientific Basis for Nuclear Waste Management VIII, eds. C. Jantzen, J. Stone, and R. Ewing, pp. 405-412, Elsevier, Amsterdam, Netherlands.

Wilson, C. N. 1985. Results from NNWSI Sertes 1 Spent Fuel Leach Tests. HFDL-TME 84-30, Hanford Engineering Development Laboratory, Richland, Washington.

Wilson, C., and V. Oversby. 1985. "Radionuclide Release from PWR Fuels in Reference Tuff Repository Ground Water." In Waste Management 85:

Proceedings of the 1985 Symposium on Waste Management, p. 497 . University of Arizona, Tucson, Arizona.

Wolery, T. J. 1983. EO3NR A Computer Program for Geochemical Aqueous Spectation-Solubility Calculations: User's Gulde and Documentation. UCRL-53414, Lawrence Livermore National Laboratory, Livermore, California.

Zavoshy, S. S., P. L. Chambré and T. H. Pigford. 1985. "Mass Transfer in a Geologic Environment." In Sctentific Basis for Nuclear Waste Management VIII, pp. 311-322. Materials Research Society, Pittsburgh, Pennsylvania. 


\subsection{EAR-FIELD GROUND-WATER-BASED TRANSPORT}

\subsection{CONCEPTUAL AND MATHEMATICAL MODEL}

Prediction of the discharge rate of radionuclides into the biosphere when waste containers have falled is a crucial step in evaluating repository system performance. The simplest transport models for far-field transport assume that the hydrologic system can be decomposed into nonintersecting stream tubes, such as streamlines, along which the hydrologic characteristics are constant. Transport along a stream tube is frequently assumed to be onedimensional to simplify the transport equations. These one-dimensional models are extremely simplistic, but it is possible to solve the transport equations in closed form. This allows transport calculations to be done very quickly and without the numerical instabllities often encountered in the numerical solution of the equations in more sophisticated models. The factors usually incorporated into the one-dimensional models are radioactive chain decay, radionuclide retardation, convective transport, and dispersion.

The equations used to describe transport in a stream tube are often written as

$$
R_{i} \frac{\partial N_{1}}{\partial t}+V \frac{\partial N_{i}}{\partial x}+R_{i} \lambda_{i} N_{i}=D \frac{\partial^{2} N_{1}}{\partial x^{2}}+R_{i-1} \lambda_{i-1} N_{i-1}, \quad i=1,2, \ldots k,
$$

for $\lambda_{0}=0$ (Burkholder and Rosinger 1980), where $N_{i}, R_{i}, \lambda_{i}$, and $D$ are the concentration, retardation coefficient, decay constant, and axial dispersion coefficient, respectively, of radionuclide $t$, while $V$ is the ground-water velocity. Note that $N_{f}$ is the dissolved radionuclide concentration, while $R_{i} N_{i}$ is the total radionuclide concentration (molecules/km) and $R_{i} N_{i}-N_{f}$ is the concentration of radionuclide adsorbed to the geologic medium. This model formulation implies that the net effect of retardation is to cause the total radionuclide concentration $R_{i} N_{i}$ to travel at the retarded velocity $V_{f}=V / R_{1}$ rather than with the ground water, even though the dissolved radionuclide, $\mathrm{N}_{j}$, travels with the ground water.

Equation (5.1) assumes that $R_{f}$ and $V$ are constant throughout the stream tube and that the various radionuclides are in sorption equilibrium with the 
geologic medium at all times. The first term in Equation (5.1) is the time rate of change of the total concentration of radionuciide $i$, the second term represents convective transport of the dissolved radionuclide, the third term is decay of the total amount of radionuclide $i$, the fourth term is axial dispersion of dissolved radionuclide $i$, and the last term represents decay of the total amount of radionuclide $i-1$ into radionuclide $i$. In Equation (5.1) dispersion is modeled as a diffusive process, which implies that Equation (5.1) will predict upstream migration as a result of dispersion in some cases. Dispersion, however, is a result of the variation of the real water velocities from the average convective velocity, which will not cause upstream transport because the real velocities in a porous medium are probabiy always oriented downstream (de Marsily 1986). The diffusive model of dispersion has other problems as well (Matheron and de Marsily 1980; Pickens and Grisak 1981; Simmons 1981). An alternative way of modeling convective transport with dispersion is tc solve

$$
R_{i} \frac{\partial N_{i}}{\partial t}+v \frac{\partial N_{i}}{\partial x}+R_{i} \lambda_{i} N_{i}=R_{j-1} \lambda_{i-1} N_{i-1}, \quad \lambda_{0}=0, \quad i=1,2, \ldots k,
$$

using a probabilitiy distribution of water travel times ( $x / V$ ) (Simmons 1981, $1982 a, b)$. Note that Equation (5.2) is obtained by setting $D \equiv 0$ in Equation (5.1).

It has been shown that solving the standard convection-dispersion equation

$$
\begin{gathered}
\frac{\partial N}{\partial t}+V \frac{\partial N}{\partial x}=D \frac{\partial^{2} N}{\partial x^{2}} \\
N(x, 0)=0 \\
N(0, t)=f(t),
\end{gathered}
$$


is equivalent to solving the simple convection equation

$$
\begin{aligned}
& \frac{\partial n}{\partial t}+v \frac{\partial n}{\partial x}=0 \\
& n(x, 0)=0, \\
& n(0, t)=f(t),
\end{aligned}
$$

with the travel times taken from a Fickian distribution (Simmons 1982a).

The travel-time distribution that makes Equations (5.3) and (5.4) equivalent depends on the form of the boundary conditions [Equations (5.3c) and $(5.4 c)]$. In particular, the problem where the fluxes are specified $V N-D \partial N / \partial x=h(t)$ for $N$ and $V n=h(t)$ for $n$ doe. not satisfy the same boundary conditions as Equations (5.3) and (5.4). However, the fluxes $F=V N-D \partial N / \partial x$, and $f=V n$ satisfy Equations (5.3) and (5.4) with the boundary conditions in Equations (5.3c) and (5.4c). Thus, solving the convection-dispersion equation is equivalent to solving the convection equation with the travel times taken from a Fickian distribution if either the concentrations are of interest or the fluxes are of interest. For example, the expected value of $n(x, t)$ in Equation (5.4) when the travel times are chosen from a Fickian distribution is also the solution to Equation (5.3).

Equations (5.3) and (5.4) do not account for either retardation or radioactive decay. On physical grounds it is reasonable to expect that the above discussion also applies to these cases. In fact, Equations (5.1) and (5.2) can be reduced to Equations (5.3a) and (5.4a) by a change of variable when $i=1$. (See Simmons, Kincaid, and Reisenauer 1986 for treatment of a single-member decay chain.)

When using the stochastic approach to modei dispersion, it is undesirable to use a Fickian distribution for the water travel times because it is equivalent to solving Equation (5.3), which incorporates the diffusive model of dispersion. The lognormal distribution is commonly used instead (Simmons 1982a; Simmons and Cole 1985). The lognormal distribution is reasonable 
because particle and pore sizes tend to have lognormal distributions. The lognormal distribution is given by

$$
p(T ; x)=\frac{1}{a(2 \pi)} \frac{e^{-(\ln T-b)^{2} / 2 a^{2}}}{T},
$$

where $E[T]=e^{b+a^{2} / 2}$, and $\operatorname{Var}[T]=\left(e^{a^{2}}-1\right) E[T]^{2}$.

The parameters $a$ and $b$ were chosen by equating the analytical expression for the expectation and variance of the lognormal distribution to the mean and variance of the travel times given in Table 5.1. The travel times in Table 5.1 are from Tables 3.5 and 3.15. The standard deviations of the water travel times for layers 1 to 4 were taken from Sinnock et al. (1986, Table 3). The value given for the Topopah Spring Welded unit was used for both layers 1 and 2. The data from Sinnock et a1. (1986) was used because it is the most current published data for the site. The standard deviation of the water travel time in layer 5 was computed from the data in Table 3.16.

Equation (5.2) has been solved (Harada et a1. 1980) for an arbitrary length chain when all the retardation values are distinct. The solution of Equation (5.2) for unrestricted retardation values is derived in Appendix $B$. Decause a stochastic travel time approach has been chosen to model diffusion, further mociel discussion is restricted to the transport of radionuclides in a single stream tube with a fixed water velocity and fixed retardation values. In particular, convective transport with radioactive decay and radionuclide retardation, but without dispersion, is treated.

Assume that transport down a stream tube is one dimensional; i.e., radionuclide concentration depends only on the distance from the beginning of the stream tube, $x$, and the time, $t$. Thus, radionuclide concentration is constant in any cross section of the stream tube. Furthermore, it is assumed that each radionuclide has two components; one dissolved in the water and one adsorbed to the geologic medium. It is assumed that the adsorbed radionuclide is fixed in space and the dissolved radionuclide moves with the water. In a porous medium the concentration of dissolved radionuclide $i$ is $N_{i}$ while $R_{i} N_{i}$ is the total concentration and $R_{i}$ is a retardation factor 
TABLE 5.1. Predicted Travel Times for Different Vertical

Profiles Using $0.5 \mathrm{~mm} / \mathrm{yr}$ Recharge

\begin{tabular}{|c|c|c|c|c|c|}
\hline \multirow[b]{2}{*}{ Layer } & \multirow[b]{2}{*}{ Name } & \multicolumn{3}{|c|}{ Mean wacer Ira } & \multirow{2}{*}{$\begin{array}{r}\text { Stanaara Ueviation } \\
\text { of Trave } 1 \text { Times } \\
(y r)\end{array}$} \\
\hline & & $\underline{U S W-G I}$ & $\underline{\text { USW-G3 }}$ & $\underline{\text { USW-G4 }}$ & \\
\hline 1 & $\begin{array}{l}\text { Topopah Spring } \\
\text { Welded }\end{array}$ & 8,580 & 1,149 & 14,652 & 1,920 \\
\hline 2 & $\begin{array}{l}\text { Basal Vitrophyre } \\
\text { of Topopah Spring }\end{array}$ & 3,811 & 10,798 & 2,308 & 1,920 \\
\hline 3 & $\begin{array}{l}\text { Calico Hills Non- } \\
\text { welded (vitric) }\end{array}$ & & 23,384 & & 7,760 \\
\hline 3 & $\begin{array}{l}\text { Calico Hills Non- } \\
\text { welded (zeolitic) }\end{array}$ & 67,420 & . & 77,476 & 8,145 \\
\hline 4 & Prow Pass Nonwelded & 13,257 & 70,404 & & 8,025 \\
\hline 5 & Saturated Zone & 44,000 & 44,000 & 44,000 & 3,330 \\
\hline & & 137,068 & 149,735 & 138,436 & \\
\hline
\end{tabular}

(Freeze and Cherry 1979). $R_{i}$ is assumed to be a constant, however, this is an approximation, because $R_{i}$ generally depends on concentration, ground-water chemistry and 5 other variables. It is also assumed that the water velocity is sufficiently low that the radionuclides are all in sorptive equilibrium at all times. Let $N_{j}(x, t)$ be the dissolved concentration, in molecules $/ \mathrm{km}$, of radionuclide $i$ at the point $(x, t)$ in the stream tube. Furthermore, assume that no radionuclides are present in the stream tube for $t \leq 0$, and the only source of radionuclides is release of radionuclide 1 into the stream tube at $x=0$. Let $\lambda_{i}$ denote the decay constant for radionuclide $i$. The governing transport equations for radionuclide concentration are Equations (5.1) when dispersion is included (Burkholder and Rosinger 1980) and (5.2) when there is no dispersion. The quantity of interest is the radionuclide flux, rather than the concentration. Let $f_{j}(x, t)$ be the total flux of radionuclide $i$, in molecules/yr, at distance $x$ along the stream tube at time $t$. Under the above assumptions [i.e., Equation (5.2) holds and $R_{i} N_{i}$ is the total radionuclide concentration], the following relation holds: 


$$
f_{j}(x, t)=V N_{j}(x, t)
$$

Substituting Equation (5.5) into Equation (5.2), it follows that $f_{i}$ also satisfies Equation (5.2). Thus, the functions $f_{i}$ must satisfy

$$
\begin{gathered}
\frac{\partial f_{i}}{\partial t}+v_{i} \frac{\partial f_{i}}{\partial x}+\lambda_{i} f_{i} \frac{R_{i-1}}{R_{i}} \quad \lambda_{i-1} f_{i-1}, \quad \lambda_{0}=0, \quad i=1,2, \ldots k, \\
f_{i}(x, 0)=0, \quad x>0, \quad i=1, \ldots, k \\
f_{1}(0, t)=\Phi(t), \quad t>0, \\
f_{j}(0, t)=0, \quad t>0, \quad i=2, \ldots, k,
\end{gathered}
$$

where

$$
v_{i}=V / R_{i}
$$

when the flux of radionuclide 1 is $\Phi(t)$ at $x=0$. Equation $(5.6)$ is solved in Appendix $B$ for an arbitrary $\Phi(t)$.

The solution of Equation (5.6) gives the total flux of radionuclide $i$, molecules/yr, at the distance $x$ along the stream tube when the flux of radionuclide 1 , in molecules/yr, is specified at $x=0$. The fluxes are converted from molecules/yr to $\mathrm{Ci} / \mathrm{yr}$ for use in subsequent dose calculations. Let $F_{j}(x, t)$ be the total flux of radionuclide $i$ in a stream tube, $\mathrm{C} i / \mathrm{yr}$, when $F_{0}(t) C i / y r$ of radionuclide 1 is released into the stream tube at $x=0$. Then

$$
F_{i}(x, t)=\frac{\lambda_{i}}{\lambda_{1}} f_{j}(x, t)
$$


where $f_{i}(x, t)$ is the solution of Equation (5.6) with $\Phi(t)=F_{0}(t)$.

Equations for $F_{1}, F_{2}$, and $F_{3}$ are derived in Appendix $C$ by using Equation (5.8) and the band release function

$$
\Phi(t)=F_{0}(t)= \begin{cases}s_{0}, & t_{0} \leq t \leq t_{1}, \\ 0, & \text { otherwise, }\end{cases}
$$

in the general solution for $f_{j}(x, t)$ obtained in Appendix B. Decay chains of up to length 3 were used in this study. Equation (C.1) is used for $F_{1}$; Equations (C.2) and (C.6) for $\mathrm{F}_{2}$; and Equations (C.7), (C.14), and (C.19) for $F_{3}$. The distance, $x$, down the stream tube is replaced by the length, $L$, of the stream tube in each of the equations from Appendix $C$, and $L / V_{j}$ is replaced by $L /\left(V / R_{i}\right)=R_{i} T$ where $T$ is the water travel time. The reason for more than one equation for chains of length two or three is that a more compact solution form can be obtained when more than one radionuclide has the same retardation coefficient.

\subsection{MODEL IMPLEMENTATION}

Yucca Mountain is modeled as having four or five hydrologic layers, depending on which borehole, USW-G1, USW-G3, or USW-G4, is being considered. The last layer always represents the saturated zone, while the other layers represent the unsaturated zone. The layers are distinguished by 1) the time it takes water to traverse a layer, 2) the standard deviation of the water travel times in a layer (a measure of dispersion), and 3 ) the radionuclide retardation values in a layer.

It is assumed that any given layer can be divided into nonintersecting stream tubes, such that all hydrologic properties are constant in any stream tube. Furthermore, it is assumed that transport in any given stream tube is governed by the one-dimensional convective transport equation with radioactive decay and chemical retardation. Dispersion in a layer is assumed to be a result of variations of the water travel times in the various stream tubes and is modeled stochastically by using a lognormal distribution of travel times in each layer. 
It is further assumed that the discharge from a multilayer system can be obtained by using the transport model to calculate the discharge from each of the individual layers and using the discharge from one layer as the input into the next layer. This approach assumes that ground-water behavior at the interface between adjacent layers is very simple. In particular, it assumes that as soon as a parcel of water leaves the upper layer all of the water enters the next layer. Thus, pooling of water between layers and any other complicated behavior is not allowed. The transport model is implemented in the computer code DOTR (Decay of Transported Radionuclides). The DOTR code replaces the previous PASS transport modules LASSY1, LASSY2, and LASSY3. DOTR requires that a radioactive decay chain be approximated by using one-, two-, and three-member radioactive decay chains. The actual decay chains and radionuclide half-lives describing the situation at Yucca Mountain and the approximations used in the transport calculations are described in Section 5.3. DOTR also requires that the release of a radionuclide into a layer be a step function release $(\mathrm{Ci} / \mathrm{yr})$ of the radionuclide. This is not a significant restriction because an arbitrary release function or curve can be approximated accurately using step functions. Given a set of decay chains, a step function release into the layer, a set of radionuclide retardation values, and a distribution of water travel times, DOTR gives the discharge $(\mathrm{C} i / \mathrm{yr})$ of radionuclides from the layer.

Although the solution for an arbitrary length decay chain could have been implemented in DOTR, the computations can be completed much faster for short chains than for long chains because the solution and computer implementation of Equation (5.2) becomes increasingly more complex for chains of length greater than three. Thus, DOTR only uses chains up to length three. Other major transport codes using closed-form solutions of the transport equations also consider chains up to length three; e.g., Burkholder and Rosinger (1980).

The input variables to DOTR are

1. definition of the decay chains to be run

2. leach data describing the step function release of radionuclides into the stream tube system ( $\mathrm{C} i / \mathrm{yr})$, as obtained from an engineered barriers release mode? 
3. the number of stream tubes to use

4. a travel time and weight for each stream tube

5. a set of retardation values and weights for each radionuclide.

The ability to specify a set of stream tubes with different travel times in DOTR allows dispersion to be taken into account by taking the travel times from a probability distribution. Note that neither water velocity, $V$, nor stream tube length, $L$, are used by DOTR, only the travel time $T=L / V$. The discharge of radionuclide $i$ from the end of a stream tube, $N_{j}(L, t)$, depends only on the ratio $L / V=T$, not on $L$ or $V$ independently.

\subsection{INPUT DATA AND REPRESENTATIVE TRANSPORT RESULTS}

This section contains a description of the hydrologic modeling results used to compute travel times for the mass transport model. The arrival time of contaminants at Alkali Flat is highly sensitive to the retardation factors used, and therefore the retardation factors chosen are given for each radioactive element that was modeled.

\subsubsection{Hydrologic Data}

The hydrologic modeling results used to compute the travel time distribution for the vertical and horizontal mass transport are given in this section. The travel times for layers 1 to 4 and the saturated zone were taken from Table 5.1. The travel time for the saturated zone represents the travel time from well $\mathrm{J}-12$ to Alkali Flat. This travel time is expected to be a conservative estimate of the travel time from wells USW-G1, USW-G3, and USW-G4 to Alkali Flat because these wells are north of well $\mathrm{J}-12$ and Alkali Flat is south of well $\mathrm{J}-12$ (see Section 3.0). A preliminary study by the USGS (Czarnecki 1985) indicates that the water table would rise, and travel times would decrease, in the region of the repository if the annual precipitation rate were to double over that of modern times. Because the modeling performed by PNL to calculate regional ground-water travel times did not explicitly incorporate a range of precipitation or recharge rates, the travel time in the saturated zone was assumed to be the same for all of the recharge rates used (see Table 5.1 and Section 7.2 ). However, the hydrologic 
modeling by PNL (see Section 3.0) indicates that regional ground-water gradients would change very 1 ittle for recharge rates that increase by $50 \%$ or less.

The standard deviations of the water travel times for layers 1 to 4 were taken from Sinnock, Lin, and Tierney (1986, Table 3). The value given for the Topopah Spring Welded unit was used for both layers 1 and 2. The information in Sinnock, Lin, and Tierney (1986) was used because it is the most current published data available for the site. Finally, the standard deviation of the water travel time in layer 5 given in Table 5.1 was obtained from the PNL hydrologic model.

\subsubsection{Retardation Data}

The retardation coefficients are given in Table 5.2 for each radioactive element modeled in the transport calculations. The arrival time of contaminants at Alkali Flat is highly sensitive to the retardation factors used since the arrival time of a radionuclide is found by multiplying the ground water travel time by the retardation coefficient.

The retardation values for all radionuclides in the saturated zone, layer 5 , were taken to be 1 , the most conservative choice possible, since there are no available data for the saturated zone. The retardation values in layer $3^{\prime}=$ Calico Hills Nonwelded (zeolitic) were taken to be twice the values in layer 3 = Calico Hills Nonwelded (Vitric). Essentially the same thing was done by Sinnock and Lin (1987), who based their argument on porosity estimates of the different layers.

The retardation values, Rd, for layers $1,2,3$, and 4 were calculated from the equation

$$
R d=1+K_{d} * 2.5 *(1-\text { porosity }) / \text { porosity }
$$

where $K_{d}$ is the sorption ratio for an element in a layer, $2.5 \mathrm{~g} / \mathrm{cm} * \star 3$ is the rock column density, and porosity denotes the porosity of the layer. This equation is taken from DOE (1986), Table 6-25, which also gives the porosity for each of the layers. The correspondence between the layers in DOE (1986, Table 6-25) and the layers in this report is

Layer 1 = Welded tuff Topopah Spring Member 
TABLE 5.2. Retardation Factors for the Transport Mode1

\begin{tabular}{lrrrrrrr}
\multicolumn{1}{c}{ Element } & Layer 1 & Layer 2 & Layer 3 & Layer 3' & Layer 4 & Layer 5 \\
\cline { 1 - 1 } Americium (Am) & 24,000 & 830 & 21,000 & 42,000 & 28,000 & 1 \\
Barium (Ba) & 18,000 & 176,000 & 436,000 & 872,000 & 1,100 & 1 \\
Carbon (C) & 1 & 1 & 1 & 1 & 1 & 1 \\
Cesium (CS) & 5,800 & 74,000 & 36,000 & 72,000 & 1,100 & 1 \\
Curium (Cm) & 24,000 & 830 & 21,000 & 42,000 & 28,000 & 1 \\
Iodine (I) & 1 & 1 & 1 & 1 & 1 & 1 \\
Neptunium (Np) & 140 & 30 & 52 & 104 & 40 & 1 \\
Nicke1 (Ni) & 1 & 1 & 1 & 1 & 1 & 1 \\
Protactinium(Pa) & 1,300 & 558 & 651 & 1,302 & 472 & 1 \\
Plutanium (Pu) & 1,300 & 558 & 651 & 1,302 & 472 & 1 \\
Radium (Ra) & 18,000 & 176,000 & 436,000 & 872,000 & 1,100 & 1 \\
Selenium (Se) & 1 & 1 & 1 & 1 & 1 & 1 \\
Technetium (Tc) & 7 & 12.6 & 1.9 & 3.8 & 2.2 & 1 \\
Thorium (Th) & 10,100 & 2,300 & 2,300 & 4,600 & 3,060 & 1 \\
Tin (Sn) & 2,000 & 465 & 465 & 930 & 613 & 1 \\
Uranium (U) & 37 & 12.6 & 25.6 & 51.2 & 12 & 1
\end{tabular}

Layer 2 = Bedded tuff Topopah Spring Member

Layer 3 = Bedded tuff-tuffaceous beds of Calico Hills

Layer 4 = Partially welded tuff Prow Pass Member.

The $K_{d} s$ for $\mathrm{Am}, \mathrm{Cs}, \mathrm{Np}, \mathrm{Pu}, \mathrm{Tc}, \mathrm{U}$, and $\mathrm{Ba}$ in layers 1, 2, 3 and 4 were taken from DOE (1986), Table 6-25. There are no $K_{d} s$ reported in DOE (1986) for Np, $T c$, and $U$ in layers 2,3 , and 4 , respectively. The missing sorption ratios were estimated from the ones listed in Table 6-25 of DOE (1986). A sorption ratio of $K_{d}=6.4$ was used for $N p$ in layer 2 . This compares to values of 7 , 11 , and 6.4 for $\mathrm{Np}$ in layers 1,3 , and 4 , respectively. A sorption ratio of $K_{d}=0.2$ was used for $T c$ in 1ayer 3 . This compares to $0.3,2.5$, and 0.2 for $T c$ in layers 1,2 , and 4 , respectively. For uranium, a sorption ratio of $\mathrm{K}_{d}$ $=1.8$ was used in layer 4 . This compares to $1.8,2.5$, and 5.3 for uranium in layers 1,2 , and 3 , respectively.

The sorption data for $\mathrm{Sn}$, Th, C, and I were taken from DOE (1986, Table 6-48). The retardation values for the welded tuff in DOE (1986) were used for 1 ayers 1 and 4 , while the retardation values for the nonwelded tuff were used for layers 2 and 3 . The sorption ratios for $\mathrm{Ni}$ and Se were taken to be zero in all layers because no data are available for them; the same approach was used by DOE (1986, Table 6-48) for C and I. 
In DOE (1986), Table 6-48 lists $\mathrm{Cm}$ and $\mathrm{Pa}$ as having the same sorption ratios as $\mathrm{Am}$ and $\mathrm{Pu}$, respectively. Therefore, the sorption ratios used for $\mathrm{Cm}$ and $\mathrm{Pa}$ were the sorption ratios for $\mathrm{Am}$ and $\mathrm{Pu}$, respectively, 1isted in DOE (1986), Table 6-25. Finaliy, in DOE (1986), Table 6-48 11sts Ba as a chemical analog of $\mathrm{Ra}$ and uses the same sorption ratios for $\mathrm{Ba}$ and $\mathrm{Ra}$. Therefore, the sorption ratio for Ra was taken to be the same as the sorption ratio for Ba given in DOE (1986, Table 6-25).

\subsubsection{Decay Chains}

The discharge rates of radionuclides released from the Yucca Mountain repository were obtained from the EBS. The radionuclides obtained from the EBS were divided into five sets of decay chains. The decay chains used in the transport calculations and the actual decay chains for the radionuclides in chains 1 through 5 are 1 isted below. Only radionuclides with half-lives greater than 1 year are included in the actual decay chains. The actual decay chains and half-life values are taken from Kocher (1981). Whenever a three-member decay chain $A \rightarrow B \rightarrow C$ is included in a chain used, it is implied that the two-member decay chains $A \rightarrow B$ and $B \rightarrow C$ are also used.

Chain 1:

Radionuclides from EBS: ${ }^{243} \mathrm{Am},{ }^{239} \mathrm{Pu}, 235 \mathrm{U}$

Actual decay chain:

${ }^{243} \mathrm{Am} \rightarrow 239 \mathrm{Pu} \rightarrow 235 \mathrm{U} \rightarrow 231 \mathrm{pa} \rightarrow 227 \mathrm{AC}$

$243 \mathrm{Am}$ was neglected because its discharge rate from the repository is negligible compared to ${ }^{239} \mathrm{Pu}$ and $235 \mathrm{U}$ for all sets of EBS data. In addition, a11 of the ${ }^{239} \mathrm{Pu}$ was assumed to have been converted into $235 \mathrm{U}$ in the EBS. A11 radionuclides below $231 \mathrm{~Pa}$ in the chain were ignored because their halflives are under 50 years. The discharge rates for the short-lived decay products of $231 \mathrm{~Pa}$ can be obtained directly from the discharge rate of $231 \mathrm{~Pa}$ because the decay products will be in equilibrium with $231 \mathrm{~Pa}$ long before they have been transported to Alkali Flat. The equilibrium assumption rests in part on the assumption that all radionuclides have a retardation value of one in the saturated zone, which is the last layer, and in part on long transport times (the mean travel time in the saturated zone is 44,000 years). 
The preceding shows that only the decay chain $235 \mathrm{U} \rightarrow 231 \mathrm{~Pa}$ needs to be approximated. The decay chains run were:

Layers in which chain was run (by borehole)

$\begin{array}{lccc}\text { On1y } 235 U & \frac{U S W-G 1}{1,2} & \frac{U S W-G 3}{1,2,3} & \frac{U S W-G 4}{1,2} \\ 235 U \rightarrow 231 \mathrm{~Pa} & 3-5 & 4,5 & 3,4\end{array}$

The two-member decay chain was neglected in layers 1, 2, and 3 of USW-G3 because any ${ }^{231} \mathrm{~Pa}$ entering layer 4 takes more than $10 \mathrm{~m} 1111$ ion years to reach the end of the layer; thus only $231 \mathrm{~Pa}$ actually produced in layer 4 wi11 contribute to the discharge of $231 \mathrm{~Pa}$ from that layer with in the time frame of this risk assessment. Likewise, the discharge of $231 \mathrm{~Pa}$ from layer 3 of USW-G4 W 111 be the result of $231 \mathrm{~Pa}$ being produced as $235 \mathrm{U}$ moves through layer 3. The two-member decay chain can also be ignored in layers 1 and 2 of USW-G1. Transport calculations show that the $231 \mathrm{~Pa}$ produced in layer 3 of USW-Gl has. a negligible contribution to the discharge of $231 \mathrm{~Pa}$ from 1 ayer 4 .

\section{Chain 2:}

Radionuclides from EBS: $240 \mathrm{Pu}, 236 \mathrm{U}$

Actual decay chain:

$$
240 \mathrm{pu} \rightarrow 236 \mathrm{U} \rightarrow 232 \mathrm{Th}+228 \mathrm{Ra}+228 \mathrm{Th}
$$

A11 240 pu was converted into $236 \mathrm{U}$ in the EBS. Al1 decay products of 232Th were ignored because they all have half-lives of less than 10 years. Thus, the decay chain implemented is $236 \mathrm{U} \rightarrow 232 \mathrm{Th}$. The decay chains run were:

\section{Layers in which chain was run (by borehole)}

$$
\begin{array}{lccc}
\text { On1y } 236 U & \frac{U S W-G 1}{1,2,3} & \frac{U S W-G 3}{1,2,3} & \frac{U S W-G 4}{1,2} \\
236 U \rightarrow 230 \mathrm{Th} & 4,5 & 4,5 & 3,4
\end{array}
$$

Thorium takes more than 10 million years to traverse layer 4 of USW-G3 and layer 3 of USW-G4, hence the two-member decay chain was neglected in layers 1, 2, and 3 of USW-G3 and layers 1 and 2 of USW-G4. Finally, thorium takes more than 8 million years to traverse layer 4 of USW-G1 using a recharge rate of $0.5 \mathrm{~mm} / \mathrm{yr}$. Thus, the two-member decay chain was neglected 
In layers 1,2 , and 3 of USW-G1 because only the recharge rate of $0.5 \mathrm{~mm} / \mathrm{yr}$ was used in the computations involving borehole USW-G1.

\section{Chain 3:}

Radtonuclides from EBS: ${ }^{14} \mathrm{C},{ }^{135} \mathrm{Cs},{ }^{129} \mathrm{I},{ }^{79} \mathrm{Se},{ }^{126} \mathrm{Sn},{ }^{99} \mathrm{Tc},{ }^{59} \mathrm{Ni}$

Actual decay chatn: None of these radionuclides have daughter products with half-lives greater than a year.

A11 radionuclides, except ${ }^{135} \mathrm{Cs}$ and ${ }^{126} \mathrm{Sn}$, were run as single-member decay chains in every layer of each borehole. ${ }^{135} \mathrm{Cs}$ and ${ }^{126} \mathrm{Sn}$ were not run at all because their high retardation values imply that these radionuclides will take well over 10 million years to reach Alkalt Flat.

\section{Chain 4:}

Radionuclides from EBS: ${ }^{245} \mathrm{Cm}, 241_{\mathrm{Am}},{ }^{237} \mathrm{~Np}, 233 \mathrm{U}$ Actual decay chain:

$$
245_{\mathrm{Cm}} \rightarrow 241_{\mathrm{Pu}}+{ }^{241_{\mathrm{Am}}} \rightarrow 237_{\mathrm{Np}} \rightarrow 23 \mathrm{U}_{\mathrm{U}} \rightarrow 229 \mathrm{Th}
$$

$245 \mathrm{Cm}$ was neglected because its discharge rate from the repository is negligible compared to ${ }^{241} \mathrm{Am}$ and ${ }^{237} \mathrm{~Np}$ for all sets of EBS data. A11 ${ }^{241} \mathrm{Am}$ was converted into ${ }^{237} \mathrm{~Np}$ in the EBS. A11 of the EBS data, except for the incongruent release case, take into account decay of $237 \mathrm{~Np}$ into $233 \mathrm{U}$. Decay of $237 \mathrm{~Np}$ can be neglected in the EBS data for the incongruent case because all of the ${ }^{237} \mathrm{~Np}$ is released from the repository in only a few thousand years. As in chain 1, a11 radionuclides below ${ }^{229}$ Th in the chain were ignored because their half-lives are under 10 years. Thus, the decay chain to be approximated is ${ }^{237} \mathrm{~Np} \rightarrow 233 \mathrm{U} \rightarrow{ }^{229} \mathrm{Th}$. The chains run were:

\section{Layers in which chain was run (by borehole)}

$$
\begin{array}{lccc}
\text { Only } 237 \mathrm{~Np} \rightarrow 233 \mathrm{U} & \frac{U S W-G 1}{1,2,3} & \frac{U S W-G 3}{1,2,3} & \frac{U S W-G 4}{1,2} \\
237 \mathrm{~Np}+233 \mathrm{U} \rightarrow{ }^{229} \mathrm{Th} & 4,5 & 4,5 & 3,4
\end{array}
$$

${ }^{229}$ Th was neglected in some layers for the same reason that 230 Th was neglected in the same layers in chain 2 . 


\section{Chatn 5:}

Radtonuclides from EBS: $245 \mathrm{Cm}, 241_{\mathrm{Am}}, 237_{\mathrm{Np}}, 233 \mathrm{U}$

Actual decay chain:

$$
242 p u+238 u
$$

$17.3 \%$

$242 \mathrm{Am}+234 \mathrm{U}+230 \mathrm{Th}+226 \mathrm{Ra}+210 \mathrm{pb}$

$82.7 \%$

$238 \mathrm{pu}$

$242 \mathrm{Am}$ was neglected because its discharge rate from the repository is negligible compared to $242 p u$ and $234 \mathrm{U}$ for all sets of EBS data. Decay of $238 \mathrm{U}$ into $234 \mathrm{U}$ was taken into account in all of the EBS data. As in chain one, all radionuclides below ${ }^{226} \mathrm{Ra}$ in the chain were ignored because their half-lives are under 50 years. Thus, the decay chain to be approximated is

$$
242 \mathrm{pu} \rightarrow 238 \mathrm{U} \rightarrow 234 \mathrm{U} \rightarrow 230 \mathrm{Th} \rightarrow 226 \mathrm{Ra}
$$

242pu was neglected in computations using the congruent and incongruent EBS data because the $242 \mathrm{pu}$ discharge rate was negligible compared to $238 \mathrm{U}$. Therefore, for the congruent and incongruent EBS data, the decay chain to be approximated is $238 \mathrm{U} \rightarrow 234 \mathrm{U}+230 \mathrm{Th} \rightarrow 226 \mathrm{Ra}$, while the decay chains used were:

\section{Layers in which chain was run (by borehole)}

$$
\begin{array}{lccc}
\text { Onty } 238 U \rightarrow 234 U & \frac{U S W-G 1}{1,2,3} & \frac{U S W-G 3}{1,2,3} & \frac{\text { USW-G4 }}{1,2} \\
238 U \rightarrow 234 U \rightarrow 230 \mathrm{Th} & 4,5 & 4,5 & 3,4 \\
234 U \rightarrow 230 \mathrm{Th} \rightarrow 226 \mathrm{Ra} & 4,5 & 4,5 & 3,4
\end{array}
$$

${ }^{230} \mathrm{Th}$ and ${ }^{226} \mathrm{Ra}$ were neglected in some layers for the same reason that 229 Th was neglected in the same layers in chain 2 (radium has a larger retardation value than thorium in every layer, hence it takes at least as long as thorium to traverse each layer). Note that in any given layer the decay chains run do not account for decay of $238 \mathrm{U}$ into $226_{\mathrm{Ra}}$. This does not, however, produce a significant error because the average travel time in the saturated zone is large compared to the half-life of $226 \mathrm{Ra}$, but small 
compared to the half-lives of $238 \mathrm{U}, 234 \mathrm{U}$, and ${ }^{230} \mathrm{Th}$. In fact, most of the ${ }^{226}$ Ra produced in layer 4 of USW-G3 will decay away in layer 5 of USW-G3, and in 7 ayer 5 the amount of ${ }^{226} \mathrm{Ra}$ produced by $238 \mathrm{U}$ will be small compared to the amount produced by decay of ${ }^{234} \mathrm{U}$ and ${ }^{230} \mathrm{Th}$. Similarly, the results obtained for ${ }^{226} \mathrm{Ra}$ in boreholes USW-GI and USW-G4 are accurate.

242. pu was included when running the mixed advective/diffusive model of Section 4.2 .1 because $242 \mathrm{pu}$ is released faster than $238 \mathrm{U}$ at early times, even though the total release of $242 \mathrm{Pu}$ is small relative to the total release of 238u. Therefore, for the mixed model data, the decay chains used were:

Layers in which chain was run (by boreho?e)

$\begin{array}{lccc}\text { On1y } 242 \mathrm{Pu} \rightarrow 238 \mathrm{U} \rightarrow 234_{U} & \frac{U S W-G 1}{1,2,3} & \frac{U S W-G 3}{1,2,3} & \frac{\text { USW-G4 }}{1,2} \\ 242 \mathrm{Pu} \rightarrow 238 \mathrm{U} \rightarrow 234_{U} & 4,5 & 4,5 & 3,4 \\ 238 \mathrm{U} \rightarrow 234 \mathrm{U} \rightarrow{ }^{230} \mathrm{Th} & 4,5 & 4,5 & 3,4 \\ 234 \mathrm{U} \rightarrow 230 \mathrm{Th} \rightarrow{ }^{226} \mathrm{Ra} & 4,5 & 4,5 & 3,4\end{array}$

${ }^{230} \mathrm{Th}$ and ${ }^{226} \mathrm{Ra}$ were neglected in some layers for the same reason they were neglected in the same layers for the congruent and incongruent cases. Because ${ }^{230} \mathrm{Th}$ and ${ }^{226} \mathrm{Ra}$ are neglected in the first few layers, the approximate decay chain is the same as the actual decay chain. The large retardation value for plutonium will cause most of the $242 p u$ to decay away before reaching the last two layers of any we11. Hence, in the last two layers of each wel1 $242 \mathrm{pu}$ can be neglected with very little error, and the decay chain to be approximated becomes $238 \mathrm{U} \rightarrow 234 \mathrm{U} \rightarrow{ }^{230} \mathrm{Th} \rightarrow 226_{\mathrm{Ra}}$. As explained for the congruent and incongruent cases, the decay chains used provide a good approximation to this decay chain.

The prececing analysis indicates that the one-, two-, and three-member decay chains used in the transport calculations should produce good approximations to the actual decay chains.

\subsubsection{Radionuclide Source Term}

The radionuclide source term for the first layer was obtained from the EBS release calculatiors reported in Section 4.0. The EBS release data represent a repository containing 1000 metric tons uranium (MTU), while the 
transport calculations were done for a repository containing 70,000 MTU. The release rates into the first layer, therefore, were obtained by multiplying the release data by 70 .

Transport calculations were done using the boreholes USW-GI, USW-G3, and USW-G4. The radionuclide discharge at Alkali Flat was computed for the cases listed in Table 5.3. The label mixed denotes the advective/diffusive model of Section 4.2.1. Both congruent and incongruent data use a diffusion only transport model within the EBS.

IABLE 5.3. Data and We11 Configurations for Mass Transport Calcu'ations

\begin{tabular}{|c|c|c|c|}
\hline EBS Data Used & Borehole & \multicolumn{2}{|c|}{ Recharge Rate } \\
\hline Congruent & USW-G1 & 0.5 & $\mathrm{~mm} / \mathrm{yr}$ \\
\hline Congruent & USW-G4 & 0.5 & $\mathrm{~mm} / \mathrm{yr}$ \\
\hline $\begin{array}{l}\text { Congruent } \\
\text { Congruent } \\
\text { Congruent } \\
\text { Congruent }\end{array}$ & $\begin{array}{l}\text { USW-G3 } \\
\text { USW-G3 } \\
\text { USW-G3 } \\
\text { USW-G3 }\end{array}$ & $\begin{array}{l}0.5 \\
0.55 \\
0.63 \\
0.75\end{array}$ & $\begin{array}{l}\mathrm{mm} / \mathrm{yr} \\
\mathrm{mm} / \mathrm{yr} \\
\mathrm{mm} / \mathrm{yr} \\
\mathrm{mm} / \mathrm{yr}\end{array}$ \\
\hline $\begin{array}{l}\text { Incongruent } \\
\text { Mixed }\end{array}$ & $\begin{array}{l}\text { USW-G3 } \\
\text { USW-G3 }\end{array}$ & $\begin{array}{l}0.5 \\
0.5\end{array}$ & $\begin{array}{l}\mathrm{mm} / \mathrm{yr} \\
\mathrm{mm} / \mathrm{yr}\end{array}$ \\
\hline
\end{tabular}

\subsection{REFERENCES}

Burkholder, H. C., and E. L. J. Rosinger. 1980. "A Model for the Transport of Radionuclides and their Decay Products through a Geologic Media." Nuc. Tech. 46:150-158.

Czarnecki, J. 1985. Simulated Effects of Increased Recharge on the GroundWater. Flow System of Yucca Mountain and Vicinity, Nevada-California. WaterResources Investigations Report USGS/WRI-84-4344, U.S. Geological Survey, Denver, Colorado.

de Marsily, G. 1986. Quantitative Hydrogeology, Ground Water Hydrology for Engineers. Academic Press, Inc., New York.

DOE. See U.S. Department of Energy.

Freeze, R. A., and J. A. Cherry. 1979. Ground Water. Prentice-Ha11, Inc., Englewood Cliffs, New Jersey. 
Harada, M., P. L. Chambré, M. Foglia, K. Higashi, F. Iwamoto, D. Leung, T. H. Pigford, and D. Ting. 1980. Migration of Radionuclides Through Sorbing Media, Analytical Solution - I. ONWI-359 (LBL-10500), Lawrence Berkeley Laboratory, Berkeley, California.

Kocher, D. C. 1981. Radioactive Decay Data Tables. DOE/TIC-11026, U.S. Department of Energy, Washington, D.C.

Matheron, G., and G. de Marsily. 1980. "Is Transport in Porous Media Always Diffusive? A Counterexample." Water Resour. Res. 16:901-917.

Pickens, J.F., and G. E. Grisak. 1981. "Scale-Dependent Dispersion in a Stratified Granular Aquifer." Water Resour. Res. 17:1191-1211.

Simmons, C. S. 1981. Relationships of Dispersive Mass Transport and Stochastic Convective Flow Through Hydrogeologic Systems. PNL-3302, Pacific Northwest Laboratory, Richland, Washington.

Simmons, C. S. 1982a. "A Stochastic-Convective Transport Representation of Dispersion in One-Dimensional Porous Media Systems." Water Resour. Res. 18:1193-1214.

Simmons, C. S. 1982b. A Stochastic-Convective Ensemble Method for Representing Dispersive Transport in Ground Water. Report No. CS2558, Electric Power Research Institute, Palo Alto, California.

Simmons, C. S., and C. R. Cole. 1985. Guidelines for Selecting Codes for Ground-Water Transport Modeling of Low-Level Waste Burial Sites. PNL-4980, Vol. 2, Pacific Northwest Laboratory, Richland, Washington.

Simmons, C. S., C. T. Kincaid, and A. E. Reisenauer. 1986. A Simplified Model for Radioactive Contaminant Transport: The Transs Code. PNL-6029, Pacific Northwest Laboratory, Richland, Washington.

Sinnock, S., Y. T. Lin, and M. S. Tierney. 1986. Preliminary Estimates of Ground Water Travel Time and Radionuclide Transport at the Yucca Mountain Repository Site. SAND85-2701, Sandia National Laboratories, Albuquerque, New Mexico.

Sinnock, S., and Y. T. Lin. 1987. "Preliminary Bounds on the Expected Postclosure Performance of the Yucca Mountain Repository Site, Southern Nevada." J. Geophys. Res. 92:7820-7842.

U.S. Department of Energy (DOE). 1986. Environmental Assessment, Yucca Mountain Site, Nevada Research and Development Area, Nevada. DOE/RW-0073, Office of Civilian Radioactive Waste Marlagement, Washington, D.C. 


\subsection{DOSE MODELING FOR GROUND-WATER-BASED TRANSPORT}

This section describes the models and assumptions used in the dose modeling and health effects estimation for radionuclide releases from the proposed Yucca Mountain repository. The purpose of the analysis is to evaluate the total population dose received following closure of the repository. The primary pathway for exposure of nearby populations has been identified as exposure to contaminated surface water. The mechanism for contamination of the surface water is ground-water transport of radionuclides from the repository. Because long time periods are involved (i.e., hundreds of thousands of years) in transport of radioactivity through the ground water to the environment, the dose is calculated as the integral of lifetime accumulated doses to future populations, where a standard lifetime is assumed to be 70 years.

The dosimetry model used is the one recommended in ICRP-26 (ICRP 1977) and ICRP-30 (ICRP 1979) for internal dosimetry and uses the concept of "effective dose equivalent" (EDE). The EDE eliminates the need to report doses to specific organs. Health risks can be estimated directly from the EDE by multiplying by a health effects conversion factor, which is usually taken to be about 200 health effects per $10^{6}$ person-rem of population dose.

A modified version of the computer program DITTY (Napier et al. 1988) was used to estimate the population dose. The program was originally developed to determine the collective dose from high-level waste geologic repositories resulting from releases to wells or surface water via ground-water pathways. The program has been modified to use the dosimetry model recommended in ICRP-26 (ICRP 1977) and applied in ICRP-30 (ICRP 1979). DITTY estimates the time integral of collective dose over a period of up to 10,000 years for time-variant radionuclide releases to water or the atmosphere. When releases are significant for more than 10,000 years, multiple runs of DITTY are made, each covering a 10,000-year period, and the doses are added together from each run. The input to DITTY includes a file containing curies per year of contamination for each radionuclide released at source locations determined by far-field ground-water transport programs. 
The 10,000-year calculation period in DITTY is broken into 143 periods of 70 years each. The average release in each period is calculated from source-term data, and the total population dose (committed effective dose equivalent) is determined for the population present in each period. The radioactivity present during any period is the sum of material released during that period (assumed to be uniformiy released over 70 years) and residual material in the environment from releases in previous periods. A cursory description of the dose models is given subsequently.

Pathways associated with waterborne releases include external exposure to contaminated water and sediment; ingestion exposure from drinking water, farm products (via irrigation), and aquatic foods; and inhalation of resuspended material after irrigation. The release of activity to water is described by a release rate $(\mathrm{Ci} / \mathrm{yr})$ defined at specified times. The activity released is assumed to result in exposure to a regional population. Only the total population is required, the spatial distribution of population is not used during calculation of effects from waterborne releases.

\subsection{ENVIRONMENTAL CONCENTRATION MODELS}

Models have been developed to determine radionuclide concentrations in air, water, soil, sediment, and food products. All concentrations (except soil and sediment) are expressed as time integrals over a 70-year period to facilitate dose calculations that use the concentration data. Each of the concentration and dose equations are radionuclide dependent. The computer code implementation accounts for all radionuclides of interest, as well as considering chain decay products.

Input to the pathways analysis is the total curies released in each 70-year time period. The total release is combined with population and dispersion parameters to estimate an environmental parameter for use in the exposure analysis. For airborne releases the value is calculated as

$$
A_{C}(t)=\operatorname{PM}(t) 3.16 E-08 \lambda^{-1} \int_{t_{0}}^{t_{0}+70} a(s) d s
$$

\section{2}


where $A_{c}(t)=$ population-weighted airborne release over 70 years as a function of chronological time $t$, person-Ci-yr $/ \mathrm{m}^{3}$

$$
\begin{aligned}
& P M(t)=\text { population exposure factor at time } t \text {, person-s/m } \mathrm{m}^{3} \\
& \lambda=\text { radiologici delay constant, } y^{-1} \\
& a(s)=\text { air release rafie of the radionuclide at time } s, \mathrm{Ci} / \mathrm{yr} \text {. }
\end{aligned}
$$

The integral is over a 70-year time period, and the constant 3.16E-08 converts seconds to years. The base-case model did not model air releases, hence $a(s)$ was zero for all $s, A_{c}(t)$ is zero for all $t$, and the calcuiation of $\operatorname{PM}(t)$ will not be described further. The equation for $A_{c}(t)$ is included here because it appears later in the general model formulation. For waterborne releases, the water concentration parameter is calculated as

$$
W_{c}(t)=P(t) N M 1.119 E-09\left(F_{r} \lambda\right)^{-1} \int_{t_{0}}^{t_{0}+70} C(s) d s
$$

where $W_{C}(t)=$ population-weighted water concentration at time period $t$, person-C $i-y r^{2} / L$

$$
\begin{aligned}
P(t) & =\text { population exposed to water for time period } t \text {, persons } \\
N & =\text { reconcentration factor, dimensionless } \\
M & =\text { mixing ration, dimensionless } \\
\lambda & =\text { radiological decay constant, } \mathrm{yr}^{-1} \\
F_{r} & =\text { flow rate of receiving water, } \mathrm{ft}^{3} / \mathrm{s} \\
C(s) & =\text { release rate to receiving water at time } \mathrm{s}, \mathrm{Ci} / \mathrm{yr} .
\end{aligned}
$$

The number 1.119E-09 is a conversion factor, $\mathrm{ft}^{3}-\mathrm{yr} / \mathrm{L}-\mathrm{s}$, and the symbol $\mathrm{L}$ denotes liter.

\subsubsection{Soil Concentration from Air Deposition}

The soil concentration parameter is calculated from the air concentration parameter assuming deposition to occur at a uniform rate over the 70-year period:

$$
S_{c a}(t)=A_{c}(t) V_{d}\left[1-\exp \left(-t \lambda_{b}\right)\right] /\left(\lambda_{b} 7.069 E+09\right)
$$


where $S_{C a}(t)=$ soil coricentration parameter for the current 70 -year period (chronological time t), person-Ci-yr $2 / \mathrm{kg}$

$V_{d}=$ deposition velocity for the radionuclide, $\mathrm{m} / \mathrm{s}$

$\lambda_{b}=$ environmental decay constant, $y r^{-1}$

and $7.069 \mathrm{E}+09$ is a constant, equal to $224 \mathrm{~kg} / \mathrm{m}^{2}$ [explained following the equation defining $\left.L_{c a}(p, t)\right]$ times $3.156 E+07 \mathrm{~s} / \mathrm{yr}$. The environmental decay constant, $\lambda_{b}$, is calculated as the sum of the radiological decay constant, $\lambda$, and a soil removal constant for weathering, $\lambda_{W}$. A detailed description of the calculation of $\lambda_{W}$ is given by Napier et a1. (1988).

\subsubsection{Leaf Concentration from Air Deposition}

The time integral of radionuclide concentration on leaves is calculated from air and soil concentration parameters assuming a constant soil concentration equal to the value at the end of the 70-year period. The equation is

$$
\begin{aligned}
L_{c a}(p, t)= & 0.25 V_{d}\left[A_{c}(t)+1.49 E-08 S_{c a}(t)\right] \\
& {\left[1-\exp \left(-\lambda_{e} T_{p} / 365\right)\right] 3.156 E+07 /\left(\lambda_{e} Y_{p}\right) }
\end{aligned}
$$

where $L_{c a}(p, t)=$ time integral of leaf concentration for pathway $p$ from air deposition and resuspension over the current period $t$, person-Ci-yr ${ }^{2} / \mathrm{kg}$

$Y_{p}=$ crop yield for food pathway $\mathrm{p}, \mathrm{kg} / \mathrm{m}^{2}$

$\lambda_{e}=$ effective retention rate constant, $\mathrm{yr}^{-1}$, computed as $\lambda+$ 18.0838 (18.0838 is the decay constant for a 14-day halfTife)

$T_{p}=$ growing period for food pathway $p$, days

$0.25=$ interception fraction, dimensionless.

The factor $1.49 \mathrm{E}-08$ represents the combination of three effects. The first effect $\left(1.0 \mathrm{E}-09 \mathrm{~m}^{-1}\right)$ represents a resuspension factor assumed constant, characteristic of aged deposited material (Anspaugh et al. 1975). The resuspended activity is assumed to deposit on the plants near the soil from which it was suspended, thus downwind transport of resuspended activity is not considered. A factor of $224 \mathrm{~kg} / \mathrm{m}^{2}$ represents the soil density to a depth of $15 \mathrm{~cm}$, the plow depth through which the contamination is assumed to be 
distributed. This value is divided by 15 , indicating that only the top centimeter of material (1/15 of the total) is considered available for resuspension. The leaf concentration as calculated above represents the time integral over a 70-year period.

\subsubsection{Concentration in Edible Plant Parts from Air Deposition}

The radionuclide concentration in edible parts of the plants includes material from direct deposition plus material from root uptake.

$$
P_{c a}(p, t)=L_{c a}(p, t) T_{v p}+S_{c a}(t) B_{v p}
$$

where $P_{C a}(p, t)=$ time integral of plant concentration for pathway $p$ from air deposited contaminants on plants and root uptake over the current period $t$, person-ci-yr2/ $\mathrm{kg}$

$T_{v p}=$ translocation factor of externally deposited radionuclides to edible parts of the plant, dimerisionless

$B_{v p}=$ concentration ratio for plant uptake of a radionuclide, $\mathrm{Ci} / \mathrm{kg}$ (wet plant weight) per $\mathrm{Ci} / \mathrm{kg}$ (dry soil weight).

The concentration used for calculating radionuclide uptake by the human population is the plant concentration for plant pathways. For animal pathways, the uptake is calculated as

$$
A_{c a}(p, t)=P_{c a}(p, t) S_{p} Q_{p}
$$

where $A_{c a}(p, t)=$ time integral of animal product concentration for animal product $p$ and time period $t$, person- $\mathrm{C} i-y r^{2} / \mathrm{kg}$, or person$\mathrm{C} i-\mathrm{yr} \mathrm{r}^{2} / \mathrm{L}$ for milk

$S_{p}=$ transfer coefficient of radionuclide from daily intake by the animal to edible portion of the animal product; $\mathrm{C} / \mathrm{L}$ per $\mathrm{Ci} / \mathrm{day}$ for milk, or $\mathrm{Ci} / \mathrm{kg}$ per $\mathrm{Ci} /$ day for animal product

$Q_{p}=$ consumption rate of contaminated feed or forage by the animal for animal product $\mathrm{p}, \mathrm{kg} /$ day.

\subsubsection{Concentration in the Soil from Irrigation Deposition}

The radionuclide concentration in the soil at the end of the period is calculated assuming uniform deposition over the period as 


$$
S_{C W}(t)=W_{C}(t) I T_{j}\left[1-\exp \left(-\lambda_{b} T\right)\right] /\left(\begin{array}{ll}
224 & \lambda_{b}
\end{array}\right)
$$

where $S_{C W}(t)=$ soll concentration for the radionuclide for the current period for irrigation deposition, person-Ci-yr2/ kg

$I=$ irrigation rate, $\mathrm{L} / \mathrm{m}^{2} / \mathrm{mo}$

$T_{j}=$ irrigation period, mo/yr.

The exponential term represents the integral over the 70-year period.

\subsubsection{Leaf Concentration from Irrigation}

The concentration on leaves is calculated for contributions from direct irrigation deposition plus resuspension from soil as

$$
\begin{gathered}
L_{c W}(p, t)=0.25\left[12 W_{c}(t) I+S_{C W}(t) 0.47 V_{d}\right] \\
{\left[1-\exp \left(-\lambda_{e} T_{p} / 365\right)\right] / \gamma_{p} \lambda_{e}}
\end{gathered}
$$

where $L_{c w}(p, t)=$ leaf concentration of the radionuclide for plant type $p$ and time period $t$ from irrigation and resuspension; person-Ci-yr ${ }^{2} / \mathrm{kg}$

$$
\begin{aligned}
0.47= & \text { conversion factor of } 1.49 \mathrm{E}-8 \text { in } L_{c a} \text { multiplied by } \\
& 3.156 \mathrm{E}+07 \mathrm{~s} / \mathrm{yr} .
\end{aligned}
$$

The concentration in edible parts of the plant is calculated for root uptake plus direct deposition as follows:

$$
P_{C W}(p, t)=L_{C W}(p, t) T_{v p}+S_{C W}(t) B_{V}
$$

where $P_{c w}(p, t)=p l a n t$ concentration for the radionuclide and pathway $p$ from irrigation deposition onto the $\mathrm{plant}$ and root uptake through the soil, person-Ci-yr $/ \mathrm{kg}$.

\subsubsection{Total Uptake for Plants and Animals}

The total uptake of plants during the 70 -year period is given by the plant concentration parameter $\mathrm{P}_{\mathrm{cW}}$. For animal products, the uptake is calculated for animal consumption of plants plus animal consumption of water as

$$
A_{c w}(p, t)=S_{p}\left[P_{C W}(p, t) Q_{p}+W_{c}(t) Q_{p w}\right]
$$


where this represents the time integral of the radionuclide for animal product $p$ and concentration in time $t$ from waterborne pathways with units of

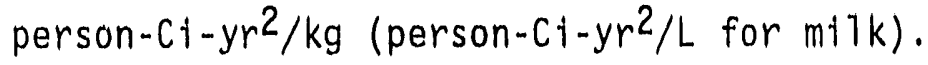

\subsubsection{Total Uptake for Aquatic Foods}

The time-integrated water concentration in aquatic foods is calculated from the water concentration as follows:

$$
A_{f w}(p, t)=W_{c}(t) B_{p}
$$

where $A_{f w}(p, t)=$ time-integrated corcentration in aquatic food $p$, person$\mathrm{c} 1-y r^{2} / \mathrm{kg}$

$$
\begin{aligned}
B_{p}= & \text { bioaccumulation factor for the radionuclide for aquatic } \\
& \text { food } p, C i / k g \text { per } C i / L \text {. }
\end{aligned}
$$

The time-integrated water concentration for the drinking water pathway is calculated as

$$
A_{d w}(t)=W_{C}(t) C
$$

where $A_{d w}(t)=$ time-integrated concentration in drinking water for time period $t$, person-C $i-y r^{2} / L$

$C=$ dimensionless water purification plant cleanup factor.

\subsubsection{Concentration in Sediment}

The concentration in the sediment is calculated similarly as

$$
S_{d W}(t)=W_{C}(t) 25300
$$

where $S_{d w}(t)=$ sediment deposition concentration for the radionuclide for the current period $t$ for the shoreline of contaminated water body, person-C $i-y r / m^{2}$

$25300=$ constant that represents deposition to sediment, $\mathrm{L} / \mathrm{m}^{2} / \mathrm{yr}$. (see Soldat, Robinson, and Baker 1974).

\section{1 .9 Special Concentration Model for ${ }^{14} \mathrm{C}$}

The radionuclide ${ }^{14} \mathrm{C}$ is handled in a special manner. The concentration of ${ }^{14} \mathrm{C}$ in environmental media (soil, plants, and animal products) is assumed 
to have the same specific activity (plcocuries of radionuclide per kilogram of stable element) as the contaminating medium (air or water). The fractional content of carbon in a plant or animal product is then used to compute the concentration of tritium or ${ }^{14} \mathrm{C}$ in the food product under consideration. It is assumed that plants obtain all of their carbon from airborne carbon dioxide and that animals obtain all their carbon through ingestion of plants.

When ${ }^{14} \mathrm{C}$ is present only in the water used for irrigation, it is difficult to model its transfer to vegetation because plants acquire most of their carbon through the air. At this time, the transfer rate of carbon from the water to the air or soil has not yet been determined. Currently available modeis for ${ }^{14} \mathrm{C}$ uptake by plants from water use specific activity models relating the activity in the plants directly to the activity in irrigation water. This is extremely conservative in that it assumes that plants receive all of their carbon from the water. An interim model has been implemented in DITTY with the basis being the ratio of grams of ${ }^{14} \mathrm{C}$ to grams of total carbon in soil and a correction for the amount of carbon plants obtain from the soil. Specific carbon ratios and correction factors are given in Napier et a1. (1988).

\subsection{PATHWAY USE MODELS}

The total dose received by the regional population is estimated as the sum of contributions from all pathways. The doses are calculated as the population dose received in each 70 -year time period from material released to the environment during that period plus any residual material released in previous periods. Precalculated dose conversion factors are used to estimate dose from uptake and environmental concentrations. Doses to organs are calculated from five sources of exposure: air submersion, inhalation, terrestrial ingestion pathways, aquatic ingestion pathways, and external exposures.

\subsubsection{Dose from Air Submersion}

Contributions for external exposure from air submersion are modeled for submersion in the initial airborne p? ume, submersion in resuspended activity from an initial airborne release, and submersion in suspended activity from an initial irrigation water deposition. The dose for the entire 70-year period ending at a specified time $t$ is calculated as

\section{8}




$$
D_{0 e}=D_{e} \lambda 3.156 E+07\left[A_{c}(t)+1.49 E-08\left(S_{C a}(t)+S_{C W}(t)\right)\right]
$$

where $D_{0 e}=$ population dose from air submersion to organ 0 , person-rem

$D_{e}=$ external exposure dose conversion factor for air submerston, rem per $\mathrm{CH}-\mathrm{s} / \mathrm{m}^{3}$.

The contribution from deposited material is based on the concentration at the end of the period. This concentration is conservatively assumed to have been present throughout the pertod.

Inhalation exposure includes contributions from the released airborne activity plus the resuspended activity from airborne and irrigation water deposition. The dose for the entire 70 -year period ending at a spectfied time $t$ is calculated as

$$
D_{\text {oh }}=D_{h o} 3.156 E+07 \lambda\left[A_{c}(t)+1.49 E-08\left(S_{C a}(t)+S_{C W}(t)\right)\right]
$$

where $\begin{aligned} D_{0 h}= & \text { dose for this radionuclide from inhalation exposure from organ } \\ & 0 \text {, person-rem }\end{aligned}$

Dho $=$ inhalation dose conversion factor for this radionuclide and organ 0 , rem per $\mathrm{C} i-\mathrm{s} / \mathrm{m}^{3}$.

\subsubsection{Dose from Terrestrial Pathways}

Terrestrial pathways include ingestion of crops and animal products. Seven terrestrial ingestion pathways were used in the base case dose estimates: leafy vegetables, other vegetables, eggs, milk, beef, pork, and poultry. The dose for each pathway is calculated from the time-integrated food product concentration over the entire 70-year period ending at a specified time t. For plants the dose is calculated as

$$
D_{0 t}=D_{g o} \wedge U_{p}\left[P_{c a}(p, t)+P_{c w}(p, t)\right]
$$

and for animal products the dose is calculated as

$$
D_{0 t}=D_{g o} \times U_{p}\left[A_{c a}(p, t)+A_{c w}(p, t)\right]
$$



where $D_{\text {ot }}=\begin{aligned} & \text { dose from terrestrial ingestion pathways for organ } 0, \\ & \text { person-rem }\end{aligned}$

$D_{g_{0}}$ - ingestion dose conversion factor for organ o for this radionuclide, rem/Ci

$U_{p}=$ usage rate by humans of food product $p, \mathrm{~kg} / \mathrm{yr}$ ( $\mathrm{L} / \mathrm{yr}$ for

The subscript $t$ on $D_{0}$ implies a terrestrial pathway and should not be confused with the time variable $t$. The total dose from terrestrial ingestion pathways is calculated by summing contributions from a11 plant and animal product food types for all radionuclides.

\subsubsection{Dose from Aquatic Pathways}

Ingestion pathways resulting from release of a radionuclide to surface water or ground water include ingestion of drinking water and aquatic foods. Pathways available for modeling in the DITTY code include fish, crustacea, mollusks, water plants, and drinking water. The dose for each pathway is calculated from the time-integrated aquatic media concentration as follows for aquatic foods:

$$
D_{0 a}=D_{g o} \lambda U_{a} A_{f w}(p, t)
$$

and for drinking water:

$$
D_{0 a}=D_{g o} \lambda U_{a} A_{d w}(t)
$$

where $D_{0 a i}=\begin{aligned} & \text { dose from ingestion of aquatic food or water for organ } 0 \text {, } \\ & \text { person-rem }\end{aligned}$

$$
\begin{aligned}
& U_{a}= \text { usage rate by humans of aquatic food pathway a, } \mathrm{kg} / \mathrm{yr} \text { ( } \mathrm{L} / \mathrm{yr} \text { for } \\
& \text { drinking water). }
\end{aligned}
$$

\subsubsection{External Doses from Contaminated Materials}

External exposures result from proximity to contaminated soil, shoreline, and water. Swimming and shoreline doses are calculated from the timeintegrated sediment concentration and water concentration as

$$
\begin{aligned}
D_{\text {oew }}=\lambda[ & \left.S_{d W}(t) D_{\text {os }} U_{\text {sh }} W+W_{C}(t) D_{\text {ow }} U_{\text {sW }}\right] \\
& +W_{C}(t) 0.5 D_{\text {ow }} U_{\text {bo }}
\end{aligned}
$$




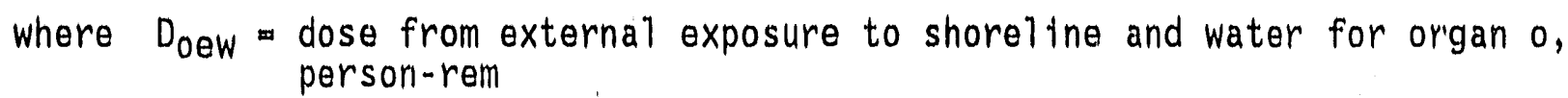

$D_{O S}=$ external dose factor for organ of for exposure to contaminated soll or shoreline, rem $/ \mathrm{h}$ per $\mathrm{Cl} / \mathrm{m}^{2}$

$D_{\text {ow }}$ a external dose factor for organ o for submersion in contaminated water, rem/h per $\mathrm{Cl} / \mathrm{L}$

$U_{\text {bo }}$ time spent boating on contaminated water, $h / y r$

$U_{\text {sh }}=$ time of exposure to contaminated shorelitie, $h / \mathrm{yr}$

$U_{S W}=$ time of exposure to contaminated water, $h / y r$

$W=$ shore width factor for shoreline exposure, dimenstonless.

The shore width factor is an approximate correction to the infinite plane geometry of the external exposure factors. Suggested shore width factors are given in Napier et a1. (1988). Aquatic recreation is not considered a 1ikely activity near the proposed Yucca Mountain site. The base-case model thus sets $U_{s h}, U_{s w}$, and $U_{\text {bo }}$ to zero. Thus, Doew is zero.

The dose from external exposure to contaminated soil is calculated as

$$
D_{\text {oes }}=\lambda E_{t} D_{\text {ow }} 224\left[S_{C a}(t)+S_{C W}(t)\right]
$$

where $D_{0 e s}=$ dose from external exposure to soil for organ o, person-rem $E_{t}=$ time of exposure to contaminated ground, $h / y r$.

Note that the external exposure is based on the integrated soll concentration.

\subsection{COMPUTATION OF LIFETIME EFFECTIVE DOSE EQUIVALENT}

The EDE is calculated as a weighted sum of dose estimates to individual organs. Specific weighting factors are given in Table 6.1. This choice of 
TABLE 6.1. Organ Weighting Factors for the Effective Dose Equivalent

\begin{tabular}{|c|c|}
\hline $\begin{array}{l}\text { Weighting } \\
\text { Factor }\end{array}$ & Organ \\
\hline $\begin{array}{l}0.25 \\
0.15 \\
0.12 \\
0.12 \\
0.03 \\
0.03 \\
0.30\end{array}$ & $\begin{array}{l}\text { Gonads } \\
\text { Breast } \\
\text { Red Marrow } \\
\text { Lung } \\
\text { Thyroid } \\
\text { Bone Surface } \\
\text { Remainder }\end{array}$ \\
\hline
\end{tabular}

organs and weighting factors is recommended by the International Commission on Radiological Protection (ICRP 1977, p. 21).

Dose to the gonads is calculated as the maximum of dose to the testes or ovaries, and dose to the breast is calculated with the same dose conversion factors as dose to muscle. The ICRP recommends that a weight of 0.06 be used with each of the five organs or tissues of the remainder of the body receiving the highest dose equivalents, and that the exposure of all other remaining tissues be neglected. The remainder organs are lymph, liver, spleen, stomach, small intestine, upper large intestine, lower large intestine, bone surface, cortical bone, cancellous bone, muscle, bladder, kidneys, liver, pancreas, spleen, adrenals, brain, and stomach wall. When the gastrointestinal tract is irradiated, as is the case in this study, the stomach, small intestine, upper large intestine, and lower large intestine are treated as four separate organs.

\subsection{SOURCE TERMS AND DATA}

\subsubsection{Irrigation Water Source Term}

Regional ground-water studies (USGS 1984) indicate that ground-water discharge for flow under Yucca Mountain, and hence radionuclide release, occurs at Alkali Flat (Franklin Lake Playa) north of Eagle Mountain in the vicinity of Death Valley Junction. The total ground-water discharge at Alkali flat is estimated to be about $0.41 \mathrm{~m}^{3} / \mathrm{s}$, of which $0.39 \mathrm{~m}^{3} / \mathrm{s}$ is 
discharged by evapotranspiration. However, for the dose calculations presented here, it was assumed that all water reaching Alkali Flat was used for drinking or irrigation.

\subsubsection{Population Data}

The base-case dose calculations used ground water as the only source of contamination for a future population. Because airborne contamination was not considered to be present, a spatial distribution of population was not required and each person in the population is assumed to receive an equal dose. A population of one was used in the computer runs. The total population dose is determined by multiplying the results for the single individual by the number of people the water supply can support. The total discharge at Alkali Flat is $1.293 \mathrm{E}+10 \mathrm{~L} / \mathrm{yr}$. Assuming an irrigation rate of $255 \mathrm{~L} / \mathrm{m}^{2} /$ month for 6 months out of the year (based on $0.0062 \mathrm{~m}^{3} /$ acre $/ \mathrm{yr}$ given in DOE 1986), the water supply will support 420 farms of 5 acres each. Assuming that each farm provides food for an average of four people, a population of roughly 1680 receives a collective dose from the water.

\subsubsection{Food Pathways Data}

The terrestrial pathway data for a reference individual near the Yucca Mountain site are given in Table 6.2. In addition to the values in this table, the external exposure time was assumed to be $8 \mathrm{~h} /$ day $(2920 \mathrm{~h} / \mathrm{yr})$. Because of the desert terrain around the proposed site, no aquatic food pathways were used in the dose model. Terrestrial food pathways were used to estimate doses from the use of contaminated irrigation water and the drinking of contaminated ground water. The terrestrial pathways data were obtained from Rupp (1980) and Shor, Baes, and Sharp (1982).

\subsubsection{Dose Model Factors}

The internal dose conversion factors by organ for each radionuclide are given in Appendix D. Food transfer coefficients and external dose factors used are also given in Appendix $D$. The values in Appendix $D$ were gathered from a large number of primary sources that are not referenced separately here. A useful starting reference for determining primary sources is Napier, Kennedy, and Russell (1980). A reviewer has indicated that an environmental pathways analysis was performed for Yucca Mountain (Daer 1989) concurrently 
IABLE 6.2. Terrestrial and Aquatic Pathway Data for an Average Individual

\begin{tabular}{lcccr}
\multicolumn{1}{c}{ Pathway } & $\begin{array}{c}\text { Growing } \\
\text { Period } \\
\text { (days) }\end{array}$ & $\begin{array}{c}\text { Yield } \\
\left(\mathrm{kg} / \mathrm{m}^{2}\right)\end{array}$ & $\begin{array}{c}\text { Consumption } \\
(\mathrm{kg} / \mathrm{yr})\end{array}$ \\
\cline { 1 - 1 } Leafy Vegetables & 90 & 0.50 & 18.0 \\
Other Vegetables & 90 & 0.76 & 73.0 \\
Eggs & 90 & 0.84 & 19.0 \\
Milk & 30 & 1.30 & 207.0 \\
Beef & 90 & 0.84 & 31.0 \\
Pork & 90 & 0.84 & 28.0 \\
Poultry & 90 & 0.84 & 9.5 \\
Drinking Water & - & - & 438.0
\end{tabular}

with this task. The work scope does not permit redoing the analysis, a) though the estimated doses could change with new pathway assumptions.

\subsubsection{Radionuclide Source Term}

The base-case radionuclide source term was obtained from the mass transport model using the stratigraphy of borehole USW-G3, a recharge rate of $0.5 \mathrm{~mm} / \mathrm{yr}$, expected retardation coefficients, a congruent dissolution rate using conservative uranium solubility assumptions, and the diffusiondominated model of mass transport in the EBS. Appreciable levels of the radionuclides ${ }^{14} \mathrm{C},{ }^{129} \mathrm{I},{ }^{79} \mathrm{Se}$, and ${ }^{59} \mathrm{Ni}$ reach $\mathrm{A} / \mathrm{kali}$ Flat starting just after 100,000 years, while ${ }^{99} \mathrm{Tc}$ starts arriving at about 250,000 years. The released radionuclides were then transported through the unsaturated zone to the water table and then through the water table to Alkali Flat. Some of the heavier radionuclides (isotopes of actinium, lead, polonium, protoactinium, radium, thorium, and uranium) start arriving at Alkali $F l$ at at about 990,000 years. The arrival rates for the heavier radionuclides remain so low for times before 1 million years that source-term plots are not presented. The source term for some of the other scenarios described in Section 7.0 contained up to 25 primary radionuclides. The dose model incorporated chain decay so that doses were calculated for a total of 35 separate radionuclides. (The complete set of decay chains contains more than 35 radionuclides, but 
dose effects for daughter nuclides are incorporated into the dose conversion factor for the parent if the daughters have extremely short half-lives. For example, the dose conversion factors for $219_{\mathrm{Rn}}, 215 \mathrm{Po}, 211 \mathrm{~Pb}, 211_{\mathrm{Bi}}$, and ${ }^{207} \mathrm{Tl}$ are all embedded in the dose conversion factor for ${ }^{223} \mathrm{Ra}$.)

\subsection{DOSE ESTIMATES}

Results of the base-case dose calculations for the first million years after repository closure are shown in Figure 6.1 , which gives lifetime cumulative EDE for one individual. The large dose rate starting shortly after 100,000 years is due to the near simultaneous arrival of the radionuclides ${ }^{14} \mathrm{C},{ }^{129} \mathrm{I},{ }^{79} \mathrm{Se}$, and ${ }^{59} \mathrm{Ni}$. of these three radionuclides, the release of ${ }^{59} \mathrm{Ni}$ is at such a low level that it has a negligible contribution to dose. The peak dose near 350,000 years is due mostly to the arrival of ${ }^{99} \mathrm{Tc}$, al though ${ }^{14} \mathrm{C},{ }^{129} \mathrm{I},{ }^{79} \mathrm{Se}$, and ${ }^{59} \mathrm{Ni}$ are still contributing to doses. The heavier radionuclides (isotopes of actinium, lead, neptunium, polonium, protoactinium, radium, thorium, and uranium) do not start to show any appreciable activity levels at Alkali Flat until about year 990,000, thus contributing a negligible amount to the base-case dose estimates.

Based on a population count of 1680 , the base-case results yield a population dose estimate of $1.80 \mathrm{E}+05$ person-rem over the first million years of repository operation. This population dose leads to an estimate of about 36 excess adverse health effects when a factor of 200 health effects per $10^{6}$ person-rem of population dose is used. The background radiation level in the Yucca Mountain region is above $100 \mathrm{mrem} / \mathrm{yr}$ (Link et al. 1982). Assuming a total time of 1 million years, a 70 -year 1 ifetime, and a steady population leve? of 1680 individuals, the background radiation would lead to an estimate of about 33,600 excess adverse health effects. The (base case) impact of locating the repository in this region leads to an estimate of about a $0.1 \%$ to $1.0 \%$ growth in health effects over those expected from background radiation. 


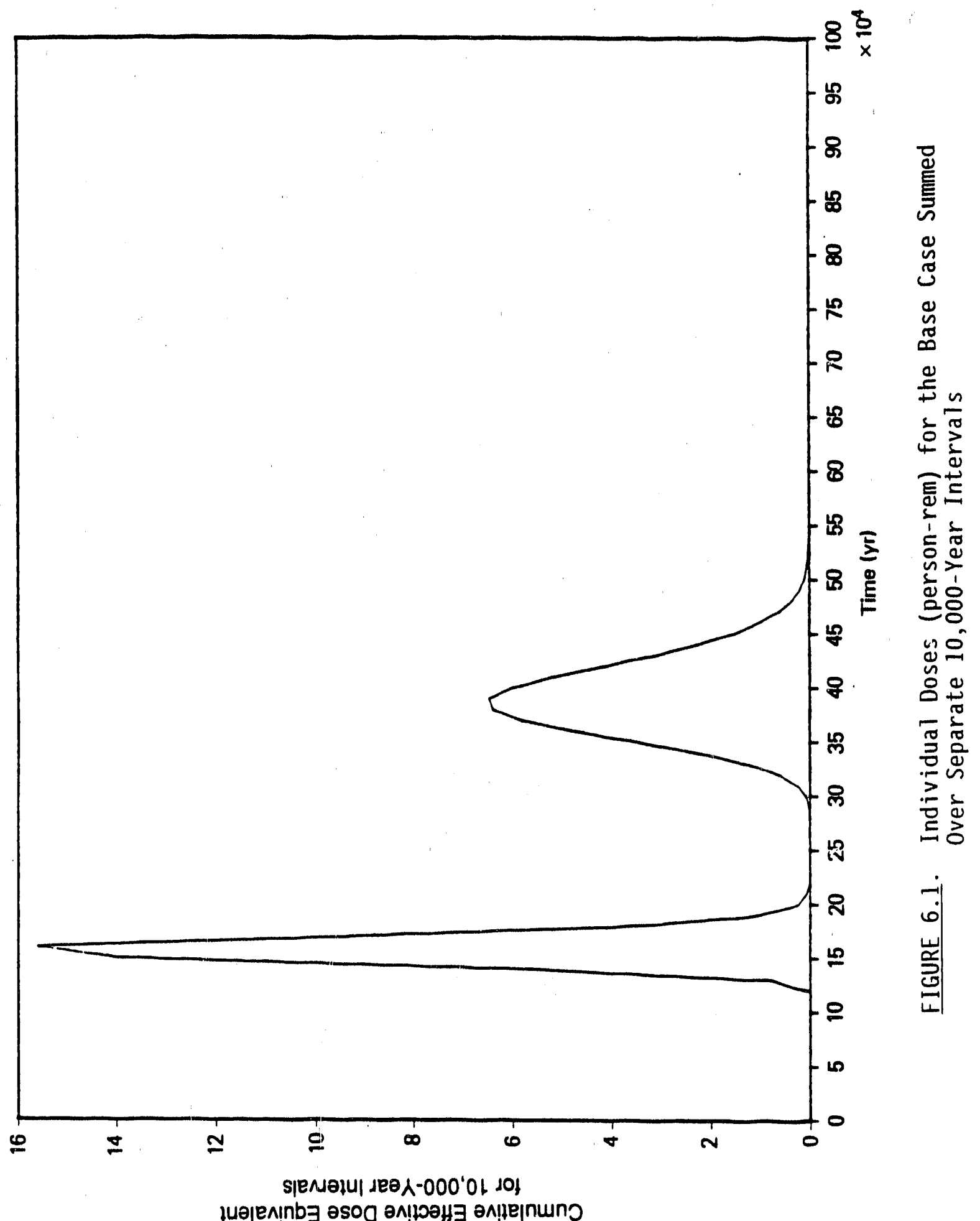

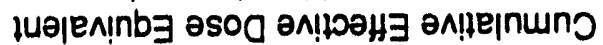

6.16 


\subsection{REFERENCES}

Anspaugh, L. R., J. H. Shinn, P. L. Phelps, and N. C. Kennedy. 1975. "Resaturation and Redistribution of Plutonium in Soils." Health Phys. 29:571-582.

Daer, G. R. 1989. Environmental Pathway Analys is Scoping Study for the Yucca Mountain Site. SAIC-87-8010, Science Applications International Corporation, Las Vegas, Nevada.

DOE. See U.S. Department of Energy.

International Commission on Radiological Protection (ICRP). 1977. Recommendations of the International Commission on Radiological Protection. ICRP Publication 26, Pergamon Press, 0xford.

International Commission on Radiological Protection (ICRP). 1979. Limits for Intakes of Radionuclides by Workers. ICRP Publication 30, Part 1, Pergamon Press, 0xford.

Link, R. L., S. E. Logan, H. S. Ng, F. A. Rockenbach, and J. J. Hong. 1982. Parametric Studies of Radiological Consequences of Basaltic Volcanism. SAND81-2375, Sandia National Laboratories, Albuquerque, New Mexico.

Napier, B. A., W. E. Kennedy, and R. L. Russe11. 1980. AARG and FO0D Computer Programs for Calculating Radiation Dose to Man from Radionuclides in the Environment. PNL-3180, Pacific Northwest Laboratory, Richland, Washington.

Napier, B. A., R. A. Peloquin, D. L. Strenge, and J. V. Ramsdell. 1988. GENII - The Hanford Environmental Radiation Dosimetry Software System Volume 1: Conceptual Representation. PNL-6584 Vol. 1, Pacific Northwest Laboratory, Richland, Washington.

Rupp, E. M. 1980. "Age Dependent Values of Dietary Intake for Assessing Human Exposures to Environmental Pollutants." Health Phys. 39:151-163.

Shor, R. W., C. F. Baes III, and R. D. Sharp. 1982. Agricultural Production in the United States by County: A Compilation of Information from the 1974 Census of Agriculture for Use in Terrestrial Food-Chain Transport and Assessment Models. ORNL-5768, Oak Ridge National Laboratory, Oak Ridge, Tennessee.

Soldat, J. K., N. M. Robinson, and D. A. Baker. 1974. Models and Computer Codes for Evaluating Environmental Radiation Doses. BNWL-1754, BattelTe, Pacific Northwest Laboratories, Richland, Washington.

U.S. Department of Energy (DOE). 1986. Environmental Assessment, Yucca Mountain Site Nevada Research and Development Area, Nevada. Vol. 1 of 3. DOE/RW-0073, Office of Civilian Radioactive Waste Management, Washington, D.C. 
U.S. Geological Survey. 1984. Hydrology of Yucca Mountain and Vicinity, Nevada-Cal ifornia - - Investigative Results Through Mid-1983. Water Resources Investigations Report, USGS/WRI-84-4267, U.S. Geological Survey, Washington, D.C. 


\subsection{DISRUPTIVE OR INTRUSIVE EVENTS}

\subsection{EXTRUSIVE MAGMATIC EVENT}

A postclosure scenario considered for the accident analysis involves basaltic volcanism that is assumed to intercept the repository. The basaltic flow is assumed to melt and carry to the surface a small fraction of the stored waste. An extensive parametric analysis of this scenario and resulting consequences has been performed by Link et a1. (1982). Because their exposure pathway analysis is very similar to the methods used in the postclosure radiological analysis, their results are presented here without modification. The atmospheric dispersion analysis performed by Link et al. (1982) was based on the AIRDOS-EPA computer program, which has been shown (Aaberg and Napier 1985) to provide results similar to those estimated using the PABLM computer program. The pathway and health effects estimates were performed using the AMRAW computer program (Logan and Berbano 1978). This program was developed for the EPA to estimate risks associated with geologic repositories.

The exposure of the population is assumed to result from two components of the eruption: fine airborne particles and non-airborne material. The airborne particles represent fine particulate material that becomes airborne and is transported downwind to a considerable distance $(100 \mathrm{~km})$. The nonairborne material includes the lava flow and material in the cone and scoria sheet, including heavier particles that are initially airborne but deposit near the cinder cone (within a few kilometers). The Link et al. (1982) analysis evaluates the health effects resulting from each of these sources. The analysis is performed for occurrence of the volcanic event at 100 years and 10,000 years after repository closure.

The work of Link et a1. (1982) did not consider changes to the hydrologic system caused by a magmatic event. It is possible that such changes in the hydrologic system (i.e., ground-water table change, surface water pathway) would change the risk of the repository.

The volcanism analysis estimates that $8 \times 10^{-5}$ of the total waste activity is entrained in the magma and that $1.3 \%$ of this amount becomes airborne as fine paricicles. The remainder of the material (98.7\%) is evenly 
dispersed in the magma and cinder material. The resulting radioactive cloud would result in doses obtained in several ways. Persons present in the area initially would receive inhalation and air submersion doses, both from the initial cloud and resuspended particles. After deposition of the particles, doses would result from exposure to the surface of deposition, from resuspended particles, and from entrance of radionuclides into the food chain. These pathways are also used for the non-airborne source component because the deposited material becomes part of the local soils and is available for resuspension (for inhalation dose and deposition onto plant surfaces). In addition to these pathways, a special pathway is considered where cone material is used for building purposes.

Site-specific data on population, agriculture, and meteorology used to calculate doses arising from the airborne particles are given in detail by Link et a1. (1982) and do not differ appreciably from the assumptions used in the DITTY code. The population density considered by Link et al. (1982) was 0.1 person $/ \mathrm{km}^{2}$ in addition to currently identified settlements.

The total activity (in curies) assumed released from the repository is given in Table 7.1. The times are years after repository closure. Maximum values of initial local dose rates (in mrem/yr) are given in Table 7.2.

TABLE 7.1. Total Activity Released in Curies from Volcanism Scenario 100 yr $\quad 10,000 \mathrm{yr}$

$\begin{array}{lll}\text { Air } & 8.15 E+02 & 2.21 E+01 \\ \text { Non-air } & & \\ \quad \text { Cone } & 8.25 E+03 & 2.27 E+02 \\ \text { Lava } & 3.51 E+03 & 9.63 E+01 \\ \text { Thick Scoria } & 4.17 E+04 & 1.14 E+03 \\ \text { Thin Scoria } & 7.95 E+03 & 2.17 E+02 \\ \text { Total Non-air } & 6.15 E+04 & 1.68 E+03\end{array}$


TABLE 7.2. Initial Dose Rates from Volcanism Scenario (in mrem/yr)

$\begin{array}{lcc} & 100 y r & 10,000 \text { yr } \\ \text { Air } & 14 & 1.1 \\ \text { Non-air } & 3700 & 2.8 \\ \text { Background rate is } 100 & \end{array}$

Results of the analysis are presented as health effects (predominately fatal cancers) expected over many years $\left(10^{4}\right.$ and $\left.10^{6}\right)$ following the event. The estimation of health effects is based on cumulative dose to specific body organs for a low- and a high-risk level. The dose to health effect conversion factors used in the AMRAW program are given in Table 7.3. Results of the consequence analysis for the volcanism scenario are presented in Tables 7.4, 7.5, and 7.6 for airborne, non-airborne, and a 77 releases, respectively (as taken from the Link report). The health effects for the non-airborne pathways are consistently about two orders of magnitude higher the health effects from the airborne pathways. The population doses from which these health effects were calculated were not reported in enough detail by Link et al. (1982) to allow computation of the effective dose equivalent used in Section 6.0. This precluded an unambiguous comparison of population doses between the base-case modeling and this disruptive scenario. However, the number of health effects estimated from this scenario range from 868 to 2825 for the first million years of repository operation depending on the health effects conversion factors used and the time of occurrence of the magmatic event. This compares with a base-case estimate of about 36 excess health effects from repository operation.

\subsection{CLIMATE CHANGE}

One of the scenarios considered credible for Yucca Mountain (see Section 2.0) is a change of the recharge rate for ground water resulting from increased precipitation. The effect of this scenario is considered by examining the effect of increased recharge on the unsaturated zone in Yucca Mountain. No changes were made to the saturated zone hydrologic model for this scenario because the saturated zone transport accounted for only a smal1 fraction of the total transport time for each radionuclide. 
TABLE 7.3. Health Effect Incidence Rates by Organ from Volcanism Scenario

\begin{tabular}{|c|c|c|c|}
\hline \multirow[b]{2}{*}{ Organ } & \multirow[b]{2}{*}{ Health Effect } & \multicolumn{2}{|c|}{$\begin{array}{c}\text { Hypothetical Deaths } / 10^{6} \\
\text { Person-Rem }\end{array}$} \\
\hline & & Lower Range & Upper Range \\
\hline Total body $(a)$ & & 18 & 293 \\
\hline GI tract & $\begin{array}{l}\text { GI tract cancer } \\
\text { (including stomach) }\end{array}$ & 7 & 93 \\
\hline Lung & Lung cancer & 5 & 50 \\
\hline Bone marrow & Leukemia & (b) & (b) \\
\hline Bone & Bone cancer & 17 & 45 \\
\hline Thyroid & & 3 & 15 \\
\hline Gonads & Genetic effects & 50 & 300 \\
\hline
\end{tabular}

(a) Includes all other cancers except those specifically listed by organ.

(b) Bone marrow effects included under bone.

TABLE 7.4. Health Effects from Volcanism Scenario: Airborne Releases

$\begin{array}{ccccc}\begin{array}{c}\text { Time of } \\ \text { Eruption }(y r)\end{array} & \begin{array}{c}\text { Accumulation } \\ \text { Time }(y r)\end{array} & \frac{3}{\text { Health Effects Estimates }} & \text { Low } & \text { High } \\ 100 & 10^{4} & & 5.6 & 19 \\ 100 & 10^{6} & 7.5 & 25 \\ 10,000 & 10^{6} & 3.8 & 12\end{array}$

TABLE 7.5. Health Effects from Volcanism Scenario: Non-Airborne Releases

$\begin{array}{ccccc}\begin{array}{c}\text { Time of } \\ \text { Eruption }(y r)\end{array} & \begin{array}{c}\text { Accumulation } \\ \text { Time (yr) }\end{array} & & \frac{\text { Health Effects Estimates }}{\text { Low }} & \frac{\text { High }}{100} \\ & 10^{4} & & 300 & 990 \\ 100 & 10^{6} & & 860 & 2800 \\ 10,000 & 10^{6} & & 670 & 2200\end{array}$


TABLE 7.6. Health Effects from Volcanism Scenario: All Releases

\begin{tabular}{|c|c|c|c|}
\hline Time of & Accumulation & Health & Estime \\
\hline Eruption (yr) & Time $(y r)$ & Low & High \\
\hline 100 & $10^{4}$ & 305 & 1008 \\
\hline 100 & $10^{6}$ & 868 & 2825 \\
\hline 10,000 & $10^{6}$ & 674 & 2212 \\
\hline
\end{tabular}

The hydrologic model described in Section 3.0 was used to predict unsaturated zone ground-water travel times for a range of recharge rates. The recharge rates evaluated $(0.55,0.63$, and $0.75 \mathrm{~mm} / \mathrm{yr})$ correspond to $10 \%$, $25 \%$, and $50 \%$ increases in the recharge rate from the base case value of $0.5 \mathrm{~mm} / \mathrm{yr}$. Tables $7.7,7.8$, and 7.9 give travel times in the different stratigraphic layers due to using the modified recharge rates. Travel times for a recharge rate of $0.5 \mathrm{~mm} / \mathrm{yr}$ were given in Table 5.1 . In general, as expected, the higher the recharge rate, the shorter the travel times through the partially saturated layers. Raising the recharge rate to $0.75 \mathrm{~mm} / \mathrm{yr}$ leads to travel times about $75 \%$ as 1 ong as the travel times computed using the base case of $0.5 \mathrm{~mm} / \mathrm{yr}$. A doubling of the recharge rate to $1.0 \mathrm{~mm} / \mathrm{yr}$ could possibly lead to fracture flow in the Topopah Springs layer and the Calico Hills nonwelded (zeolitic) layer (Sinnock and Lin 1987). If fracture flow were to occur, ground-water travel times in the partially saturated layers could decrease to a small fraction of the values given in Table 7.9 and, equally important, the retardation factors for most radionuclides would be much smaller than the large values reported in Table 5.2. Fracture flow could lead to dose estimates several orders of magnitude larger than the base-case values. The current study did not include any investigation of fracture flow. The computer model used for the unsaturated zone was a continuum model that did not incorporate the effect of fractures. Given the available hydrologic data, when the ground-water infiltracion rate approached $1.0 \mathrm{~mm} / \mathrm{yr}$, this model predicted that the entire mountain would became saturated. A fracture flow code was not available, and new code development was outside the scope of work for the project, thus only the lower recharge rates were investigated. Additional work on the concept of fracture flow is needed to properly model climate change scenarios. 
TABLE 7.7. Predicted Travel Times for Different Vertical Profiles Using $0.55 \mathrm{~mm} / \mathrm{yr}$ Recharge

\begin{tabular}{|c|c|c|c|c|c|}
\hline \multirow[b]{2}{*}{ Layer } & \multirow[b]{2}{*}{$\underline{\text { Name }}$} & \multicolumn{3}{|c|}{ Mean Water Travel Time (yr) } & \multirow{2}{*}{$\begin{array}{l}\text { Standard Deviation } \\
\text { of Trave } 1 \text { Times } \\
\text { (yr) }\end{array}$} \\
\hline & & USW-G1 & USW-G3 & USW-G4 & \\
\hline 1 & $\begin{array}{l}\text { Topopah Spring } \\
\text { Welded }\end{array}$ & 7,811 & 967 & 13,356 & 1,920 \\
\hline 2 & $\begin{array}{l}\text { Basal Vitrophyre } \\
\text { of Topopah Spring }\end{array}$ & 3,483 & 9,967 & 2,121 & 1,920 \\
\hline 3 & $\begin{array}{l}\text { Calico Hills Non- } \\
\text { welded (vitric) }\end{array}$ & & 21,354 & & 7,760 \\
\hline $3^{\prime}$ & $\begin{array}{l}\text { Calico Hills Non- } \\
\text { welded (zeolitic) }\end{array}$ & 61,407 & & 70,608 & 8,145 \\
\hline 4 & Prow Pass Nonwelded & 12,028 & 66,076 & & 8,025 \\
\hline 5 & Saturated Zone & 44,000 & 44,000 & 44,000 & 3,330 \\
\hline & & 128,729 & 142,364 & 130,085 & \\
\hline
\end{tabular}

IABLE 7.8. Thickness and Predicted Travel Times for Different Vertical Profiles Using $0.63 \mathrm{~mm} / \mathrm{yr}$ Recharge

\begin{tabular}{|c|c|c|c|c|c|}
\hline \multirow[b]{2}{*}{ Layer } & \multirow[b]{2}{*}{$\underline{\text { Name }}$} & \multicolumn{3}{|c|}{ Mean Water Travel Time $(y r)$} & \multirow{2}{*}{$\begin{array}{c}\text { Standaru Deviation } \\
\text { of Travel Times } \\
\text { (yr) }\end{array}$} \\
\hline & & $\underline{U S W-G 1}$ & $\underline{U S W-G 3}$ & $\underline{U S W-G 4}$ & \\
\hline 1 & $\begin{array}{l}\text { Topopah Spring } \\
\text { Welded }\end{array}$ & 6,835 & 919 & 11,708 & 1,920 \\
\hline 2 & $\begin{array}{l}\text { Basal Vitrophyre } \\
\text { of Topopah Spring }\end{array}$ & 3,071 & 8,885 & 1,861 & 1,920 \\
\hline 3 & $\begin{array}{l}\text { Calico Hills Non- } \\
\text { welded (vitric) }\end{array}$ & & 18,689 & & 7,760 \\
\hline $3^{\prime}$ & $\begin{array}{l}\text { Calico Hills Non- } \\
\text { welded (zeolitic) }\end{array}$ & 53,781 & & 61,882 & 8,145 \\
\hline 4 & Prow Pass Nonwelded & 10,460 & 58,209 & & 8,025 \\
\hline 5 & Saturated Zone & 44,000 & 44,000 & 44,000 & 3,330 \\
\hline & & 118,147 & 130,702 & 119,451 & \\
\hline
\end{tabular}


TABLE 7.9. Thickness and Predicted Travel Times for Different Vertical Profiles Using $0.75 \mathrm{~mm} / \mathrm{yr}$ Recharge

\begin{tabular}{|c|c|c|c|c|c|}
\hline \multirow[b]{2}{*}{ Layer } & \multirow[b]{2}{*}{ Name } & \multicolumn{3}{|c|}{ Mean Water Travel Time (yr) } & \multirow{2}{*}{$\begin{array}{c}\text { Standard Deviation } \\
\text { of Travel Times } \\
(y r)\end{array}$} \\
\hline & & USW-GI & $\underline{\text { USW-G3 }}$ & USW-G4 & \\
\hline 1 & $\begin{array}{l}\text { Topopah Spring } \\
\text { Welded }\end{array}$ & 5,758 & 842 & 9,845 & 1,920 \\
\hline 2 & $\begin{array}{l}\text { Basal Vitrophyre } \\
\text { of Topopah Spring }\end{array}$ & 2,594 & 7,707 & 1,564 & 1,920 \\
\hline$c$ & $\begin{array}{l}\text { Calico Hills Non- } \\
\text { welded (vitric) }\end{array}$ & & 14,973 & & 7,760 \\
\hline $3^{\prime}$ & $\begin{array}{l}\text { Calico Hills Non- } \\
\text { welded (zeolitic) }\end{array}$ & 45,384 & & 51,975 & 8,145 \\
\hline 4 & Prow Pass Nonwelded & 8,705 & 50,408 & & 8,025 \\
\hline 5 & Saturated Zone & 44,000 & 44,000 & 44,000 & 3,330 \\
\hline & & $\overline{106,441}$ & 117,930 & 107,384 & \\
\hline
\end{tabular}

Cumulative population doses (person-rem) for a population of size 1 are plotted in Figure 7.1 for the four different recharge rates studied. The cumulative doses at 1 million years for a population of 1680 are $1.80 \times 10^{5}$ for the base case and $1.89 \times 10^{5}, 2.24 \times 10^{5}$, and $4.29 \times 10^{5}$, with respect to increasing recharge rates. The major reason for the increased dose estimates is that the heavier radionuclides (isotopes of actinium, lead, neptunium, polonium, protoactinium, radium, thorium, and uranium) have started to arrive at Alkali Flat in significant quantities just prior to 1 million years. Examination of the source concentration leve?s and the dose conversion factors (see Table 0.3 ) reveals that thorium is the largest contributor to dose (bone effects) among the heavier radionuclides.

In conclusion, climate changes leading to increased recharge rates cause an increase in dose estimates. If the recharge rates are below the $0.75 \mathrm{~mm} / \mathrm{yr}$ level, the dose estimates increase by less than a factor of 3 from the base-case estimates. As can be seen in Figure 7.1 , the relationship between dose and infiltration rate is not linear. The dose estimates would increasesignificantly if the ground-water travel time or radionuclide 


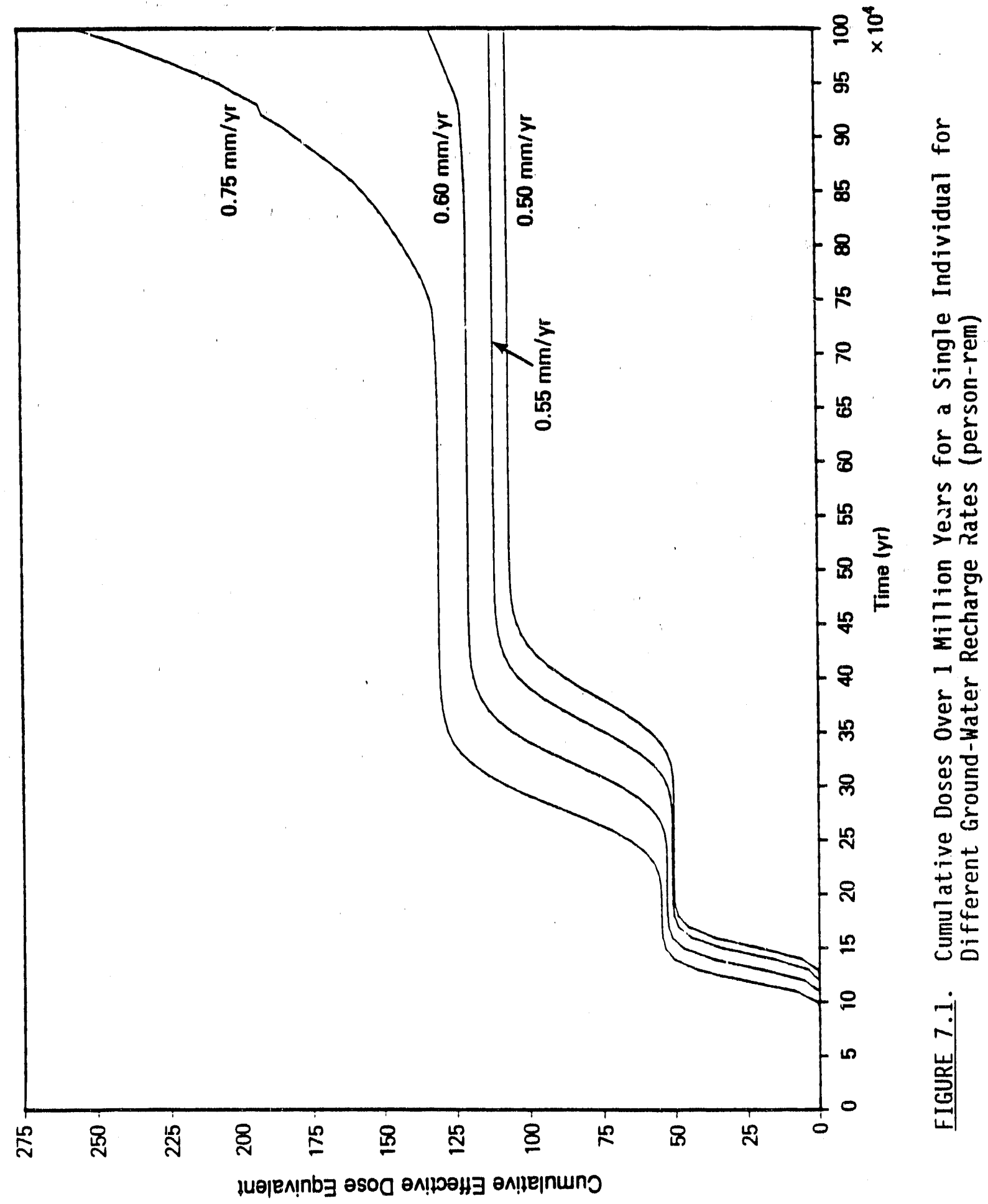


sorption values were to decrease. Both of these events could occur simultaneously if the ground-water infiltration rate were to increase.

A reviewer has pointed out that a drilling scenario for drinking water and farming purposes could have been considered as an alternative to calculating all doses based on a natural ground-water discharge point. The effect of this scenario would be twofold: 1) the time to release would be smaller thari those reported here (smaller by about $10^{4}$ years on a $10^{5}$-year or longer arrival time), and 2) some doses would be higher due to less radioactive decay (most notably ${ }^{14} \mathrm{C}$ ). Only a few people would be exposed to a slightly higher dose rate in this scenario, thus the population doses would not be significantly altered.

\subsection{GAS-PHASE ${ }^{14} \mathrm{C}$ RELEASE MODELING}

Preliminary work on determining the travel time of gas-phase ${ }^{14} \mathrm{C}$ to the surface of Yucca Mountain has been completed by Amter, Behl, and Ross (1988) and is included in this report as Appendix E. The travel-time calculations depend on a conceptual model that has two principal features:

- Gas-phase ${ }^{14} \mathrm{CO}_{2}$ moves upward through air-filled pores of the unsaturated tuffs by advection in a thermally driven air convection cell.

- An isotropic equilibrium exists between $\mathrm{CO}_{2}$ in the gas phase, which is mobile, and dissolved bicarbonate, which is immobile.

The trave1-time analysis by Amter, Beh1, and Ross was received too 1 ate by PNL to make detailed dose calculations for gas-phase ${ }^{14} \mathrm{C}$ for this report. However, time-integrated population dose estimates will probably be negligible for this transport mechanism. This judgment is based on the following premises: 1) the inventory of gas-phase ${ }^{14} \mathrm{C}$ is 1 imited, 2) the inventory reaching the surface will mostly be dispersed directly into the atmosphere, and 3 ) the population base for potential exposure is virtually nonexistent.

The inventory of gaseous ${ }^{14} \mathrm{C}$ in the repository is limited to about $480 \mathrm{Ci}$ out of a total ${ }^{14} \mathrm{C}$ inventory of $48,300 \mathrm{Ci}$ because only the oxidation of ${ }^{14} \mathrm{C}$ trapped on the claddins surface, crud, is expected to be in a gas phase (see Tables 4.4 and 4.5). Although travel times to the surface from the repository are short--on the order of 1000 years or less for the first 
50,000 years after repository closure--the half-1ife of ${ }^{14} \mathrm{C}$ is short enough (5730 years) that significant decay of the initial inventory may have occurred before many of the waste containers have failed.

When gas-phase ${ }^{14} \mathrm{C}$ reaches the surface, it will either be taken up by vegetation or dispersed directly into the atmosphere. Within minutes, the activity released into the atmosphere will be diluted into insignificant concentration levels.

No agricultural or recreational activities currently take place on Yucca Mountain. The current work assumes that present conditions hold for the entire study period. Thus, ${ }^{14} \mathrm{C}$ that is taken up by vegetation is assumed to not enter the human food chain. With these assumptions, virtually no population dose is expected from the release of ${ }^{14} \mathrm{C}$.

\subsection{REFERENCES}

Aaberg, R. L., and B. A. Napier. 1985. Hanford Dose Overview Program: Comparison of AIRDOS-EPA and Hanford Site Dose Codes. PNL-5633, Pacific Northwest Laboratory, Richland, Washington.

Link, R. L., S. E. Logan, H. S. Ng, F. A. Rockenbach, and J. J. Hong. 1982. Parametric Studies of Radiological Consequences of Basaltic Volcanism. SAND81-2375, Sandia National Laboratories, Albuquerque, New Mexico.

Logan, S. E., and M. C. Berbano. 1978. Development and Application of Risk Assessment Method for Radioactive Waste Management. Volumes I-IV, Final Report on Contract No. 68-01-3256. EPA 520/6-78-005, U.S. Environmental Protection Agency, Washington, D.C.

Sinnock, S., and Y. T. Lin. 1987. "Preliminary Bounds on the Expected Postclosure Performance of the Yucca Mountain Repository Site, Southern Nevada." J. Geophys. Res. 2(B8):7820-7842. 


\subsection{SENSITIVITY ANALYSIS}

This section contains observations and conclusions concerning the sensitivity of the dose modeling results to several important parameters. Because the conceptual moafils are still preliminary, and computing resources are finite, a complete sensitivity analysis of every input parameter was not attempted. Instead, some of the more important variables were identified and their effects were investigated. The important variables include the groundwater recharge rate, the forward dissolution rate of the spent fuel matrix, solubility of individual radionuclides, population size, and dose conversion factors. Important conceptual model corsiderations include whether the spent fuel matrix dissolves congruently or there is preferential leaching of one or more radionuclides, whether the releases from the engineered barrier system are dominated by a diffusion mechanism or an advection mechanism, and the population size.

The study on different ground-water recharge rates summarized in Section 7.2 yields information of the sensitivity of dose estimates to groundwater travel times. Cumulative population doses for the first million years were $1.80 \times 10^{5}, 1.89 \times 10^{5}, 2.24 \times 10^{5}$, and $4.29 \times 10^{5}$ (person-rem) for the four recharge rates of $0.5,0.55,0.63$, and $0.75 \mathrm{~mm} / \mathrm{yr}$. If the recharge rate stays under $0.75 \mathrm{~mm} / \mathrm{yr}$, then dose estimates over the first million years are not very sensitive to the recharge rate. However, higher recharge rates on the order of $1.0 \mathrm{~mm} / \mathrm{yr}$ could lead to fracture flow, and thus to ground-water travel times to the water table that are a small fraction of the current estimate of around 100,000 years. Doses would increase by several orders of magnitude if this were to occur. Reasons for this increase include: 1) the activity level reaching the accessible environment would increase significantly because of less radioactive decay, especially for ${ }^{14} \mathrm{C}$; and 2) additional radionuclides would reach the environment. For example, the retardation values for ${ }^{126} \mathrm{Sn},{ }^{239} \mathrm{Pu},{ }^{240} \mathrm{Pu}$, and ${ }^{242} \mathrm{Pu}$ were so large that they did not reach Alkali Flat within 1 million years for any data configuration evaluated for this report, and very little of the inventory of ${ }^{237} \mathrm{~Np}$ arrived. The dose conversion factors for the plutonium isotopes are very high with regard to bone effects, hence tney would become significant contributors to health effects estimates. 
The current study did not include any investigation of fracture flow. The computer model used for the unsaturated zone was a continuum model that did not incorporate the effect of fractures. Given the available hydrologic data, when the ground-water infiltration rate approached $1.0 \mathrm{~mm} / \mathrm{yr}$, this model predicted that the entire mountain would became saturated. A fracture flow code was not available, and new code development was outside the scope of work for the project, thus only the lower recharge rates were investigated. Additional work on the concept of fracture flow is needed to properly model climate change scenarios.

The values of factors for converting radionuclide concentrations to radiation dose play a significant part in the population dose estimates. For example, the total release (curies) of ${ }^{230}$ Th over the first million years is about three orders of magnitude lower than that of ${ }^{129}$ I when the recharge rate of $0.75 \mathrm{~mm} / \mathrm{yr}$ was used. However, its dose conversion factor is about three orders of magnitude higher than that of ${ }^{129} \mathrm{I}$ (bone effects for ${ }^{230} \mathrm{Th}$ versus thyroid effects for ${ }^{129}$ I); thus both radionuclides contribute about the same amount to the integrated population dose. The dose conversion factors are still a subject of much study among the scientific community; some of the recommended values changed by more than an order of magnitude during the course of PNL's risk study. Because only a few radionuclides contribute the major portion of the doses for the base-case estimates, a change in a single dose conversion factor can have a major effect on population dose estimates.

Another major factor in computing population doses is the size of the exposed population. In this study, the population dose was computed by multiplying the dose for a single individual by the number of people who were exposed. It is unreasonable to think that reliable predictions on population characteristics can be made for time periods that may reach 1 million years, in light of world history over the last few hundred years.

The irrigation rate in the base-case dose model was varied to determine its effect on the population dose. The base-case irrigation rate was $255 \mathrm{~L}^{2} /$ mo, and additional runs were performed at 205 and $305 \mathrm{~L}^{2} / \mathrm{mo}$. The cumulative doses over 1 million years for a population of one were 87.8 , 107.0, and 126.2 person-rem respectively for increasing irrigation rates. 
The irrigation rate has almost a linear effect on dose estimates for this range of values. A similar set of dose estimates was done by varying the food consumption parameters identified in Table 6.2. Two additional dose estimates were made, one using values which were $75 \%$ of the base case, and one with values that were $150 \%$ of the base case. The cumulative doses over 1 million years for a population of one were $73.3,107.0$, and 157.5 for the increasing consumption rates. The consumption rate also has almost a linear effect on doses over this range of input values.

Different mathematical models are used when it is assumed that the release of individual radionuclides from the spent fuel waste form is limited by the dissolution rate of the spent fuel matrix (congruent dissolution), or when it is assumed there is preferential leaching of individual radionuclides (incongruent dissolution). The base-case modeling used a congruent dissolution assumption with a saturation value at the surface of the waste form on the order of $10^{-7} \mathrm{~mol} / \mathrm{L}$. The saturation value was calculated as a function of temperature and water chemistry (see Section 4.3.2). Another run was made with an incongruent dissolution rate assumption with the releases of each radionuclide governed by the solubilities given in Table 4.6. For the first million years, the doses computed with the incongruent assumption were about an order of magnitude higher than for the congruent dissolution case, 1125 versus 107 person-rem for a population of one. This is mainly due to the increased inventory of each radionuclide reaching the accessible environment. The inventory released at Alkali Flat is given in Table 8.1 for the five radionuclides showing nonnegligible activity levels over the first million years for congruent and incongruent release assumptions. The doses from these radionuclides have reached their maximum (for the given ground-water travel times) in the incongruent dissolution case because essentially the entire inventory of the radionuclide has been transported to Alkali Flat.

Examples of dose estimates to specific organs for a single 70-year 1 ifetime near the 170,000-year time are given in Table 8.2 for the congruent dissolution case. Similar results showing the effect of increased releases are given in Table 8.3 for the incongruent dissolution rate case. The doses 
TABLE 8.1. Inventory of Radionuclides Reaching Alkali Flat in 1 Million Years for Different Release Assumptions (Ci)

$\begin{array}{ccc}\text { Radionuclide } & \text { Congruent } & \text { Incongruent } \\ {^{14} \mathrm{C}} } & 6.84 \mathrm{E}-5 & 1.59 \mathrm{E}-3 \\ { }^{129} \mathrm{I} & 2.16 \mathrm{E}+2 & 2.31 \mathrm{E}-3 \\ { }^{59} \mathrm{Ni} & 1.18 \mathrm{E}-1 & 5.27 \mathrm{E}+2 \\ { }^{99} \mathrm{Tc} & 2.74 \mathrm{E}+4 & 2.62 \mathrm{E}+5 \\ { }^{79} \mathrm{Se} & 4.86 \mathrm{E}+2 & 6.02 \mathrm{E}+3\end{array}$

TABLE 8.2. Cumulative Effective Dose Equivalent as a Function of Individual Organs for a Single Lifetime Using the Congruent Waste Form Release Assumption (person-rem)

\begin{tabular}{|c|c|c|c|}
\hline Organ & $\begin{array}{c}\text { Cumulative } \\
\text { Dose } \\
\text { Equivalent }\end{array}$ & $\begin{array}{l}\text { Weighting } \\
\text { Factors } \\
\end{array}$ & $\begin{array}{c}\text { Weighted } \\
\text { Cumulative } \\
\text { Dose } \\
\text { Equivalent }\end{array}$ \\
\hline Gonads & $7.47 E-03$ & $2.50 E-01$ & $1.87 E-03$ \\
\hline Breast & $7.66 \mathrm{E}-03$ & $1.50 E-01$ & $1.15 E-03$ \\
\hline R Marrow & $8.02 E-03$ & $1.20 E-01$ & $9.62 E-04$ \\
\hline Lung & $7.49 E-03$ & $1.20 E-01$ & $8.99 E-04$ \\
\hline Thyroid & $2.44 E+00$ & $3.00 E-02$ & 7. $33 \mathrm{E}-02$ \\
\hline Bone Sur & $5.17 E-03$ & $3.00 E-02$ & $1.55 \mathrm{E}-04$ \\
\hline Kidneys & $1.02 E-01$ & $6.00 \mathrm{E}-02$ & $6.14 E-03$ \\
\hline Liver & $5.19 \mathrm{E}-02$ & $6.00 E-02$ & $3.12 E-03$ \\
\hline Spleen & $3.51 E-02$ & $6.00 E-02$ & $2.11 E-03$ \\
\hline LL Int. & $8.93 E-03$ & $6.00 E-02$ & $5.36 E-04$ \\
\hline UL Int. & $5.20 E-03$ & $6.00 E-02$ & $3.12 E-04$ \\
\hline $\begin{array}{l}\text { Lifetime } \\
\text { Lifetime }\end{array}$ & \multicolumn{2}{|l|}{$\begin{array}{l}\text { Cumulative EDE } \\
\text { External Dose }\end{array}$} & $\begin{array}{l}9.1 E-02 \\
8.5 E-04\end{array}$ \\
\hline Total Li & \multicolumn{2}{|c|}{ Cumulative } & $9.1 E-U L$ \\
\hline
\end{tabular}


TABLE 8.3. Cumulative Effective Dose Equivalent as a Function of Individual Organs for a Single Lifetime Using the Incongruent Waste Form Release Assumption (person-rem)

\begin{tabular}{|c|c|c|c|}
\hline Organ & $\begin{array}{l}\text { Cumulative } \\
\text { Dose } \\
\text { Equivalent }\end{array}$ & $\begin{array}{l}\text { Weighting } \\
\text { Factors }\end{array}$ & $\begin{array}{c}\text { Weighted } \\
\text { Cumulative } \\
\text { Dose } \\
\text { Equivalent }\end{array}$ \\
\hline Gonads & $7.83 E-02$ & $2.50 E-01$ & $1.96 \mathrm{E}-02$ \\
\hline Breast & $8.00 E-02$ & $1.50 E-01$ & $1.20 \mathrm{E}-02$ \\
\hline R Marrow & $8.35 E-02$ & $1.20 \mathrm{E}-01$ & $1.00 \mathrm{E}-02$ \\
\hline Lung & $7.85 E-02$ & $1.20 E-01$ & $9.41 E-03$ \\
\hline Thyroid & $2.34 E+01$ & $3.00 E-02$ & $7.03 E-01$ \\
\hline Bone sur & $5.30 E-02$ & $3.00 E-02$ & $1.59 \mathrm{E}-03$ \\
\hline Kidneys & $1.07 E+00$ & $6.00 E-02$ & $6.43 E-02$ \\
\hline Liver & $5.44 E-01$ & $6.00 E-02$ & $3.26 E-02$ \\
\hline Spleen & $3.68 \mathrm{E}-01$ & $6.00 E-02$ & $2.21 E-02$ \\
\hline LL Int. & $9.44 \mathrm{E}-02$ & $6.00 \mathrm{E}-02$ & $5.66 \mathrm{E}-03$ \\
\hline UL Int. & $5.48 E-C 2$ & $6.00 E-02$ & $3.29 E-03$ \\
\hline $\begin{array}{l}\text { Lifetime } \\
\text { Lifetime }\end{array}$ & \multicolumn{2}{|l|}{$\begin{array}{l}\text { Cumulative EDE } \\
\text { External Dose }\end{array}$} & $\begin{array}{l}8.8 E-01 \\
1.8 E-02\end{array}$ \\
\hline Total Li & \multicolumn{2}{|c|}{ Cumulative EDE } & $9.0 \mathrm{E}-01$ \\
\hline
\end{tabular}

presented are mostly from ${ }^{129} \mathrm{I},{ }^{79} \mathrm{Se}$, and ${ }^{59} \mathrm{Ni} .{ }^{99} \mathrm{Tc}$ has not yet arrived because of its larger retardation value, and ${ }^{14} \mathrm{C}$ has decayed to very low levels.

A simple investigation of the effect of using an advection-dominated model versus a diffusion-dominated model for the release from the EBS was also done. The logic outlined in Table 4.1 was used to determine if a radionuclide was solubility limited or inventory limited as it was released 
from the dissolving spent fuel waste form. The flow rate of ground water was then used to determine if the dominant component of radionuclide movement was advection or diffusion.

A forward matrix dissolution rate of $10 \mathrm{~g} / \mathrm{m}^{2}-\mathrm{yr}$ was used for the spent fuel waste form, thus it was completely dissolved in about 50,000 years. This forward dissolution rate is an average of values reported in the liter. ature (see Table 4.2), and thus is representative of the value expected. Note that the NRC fractional release rate criteria of 1 part in 100,000 per year will not be met using this forward dissolution rate. The population doses for a population of one from this case (1070 person rem) over the first million years of repository operation were almost the same as the doses from the incongruent model (1125 person-rem). This is to be expected because even though the highly soluble radionuclides are released much slower in the mixed advection/diffusion model with a congruent dissolution assumption than in a model with an incongruent release rate assumption, when the forward matrix dissolution rate is high enough essentially the whole inventory is transported to Alkali Flat.

The two models just discussed also help evaluate the validity of using a diffusion-only model in the engineered barriers system versus using a model that incorporates advection as we11. When the model output is the computation of doses to the population over long time periods ( $10^{6}$ years) the modeling assumption of diffusion only through the engineered barriers system does not yield appreciably different doses from a model that also accounts for advective movement of radionuclides.

The analyses also show that the spent fuel waste form dissolution rate is an important variable in the computation of doses. In Table 4.2 a forward matrix dissolution rate of $10 \mathrm{~g} / \mathrm{m}^{2}-\mathrm{yr}$ is identified as an average of pub1 ished values. This rate leads to complete dissolution of the waste form at about 50,000 years when the ground-water flux is $0.5 \mathrm{~mm} / \mathrm{yr}$. For the basecase dose modeling the dissolution of the waste form is controlled by the solubility of uranium, which is calculated as a function of temperature and ground-water chemistry. The claim is that (in the absence of colloid formation) the calculated uranium solubility is conservative, yet it leads to a dissolution time of over 10 million years. The two rates lead to cumulative 
population doses that are different by about one order of magnitude. More complete information on the mechanism of waste form dissolution is required before this substantial difference can be resolved.

Table 5.1 gives travel-time estimates for the different layers in the partially saturated zone and for the saturated zone for three different wells. All of the population dose estimates previously discussed were calculated assuming transport through the unsaturated zone for a stratigraphy similar to that of well USW-G3. Even though well USW-G3 had the longest mean ground-water travel time, radionuclide transport involves retardation factors as well as ground-water movement. Based on this, doses from well USW-G3 were expected to be larger than doses computed using a stratigraphy defined by the other two wells. Dose estimates were computed for transport through wells USW-G1 and USW-G4 using a recharge rate and the congruent dissolution model; i.e., they are similar to the base-case estimates discussed in Section 6.5. The dose estimates (person-rem) for the first million years for a population of one are 97.6 for wel1 USW-G4, 102.0 for USW-GI, and 107.0 for we11 USW-G3. Even though regions of the repository will lie above different stratigraphic units, the dose estimates change by $10 \%$ or less depending on the we 11 chosen. The stratigraphy does not have a major impact on dose estimates, and when the repository is built, radionuclide transport will occur through a11 stratigraphies simultaneousiy. 


\subsection{RISK ESTIMATES}

The results presented thus far in this report are representative of what can be called consequence modeling: the consequences of postclosure repository performance are estimated from a suite of models and a particular data configuration. What remains is to combine the consequence modeling results into a comprehensive risk for a postclosure repository performance. Several things must occur for useful risk estimates to be generated: the suite of conceptual models must more closely mimic reality and must be conservative; data must be available to define the important model parameters; timeevolving scenarios must be evaluated or bounding results estimated; and the set of scenarios evaluated must somehow span the set of all possible scenarios in a probabilistic fashion.

The isst requirement, that the set of scenarios be comprehensive and be assigned probabilities of occurrence, is probably the most difficult requirement of the whole modeling process. It is difficult because there is no way known to collect data that will validate scenario probabilities. A more detailed discussion of current opinion on this difficult step is contained in Section 2.1. The consensus of opinion appears to be that only expert judgment can be used to assign most scenario probabilities, and hence the judgment will always be open to question and refutation.

Even given these caveats, this work investigates in some detail all of the scenarios considered applicable to a repository located at Yucca Mountain. In addition to the base-case model, climate changes, magmatic events, and gas-phase release of ${ }^{14} \mathrm{C}$ were addressed. Some of the major assumptions necessary to obtain an estimate of number of health effects for the base case were:

- Ground-water flow in the saturated zone is described by Darcy's 1aw, and regional gradients were established from head measurements.

- Ground-water flow in the partially saturated zone is restricted to matrix flow; there is no fracture flow.

- Waste form dissolution is such that al1 radionuclides are released congruently with the spent fuel matrix. 
- The waste form dissolution rate is governed by the solubility of uranium, which was calculated as a function of temperature and groundwater chemistry (based on the composition of well water).

- Radionuclide mass transport is described using a one-dimensional flow tube model that uses stochastic travel times to estimate the effect, of dispersion.

- The radionuclide source term for the base-case dose estimates is obtained from contaminated ground water at Alkali Flat.

- The conversion of radionuclide concentration to effective dose equivalent is based on the ICRP model described in Section 6.0 that combines dose estimates from separate body organs into an effective dose equivalent.

- Excess adverse health effects were computed based on a conversion factor of 200 health effects per $10^{\circ}$ person-rem of exposure.

- Gas-phase releases of ${ }^{14} \mathrm{C}$ are mostly driven by the thermal gradient induced by radioactive decay in the waste form.

- Exposure pathways included both external exposure and internal exposures. Contaminated ground water was used for drinking and producing agricultural and livestock products.

- Population levels are constant at 1680 individuals, based on estimated ground-water supplies.

Results obtained using several alternative assumptions are described in Section 8.0.

The base-case estimates were generated using what are believed to be conservative models and data values throughout the modeling process. As always, the estimates can be misleading if sume of the conceptual models do not adequately approximate reality. From the assumptions and data values for the base case, the risk estimate is approximately 36 excess health effects over 1 million years afier repository closure. This value can be compared to 48 health effects expected from natural background radiation. The risk is computed as the consequence (number of excess health effects) times the probability of occurrence.

The occurrence probability (see Section 2.2.1) for a magmatic event is estimated to range from $4.7 \times 10^{-8} / \mathrm{yr}$ to $3.3 \times 10^{-10} / \mathrm{yr}$, and health effects ranges for a magmatic event are given in Table 7.6. Inclusion of a magmatic event would increase the risk to between 0.3 and 131 health effects over the 
1 million years after repository closure. The upper end of the range of increased health effects may be greatly exaggerated because it is based on the bounding case of a magmatic event occurring 100 years after repository closure. A magmatic event occurring at a later time would intercept a smallèr inventory in the repository.

Estimates of occurrence probabilities have not been postulated for individual climate change scenarios, so inclusion of climate changes in a risk estimate is difficult. However, if a bounding case of a ground-water recharge rate $50 \%$ larger than currentiy expected is chosen, the risk estimate is increased by 14 health effects. The dose estimates are very sensitive to increases in the ground-water recharge rate above this bounding case.

A detailed dose calculation for population health effects from the gasphase release of ${ }^{14} \mathrm{C}$ has not yet been done. However, preliminary considerations suggest that the number of health effects will be negligible. Thus, inclusion of gas-phase releases as a scenario does not appreciably change the risk estimate.

An upper bound on health effects can be obtained by adding the maximum increase on health effects calculated from each scenario. This approach yields a risk estimate of between 36 and 181 excess adverse health effects during the first million years after repository closure. 


\section{APPENDIX A}

MOISTURE RETENTION CHARACTERISTICS AND GENERAL HYDRAULIC CONDUCTIVITY DATA AND CORRESPONDING FITTED CURVES FOR CORE SAMPLES 

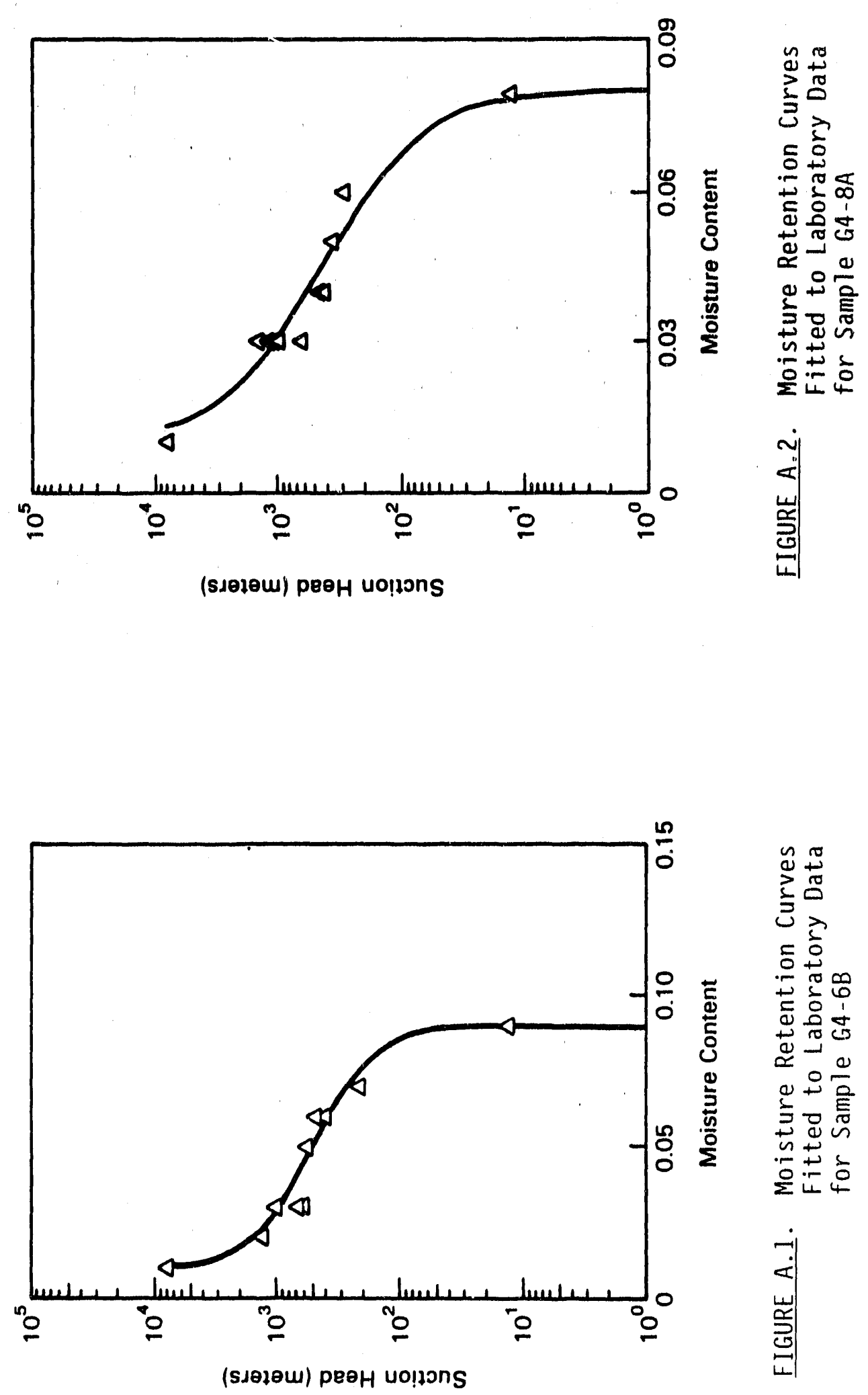

A. 1 

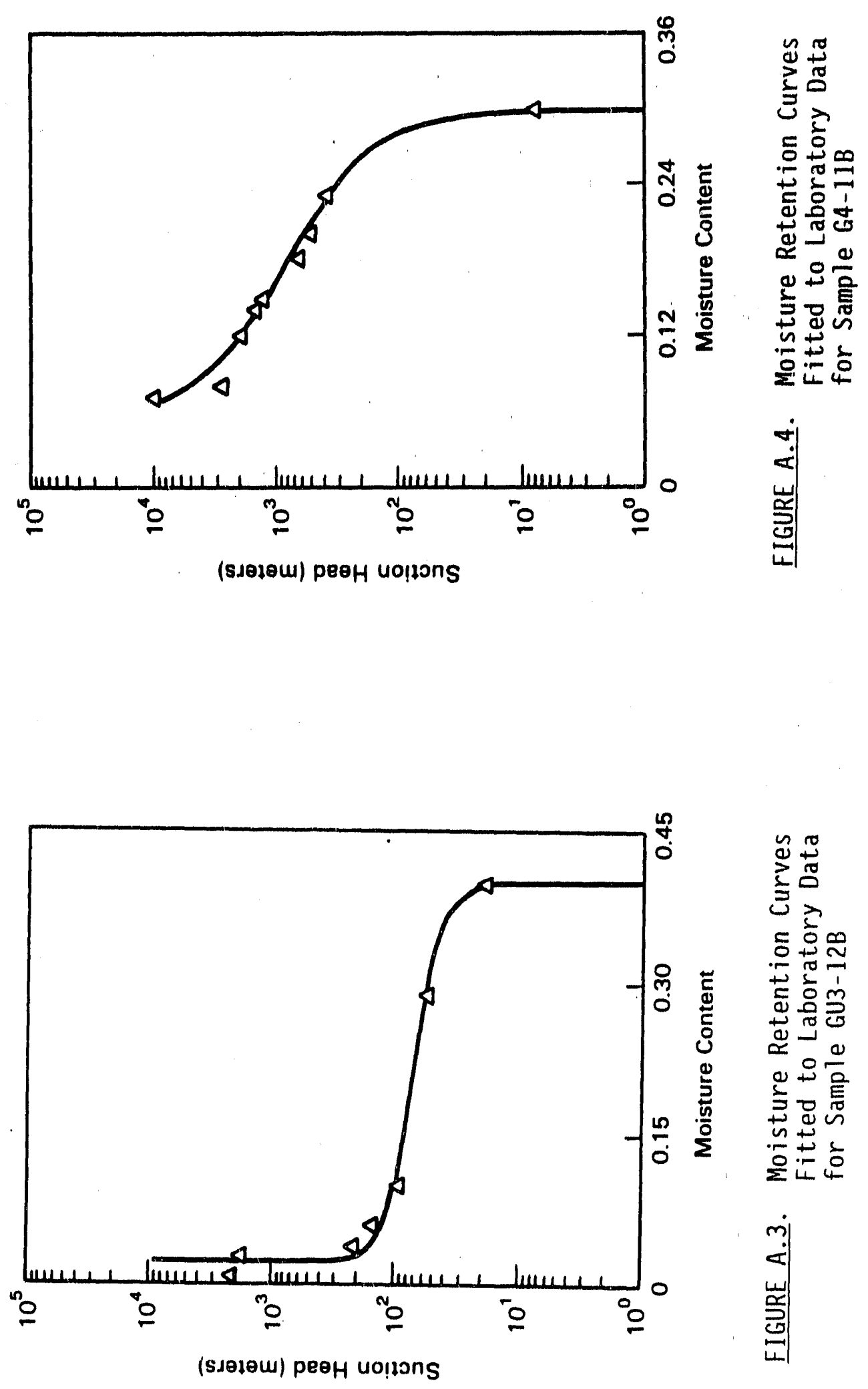

A. 2 

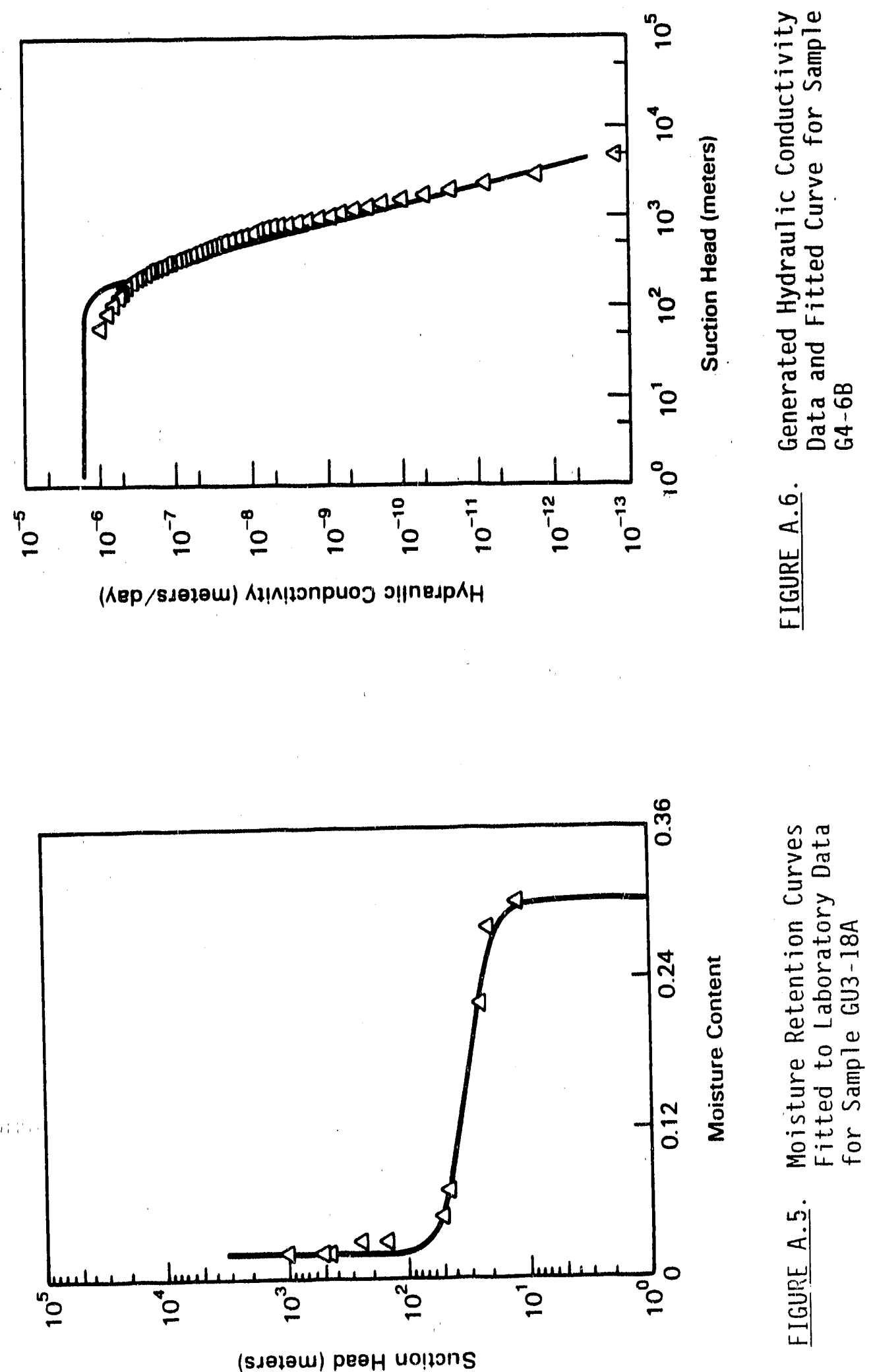

A. 3 

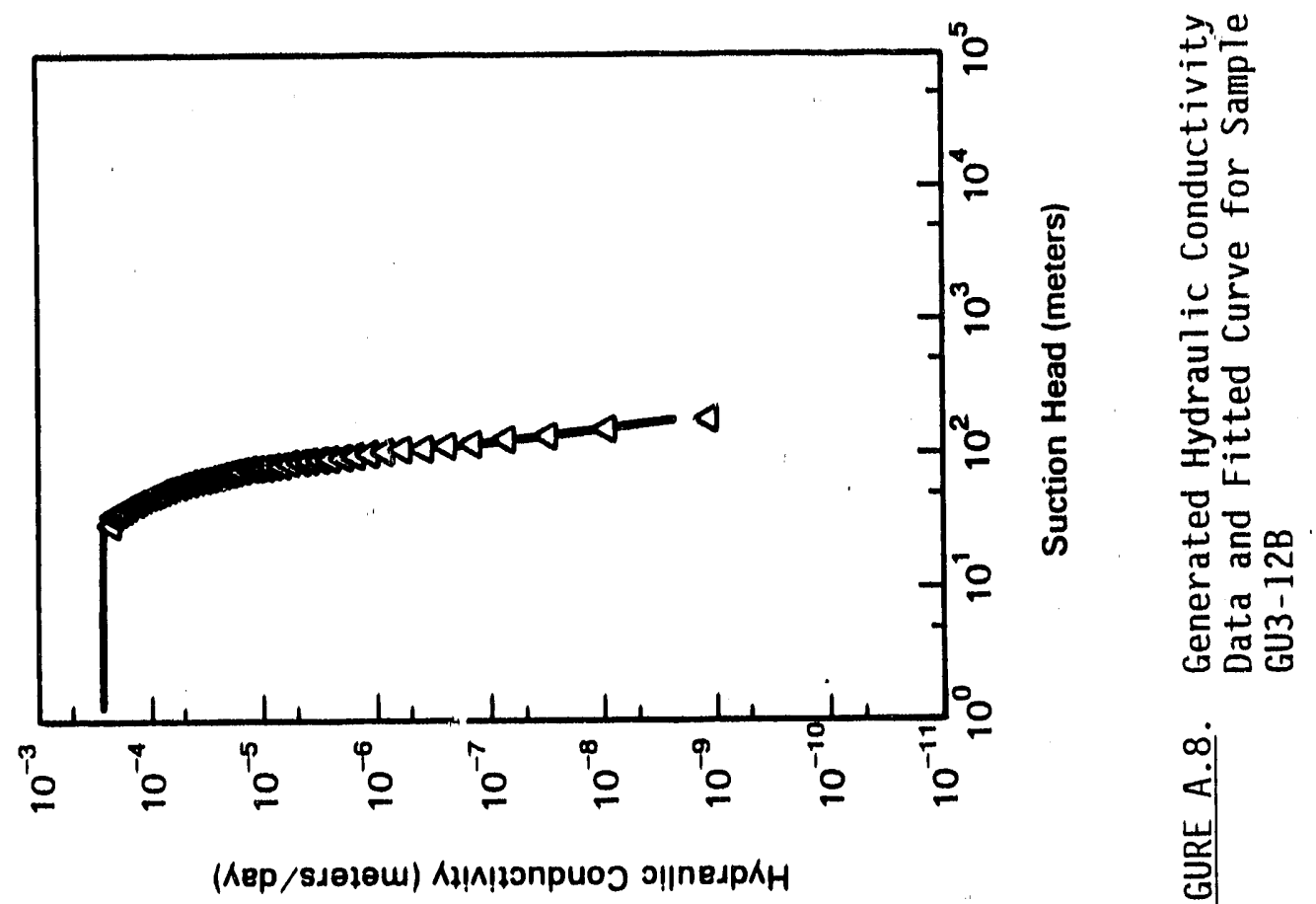

$\infty$
$\dot{\alpha}$
$\frac{1}{5}$
$\square$
$\square$
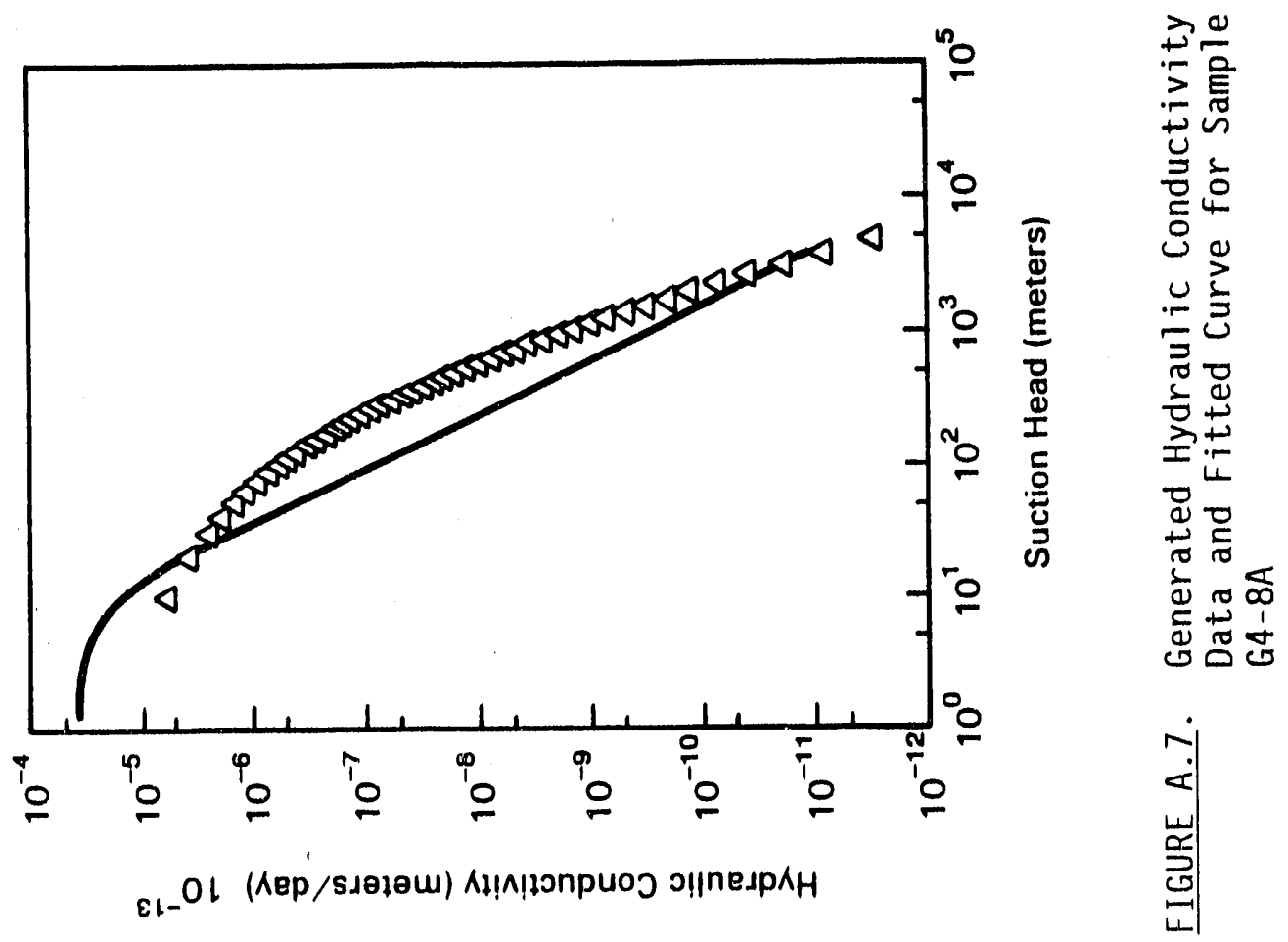

A. 4 

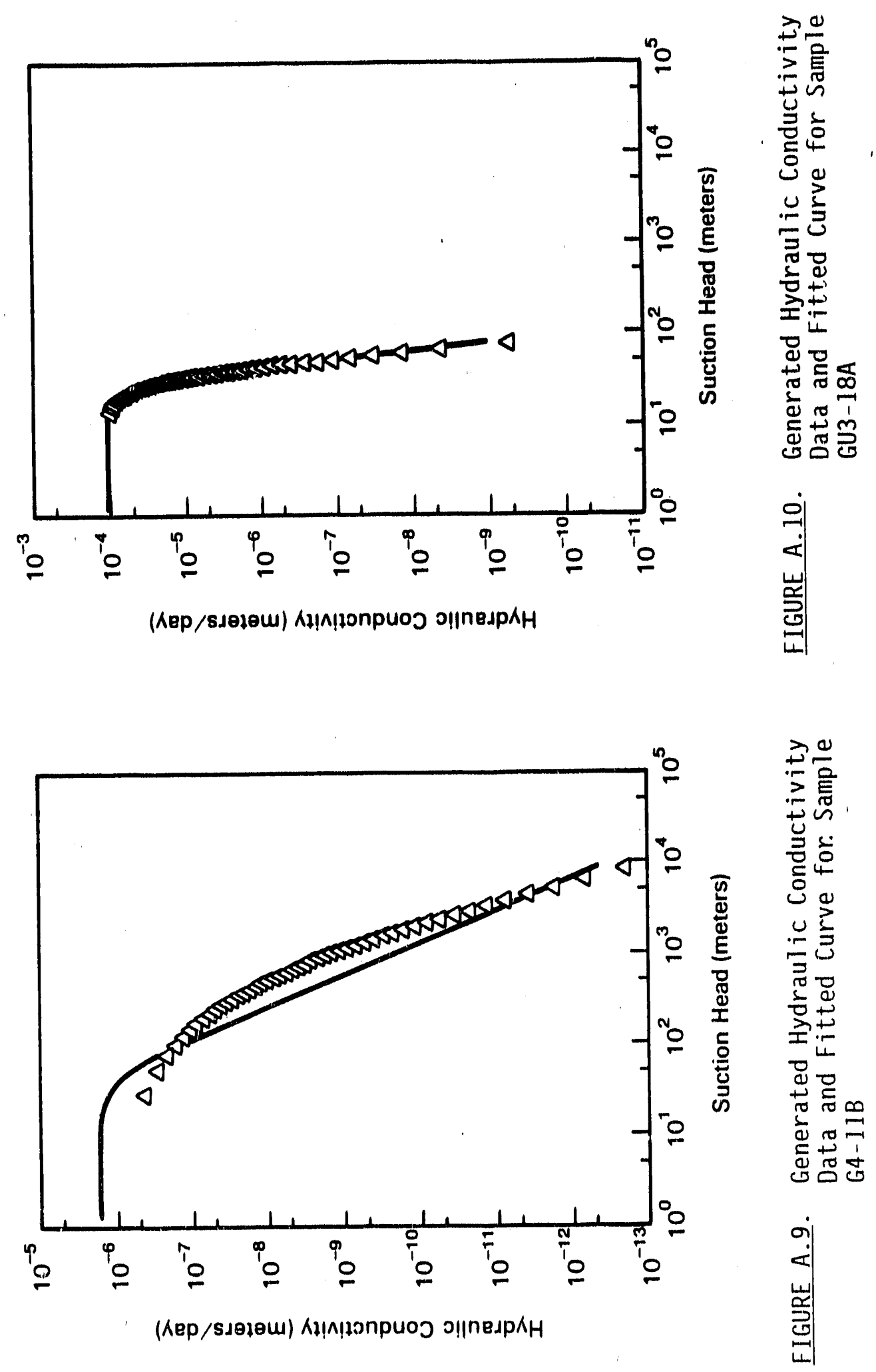

A. 5 


\section{APPENDIX B}

SOLUTION OF EQUATION 5.6 FOR AN ARBITRARY $\theta(t)$ 


\section{APPENDIX B}

\section{SOLUTION OF EQUATION 5.6 FOR AN ARBITRARY $\theta(t)$}

In this appendix the system of equations

$$
\frac{\partial f_{i}}{\partial t}+v_{i} \frac{\partial f_{i}}{\partial x}+\lambda_{i} f_{i}=\frac{R_{i-1}}{R_{i}} \quad \lambda_{i-1} f_{i-1}, \quad \lambda_{0}=0, \quad i=1,2, \ldots k,
$$

is solved subject to the initial conditions

$$
f_{i}(x, 0)=0, \quad i=1, \ldots, k,
$$

and the boundary conditions

$$
\begin{gathered}
f_{1}(0, t)=\Phi(t), \quad t>0, \\
f_{i}(0, t)=0, t>0, \quad i=2, \ldots, k,
\end{gathered}
$$

where

$$
V_{i}=V / R_{i}
$$

The system (B.1) has been solved when all of the retardation values are distinct (Harada et a 1. 1980). There are times, however, when it is of interest to solve (B.1) when two or more retardation values are the same. Because retardation is a chemical phenomenon all isotopes of the same element will always have the same retardation value. Hence, the retardation values will not all be distinct whenever a decay chain contains two or more isotopes of the same element. An example is the decay chain $238 \mathrm{U}=234 \mathrm{U}=230 \mathrm{Th}$. The method used in Harada et a1. (1980) to solve (B.1) will be used with minor modifications to solve (B.1) even when the retardation values are not all distinct. 
The system (B.1) is solved using Laplace transformations. The properties of Laplace transformations are well known and will be used freely in the following work. Define

$$
\begin{aligned}
n_{j}(x, s) & =z e^{-s t} f_{j}(x, t) d t, \\
0 & \\
& \infty \\
n_{f}(p, s)= & z \\
0 & e^{-p x} n_{f}(x, s) d x,
\end{aligned}
$$

and

$$
\phi(s)=\begin{array}{ll}
z^{\infty} & e^{-s t} \Phi(t) d t . \\
0 &
\end{array}
$$

Taking the Laplace transform of (B.1) with respect to $t$ and then $x$ ytelds, after rearrangement and use of (B.2) and (B.3),

$$
\left(p+\mu_{1}\right) n_{1}(p, s)-\phi(s)=0
$$

and

$$
\left(p+\mu_{j}\right) n_{j}(p, s)=\nu_{i-1} n_{j-1}(p, s), \quad i=2, \ldots, k,
$$

where

$$
\mu_{i} \equiv \frac{s+\lambda_{i}}{v_{i}}, \quad \nu_{i-1} \equiv \frac{\lambda_{i-1}}{v_{i-1}}, \quad \lambda_{0}=0
$$

By solving (B. 4a,b) for $n_{1}, \ldots, n_{k}$ successively, one obtains

$$
n_{1}(p, s)=\frac{\phi(s)}{p+\mu_{1}}
$$

$$
\text { B. } 2
$$


Equation (B.6C) can be written

$$
n_{f}(p, s)=A_{f} \phi(s) \underset{m}{\stackrel{t}{x}} \frac{c_{m}}{\left(p+\mu_{m}\right)}
$$

provided the $k_{m}$ are all unequal, where

$$
C_{m} \equiv z \prod_{\substack{j \\ j \neq 1}}^{i \neq m}\left(\mu_{j}-\mu_{m}\right) i^{-1} .
$$

Because the decay constants for varlous radionuclides are almost always different the $\mu_{m}$ will almost always be distinct, even if some of the retardation values, hence velocities, are the same. The only case requiring spectal consideration is $V_{a}=V_{b}$ and $\mu_{a}=\mu_{b}$, for some $a, b, a \neq b$.

Taking the inverse Laplace transform of (B.9) with respect to $p$ gives

$$
n_{i}(x, s)=A_{f} \phi(s) \underset{m=1}{\stackrel{1}{x}} C_{m} e^{-\mu_{m} x}
$$

Up to this point the analysis has been essentially a simplification of the results in Harada et a1. (1980). Now, however, the cases will be

I) $R_{j}=R_{0}, \quad i=1, \ldots, k$,

II) $R_{j} \neq R_{j}, i, j=1, \ldots, k, i \neq j$, and

III) neither I) nor II) hold, considered. The only case treated in Harada et al. (1980) is case II.

CASE I. Let $R_{i}=R_{0}, \quad t=1, \ldots, k$ and define $V_{0}=\dot{V} / R_{0}$. It follows from (B.5) that

$$
\mu_{j}-\mu_{m}=\left(\lambda_{j}-\lambda_{m}\right) / V_{0}
$$

B. 4 
hence

$$
C_{m}=v_{0}^{i-1}\left(\prod_{\substack{i \\ j \neq m}}^{i}\left(\lambda_{j}-\lambda_{m}\right)\right)^{-1} .
$$

Substituting (B.5), (B.7) and (B.12) into (B.11) one finds

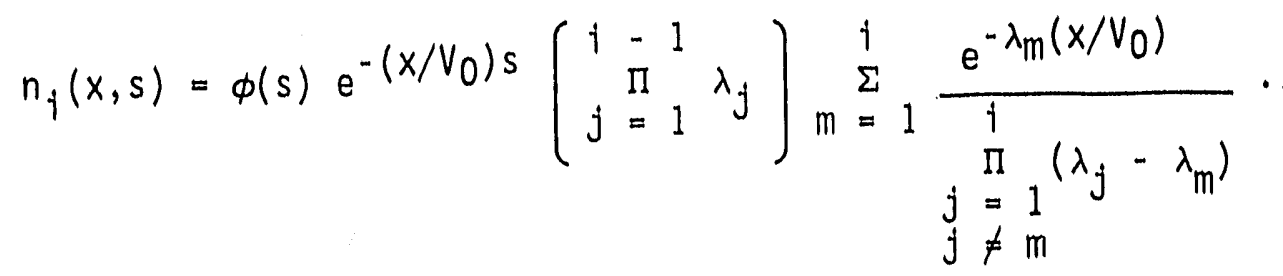

Finally, using the shift rule to invert (B.13) with respect to s yields

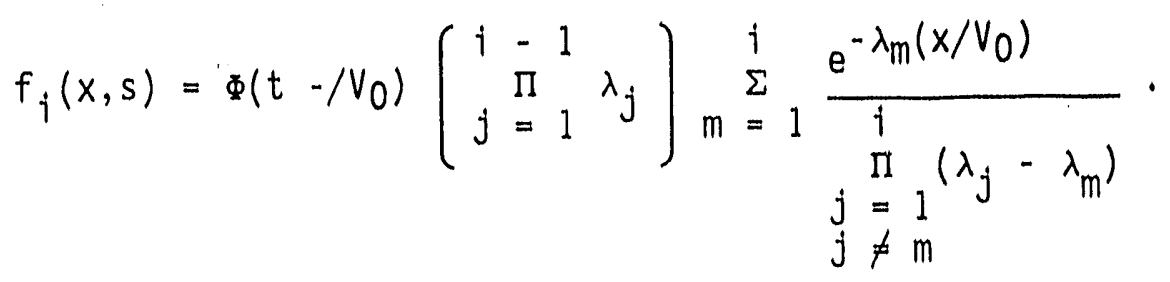

when $R_{1}=R_{0}, i=1, \ldots, k$, where $V_{0}=V / R_{0}$.

CASE II. Let $R_{f} \neq R_{j}$ for $i \neq j$, then $v_{j} \neq v_{j}$ for $i \neq j$. Defining

$$
\Gamma j, m \equiv \frac{V_{m}-V_{j}}{V_{m} V_{j}}, \quad \Delta j, m \equiv \frac{\lambda_{j} V_{m}-\lambda_{m} V_{j}}{V_{m}-V_{j}} j \neq m,
$$

and using (B.5) one obtains

$$
\mu_{j}-\mu_{m}=\Gamma_{j, m}\left(s+\Delta_{j, m}\right), \quad j \neq m .
$$

Substituting $(B .5),(B .10)$, and $(B .16)$ into $(B .11)$ gives

$$
\text { B. } 5
$$




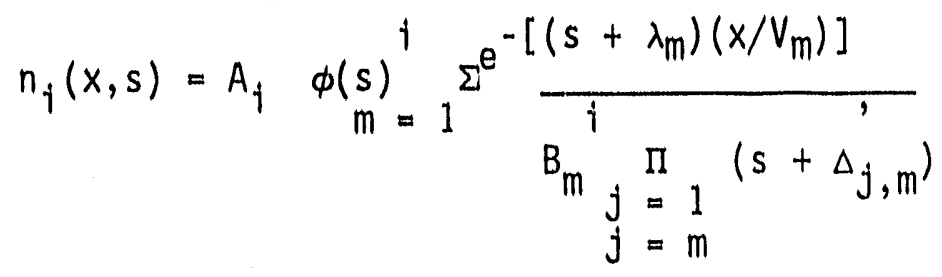

where

$$
B_{m} \equiv \prod_{j=m}^{i} \Gamma_{j, m} .
$$

Next, using the partial fraction expansion of

$\frac{1}{j=1} \underset{j \neq m}{\left.i=\Delta_{j, m}\right)}$

in (B.17) gives

$$
n_{j}(x, s)=A_{i} \phi(s) \sum_{m=1}^{i} \frac{e^{-\lambda_{m}\left(x / V_{m}\right)}}{B_{m}} \sum_{\substack{j=1 \\ j=m}}^{i} D_{j, m} \frac{e^{-\left(x / V_{m}\right) s}}{s+\Delta_{j, m}}
$$

where

$$
D_{j, m}=\left(\begin{array}{l}
i \\
\prod_{q 1}\left(\Delta_{q, m}-\Delta_{j, m}\right) \\
q \neq j \neq m
\end{array}\right)^{-1}
$$

and $D_{j, m}=1$ when $i=2$. By the shift rule

$$
L^{-1}\left(\frac{e^{-\left(x / V_{m}\right) s}}{s+\Delta_{j, m}}\right)=g_{j, m}(t)=e^{-\Delta_{j}, m}\left(t-x / V_{m}\right) H\left(t-x / V_{m}\right),
$$


where $H$ is the Heaviside function

$$
H(z)= \begin{cases}0, & z<0 \\ 1, & z \geq 0\end{cases}
$$

and $\mathrm{L}^{-1}$ is the inverse Laplace transform with respect to $\mathrm{s}$. Therefore by the convolution rule

$$
f_{i}(x, t): A_{i}\left(\sum_{m=1}^{i} \frac{e^{-\lambda_{m}\left(x / V_{m}\right)}}{B_{m}} \sum_{\substack{j=1 \\ j \neq m}}^{i} D_{j, m} g_{j, m}(t)\right) \otimes \Phi(t)
$$

where $\mathrm{N}$ is defined by

$$
F(t) N \Phi(t)=\int_{0}^{t} F(\tau) \Phi(t-\tau) d \tau
$$

Equation (B.23) is a special case of the result in Harada et al. (1980).

CASE III. It is assumed that $i \geq 3$, otherwise either case I or case II holds. Assume neither case I nor case II hold; i.e., assume 1) at least two retardation values are the same, and 2) there are at least two different retardation values. A simple modification of (B.15)-(B.24) allows the solution of (B.1) to be obtained for this case. The changes required in (B.15)-(B.24) are 1) the condition $v_{j} \neq V_{m}$ must be added everywhere the condition $j \neq m$ holds, since $\Delta_{j, m}$ is undefined for $\left.v_{j} \neq v_{m}, 2\right)$ an additional factor must be included in the denominator of (B.17), and 3 ) the condition $V_{\mathrm{q}} \neq \mathrm{V}_{\mathrm{m}}$ must be included in (B.20). Making the indicated changes one obtains

$$
f_{j}(x, t)=A_{i}\left(\sum_{m=1}^{i} \frac{e^{-\lambda_{m}\left(x / V_{m}\right)}}{B_{m}^{\prime}} \sum_{\substack{j=1 \\ j \neq m \\ V_{j} \neq V_{m}}}^{i} D_{j, m}^{\prime} g_{j, m}(t)\right) \otimes \Phi(t),
$$

B.7 
where

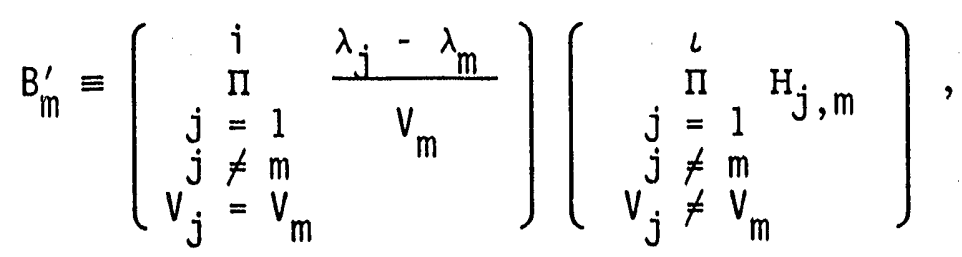

and

$$
D_{j, m}^{\prime} \equiv\left(\begin{array}{l}
\quad{ }^{i}\left(\Delta_{q, m}-\Delta_{j, m}\right) \\
q=1 \\
q \neq j \neq m \\
v_{j} \neq v_{m} \\
v_{q} \neq v_{m}^{m}
\end{array}\right)^{-1}
$$

with $D_{j, m}^{\prime}=1$ when the product (B.20) contains no terms. Finally, $g_{j, m}$ is still defined by (B.21).

\section{B.1 REFERENCES}

Harada, M., P. L. Chambré, M. Foglia, K. Higashi, F. Iwamoto, D. Leung, T. H. Pigford, and D. Ting. 1980. Migration of Radionuclides Through Sorbing Media, Analytical Solution - I. ONWI-359 (LBL-10500), Lawrence Berkeley Laboratory, Berkeley, California. 
APPENDIX C

BAND RELEASE 


\section{APPENDIX C}

\section{BAND RELEASE}

This appendix derives the equations for $F_{i}(x, t), i=1,2,3$, where $F_{i}$ is defined by Equation (5.8) and $f_{j}$ satisfies Equations (5.6) and (5.9). The $F_{i}$ are found by using Equation (5.8) and substituting Equation (5.9) into the results of Appendix $B$.

C.1. $F_{1}(x, t)$. Substituting Equation (5.9) into (B.8) and using (5.8) yields

$$
F_{1}(x, t)= \begin{cases}s_{0} e^{-\lambda_{1}\left(x / V_{1}\right)}, & t_{0}+x / v_{1} \leq t \leq t_{1}+x / v_{1} \\ 0, & \text { otherwise. }\end{cases}
$$

C.2. $F_{2}(x, t)$.

Case i. $\quad R_{1}=R_{2}=R_{0}, \quad V_{0}=V / R_{0}$. Substituting Equation (5.9) into (B.14), with $i=2$ and using (5.8), one finds

$F_{2}(x, t)=\left\{\begin{array}{cc}S_{0} \frac{\lambda_{2}}{\lambda_{2}-k_{1}}\left\{e^{-\lambda_{1}\left(x / V_{0}\right)}-e^{-\lambda_{2}\left(x / V_{0}\right)}\right\}, t_{0}+x / V_{0} \leq t \leq t_{1}+x / V_{0} \\ 0, \quad \text { otherwise. }\end{array}\right.$

Case $i i . \quad R_{1} \neq R_{2}$. Taking $i=2$ in Equation (B.23) and rearranging terms and using (5.8) yields

$$
F_{2}(x, t)=\frac{\lambda_{2} V_{2}}{V_{1}-V_{2}} e^{K_{0} x}\left\{e^{-\Delta} 1,2 t\left[H\left(t-x / V_{1}\right)-H\left(t-x / V_{2}\right)\right]\right\} \otimes \Phi(t),
$$

where

$$
K_{0}=\frac{\lambda_{2}-\lambda_{1}}{V_{1}-V_{2}}
$$

C. 1 
Define

$$
v_{a} \equiv \max \left\{v_{1}, v_{2}\right\}, \quad v_{b} \equiv \min \left\{v_{1}, v_{2}\right\}
$$

Substituting Equations (5.9), (B.2), and (B.22) into (C.3), using $\Delta_{a, b}=\Delta_{1,2}$ $=\Delta_{2,1}$ and (C.5) and integrating (B.24) now yields

$$
F_{2}(x, t)= \begin{cases}\frac{S_{0} \lambda_{2} R_{1}}{\lambda_{a} R_{a}-\lambda_{b} R_{b}}\left(e^{K_{0} x-\Delta_{a}, b^{\text {low }}}-e^{K_{0} x}-\Delta_{a}, b^{h i g h}\right) \\ 0, & t_{0}+x / V_{a}<t<t_{f}+x / V_{b}, \\ \text { otherwise, } & \text { (C.6a) }\end{cases}
$$

where

$$
10 w=\max \left\{x / V_{a}, t-t_{f}\right\}
$$

and

$$
\text { high }=\min \left\{x / v_{b}, t-t_{0}\right\}
$$

c.3. $F_{3}(x, t)$.

Case $i$. Assume $R_{1}=R_{2}=R_{3}=R_{0}$ and define $V_{0}=V / R_{0}$. Substituting Equation (5.9) into (B.14) and using (5.8) results in

$$
F_{3}(x, t)=S_{0} \lambda_{2} \lambda_{3} \stackrel{\Sigma}{m=1}_{\substack{\prod_{1}\left(\lambda_{j}-\lambda_{m}\right) \\ j \neq 1 \\ j \neq m}}^{e^{-\lambda_{m}\left(x / V_{0}\right)}}
$$

Case $i j$. Assume two retardation values are the same, but distinct from the third. Choose $a, b, c$ such that

$$
v_{a}=V_{b} \neq V_{c}
$$


Setting $i=3$ and taking the sum $m=1,2,3$ in the order $m=a, b, c$ in (B.25) one obtains

$$
\begin{aligned}
f_{3}= & \left\{K _ { 1 } \left[e^{\left.\left(\Delta_{c}, b-\lambda_{b}\right)\left(x / V_{b}\right)-\Delta_{c}, b^{t}-e^{\left(\Delta_{c}, a-\lambda_{a}\right)\left(x / V_{a}\right)-\Delta_{c}, a^{t}}\right]}\right.\right. \\
& +K_{2}\left[e^{\left.\left.\left(\Delta_{b}, c-\lambda_{c}\right)\left(x / V_{c}\right)-\Delta_{b}, c^{t}-e^{\left(\Delta_{a}, c-\lambda_{c}\right)\left(x / V_{c}\right)-\Delta_{a}, c^{t}}\right]\right\}}\right. \\
& \otimes \Phi(t),
\end{aligned}
$$

where

$$
\begin{gathered}
K_{1}=\frac{V_{b} H\left(t-x / V_{a}\right)}{\Gamma_{c, a}\left(\lambda_{a}-\lambda_{b}\right)}, \\
K_{2}=\frac{H\left(t-x / V_{c}\right)}{\Gamma_{a, c} \Gamma_{b, c}\left(\Delta_{a, c}-\Delta_{b, c}\right)} .
\end{gathered}
$$

Simplifying Equation (C.9) and using (5.8) and (B.2), one has

$$
F_{3}(x, t)=K_{3} \Phi(t) \otimes \begin{cases}e\left[\left(\Delta_{b}, c-\lambda_{c}\right)\left(x / V_{c}\right)-\Delta_{b}, c^{t}\right] \\ -e\left[\left(\Delta_{a}, c-\lambda_{c}\right)\left(x / V_{c}\right)-\Delta_{a}, c^{t}\right], x / V_{\max }<t<x / V_{\min } \\ 0, & \text { otherwise, }\end{cases}
$$

where

$$
K_{3}=\frac{\lambda_{2} \lambda_{3} R_{a} R_{b} / R_{3}}{\left(\lambda_{a}-\lambda_{b}\right)\left|R_{c}-R_{a}\right|} .
$$

Finally, substituting Equations (5.9) and (B.24) into (C.12) yields

$$
\begin{aligned}
F_{3}(x, t)=S_{0} K_{3}\{ & \frac{\left.e^{\left(\Delta_{b}, c\right.}-\lambda_{c}\right)\left(x / V_{c}\right)}{\Delta_{b}, c}\left(e^{\Delta_{b}, c}{ }^{l o w}-e^{\Delta_{b}, c^{h i g h}}\right) \\
+ & \left.\frac{e^{\left(\Delta_{a}, c-\lambda_{c}\right)\left(x / V_{c}\right)}}{\Delta_{a, c}}\left(e^{\Delta_{a}, c l o w}-e^{\Delta_{a}, c^{h i g h}}\right)\right\},
\end{aligned}
$$

C. 3 
$x / V_{\max }<t<x / V_{\min }$, zero otherwise, where

$$
\begin{gathered}
\text { Iow }=\max \left\{x / V_{\text {max }}, t-t_{f}\right\} \\
\text { high }=\min \left\{x / v_{\min }, t-t_{0}\right\}, \\
V_{\max }=\max \left\{V_{1}, v_{2}, v_{3}\right\}, \quad v_{\min }=\min \left\{v_{1}, v_{2}, v_{3}\right\},
\end{gathered}
$$

and $K_{3}$ is defined by Equation (C.13).

Case ili. All retardation values are distinct. Let $a, b, c$ be integers such that $V_{a}<V_{b}<V_{c}$. Setting $f=3$ in Equation (B.23) and taking the sum $m=1,2,3$ in the order $m=a, b, c$ one finds

$$
\begin{aligned}
f_{3}(x, t)=A_{3} \Phi(t) \otimes & \left\{\frac{H\left(t-x / V_{a}\right)}{K_{4}} I_{a, b, c}+\frac{H\left(t-x / V_{b}\right)}{K_{5}} I_{b, a, c}\right. \\
& \left.+\frac{H\left(t-x / V_{c}\right)}{K_{6}} I_{c, a, b}\right\}
\end{aligned}
$$

where

and

$$
\begin{aligned}
& K_{4}=\Gamma_{b, a} \Gamma_{c, a}\left(\Delta_{c, a}-\Delta_{b, a}\right), \\
& K_{5}=\Gamma_{a, b} \Gamma_{c, b}\left(\Delta_{c, b}-\Delta_{a, b}\right), \\
& K_{6}=\Gamma_{a, c} \Gamma_{b, c}\left(\Delta_{b, c}-\Delta_{a, c}\right),
\end{aligned}
$$

$$
I_{a, b, c}=e^{\left[\left(\Delta_{b}, a-\lambda_{a}\right)\left(x / V_{a}\right)-\Delta_{b}, a t\right]}-e^{\left[\left(\Delta_{c}, a-\lambda_{a}\right)\left(x / V_{a}\right)-\Delta_{c}, a t\right]}
$$

But,

$$
\frac{1}{K_{4}}=\frac{-1}{K_{5}}=\frac{1}{K_{6}}=\frac{-V_{1} V_{2} V_{3}}{\lambda_{a}\left(V_{c}-V_{b}\right)+\lambda_{b}\left(V_{a}-V_{c}\right)+\lambda_{c}\left(V_{b}-V_{a}\right)} .
$$

Substituting the preceding, Equations (B.2) and (B.22) into (C.15) and using (5.8), one finds

C. 4 


$$
F_{3}(x, t)=K_{7} \Phi(t) \otimes\left\{h_{1}(x, t)+h_{2}(x, t)\right\},
$$

where

$$
\begin{aligned}
& K_{7}^{\prime}=\frac{\lambda_{2} \lambda_{3} R_{1} R_{2}}{\lambda_{a} R_{a}\left(R_{b}-R_{c}\right)+\lambda_{b} R_{b}\left(R_{c}-R_{a}\right)+\lambda_{c} R_{c}\left(R_{a}-R_{b}\right)},
\end{aligned}
$$

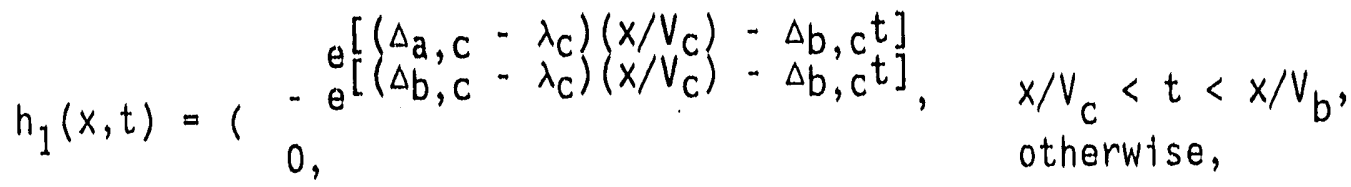

and

$$
\begin{aligned}
& e^{\left[\left(\Delta_{a}, b-\lambda_{a}\right)\left(x / V_{a}\right)-\Delta_{a}, b t\right]} \\
& h_{2}(x, t)=\left(\begin{array}{ll}
-e^{\left[\left(\Delta_{a}, c-\lambda_{a}\right)\left(x / V_{a}\right)-\Delta_{a}, c t\right]}, & x / V_{b}<t<x / V_{a}, \\
0, & \text { otherwise. }
\end{array}\right.
\end{aligned}
$$

Finally, using Equations (5.9) and (B.24) in (C.17) and defining

and

$$
10 w=\max \left\{x / V_{c}, t-t_{f}\right\}
$$

$$
h i g h=\min \left\{x / V_{a}, t-t_{0}\right\}
$$

one finds

$$
F_{3}(x, t)=0, \quad t \geq t_{f}+x / V_{a} \text { or } t \leq t_{0}+x / V_{c} .
$$

For $t_{0}+x / V_{c}<t<t_{f}+s / V_{a}$ there are three cases.

Case iti.a. If high $\leq x / V_{b}$, then

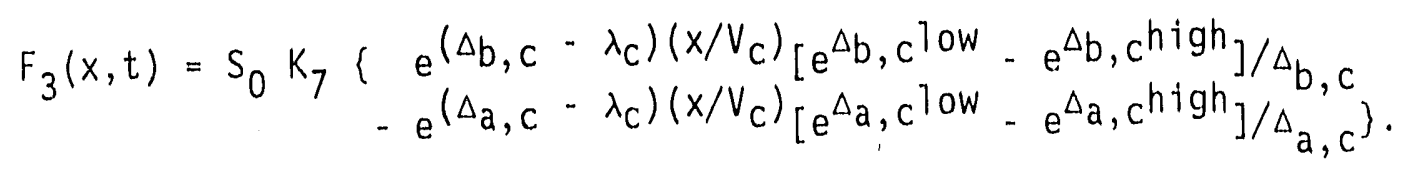


Case thi,b. If low $\geq x / V_{b}$, then

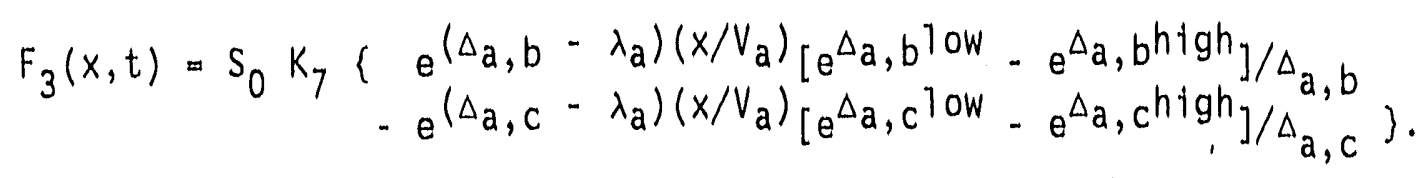

Case itl.c. If low $<x / V_{b}$ and high $>x / V_{b}$, then

$$
\begin{aligned}
& F_{3}(x, t)=S_{0} K_{7}\left\{e^{\left(\Delta b, c-\lambda_{c}\right)\left(x / V_{c}\right)}\left[e^{\Delta b, c} c^{10 w}-e^{\Delta b, c}\left(x / V_{b}\right)\right] / \Delta_{b}, c\right. \\
& \text { - } e^{\left(\Delta_{a}, c-\lambda_{c}\right)\left(x / V_{c}\right)}\left[e^{\Delta_{a}, c} c^{10 w}-e^{\Delta_{a}, c}\left(x / V_{b}\right)\right] / \Delta_{a, c} \\
& +e^{\left(\Delta_{a}, b-\lambda_{a}\right)\left(x / V_{a}\right)}\left[e^{\Delta_{a}, b\left(x / V_{b}\right)}-e^{\Delta_{a}, b^{h i g h}}\right] / \Delta_{a, b} \\
& \text { - } \left.e^{\left(\Delta_{a}, c-\lambda_{a}\right)\left(x / V_{a}\right)}\left[e^{\Delta_{a}, c}\left(x / V_{b}\right)-e^{\Delta_{a}, c h i g h}\right] / \Delta_{a, c}\right) \text {, }
\end{aligned}
$$

where low and high are defined by $(C .18), V_{a}<V_{b}<V_{c}$, and $K_{7}$ is defined by (C.17). 
1

APPENDIX D

DOSE MODEL COEFFICIENTS 
APYENDIX, D

\section{DOSE MODEL COEFFICIENTS}

TABLE D.1. Food Transfur Coeffictents

D. Vel. Plant Egg Milk Beef Pork Poultry Percolation $(\mathrm{m} / \mathrm{s}) \quad \ldots \quad($ day $/ \mathrm{kg})$ (day $/ \mathrm{l})($ day $/ \mathrm{kg})($ day $/ \mathrm{kg})($ day $/ \mathrm{kg})$ constant

\begin{tabular}{|c|c|c|c|c|c|c|c|}
\hline $\begin{array}{ll}C & 0.0 \\
\text { NI } & 1.0 \mathrm{E}-3 \\
\text { SE } & 1.0 \mathrm{E}-3 \\
\text { TC } & 1.0 \mathrm{E}-3 \\
\text { I } & 1.0 \mathrm{E}-2 \\
\mathrm{~PB} & 1.0 \mathrm{E}-3 \\
\mathrm{BI} & 1.0 \mathrm{E}-3 \\
\mathrm{PO} & 1.0 \mathrm{E}-3 \\
\mathrm{RA} & 1.0 \mathrm{E}-3 \\
\mathrm{AC} & 1.0 \mathrm{E}-3 \\
\mathrm{TH} & 1.0 \mathrm{E}-3 \\
\mathrm{PA} & 1.0 \mathrm{E}-3 \\
\mathrm{C} & 1.0 \mathrm{E}-3 \\
\mathrm{NP} & 1.0 \mathrm{E}-3\end{array}$ & $\begin{array}{l}0.0 \\
1.9 E-2 \\
1.3 E+0 \\
1.0 \\
2.0 E-2 \\
6.8 E-2 \\
1.5 E-1 \\
9.0 E-3 \\
1.4 E-3 \\
2.5 E-3 \\
4.2 E-3 \\
2.5 E-3 \\
2.5 E-3 \\
2.5 E-3\end{array}$ & $\begin{array}{l}0.0 \\
1.0 E-1 \\
2.1 E+0 \\
9.9 E-4 \\
1.6 E+0 \\
9.9 E-4 \\
9.9 E-4 \\
9.9 E-4 \\
2.0 E-5 \\
2.0 E-3 \\
2.0 E-3 \\
2.0 E-3 \\
3.4 E-1 \\
2.0 E-3\end{array}$ & $\begin{array}{l}0.0 \\
3.4 \mathrm{E}-3 \\
2.3 \mathrm{E}-2 \\
1.2 \mathrm{E}-2 \\
1.0 \mathrm{E}-2 \\
1.0 \mathrm{E}-5 \\
2.5 \mathrm{E}-4 \\
1.2 \mathrm{E}-4 \\
2.0 \mathrm{E}-4 \\
2.5 \mathrm{E}-6 \\
2.5 \mathrm{E}-6 \\
2.5 \mathrm{E}-6 \\
6.0 \mathrm{E}-4 \\
2.5 \mathrm{E}-6\end{array}$ & $\begin{array}{l}0.0 \\
1.0 E-3 \\
1.0 E+0 \\
9.9 E-4 \\
2.0 E-2 \\
9.9 E-4 \\
9.9 E-4 \\
9.9 E-4 \\
9.9 E-4 \\
5.0 E-3 \\
5.0 E-3 \\
5.0 E-3 \\
5.0 E-3 \\
5.0 E-3\end{array}$ & $\begin{array}{l}0.0 \\
5.0 E-3 \\
4.5 E-1 \\
9.9 E-4 \\
9.0 E-2 \\
9.9 E-4 \\
9.9 E-4 \\
9.9 E-4 \\
9.9 E-4 \\
1.0 E-2 \\
1.0 E-2 \\
1.0 E-2 \\
6.0 E-4 \\
1.0 E-2\end{array}$ & $\begin{array}{l}0.0 \\
1.0 E-3 \\
3.7 E-1 \\
9.9 E-4 \\
4.0 E-3 \\
9.9 E-4 \\
9.9 E-4 \\
9.9 E-4 \\
9.9 E-4 \\
4.0 E-3 \\
4.0 E-3 \\
4.0 E-3 \\
1.2 E-3 \\
4.0 E-3\end{array}$ & $\begin{array}{l}8.0 \mathrm{E}-01 \\
2.3 \mathrm{E}-03 \\
8.0 \mathrm{E}-01 \\
8.0 \mathrm{E}-01 \\
7.0 \mathrm{E}-02 \\
1.1 \mathrm{E}-04 \\
0.0 \\
0.0 \\
2.3 \mathrm{E}-03 \\
0.0 \\
2.3 \mathrm{E}-04 \\
4.6 \mathrm{E}-04 \\
9.0 \mathrm{E}-03 \\
2.2 \mathrm{E}-02\end{array}$ \\
\hline
\end{tabular}


IABLE D.2. External Dose Factors in Person Sv/yr per $B q / n$

Atr Water Soll Burted Burted Buried Submersion Surface Surface $0.15 \mathrm{~m} \quad 0.5 \mathrm{~m} \quad 1.0 \mathrm{~m}$

$\left(n=m^{3}\right) \quad(n=L) \quad\left(n=m^{2}\right) \quad\left(n=m^{3}\right) \quad\left(n=m^{3}\right) \quad\left(n=m^{3}\right.$

\begin{tabular}{|c|c|c|c|c|c|c|}
\hline $\begin{array}{l}-14 \\
f-59 \\
e-79 \\
c-99 \\
-129 \\
h-230 \\
a-226 \\
h-222 \\
b-210 \\
i-210 \\
0-210 \\
h-232 \\
a-228 \\
c-228 \\
h-228 \\
a-224 \\
b-212 \\
j-212 \\
-234 \\
-236 \\
-235 \\
h-231 \\
a-231 \\
c-227 \\
r-223 \\
a-223 \\
-237 \\
p-237 \\
-233 \\
h-229 \\
a-225 \\
c-225 \\
-238 \\
h-234 \\
a-234\end{array}$ & $\begin{array}{l}1.41 E-11 \\
7.37 E-10 \\
1.05 E-11 \\
6.61 E-11 \\
1.55 E-08 \\
5.11 E-10 \\
6.55 E-09 \\
3.28 E-06 \\
2.16 E-09 \\
2.13 E-09 \\
1.55 E-11 \\
3.49 E-10 \\
5.40 E-14 \\
1.70 E-06 \\
2.51 E-09 \\
1.72 E-08 \\
2.26 E-07 \\
2.79 E-06 \\
3.56 E-10 \\
2.75 E-10 \\
1.67 E-07 \\
1.43 E-08 \\
5.54 E-08 \\
2.05 E-10 \\
6.96 E-08 \\
4.88 E-07 \\
2.08 E-07 \\
2.45 E-08 \\
4.17 E-10 \\
1.01 E-07 \\
1.30 E-08 \\
4.49 E-07 \\
2.43 E-10 \\
3.87 E-08 \\
3.44 E-06\end{array}$ & $\begin{array}{l}4.34 \mathrm{E}-12 \\
1.23 \mathrm{E}-10 \\
3.11 \mathrm{E}-12 \\
2.87 \mathrm{E}-11 \\
3.25 \mathrm{E}-09 \\
2.41 \mathrm{E}-10 \\
5.13 \mathrm{E}-09 \\
3.74 \mathrm{E}-06 \\
6.22 \mathrm{E}-10 \\
1.64 \mathrm{E}-09 \\
1.71 \mathrm{E}-11 \\
1.32 \mathrm{E}-10 \\
8.79 \mathrm{E}-15 \\
2.01 \mathrm{E}-06 \\
1.93 \mathrm{E}-09 \\
1.62 \mathrm{E}-08 \\
2.07 \mathrm{E}-07 \\
3.23 \mathrm{E}-06 \\
1.21 \mathrm{E}-10 \\
6.91 \mathrm{E}-11 \\
1.34 \mathrm{E}-07 \\
8.34 \mathrm{E}-09 \\
5.47 \mathrm{E}-08 \\
1.46 \mathrm{E}-10 \\
5.68 \mathrm{E}-08 \\
4.89 \mathrm{E}-07 \\
1.73 \mathrm{E}-07 \\
1.66 \mathrm{E}-08 \\
2.75 \mathrm{E}-10 \\
7.74 \mathrm{E}-08 \\
4.19 \mathrm{E}-09 \\
4.75 \mathrm{E}-07 \\
6.08 \mathrm{E}-11 \\
3.97 \mathrm{E}-08 \\
3.93 \mathrm{E}-06\end{array}$ & $\begin{array}{l}1.04 \mathrm{E}-12 \\
2.01 \mathrm{E}-10 \\
8.02 \mathrm{E}-13 \\
3.90 \mathrm{E}-12 \\
1.05 \mathrm{E}-09 \\
5.96 \mathrm{E}-11 \\
1.79 \mathrm{E}-10 \\
5.94 \mathrm{E}-08 \\
2.06 \mathrm{E}-10 \\
6.70 \mathrm{E}-11 \\
2.95 \mathrm{E}-13 \\
5.45 \mathrm{E}-11 \\
1.17 \mathrm{E}-14 \\
3.22 \mathrm{E}-08 \\
1.18 \mathrm{E}-10 \\
3.99 \mathrm{E}-10 \\
5.49 \mathrm{E}-09 \\
4.44 \mathrm{E}-08 \\
6.57 \mathrm{E}-11 \\
6.07 \mathrm{E}-11 \\
4.53 \mathrm{E}-09 \\
9.09 \mathrm{E}-10 \\
1.53 \mathrm{E}-09 \\
1.18 \mathrm{E}-11 \\
2.01 \mathrm{E}-09 \\
1.09 \mathrm{E}-08 \\
5.75 \mathrm{E}-09 \\
1.13 \mathrm{E}-09 \\
3.19 \mathrm{E}-11 \\
3.23 \mathrm{E}-09 \\
5.81 \mathrm{E}-10 \\
9.12 \mathrm{E}-09 \\
5.37 \mathrm{E}-11 \\
9.53 \mathrm{E}-10 \\
6.70 \mathrm{E}-08\end{array}$ & $\begin{array}{l}8.89 \mathrm{E}-19 \\
0.00 \mathrm{E}+00 \\
5.17 \mathrm{E}-19 \\
4.52 \mathrm{E}-17 \\
5.72 \mathrm{E}-19 \\
4.90 \mathrm{E}-16 \\
2.50 \mathrm{E}-14 \\
2.83 \mathrm{E}-10 \\
1.31 \mathrm{E}-20 \\
3.15 \mathrm{E}-14 \\
9.75 \mathrm{E}-16 \\
2.92 \mathrm{E}-16 \\
9.00 \mathrm{E}-31 \\
1.40 \mathrm{E}-10 \\
1.77 \mathrm{E}-14 \\
3.05 \mathrm{E}-13 \\
3.68 \mathrm{E}-12 \\
3.39 \mathrm{E}-10 \\
2.78 \mathrm{E}-16 \\
3.56 \mathrm{E}-18 \\
8.96 \mathrm{E}-13 \\
1.82 \mathrm{E}-14 \\
1.68 \mathrm{E}-12 \\
6.81 \mathrm{E}-16 \\
1.40 \mathrm{E}-12 \\
1.66 \mathrm{E}-11 \\
2.09 \mathrm{E}-12 \\
5.14 \mathrm{E}-14 \\
1.26 \mathrm{E}-15 \\
4.33 \mathrm{E}-13 \\
8.50 \mathrm{E}-17 \\
2.27 \mathrm{E}-11 \\
3.11 \mathrm{E}-18 \\
2.05 \mathrm{E}-12 \\
2.46 \mathrm{E}-10\end{array}$ & $\begin{array}{l}3.86 E-24 \\
0.00 E+00 \\
2.03 E-24 \\
2.44 E-21 \\
2.27 E-24 \\
1.76 E-20 \\
6.04 E-18 \\
8.70 E-12 \\
1.12 E-35 \\
1.21 E-16 \\
1.05 E-17 \\
1.07 E-20 \\
0.00 E+00 \\
2.84 E-12 \\
9.30 E-18 \\
4.70 E-16 \\
4.38 E-15 \\
2.05 E-11 \\
1.02 E-20 \\
2.64 E-26 \\
2.43 E-16 \\
3.88 E-19 \\
4.93 E-15 \\
2.51 E-20 \\
7.83 E-15 \\
8.84 E-14 \\
1.94 E-15 \\
7.12 E-18 \\
4.65 E-20 \\
1.38 E-16 \\
1.11 E-20 \\
2.76 E-13 \\
2.31 E-26 \\
3.45 E-14 \\
4.38 E-12\end{array}$ & $\begin{array}{l}3.56 E-31 \\
0.00 E+00 \\
1.33 E-31 \\
3.90 E-26 \\
1.51 E-31 \\
1.12 E-26 \\
1.65 E-21 \\
1.11 E-13 \\
0.00 E+00 \\
9.31 E-20 \\
1.89 E-20 \\
6.84 E-27 \\
0.00 E+00 \\
1.58 E-14 \\
2.96 E-22 \\
2.48 E-19 \\
8.97 E-19 \\
5.35 E-13 \\
6.52 E-27 \\
1.24 E-37 \\
7.19 E-21 \\
2.61 E-25 \\
1.54 E-18 \\
1.60 E-26 \\
9.46 E-18 \\
9.54 E-17 \\
3.57 E-19 \\
1.99 E-22 \\
2.96 E-26 \\
4.22 E-21 \\
3.08 E-25 \\
1.48 E-15 \\
1.04 E-37 \\
1.39 E-16 \\
2.53 E-14\end{array}$ \\
\hline
\end{tabular}


密余最

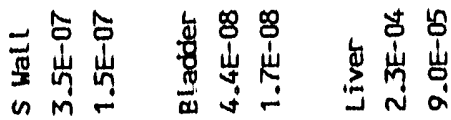

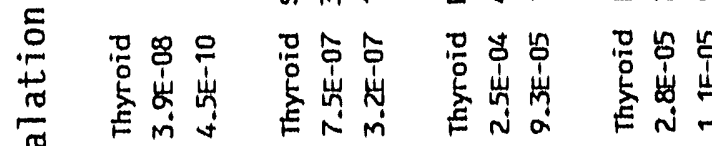

蛋

D

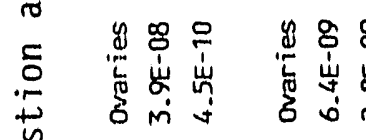

岂

巳嵒虽

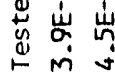

중 웅

雚出

$\propto \dot{m}$

点 8

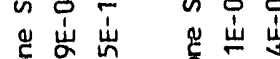

品的安

芒窝

苍思离

y虽㟔

Ð

항 영

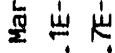

$\alpha$ is

o 8

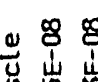

尊峲

\&

苟岁岕

y

岁幽岀

है

举岀崫

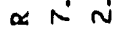

点 各品

总岀厥

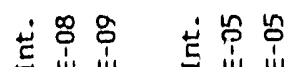

总总㟔

电贻

点岕岕

斗总总

琶管等

$\propto \infty \dot{m}$

点 $\overline{0}$

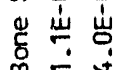

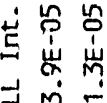

」实岕

点贺虽

芒思离号

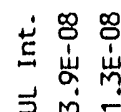

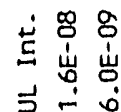

$\infty$ 음

o 0

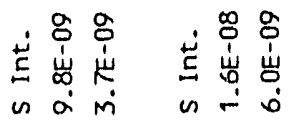

ज行

总是足

\& 응

罗峜点

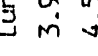

ט I

$\pm$
ธิธิธิธ丶㇀

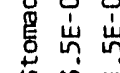

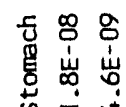

o \%

思总

$\infty$

罗岕岕

$$
0 x
$$

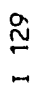

in

总贻

宸岕禽

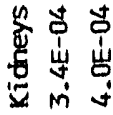

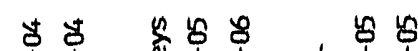

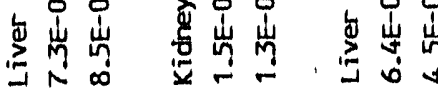

18. 告

惫岗㟧

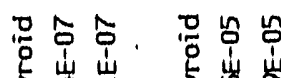

崖岁

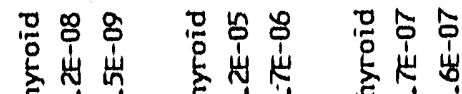

능

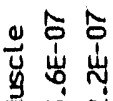

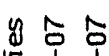

崖出

y莒站

岛㟧

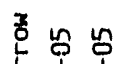

零岁岁

$\alpha$ in $m$

点 ¿

岁耑

00

它草是

岁岕岕

$\infty 8$

(c)

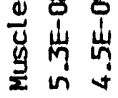

氙点岕

y 4 告

yㅇㅇㅇ

y 녕 8

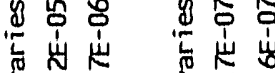

"㟧岁岕岕

ठำ

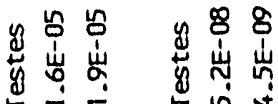

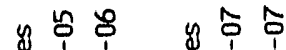

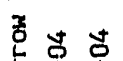

\section{o}

重离㞻

焉岀嵌

点口品

点 8

造岕岕

总㟧岕

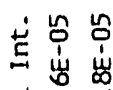

$\dot{0} 5$

岁岕㟧

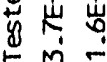

ํํㄴ 웅 훈

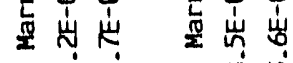

$\alpha \div \infty$ a

与 0

急就台

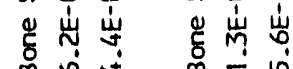

岀岕

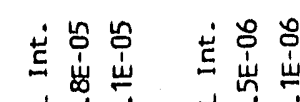

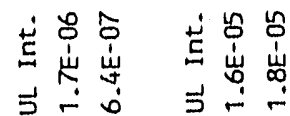

峛岁

J

$J$ in

芒芯全

芑莒营

ن웅

د

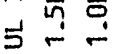

$\Rightarrow$

苍点草

壳莒点点

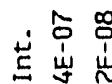

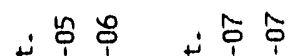

点岁㤩出总

un

的-

n - $m$

क -2

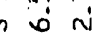

点余全

5 4 告

总虬出

fo $⿻$

당 눙

总峜

与ํㅗ

崖

舟

疑

농

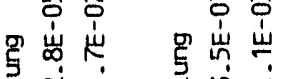

篹晏

罗峲

罗点

-

$0 x$

$0 x$

जI

号

음

용

㟧

ธิธ

罗岕

(1) $x$

N 
密号总

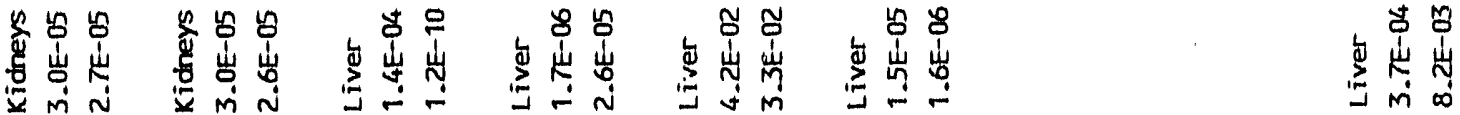

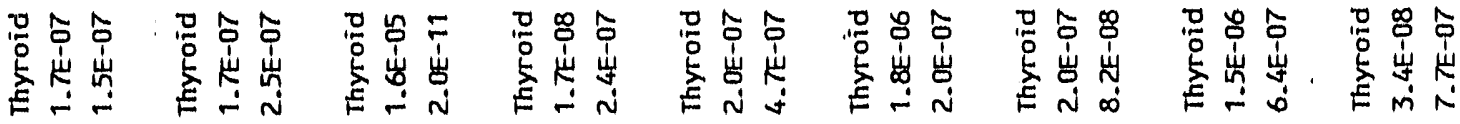

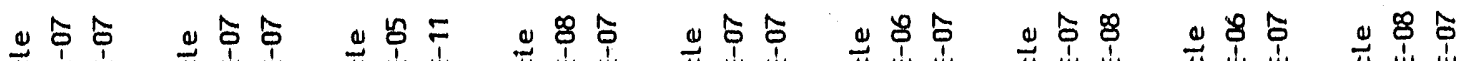

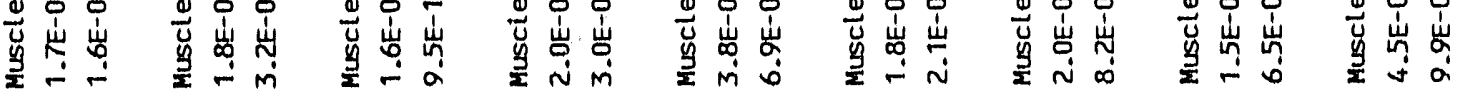

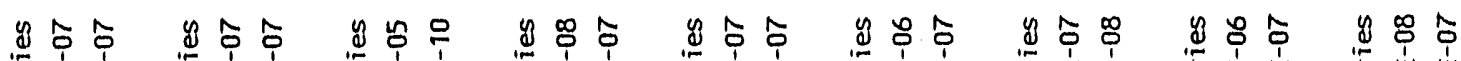

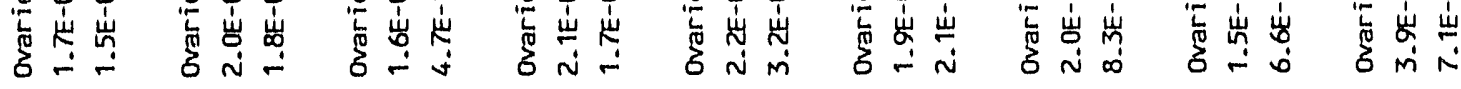

ఫิy

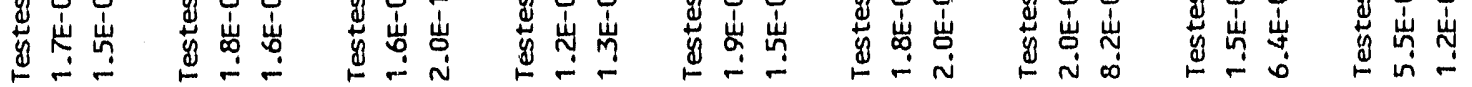

志

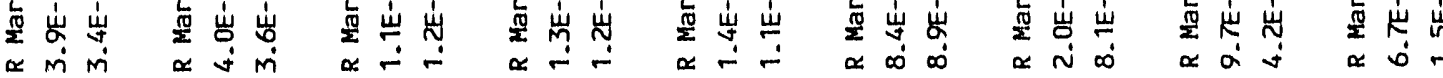

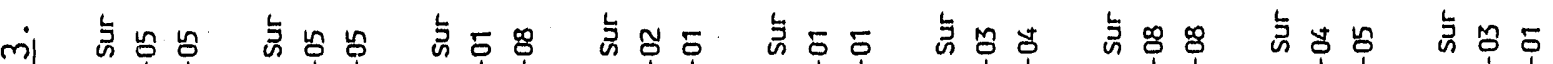

అ.

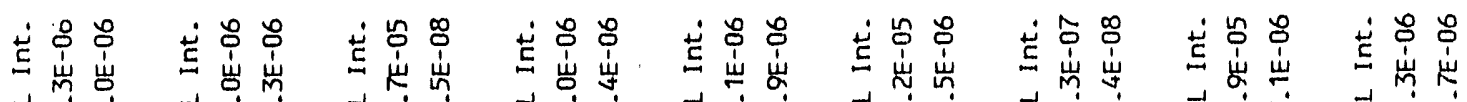

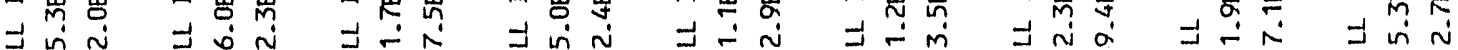

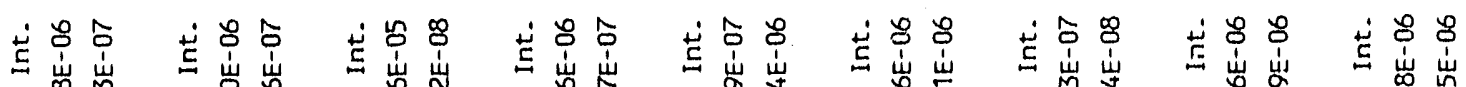

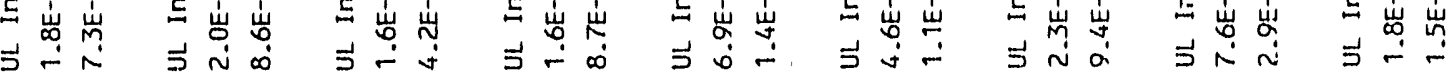

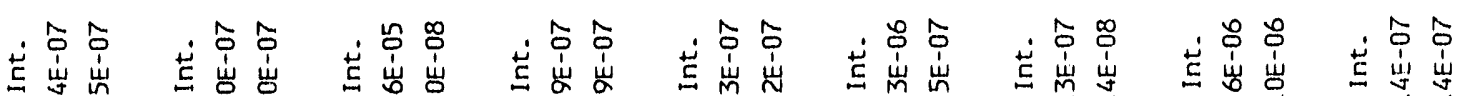

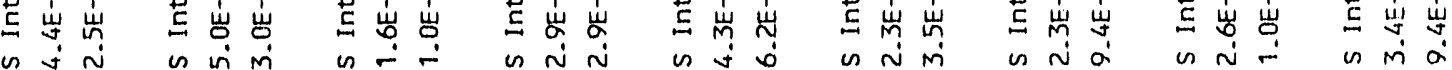

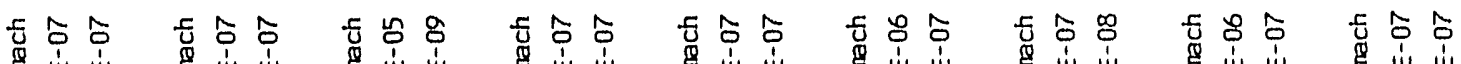

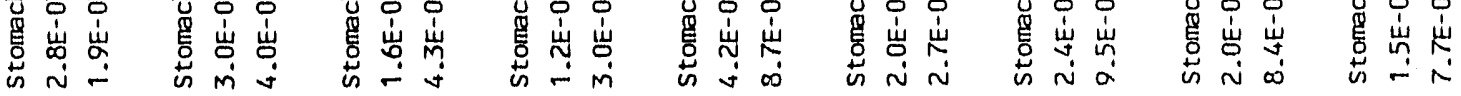

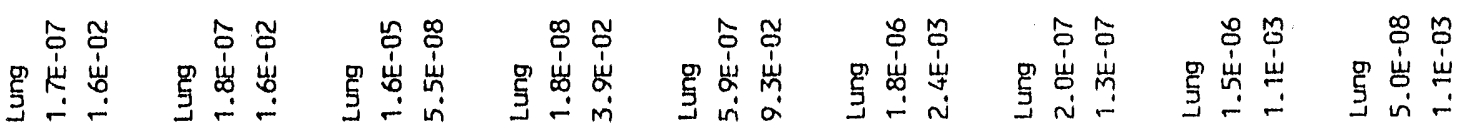

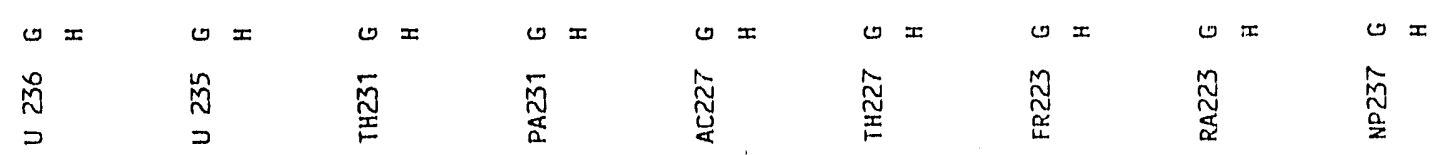




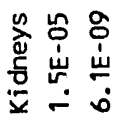

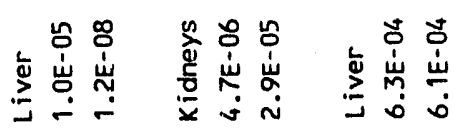

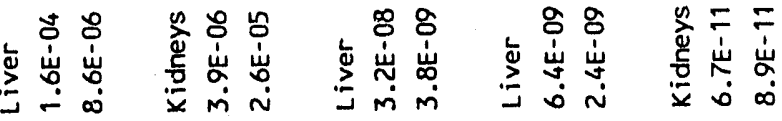

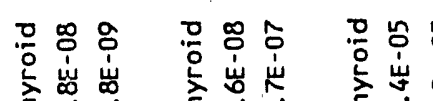

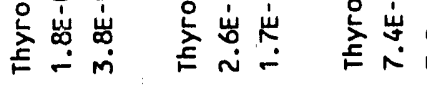

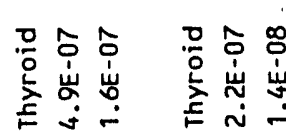

To

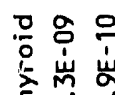

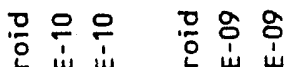

옹

害崖离

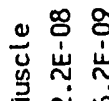

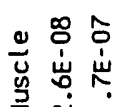

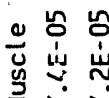

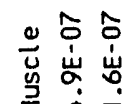

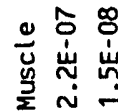

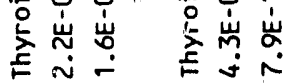

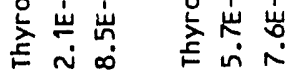

\&

\&

in

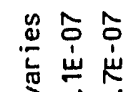

\section{ڤิำ}

空岂岀

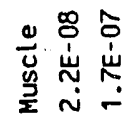

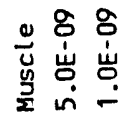

ㅇㅇ o o 8

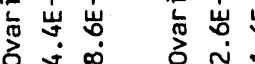

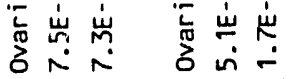

\&

\&

产出出

究息

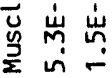

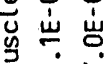

\& 0 o

管

$\infty$

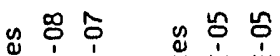

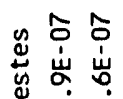

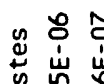

过

总

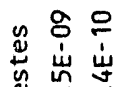

g के के

○ற

ir

只

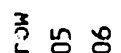

혼 능

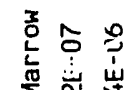

운

훈

它莨旁

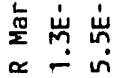

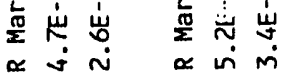

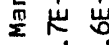

$\alpha \stackrel{\sim}{\sim} \alpha \dot{0}$

$\propto \sim$

点过骂

急宁的

今

$\alpha-$

零岁

인

今े

弆可可

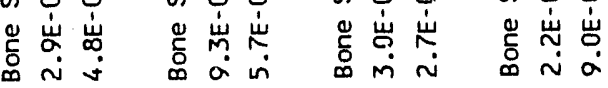

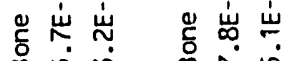

点客号

5

需峲耑

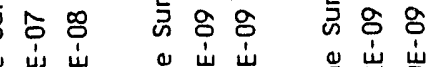

它号产

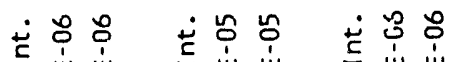

唯

的

品岱

岕岕

苍岀

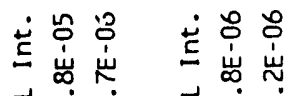

送号

نे

$\sqsupset \stackrel{\infty}{\sim} \underset{\infty}{\infty}=\stackrel{\infty}{\sim} \underset{\sim}{\sim}$

J筞

岕䋇

岁嵌

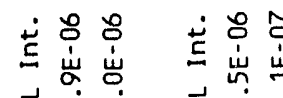

苍总食

它舒品

-

恙总

宅究

芒苍

芒莣忘

与

כ穴

5 -

د

गิ

吉孚

与 m

용

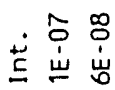

$\dot{0} \hat{i} \hat{i}$

㭊

产全

送草总

苍食虽

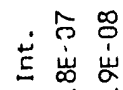

$\dot{0} \begin{gathered}0 \\ \dot{1} \\ \mathrm{H}\end{gathered}$

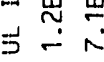

.

든ํํㅇ

करr

的岁积

⿰ N in w $\sim$

" N

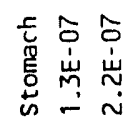

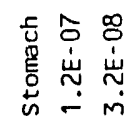

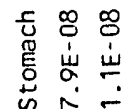

용

동

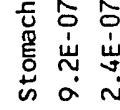

\%

o

o

\&

क :

농

옹

웅

号芫总

号岕岕

올 峑

$0 x$

$0 x$

क ज

$0 x$ ox

$0 x$

$0 x$

$0 x$

$0 x$

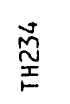

$\stackrel{\text { Nิ }}{a}$

岳 8 o

$\underset{\varpi}{\stackrel{\sim}{\approx}}$

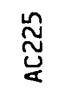

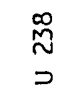

D. 5 


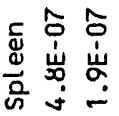

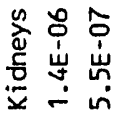

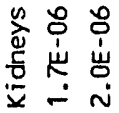

今o

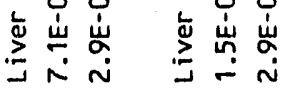

mo

8

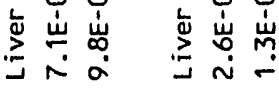

ชั ำ

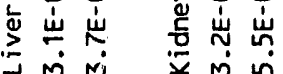

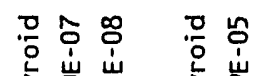

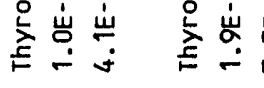

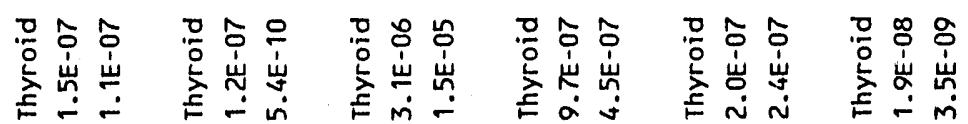

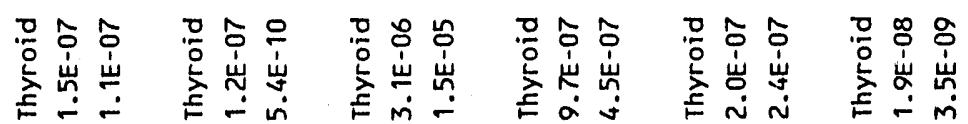

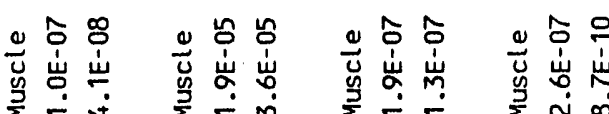

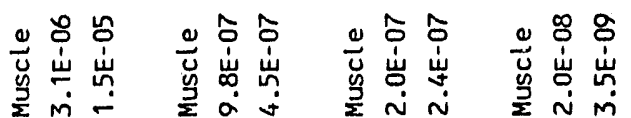

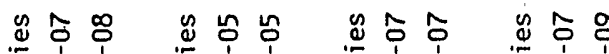

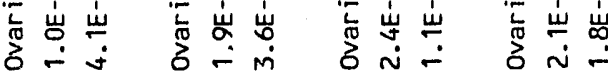

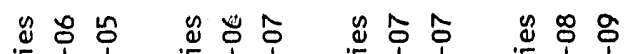

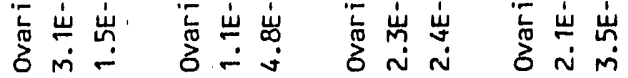

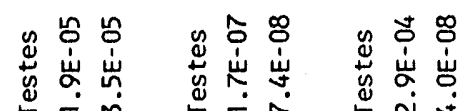

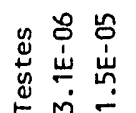

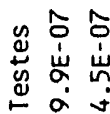

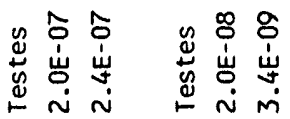

勇余品

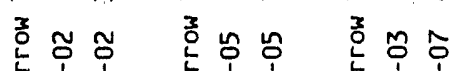

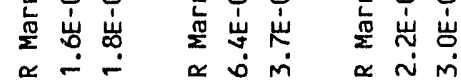

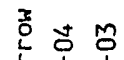

วิ용

วิ

?인

$\propto \div$

点 号

管

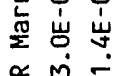

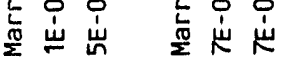

m.

点 $\overline{0}$

急吉政

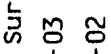

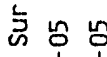

号

今ั

总 岀

气 岁

气̊

崖岕点

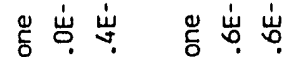

容岕㟧

宅食品

台贺

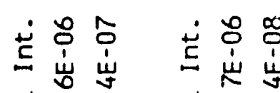

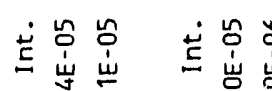

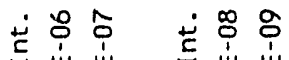

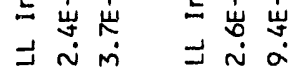

$=\stackrel{-}{-}$

J岕崖

J嵌

送号定

它总晏耑

它全禽

芒迢品

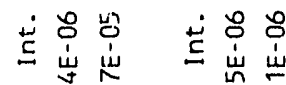

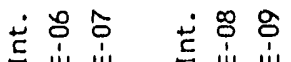

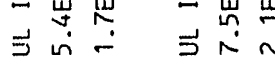

כ岁 岁

J㟧㟋

莣点离

is 0 i

. นิㅇํㅇ

芒莣 莒

ㅇㅇㅇ

율

웅

.

. 0

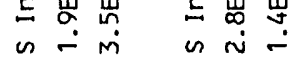

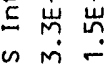

的岕崇

5 岁

的崖岕

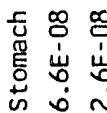

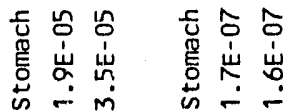

등ㅇㅇㅇ

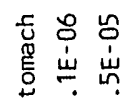

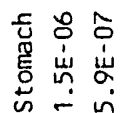

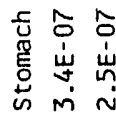

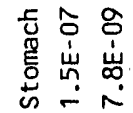

金实

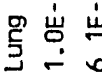

\section{กิำ}

ก

ก

8 व

กั

o

$\infty$ 웅

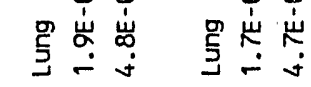

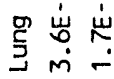

号离率

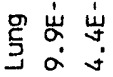

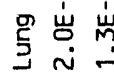

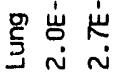

$0=$

$0 x$

$0 x$

o $x$

(1) $x$

$0 x$

$0 x$

$0 x$

点

$\stackrel{\widetilde{N}}{\underline{T}}$

$\underset{\sim}{\stackrel{\infty}{\sim}}$

$\underset{\sim}{\mathbb{U}}$

$\underset{\sim}{\stackrel{\infty}{N}}$

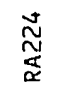

$\frac{\sim}{\pi}$

$\stackrel{\sim}{\frac{N}{n}}$ 


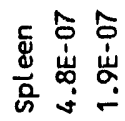

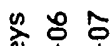

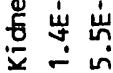

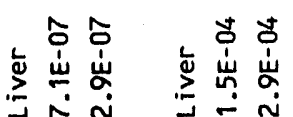

总旁总

궁

昱岕

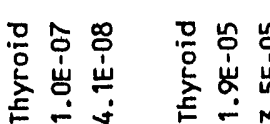

88

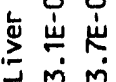

帘

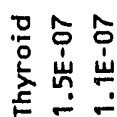

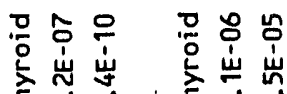

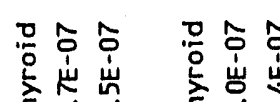

웅 웅 융

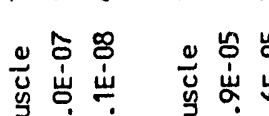

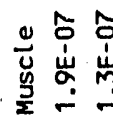

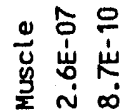

产莡总

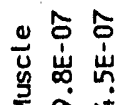

웅 용

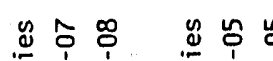

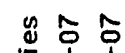

\& 0

\section{\&ั 웅}

๓ำ

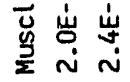

岕崖㟧

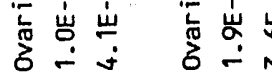

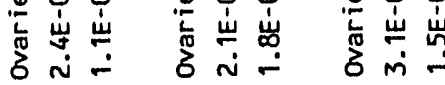

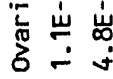

起余点

\&

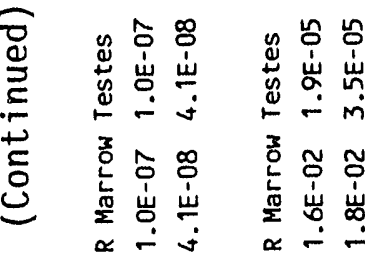

竞莣

岁岕岀

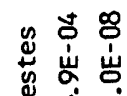

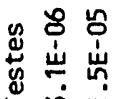

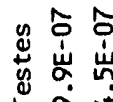

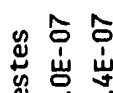

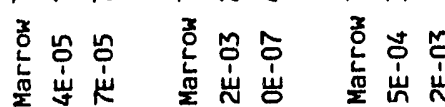

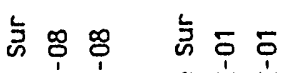

m.

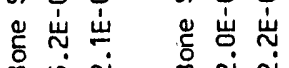

$\propto \dot{m}$

$\propto$ i m

$\alpha \stackrel{\sim}{\sim}$

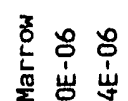

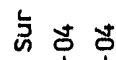

点 号 8

点

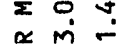

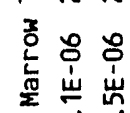

$\alpha$ i

点的骂

点貉的

芆

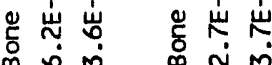

岩㞾

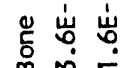

范苮㟧

\& क \&

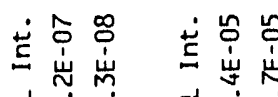

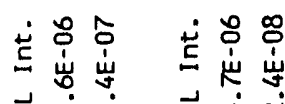

ن

능

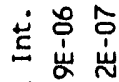

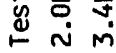

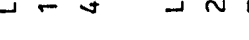

$\exists$ 우

.

」

至㟋㟋

点岕

존

誉崫

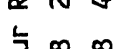

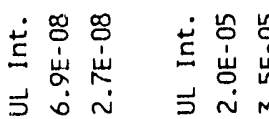

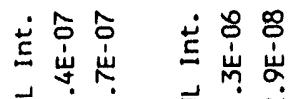

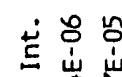

芒莣总

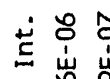

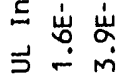

o

总岕充

苍总总

荌草莒

क m

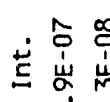

डरत

苍苔

范品品

总总总

至岩

용

三峲

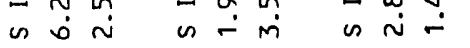

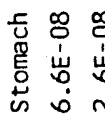

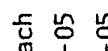

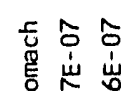

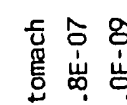

ᄃ 8 in

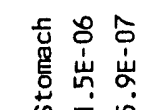

ᄃ

艺总品

与

余主

के - m

$\therefore$

实

唇苫 - in

密舒

. 0

농 응

全莒

웅

全草

응

罗离菂

罗岕㟧

守岀讪

\%

实安

与ิ

ox

号

$\underset{\tilde{n}}{\widetilde{1}}$

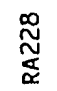

$\stackrel{\infty}{\mathbb{N}}$

$0 x$

$0 x$

$\underset{\mathbb{*}}{\stackrel{\sim}{\approx}}$

0
$\stackrel{0}{N}$
$\frac{0}{0}$

$0 x$

$\stackrel{\infty}{\underset{N}{I}}$ 


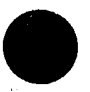

APPENDIX E

${ }^{14} \underline{C}$ TRAVEL TIME AT YUCCA MOUNTAIN 
Steven Amter

Elizabeth Behl

Benjamin Ross

May 27, 1988

Prepared for:

Pacific Northwest Laboratory

Richland, WA 99352

Prepared by:

Disposal Safety Incorporated

1629 K Street, N.W., Suite 600

Washington, DC 20006

(202) 293-3993

E. 1 


\section{CALCULATION OF CARBON-14 TRAVEL TIME A'T YUCCA MOUNTAIN}

\section{INTROCUTION}

In determining whether a high-level waste repository at Yucca Mountain, Nevada, would satisfy regulatory requirements concerning the release of radioactivity to the accessible environment, one issue that must be addressed is the transport of gaseous ${ }^{14} \mathrm{CO}_{2}$ from the repository to the surface. In this memorandum the ${ }^{14} \mathrm{CO}_{2}$ travel time for three different times after waste emplacement is calculated. The calculation depends upon a conceptual model that has two principal features:

- Gas-phase ${ }^{14} \mathrm{CO}_{2}$ moves upward through air-filled pores of the unsaturated tuffs by advection in a thermally driven air convection cell.

- An isotopic equilibrium exists between carbon dioxide in the gas phase, which is mobile, and dissolved bicarbonate, which is immobile.

To describe this systern, two quantitative inputs are needed:

- A description of the chemical environment; and

- Gas-flow velocities within Yucca Mountain.

Section 2 of this report gives a general equation for the transport of any gas in a porous medium partially saturated with water. Section 3 is a discussion of those mechanisms and terms which are neglected in the present calculation of travel time. In Section 4, the finite-difference model used to calculate gas fluxes is described. A conceptual model of the geochemical system and the calculation of a retardation factor that expresses the relationship between mobile gaseous ${ }^{14} \mathrm{CO}_{2}$ and immobile dissolved bicarbonate are the subject of Section 5. Travel times are calculated in Section 6, and Section 7 summarizes the conclusions of the report. 


\section{THEORY OF ${ }^{14} \mathrm{C}$ MIGRATION}

Thorstenson et al. (1983) point out that each isotopic species of $\mathrm{CO}_{2}$ within unsaturated-zone gas diffuses according to its own concentration gradient. Advective transfer also will depend on the local concentration of any given species, independent of the presence of other isotopes. Mass transfer among phases can, however, depend on the concentrations of other isotopic species.

\subsection{Governing Equation}

With these considerations in mind, one can write a governing equation for the concentration of any gas in the unsaturated zone. This is obtained by adding advection terms to Eq. (12) of Thorstenson et al. The equation is, in one dimension:

$-q_{\mathrm{g}} \frac{\partial C_{\mathrm{A}}}{\partial x}-q_{\mathrm{L}} \frac{\partial C_{\mathrm{A}}^{*}}{\partial x}+\tau \theta_{\mathrm{D}} D_{\mathrm{A}} \frac{\partial^{2} C_{\mathrm{A}}}{\partial x^{2}}=\theta_{\mathrm{D}} \frac{\partial C_{\mathrm{A}}}{\partial t}+\left(\theta_{\mathrm{T}}-\theta_{\mathrm{D}}\right) \frac{\partial C_{\mathrm{A}}^{*}}{\partial t}+\frac{\partial \vec{C}_{\mathrm{A}}}{\partial t}+\alpha_{\mathrm{A}}$

where

$q_{\mathrm{g}}=$ Darcy velocity of mass flow of the pore gas $(\mathrm{cm} / \mathrm{sec})$;

$q_{L}=$ Darcy velocity of liquid water flow $(\mathrm{cm} / \mathrm{sec})$;

$C_{\mathrm{A}}=$ concentration of gas $A\left(\mathrm{~mole} / \mathrm{cm}^{3}\right)$;

$C_{\mathrm{A}}^{*}=$ concentration of gas $A$ and its reaction products in the soil water (mole $/ \mathrm{cm}^{3}$ of water; note that Thorstenson et al. define this variable as a concentration per unit mass);

$\bar{C}_{\mathrm{A}}=$ concentration of substance $A$ and its reaction products in the solid phase (mole/[ $\mathrm{cm}^{3}$ of medium], where $\left[\mathrm{cm}^{3}\right.$ of medium] refers to the space occupied by solids + liquids + gases)

$x=$ dimension increasing with depth; 0 at land surface $(\mathrm{cm})$; 
$\tau=$ a tortuosity factor accounting for the added resistance to diffusion imposed by the structure of the porous medium (dimensionless);

$\theta_{D}=$ drained or gas-filled porosity (dimensionless);

$\mathrm{D}_{\mathrm{A}}=$ molecular diffusion constant for diffusion of gas $A$ into the pore gas $\left(\mathrm{cm}^{2} / \mathrm{sec}\right)$;

$t=$ time (sec);

$\theta_{\mathrm{T}} \quad=\quad$ total porosity (dimensionless);

and $\alpha_{A}=$ a production term for substance $A\left[\right.$ mole $/\left(\mathrm{cm}^{3}\right.$ of medium $\left.) / \mathrm{sec}\right]$.

In addition to the measurable parameters $\tau, \theta_{\mathrm{D}}, D_{\mathrm{A}}$, and $\theta_{\mathrm{T}}$, Equation $(2-1)$ contains five quantities that must be calculated from other models: $q_{\mathrm{L}}, q_{\mathrm{g}}, \partial C_{\mathrm{A}}{ }^{*} / \partial t, \partial \widetilde{C}_{\mathrm{A}} / \partial t$, and $\alpha_{\mathrm{A}}$. The production term $\alpha_{A}$ will, for carbon-14 originating from a repository, be obtained from waste-package models that will not be discussed here. The interphase transfer terms $\partial C_{\mathrm{A}}^{*} / \partial t$ and $\partial \vec{C}_{\mathrm{A}} / \partial t$ depend on $C_{\mathrm{A}}$, and if species $A$ is total carbon dioxide the relationship is nonlinear. The chemical models describing this relationship must therefore be incorporated into the transport model; these topics are discussed in Section 5.

Equation (2-1) requires two boundary conditions, one at the water table and the other at or near the surface.

The quantity which must be calculated to determine regulatory compliance is not the concentration $C_{\mathrm{A}}$, but the flux to the accessible environment. The mass flux of species $A$, which will de denoted $q_{A}$, can be computed from solutions to Eq. (2-1) as

$$
q_{\mathrm{A}}=q_{\mathrm{g}} C_{\mathrm{A}}+q_{\mathrm{L}} C_{\mathrm{A}}^{*}-\tau \theta_{\mathrm{D}} \frac{\partial C_{\mathrm{A}}}{\partial x}
$$

Note that in the sign convention used here, the fluxes $q$ are positive downward.

Because of the rapid gas-phase diffusional exchange of carbon dioxide between fractures and matrix, the fractured tuff can be treated with regard to migration of carbonate 
species as a porous medium in which fractures and matrix form a single continuum. The pore velocity of the water can therefore be calculated simply by dividing the flux by the total moisture content of the tuff.

Once chemical equilibrium is attained between gas and liquid, the net transport flux is the resultant of a vector addition of the gas-phase and liquid-phase fluxes. As is shown in Section 3.1, the liquid-phase flux contributes negligibly to the total. Dissolved bicarbonate can thus be treated as immobile and the $q_{\mathrm{L}}$ term from Equation $(2-1)$ can be dropped. The presence of the dissolved phase will then have the' effect of reducing the speed of carbon-14 transport by a "retardation factor" equal to the ratio of the concentration of total carbon per volume of porous medium in both liquid and gas phases to that in the gas phase alone.

Liquid-phase diffusion makes a negligible contribution to the movement of carbon species because liquid-phase diffusion constants are several orders of magnitude smaller than gas-phase constants. For this reason, no liquid-phase diffusion term has been included in Equation (2-1),

Application of Equation (2-1) to Yucca Mountain requires that one approximate the fractured tuff as a homogeneous porous medium. Whether this approximation is appropriate can be determined from the values of certain dimensionless groups involving the diffusion constant, which appear in solutions of the radionuclide transport equation (Neretnieks, 1981; Rasmuson and Neretnieks, 1981). With gas-phase diffusion, which is much faster than liquid-phase diffusion, playing a significant role, the Yucca Mountain system can be treated as a homogeneous porous medium for any reasonable combination of the parameters appearing in these groups.

\subsection{Gas Flow}

The gas advection velocity $q_{\mathrm{g}}$ at any point depends on the distribution of gils densities throughout the mountain; the gas density depends on temperature and on the partial pressures of water vapor (which in turn, depends on temperature because the relative humidity of pore gas is always close to 100\%) and carbon dioxide. Both of these gases are more concentrated in unsaturated-zone gases than in the atmosphere; water vapor is lighter than air and carbon dioxide is heavier. 
It is possible at Yucca Mountain to decouple air-flow and carbon-dioxide-transport models and solve the air-flow problems without reference to $\mathrm{CO}_{2}$. The advection velocity

$q_{\mathrm{g}}$ is essentially independent of carbon dioxide concentration because humidity and temperature effects are much greater than the density changes associated with variations in $\mathrm{CO}_{2}$ partial pressures. Temporature differences between the mountain interior and the outside arise from the damping out of daily and annual temperature variations in the subsurface, the geothermal gradient, and the heat source in the repository. The first two of these factors, combined with the topographic relief of the mountain, induce a non-negligible air flow under existing conditions (Weeks, 1987; Kipp, 1987). Another, steadier, component of air flow will be induced by repository heating and continue until the rock temperature throughout the mountain has returned to its initial temperature. The relative magnitude of these flows is calculated using a gas-flow model that is described in Section 4.

Steady air flows, such as those that result from repository heating or mean humidity differences between pore gas and atmosphere, are incorporated into Equation (2-1) through the $q_{\mathrm{g}}$ term. As shown in Section 3.4, oscillating flows due to daily and annual temperature variation may be neglected.

\section{TRANSPORT MECHANISMS NOT INCLUDED IN THE CALCULATION}

A number of mechanisms by which carbon-14 might move are not included in the calculation here. In this section the reasons for omitting these mechanisms are described.

\subsection{Liquid-phase Advection}

Because there is isotopic equilibrium between carbon-14 and other carbon isotopes, the ratio between advective carbon-14 fluxes in the liquid and gas phases will be the same as the ratio of total carbon fluxes. Liquid-phase advection of carbon-14 will therefore be negligible if the liquid-phase flux of total carbon is sufficiently smaller than the gas-phase flux.

The downward flux of liquid water is established as being less than $0.3 \mathrm{~mm} / \mathrm{yr}$, or $10^{-9} \mathrm{~cm} / \mathrm{sec}$. The liquid phase concentration of carbonate species at $27^{\circ} \mathrm{C}$ is about 1.3 $\mathrm{mmol} / \mathrm{L}$, and less at higher temperatures. This gives a downward flux of dissolved carbonate of less than $1.3 \times 10^{-15} \mathrm{~mol} \mathrm{sec}^{-1} \mathrm{~cm}^{-2}$. 
The upward gas flux is calculated below to be on the order of $10^{-8}$ to $10^{-7} \mathrm{~cm} / \mathrm{sec}$ under ambient conditions, and approximately $10^{-7}$ to $10^{-6} \mathrm{~cm} / \mathrm{sec}$ when repository heating is significant. The gas-phase concentration of carbon dioxide is about $0.04 \mathrm{mmol} / \mathrm{L}$ at $27^{\circ} \mathrm{C}$, and more at higher temperatures. This gives an upward flux of carbon dioxide of approximately $4 \times 10^{-16}$ to $4 \times 10^{-14} \mathrm{~mol} \mathrm{sec}^{-1} \mathrm{~cm}^{-2}$.

Under ambient conditions, therefore, the liquid flux of carbon is comparable to or smaller than the gas flux. During the period of repository heating, the liquid flux is at least an order of magnitude smaller.

Liquid-phase advection is therefore no larger than gas-phase advection during the period when gas-phase transport is slowest. During the time of more rapid gas-phase transport, which is the period of greatest concern, it is considerably smaller. Consequently, neglecting liquid-phase advection is an acceptable approximation.

\subsection{Diffusion}

It is well known that the time constant $T$ for a substance to move a distance $L$ by molecular diffusion in a porous medium is given by

$$
T=B L^{2} / 4 \tau D
$$

where $B$ is the retardation factor defined below, $\tau$ is the tortuosity, and $D$ is the diffusion constant. The molecular diffusion constant of carbon dioxide, corrected to ambient temperature and pressure, is about $0.17 \mathrm{~cm}^{2} / \mathrm{sec}$ or $500 \mathrm{~m}^{2} / \mathrm{yr}$. A typical value of tortuosity is 0.1 .

Using a typical travel distance of $350 \mathrm{~m}$ and a retardation factor of 70 gives a travel time of $43,000 \mathrm{yr}$ under ambient conditions. This is several times greater than the ambient-conditions travel time and much greater than travel times affected by repository heat. 


\subsection{Elow Driven by Binary Diffusion}

In the presence of a temperature gradient in the subsurface, there is a partial pressure gradient of water vapor because relative humidity in the deep subsurface is always close to $100 \%$. Because the total pressure is approximately uniform (Ross, 1984), there will be a partial pressure gradient of the other components of air (referred to here as "dry air") in the opposite direction.

Evaporation and condensation will provide a source or sink of water vapor to maintain a steady-state diffusive flow. However, the countervailing diffusion of air requires a return flow to maintain a constant partial pressure. Consequently, a mass flow of air from higher to lower temperatures will be driven by this diffusion mechanism. This flow can be neglected because it is smaller than the temperature-driven flow.

To show this, one observes that the diffusion-driven mass flow of dry air, which is approximately equal to the total diffusion-driven flow, is equal in magnitude to the diffusion flux. The volumetric gas flux due to diffusion, $q_{\mathrm{d}}$, is

$$
q_{\mathrm{d}}=\tau D n_{\mathrm{D}} \gamma \frac{1}{P} \frac{d P_{\gamma}}{d T^{1}}
$$

where $n_{\mathrm{D}}$ is the drained porosity, $\gamma$ is the temperature gradient, and $\frac{1}{P} \frac{d P_{Y}}{d T}$ is the temperature derivative of the partial pressure of saturated water vapor as a fraction of ambient pressure.

Under ambient conditions, the temperature gradient is $2 \times 10^{-4} \mathrm{~K} / \mathrm{cm}$. The derivative $\frac{1}{P} \frac{d P_{v}}{d T}$ is equal to about $2.2 \times 10^{-3} \mathrm{~K}^{-1}$ at $30^{\circ} \mathrm{C}$. Using values of other constants given in the previous section and a drained porosity of 0.05 , a gas flux of about $4 \times 10^{-10}$ $\mathrm{cm} / \mathrm{sec}$ is obtained. This is negligible compared to the temperature-driven flow. Redoing the calculation at any of the higher temperatures considered in this analysis would not change this conclusion.

\subsection{Mixing by Seasonally Alternating Elow}

The density contrast between the subsurface gas, which is at a constant temperature, and the atmosphere, which is warm in summer and cool in winter, causes seasonal buoyant 
gas flows beneath Yucca Mountain. Under ambient conditions, gas within the mountain moves upward in winter and, to a lesser extent, downward in summer. This back-and-forth gas movement will presumably cause some mixing and spreading of gas constituents. It is necessary to evaluate whether this will be a significant transport mechanism for carbon-14.

The magnitude of these seasonal flows has been calculated

using the same model as in these calculations but a different geometry. The upward component of the winter gas flux in the Topopah Spring Welded Unit is approximately $2 \times$ $10^{-6} \mathrm{~cm} / \mathrm{sec}$ or less. With a drained porosity of 0.05 and a retardation factor of 70 , this flux will move a molecule of carbon-14 a distance of $3 \mathrm{~cm}$ in 3 months. Molecular diffusion in the same time period will, according to Eq. (3-1), move the molecule a typical distance of $85 \mathrm{~cm}$. Therefore seasonal oscillatory movement is much smaller than molecular diffusion. Straightforward calculations yield the same conclusion for the overlying units.

\section{MODELING OF GAS FLOW}

A finite difference computer model was used to predict the gas flow in Yucca Mountain, a condensed description of which is contained below.

\subsection{Modeling Approach}

\subsubsection{Physical Basis}

The density of a gas is dependent upon temperature, composition, and pressure. Temperatures inside Yucca Mountain vary much less than in the surrounding atmosphere and the density of pore gas in the mountain reflects this. The composition of the gas in the mountain differs markedly from the atmosphere. Inside the mountain, the gas is generally saturated with water vapor, while the surrounding atmosphere is usually extremely dry. The gas inside the mountain also appears to contain more carbon dioxide than the atmosphere (Yang et al., 1985). Because water vapor is lighter than air, soil gas will be less dense than air at equal temperature. (The density effects of carbon dioxide are small compared to those of water vapor.) 


\subsubsection{Assumptions}

The following physical assumptions about the Yucca Mountain system under present-day conditions are well justified and simplify the problem:

1) Water vapor constitutes only a small component of the soil gas, that is, its partial pressure is much less than one bar.

2) Relative humidity in the unsaturated zone is approximately equal to $100 \%$.

3) The soil gas behaves as an ideal gas.

4) Because the compressibility of the gas is much greater than that of the rock, the rock matrix can be treated as rigid.

5) All gas-filled voids in the matrix may be treated as a single porosity because the propagation of a pressure pulse from fractures into the matrix is rapid compared to a seasonal time scale.

6) Diurnal temperature changes do not penetrate a significant distance into the mountain (Montazer et al., 1985), nor does the resulting change of gas pressure.

7) Changes in the partial pressure of water vapor are accommodated by changes in gas composition, with total pressure remaining nearly constant (Ross, 1984). This implies, for examples, that a rise in temperature evaporates additional water (relative humidity remains at $100 \%$ ), increasing both the mass of water in the vapor state and the vapor pressure, but the partial pressure of air decreases almost equally (air flows out of the elemental volume) and total pressure remains nearly constant.

Three additional assumptions are made, although they are somewhat conjectural in nature.

8) Gas pressures in the mountain are at equilibrium with seasonal temperature trends (i.e., temperature variations on time scales of days or weeks have negligible effect, but changes in pressure track seasonal temperature trends with no significant time delay).

9) The unsaturated zone stays at constant saturation. This implies that there is a source of water that replenishes water lost to evaporation and mixing with drier air from the surrounding atmosphere. The water source is probably some combination of precipitation and upward flow from the water table.

10) Molecular diffusion resulting from gradients of water vapor partial pressure has a negligible effect on gas flow. 
These assui ptions make possible some important simplifications in the governing equations. Assumptions (6), (8), and (9) allow the gas flow during any season to be calculated as a steady-state flow, with the air pressure at the surface an average over diurnal and weather-related fluctuations. The flow equations need be solved only in the subsurface; atmospheric pressure as a function of elevation can be calculated explicitly from the temperature and humidity and applied as a boundary condition.

Assumptions (2), (3), and (7) allow one to calculate the properties of the soil gas (density in particular) as a function of pressure and temperature. The equation used here to calculate gas flow is therefore derived on the assumption that temperature is known as a function of position.

\subsubsection{Numerical A.pproach}

Like water, air may flow in response to gradients of a number of fields, including temperature, density, pressure, gravitational potential, and chemical composition. However, gas is much more compressible than water, and density changes that result from variations in temperature and pressure are much more pronounced. This constrains the application of simplifying assumptions (such as isothermal conditions) that "de-couple" the equations.

Analysis of gis flow in the subsurface therefore begins from a system of equations that describe the coupled effects of temperature, pressure, and density. The system of governing equations is expanded around reference values of temperature, pressure, and density. In doing so, the leading gravity and pressure-gradient terms are explicitly canceled. This process yields a single elliptic partial differential equation for a variable which resembles the "fresh-water head" sometimes used by field hydrogeologists (Lusczynski, 1961). The equation is not Laplace's or Poisson's equation; it involves first-derivative terms. Here, it is solved by the finite-difference method.

In this approach, the treatment of boundaries requires special attention. The presence of first-derivative and constant terms in the governing equation rules out some frequently used techniques such as reflection at no-flow boundaries. Because permeability gradients are explicitly factored out as separate terms in order to facilitote elimination of small terms, permeability variations cannot be incorporated directly into the finite-difference expression 
for the divergence (as described by Freeze and Cherry, 1979, Appendix IX). Instead, special finite-difference formulations are developed for boundaries. These are simplified somewhat by the use of node-centered rather than block-centered finite differences. This approach does have the advantage of making explicit the approximations in the treatment of the boundaries.

\subsubsection{Fundamental Equations}

The assumptions described in the previous section allow the specification of a system of five equations in five unknowns, from which a single governing (point) equation will be obtained. The five unknowns are gas pressure, gas density, and three components of Darcy velocity or volumetric flux. The five equations are a volume balance equation, three components of Darcy's law which relates flux to applied forces, and a constitutive relation which specifies density as a function of pressure and temperature. A volume balance equation, rather than the more usual mass balance, is used because Darcy's law gives a volumetric flux rather than a mass flux.

The volume balance equation is

$$
\nabla \cdot \mathrm{q}=\mathbf{q} \cdot\left[\left[\frac{1}{T}+\frac{1}{P_{\mathrm{a}}} \frac{d P_{\mathrm{v}}}{d T}\right] \nabla T-\frac{1}{P_{\mathrm{a}}} \nabla P\right]
$$

The constitutive relation is

$$
\rho=\frac{P_{\mathrm{v}} \Omega_{\mathrm{v}}+\left(P-P_{\mathrm{v}}\right) \Omega_{\mathrm{a}}}{R T}
$$

Darcy's Law is

$$
\mathbf{q}=-\frac{k}{\mu}(\nabla P-g \rho \hat{\mathbf{z}})
$$

From these basic equations, the following governing equation can be derived 


$$
\begin{aligned}
\nabla 2 P^{\prime}+\nabla P^{\prime} & {\left[\frac{1}{k} \nabla k-\left[\frac{1}{\mu} \frac{\partial \mu}{\partial T}+\frac{1}{T_{\mathrm{o}}}+\frac{1}{P_{\mathrm{a}}} \frac{d P_{\mathrm{v}}}{d T}\right] \nabla T\right]-\frac{g}{k} \rho^{\prime} \frac{\partial k}{\partial z} } \\
+g & {\left[\left[\frac{\rho_{\mathrm{o}}}{T}+\frac{\Omega_{\mathrm{a}}-\Omega_{\mathrm{v}}}{R T} \frac{d P_{\mathrm{v}}}{d T}\right]+\rho^{\prime}\left[\frac{1}{\mu} \frac{\partial \mu}{\partial T}+\frac{2}{T_{\mathrm{o}}}+\frac{1}{P_{\mathrm{a}}} \frac{d P_{\mathrm{v}}}{d T}\right]\right] \frac{\partial T}{\partial z} } \\
& -g^{2} \rho_{\mathrm{o}}\left[\frac{\Omega_{\mathrm{a}}}{R T}+\frac{\rho^{\prime}}{P_{\mathrm{a}}}\right]=0
\end{aligned}
$$

where

$$
\begin{aligned}
& \rho^{\prime}=\left[\frac{P_{\mathrm{v}} \Omega_{\mathrm{v}}+\left(P_{0}+g \rho_{0} z+P^{\prime}-P_{\mathrm{v}}\right)}{R T}-\rho_{0}\right]=\rho-\rho_{0} \\
& P^{\prime}=P-P_{0}-\rho_{0} g z
\end{aligned}
$$

$q$ is the specific flux

$P$ is pressure

$k$ is intrinsic permeability

$\mu$ is dynamic viscosity

$T_{\mathrm{o}}$ is a reference temperature

$P_{\mathrm{a}}$ is the partial pressure of dry air

$P_{\mathrm{v}}$ is vapor pressure of water

$T$ is temperature

$g$ is the gravitational constant

$\rho$ is the gas density

$\rho_{0}$ is a reference gas density

$\Omega_{\mathrm{a}}$ is the molecular weight of dry air

$\Omega_{\mathrm{v}}$ is the molecular weight of water vapor

$R$ is the universal gas constant

$z \quad$ is the elevation below a datum

$\hat{\mathbf{z}}$ is a downward-pointing unit vector

An equation that gives the flux is

$$
\mathrm{q}=\frac{k}{\mu}\left[\nabla P^{\prime}-g\left[\frac{P_{\mathrm{v}} \Omega_{\mathrm{v}}+\left(P_{\mathrm{o}}+g \rho_{\mathrm{o}} z+P^{\prime}-P_{\mathrm{v}}\right) \Omega_{\mathrm{a}}}{R T}-\rho_{\mathrm{o}}\right] \hat{\mathbf{z}}\right]
$$




\subsubsection{Boundary Conditions}

The gas flow system has two types of boundary conditions. The first is a Dirichlet condition along the atmospheric boundary of the mountain. The second is a Neumann condition corresponding to no flow across the base of the Topopah Spring Member. No-flow boundaries are also used for convenience in the subsurface portions of the lateral boundaries of the model.

The atmospheric boundary condition is

$$
P^{\prime}=P_{\mathrm{o}} \exp \left\{\left[\Omega_{\mathrm{a}}+\eta \frac{P_{\mathrm{v}}}{P_{\mathrm{o}}}\left(\Omega_{\mathrm{v}}-\Omega_{\mathrm{a}}\right)\right] \frac{g z}{R T}\right\}-P_{\mathrm{o}}-\rho_{\mathrm{o}} g z
$$

where $\eta$ is the relative humidity.

From the flux equation, the condition for no flow across an arbitrary plane is

$$
\mathbf{q} \cdot \hat{\mathbf{n}}=-\frac{\mathrm{k}}{\mu}\left[\frac{\partial P^{\prime}}{\partial n}-g \rho^{i} \hat{\mathbf{z}} \cdot \hat{\mathbf{n}}\right]=0
$$

where $\hat{\mathbf{n}}$ is a unit vector normal to the boundary.

\subsubsection{Construction of the Finite Difference Grid}

Figure 4-1 (adapted from Sinnock, 1988) is a cross-section of the simulation region. The location of the cross-section is shown on Figure 4-2. The mountain has a number of layers dipping approximately six degrees to the east, with varying intrinsic permeabilities. The simulation region is surrounded by two boundary conditions:

- The mountain's atmospheric contact along its surface.

- No-flow conditions along the base, which lies a small distance above the less permeable non-welded and bedded tuff, and portions of the sides.

The no-flow condition at the base of the simulated region may have a physical basis because the permeability contrast would tend to keep inflow from Solitario Canyon largely horizontal. The vertical no-flow boundaries have been chosen for convenience. 


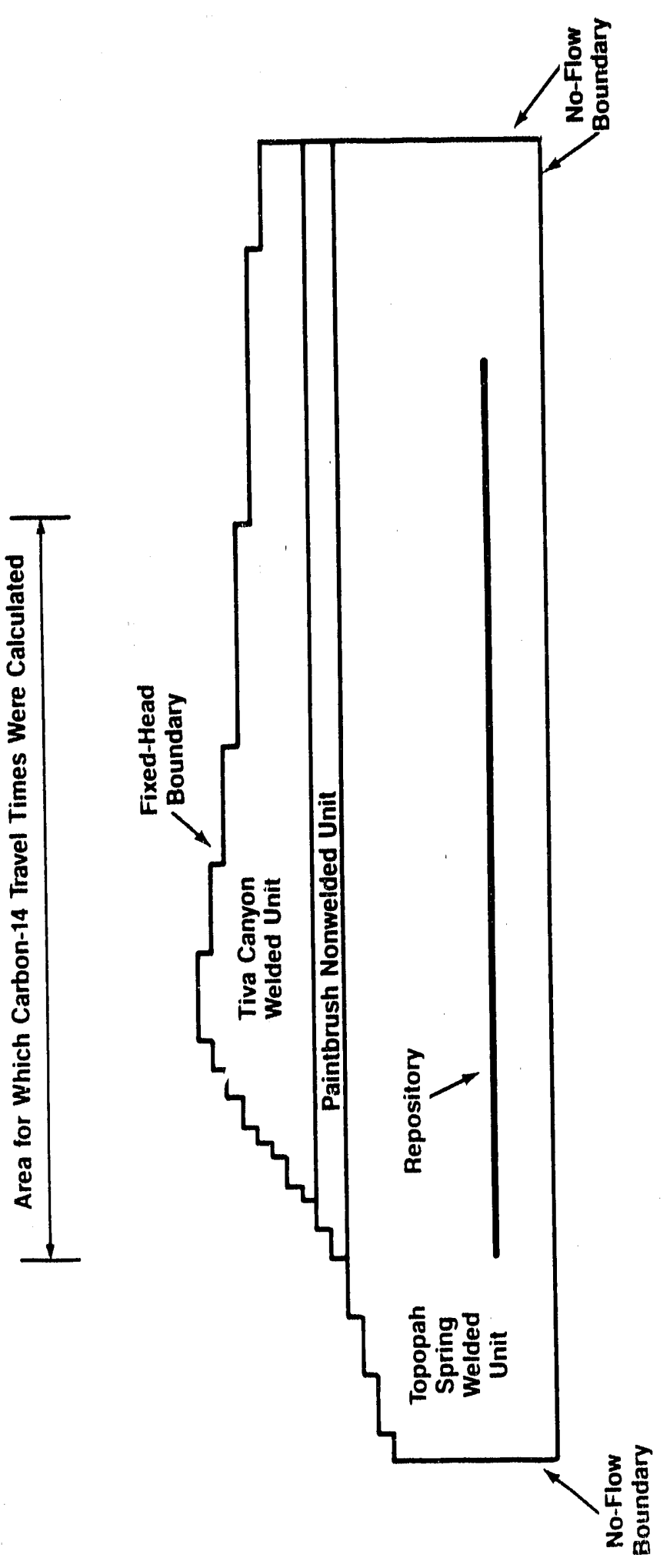

Figure 4-1. Cross-section used in simulation. 


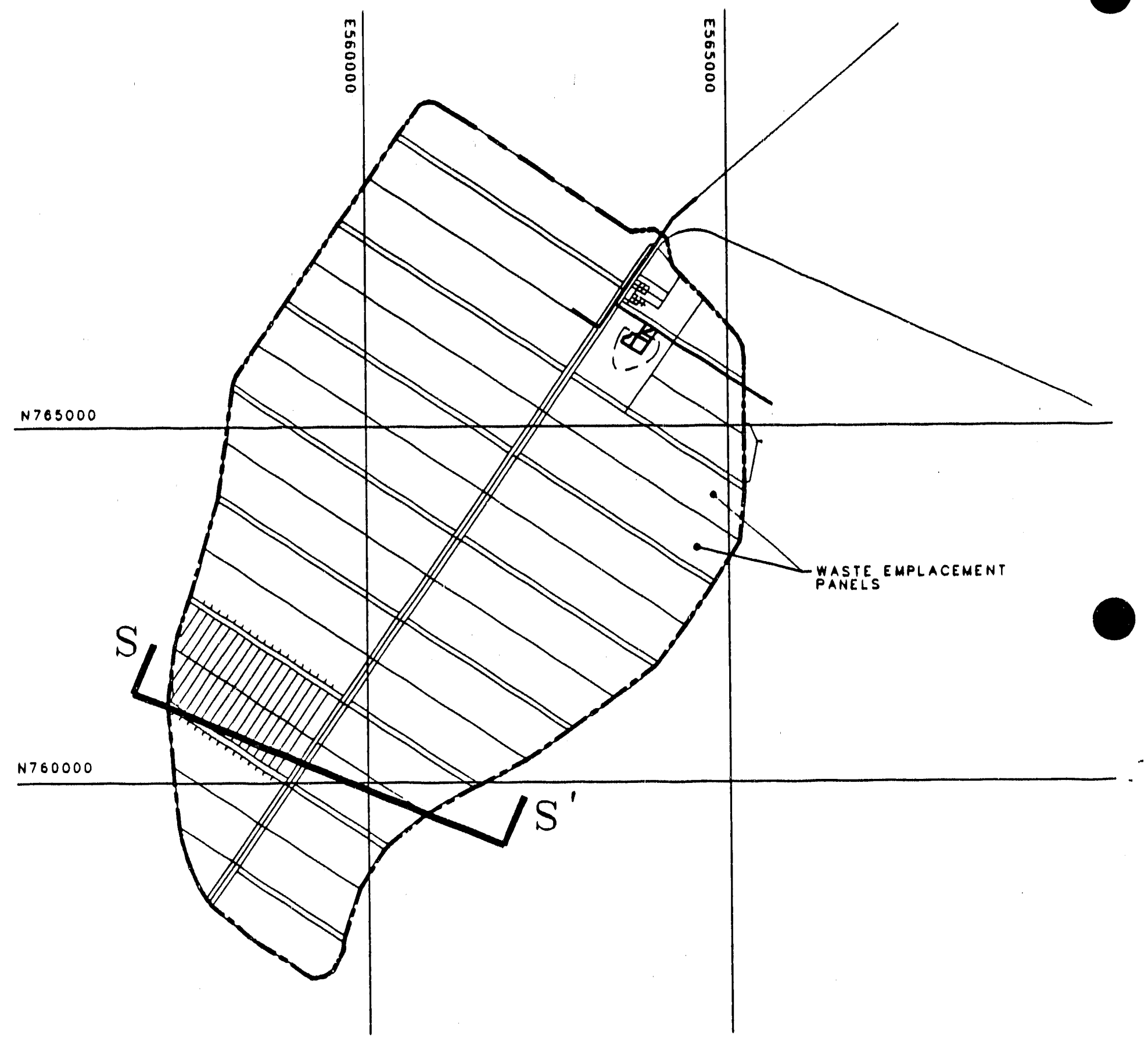

Figure 4-2. Location of cross-section used in simulation. Cross section extends along line SS', and to the west of S. 
A grid of approximately 2000 nodes, defining square blocks 20 meters on a side, was constructed for the finite difference simulation. The grid was oriented parallel to the bedding to simplify the implementation of internal layering and external boundary conditions.

\subsection{Temperatures}

Most published calculations of far-field temperatures for a Yucca Mountain repository consider only thermal conduction as a heat transfer mechanism, neglecting the transport of latent heat by the water vapor in flowing subsurface gas. It would be inconsistent to use temperatures calculated in this way in a calculation of gas flow. Consequently, temperatures were estimated for these calculations by extrapolating calculations by Tsang and Pruess (1987) that do take latent heat into account.

Temperature values during the thermal period were obtained as follows. From Tsang and Pruess, the repository temperature at $1000 \mathrm{yr}$ after closure was taken to be $53^{\circ} \mathrm{K}$ above pre-emplacement temperatures at the same elevations. The temperature increase $\Delta \mathrm{T}\left({ }^{\circ} \mathrm{K}\right)$ at nodes located above or below the repository at 1000 years was given by

$$
\Delta T(1000)=53 \frac{L}{S}
$$

where $L$ is the distance from the node to the repository and $S$ is the distance from the repository to the surface, both measured along a line perpendicular to the repository plane passing through the node.

At later times, the temperature increase was reduced in proportion to the decay of the heat source. This is equivalent to assuming that the time for the system to reach steady state is small compared to the times over which the heat source changes, and that heat transfer coefficients are temperature-independent. Thus at any grid block

$$
\Delta T(t)=\Delta T(1000) \frac{P(t)}{P(1000)}
$$


where time $t$ is measured in years and the heat source $P(t)$ is given by

$$
\begin{array}{ll}
P(t)=\sum_{\mathfrak{n}} A_{\mathfrak{n}} e^{-B_{n} t} & \\
\mathrm{~A}_{1}=11.226 & \mathrm{~B}_{1}=2.8283 \times 10^{-5} \\
\mathrm{~A}_{2}=15.852 & \mathrm{~B}_{2}=1.2949 \times 10^{-4} \\
\mathrm{~A}_{3}=155.78 & \mathrm{~B}_{3}=1.7590 \times 10^{-3}
\end{array}
$$

Three additional terms given by Mansure are omitted here because they are negligible at times of $1000 \mathrm{yr}$ or greater. Mansure describes this formula as accurate to $50,000 \mathrm{yr}$.

Ambient temperatures $T$ are calculated from

$$
T=T_{\mathrm{u}}+0.02 S_{\mathrm{p}}
$$

where $\quad T_{\mathrm{a}} \quad$ is the air temperature measured on the mountain peak

$S_{\mathrm{p}} \quad$ is the difference in elevation between the node and the mountain peak

0.02 is the geothermal gradient measured in boreholes at Yucca Mountain (Montazer et al., 1985) in ${ }^{\circ} \mathrm{K} / \mathrm{m}$.

To the extent that heat transfer at $1000 \mathrm{yr}$ has not reached steady state, and that heat transfer becomes less efficient at declining temperatures, this approach will underestimate temperatures. On the other hand, temperatures will be overestimated to the extent that the 1000-yr temperatures calculated by Tsang and Pruess (1987) are affected by their use of a gas permeability several orders of magnitude smaller than assumed here and the omission from their model of the enhancement of water-vapor diffusion by the "liquid island" effect (see Jury and Letey, 1979). The relative importance of these errors is unknown.

\subsection{Input Values}

With the exception of internal temperature, each simulation used the same input values, listed in Table 4-1, for constants. Reference values have been computed at $z=0$, 
located inside the mountain at approximately 375 meters below Yucca Mountain crest at an altitude of 1,075 meters. The external air temperature of $294^{\circ} \mathrm{K}$ was chosen to be an approximate yearly average.

\subsection{Results}

Four simulations were run: pre-repository ambient conditions, 2,000, 10,000, and 50,000 years, generating vertical and horizontal fluxes of gas within the mountain. As expected, the 2,000 year (repository temperature approximately $330^{\circ} \mathrm{K}$ ) simulation yielded the largest vertical fluxes, while the ambient conditions simulation yielded the smallest; the difference exceeded an order of magnitude. Flow vectors for the four simulations are shown in Figures 4-3 through 4-6.

\section{CHEMICAL MODELING}

To estimaie the time that it will take carbon-14 to migrate from the repository to the surface, the effects of chemical interactions between the gas and the media through which the gas flows must be considered. At Yucca Mountain the the reactions between the gas, liquid, and solid phases will be complex, depending upon chemical parameters such as the partial pressures of gases, temperature, ion concentrations, solution $\mathrm{pH}$, ionic strength, mineral phases present, and the concentrations of carbon isotopes. The overall effect of chemical interactions in the unsaturated zone system will be to retard the migration of carbon-14.

\subsection{Conceptual Model}

The geochemical conceptual model presented below is based upon observed characteristics of the geology and aqueous chemistry at and near Yucca Mountain. Data limitations placed significant constraints upon the model that are reflected in its underlying assumptions. Although a comprehensive geochemical model should account for all chemical reactions, such a model is not possible at present because it would require a larger data base than is presently available. 
TABLE 4-1

Values of Input Constants

\begin{tabular}{|c|c|c|}
\hline Parameter & Symbol & Value \\
\hline external temperature & $\mathrm{T}_{\mathrm{e}}$ & $294^{\circ} \mathrm{K}$ \\
\hline reference density of air & $\rho_{0}$ & $0.1007 \mathrm{~g} \mathrm{~cm}^{-3}$ \\
\hline reference temperature & $\mathrm{T}_{\mathrm{o}}$ & $300^{\circ} \mathrm{K}$ \\
\hline reference pressure & $\mathrm{P}_{\mathrm{o}}$ & 880,521 dyn $\mathrm{cm}^{-2}$ \\
\hline reference viscosity & $\mu_{0}$ & $1.86 \times 10^{-4} \mathrm{~g} \mathrm{~cm}^{-1} \mathrm{~s}^{-1}$ \\
\hline $\mathrm{T}$-dependent viscosity change & $\frac{d \mu}{d T}$ & $3.5 \times 10^{-7} \mathrm{~g} \mathrm{~cm}^{-1} \mathrm{~s}^{-1}{ }^{\circ} \mathrm{K}^{-1}$ \\
\hline atmospheric relative humidity at $\mathrm{z}=0$ & $\eta$ & $20 \%$ \\
\hline gravitational constant & g & $980 \mathrm{~cm} \mathrm{~s}^{-1}$ \\
\hline universal gas constant & $\mathbf{R}$ & $8.31 \times 10^{-7} \mathrm{~g} \mathrm{~cm}^{2} \mathrm{~s}^{-2} \mathrm{~mol}^{-1}{ }^{\circ} \mathrm{K}$ \\
\hline gmw of air & $\Omega_{\mathrm{a}}$ & $28.96 \mathrm{~g} \mathrm{~mol}^{-1}$ \\
\hline gmw water & $\Omega_{\mathrm{v}}$ & $18.02 \mathrm{~g} \mathrm{~mol}^{-1}$ \\
\hline node spacing & $\mathrm{D}$ & $2,000 \mathrm{~cm}$ \\
\hline angle of dip & $\theta$ & $6 \mathrm{deg}$ or 0.10472 radians \\
\hline geothernal gradient & & $2^{\circ} \mathrm{K}$ per 100 meters \\
\hline $\begin{array}{l}\text { intrinsic permeability of the Tiva } \\
\text { Canyon and Topopah Spring Members }\end{array}$ & $\mathrm{k}_{\mathrm{a}}, \mathrm{k}_{\mathrm{c}}$ & $1.2 \times 10^{-7} \mathrm{~cm}^{2}$ \\
\hline $\begin{array}{l}\text { intrinsic permeability of the } \\
\text { non-welded and bedded tuff }\end{array}$ & $\mathrm{k}_{\mathrm{b}}$ & $1.2 \times 10^{-8} \mathrm{~cm}^{2}$ \\
\hline
\end{tabular}




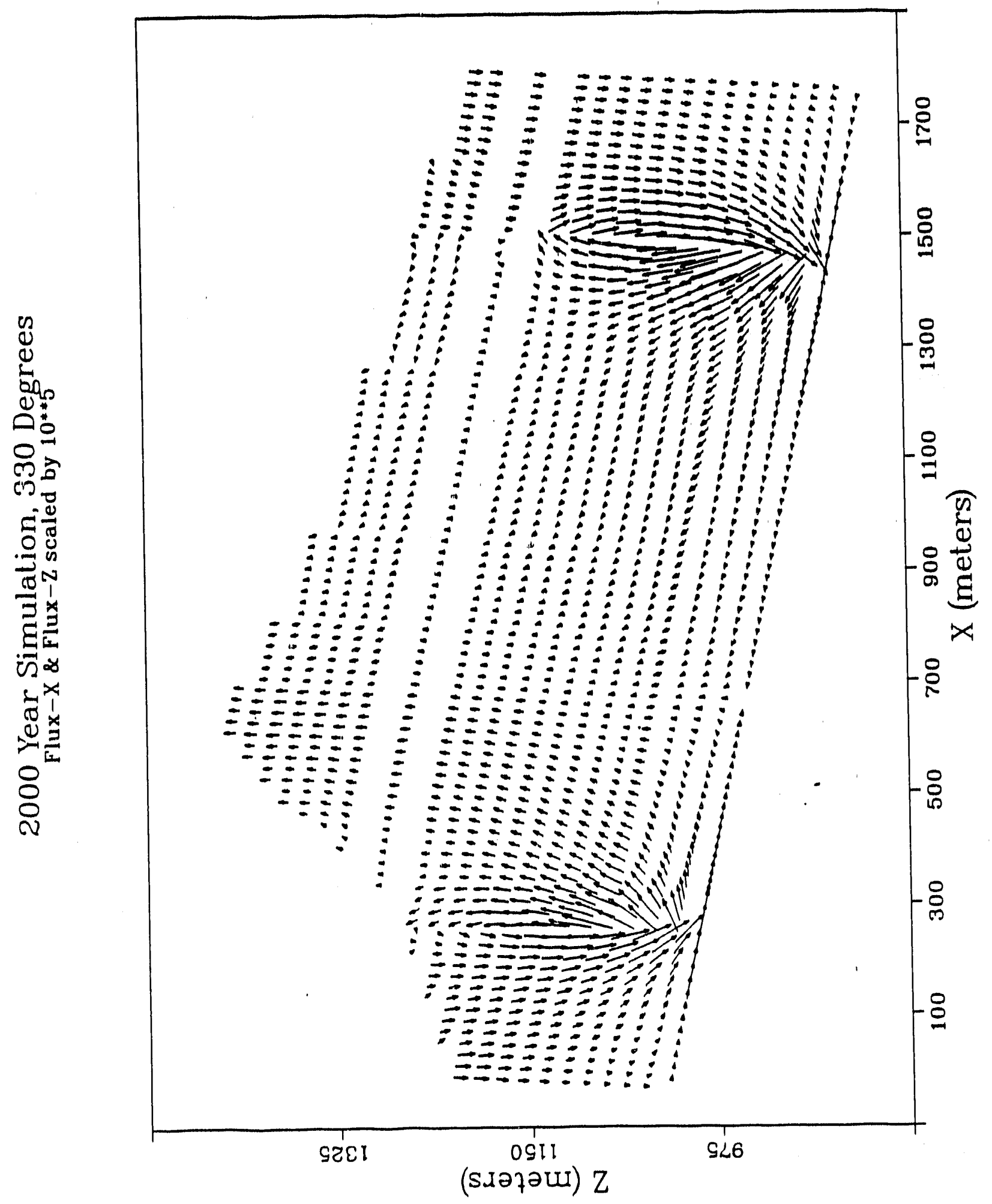

Figure 4-3. Gas flow at 2000 yr. 


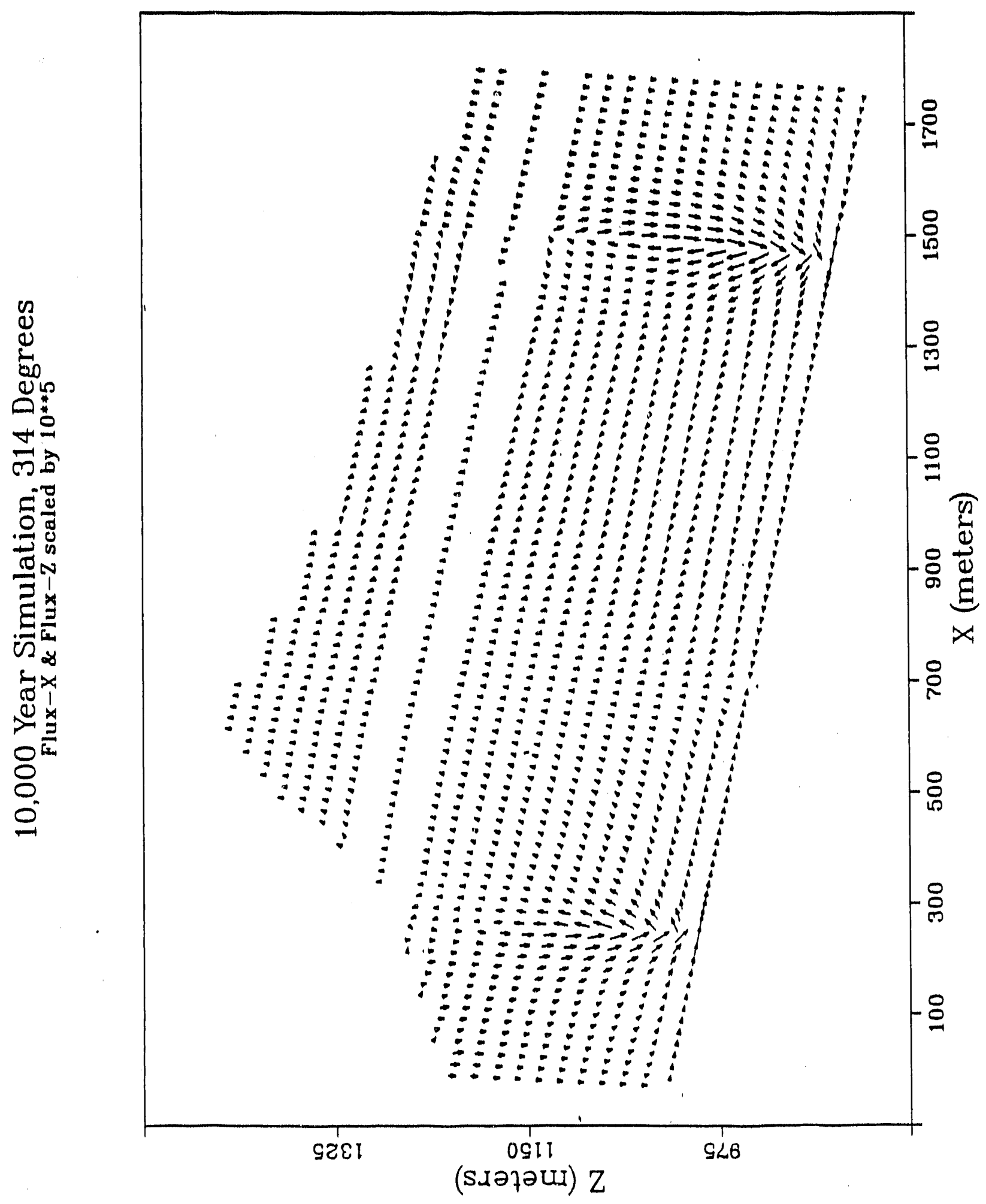

Figure 4-4. Gas flow at $10000 \mathrm{yr}$. 


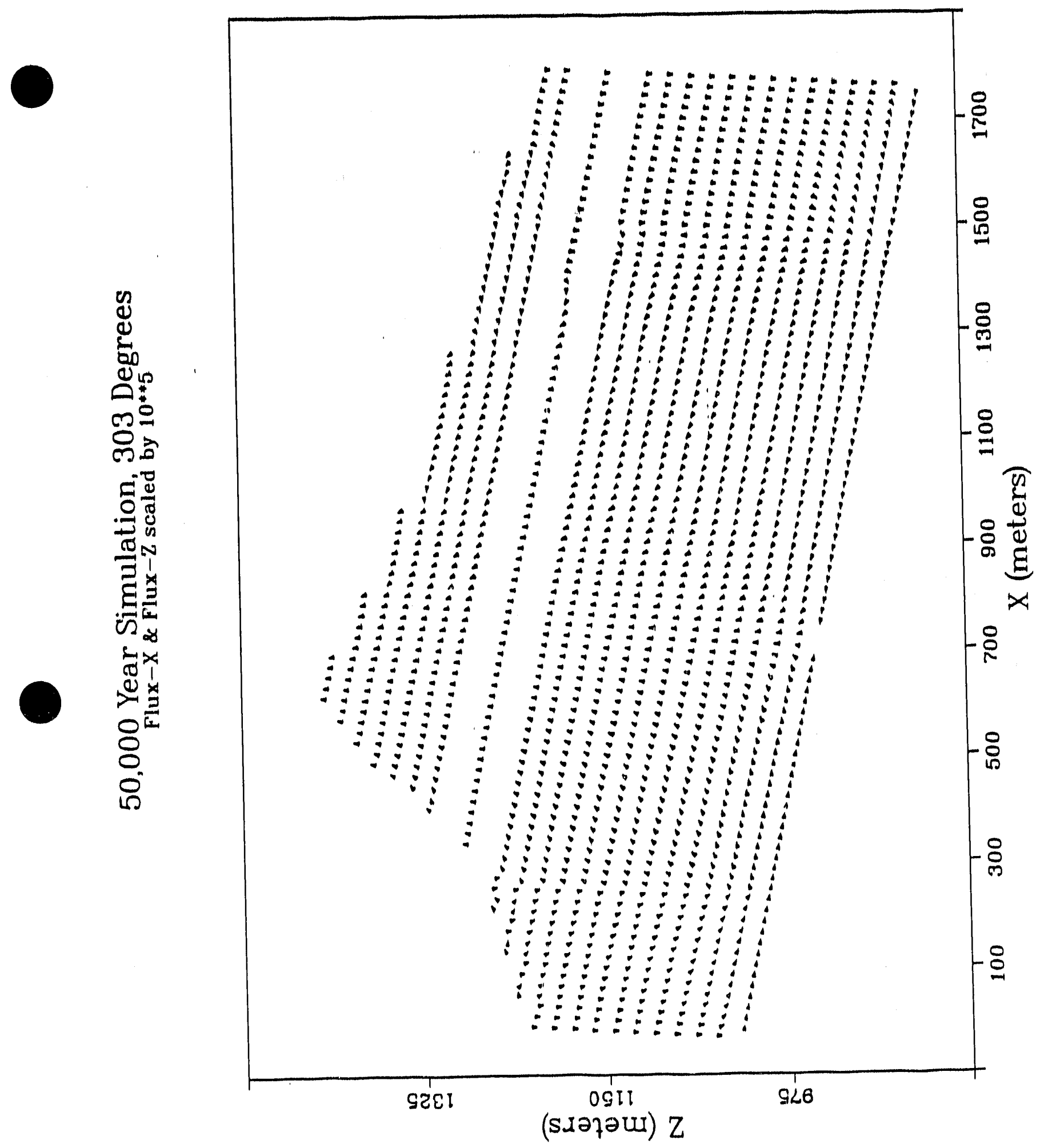

Figure 4-5. Gas flow at $50000 \mathrm{yr}$. 


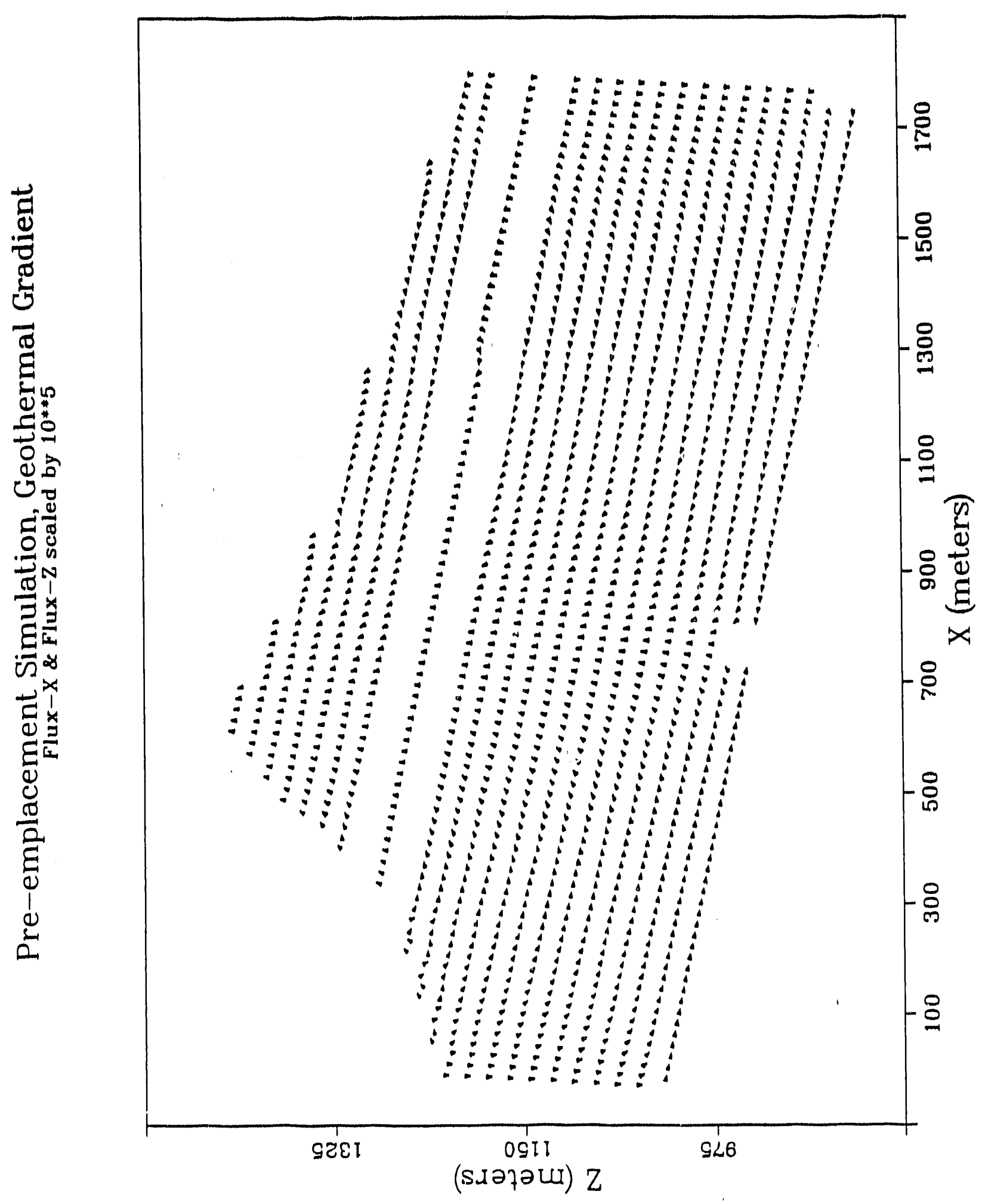

Figure 4-6. Gas flow at annual-average pre-emplacement temperatures. 
Perhaps the most fundamental property of the geochemical system that must be defined is the identity of the mineral phases that govern water chemistry. If secondary calcite is found in the unsaturated zone in significant quantities and an exogenous source of calcium can be identified, it is reasonable to conclude that the carbonate system buffers the water chemistry. If calcium is present in only minor amounts, the weathering of tuffacous silicate minerals may be the source, and more complex reactions are needed to predict chemical reactions. Precipitation of solid phases may alter total dissolved carbon concentrations and thereby influence carbon-14 concentrations in all phases; this mechanism is discussed in some detail in Section 5.4.1.

The conceptual model of the geochemical system adopted here has three principal features:

- Sufficient calcium carbonate is present in the unsaturated zone to dominate the aqueous chemistry and buffer the $\mathrm{pH}$ of the water.

- A relatively minor amount of calcium is derived from silicate weathering reactions. As a first approximation, it can be assumed that calcium concentrations are the result of equilib ation with calcium carbonate.

- Fractionation plays a negligible role in removing carbon-14 from the gas phase, and concentrations of carbon-14 are proportional to those of carbon-12.

The hydrogeologic environment at Yucca Mountain is believed to have been relatively constant since shortly after emplacement of the tuff. Thus, any model of the present geochemical system should be consistent with observed mineral alterations and secondary mineralization.

\subsubsection{Calcium}

Three possible sources of the calcium ions present in unsaturated-zone water at Yucca Mountain have been suggested:

- Leaching of carbonate-rich eolian deposits emplaced during the Pleistocene (Matuska and Hess, 1987)

- Irreversible weathering of volcanic glass in the tuff (White and Chuma, 1987; White et al., 1980; Kerrisk, 1987)

- Rechäge from the underlying Paleczoic carbonate aquifer (Broxton et al., 1987) 
In this report it is assumed that that the leaching of carbonate-rich eolian deposits generated sufficient secondary calcite to control the carbonate chemistry of the soil water. A more complex model would include tuff weathering reactions that are consistent with the zone of increasing zeolitization observed near the water table.

\subsubsection{Carbonate}

In unpolluted terrain, the chemistry of the ground water is largely controlied by the geology. Concentrations of dissolved carbonate species are thus mostly a reflection of the composition of carbunate minerals, which regulate and limit the solubility of calcium in many natural waters (Hem, 1986).

In neutral or moderately basic waters the predominant form of dissolved carbonate is the bicarbonate ion $\left(\mathrm{HCO}_{3}^{-}\right)$. Bicarbonate is in equilibrium with dissolved carbonic acid $\left(\mathrm{H}_{2} \mathrm{CO}_{3}\right)$ and carbonate ion $\left(\mathrm{CO}_{3}{ }^{2-}\right)$. All these aqueous species are, in turn, in equilibrium with gaseous carbon dioxide and solid calcite $\left(\mathrm{CaCO}_{3}\right)$, when the latter are present.

The concentration of dissolved bicarbonate can be obtained from the gaseous carbon dioxide concentration by considerations of chemical equilibrium. Gas-liquid reactions in a porous medium proceed quickly and it is safe to assume that equilibrium will be reached much faster than the time scales of concern here.

Calcite is almost surely the only carbonate mineral of significance in this system. Of the $\mathrm{CaCO}_{3}$ polymorphs, calcite is the thermodynamically stable phase in the temperature and pressure conditions of this environment. All the other metal carbonates are much rarer minerals (except possibly for siderite which will not form in an oxidizing environment). Dolomite is not expected to form in this geologic setting. It is assumed here that the chemical system is at equilibrium with solid calcite, which is present in sufficient quantities to buffer the system.

Non-carbonate mineral phases may affect carbonate equilibria. For example, dissolution of silicate minerals will increase the $\mathrm{pH}$ of a system, to a small extent changing the concentration of total dissolved carbon. Kerrisk (1987) reviewed the ground-water chenistry near Yucca Mountain and found that the chemistry of the saturated zone in the 
tuffaceous aquifer is dominated by sodium and carbonate ions. The concentrations of major ions, such as calcium, potassium, magnesium, sulfate, and chloride are controlled by dissolution and precipitation, and cation exchange with zeolite minerals. Water west of the mountain was found to contain less calcium than water to the east, in agreement with observed trends of calcium content in the minerals composing tuff (Broxton et al., 1987). Kerrisk reports that most. waters had a $\mathrm{pH}$ in the range of 7 to 8 , and total carbon concentrations in the range of 2 to $10 \mathrm{mmol} / \mathrm{L}$.

The only published data on chemical characteristics of unsaturated-zone water in the vicinity of Yucca Mountain come from a study of Rainier Mesa (White et al., 1980). Because Rainier Mesa is at a higher elevation, it receives more rainfall than Yucca Mountain. The geology is, however, quite similar at both locations, so that water samples taken from the unsaturated zone at Rainier Mesa may be similar to water at Yucca Mountain. Analysis of fracture and pore water from Rainier Mesa reveals that the dominant cations are sodium and calcium, while the dominant anions are bicarbonate and chloride (White et al., 1980). The $\mathrm{pH}$ of fracture water range between 6.8 and 8.3; bicarbonate concentrations range from 3.62 to $0.79 \mathrm{mmol} / \mathrm{L}$. The ranges of $\mathrm{pH}$ and bicarbonate in pore water are 7.2 to 8.2 and 0.37 to $2.25 \mathrm{mmol} / \mathrm{L}$ respectively.

\subsubsection{Fractionation and ${ }^{14} \mathrm{C}$ Migration}

Difierences in the isotopic ratios in the different phases can be caused by chemical reactions between isotopically different products and reactants or isotopic exchange between molecules containing the same element. Fractionation can also result from physical processes such as evaporation and condensation, crystallization, adsorption, and diffusion (Faure, 1986).

Fractionation will affect carbon-14 concentrations by transferring carbon-14 from the gas phase to liquid and solid phases. The degree to which fractionation will affect ${ }^{14} \mathrm{CO}_{2}$ transport rates can be estimated $k_{y}$ analyzing enrichment factors reported in the literature for the carbonate system. Because fractionation is roughly proportional to differences in mass, the ${ }^{14} \mathrm{C}$ enrichment factor can be approximated using enrichment factors for reported ${ }^{13} \mathrm{C}$ (Fontes and Garnier, 1979). 
The formula of Fontes and Garnier predicts that the denser phases will be enriched in the heavier isotope by approximately only 2 percent. The effect of fractionation in removing carbon-14 is therefore small in comparison to other processes and, given the poor precision of the chemical data, can be safely neglected.

\subsection{Modeling Approach}

A chemical model that represents the present geochemical conditions in the unsaturated zone at Yucca Mountain is developed here. The model is used to predict the distribution of carbon-14 between the liquid and gas phases at both ambient temperatures and the increased temperatures following waste emplacement.

\subsubsection{Definition of Retardation Factor}

In the travel-time analysis it is assumed that there is no isotopic exchange of carbon-14 with the solid phase and that dissolved carbon and gaseous $\mathrm{CO}_{2}$ are in isotopic equilibrium. With these assumptions, the effect of isotopic equilibrium between phases is to reduce the speed of carbon-14 transport by a factor $B$ which is proportional to the concentration ratio of carbon in the liquid and gas phases to gaseous carbon:

$$
B=1+\frac{\left[\theta_{\mathrm{T}}-\theta_{\mathrm{D}}\right]}{\theta_{\mathrm{D}}}\left[\frac{C_{\mathrm{T}}^{*}}{C_{\mathrm{T}}}\right]
$$

where

$$
\begin{aligned}
& \epsilon_{T}=\text { total porosity for each hydrologic unit } \\
& \theta_{\mathrm{D}}=\text { drained porosity for each hydrologic unit } \\
& C_{\mathrm{T}}{ }^{*}=\text { concentration of carbon ion in the liquid phase at equilibrium } \\
& C_{\mathrm{T}}=\text { concentration of carbon ion in the gas phase at equilibrium }
\end{aligned}
$$

The factor $B$ is known as the retardation factor. 
Solution of Equation (5-1) requires that the concentration of dissolved inorganic carbon and the partial pressure of carbon dioxide as functions of temperature be known. A relationship between pressure and temperature in a non-reacting gas phase can easily be developed; however, the temper: The reaction path model PHREEQE allows available chemical data to be used to model the geochemical system, concentrating on reactions of carbonate species. This model can be used to simulate expected equilibria with mineral phases and predict changes in speciation with temperature.

\subsubsection{Data Limitations and Model Assumptions.}

At present few data are available on the chemistry of water in the highly unsaturated rocks at the repository site. The data that do exist were obtained frorn water samples extracted at high pressures, making it impossible to quantify pressure-dependent parameters such as carbonate concentrations and $\mathrm{pH}$. Modeling efforts based on these data are subjective and are biased by the basic assumptions used.

The following assumptions are, however, well justified, and simplify the system:

1. The soil gas behaves as an ideal gas.

2. Soil water is in equilibrium with both the gas phase and calcite.

3. Ion exchange can be ignored.

4. Fractionation effects can be neglected.

The following additional assumptions, which are more conjectural in nature, are dictated by the conceptual model described above.

5. The data available are representative of the overall system.

6. Soil water chemistry is buffered by the carbonate system, which therefore controls $\mathrm{pH}$.

7. The distribution of ${ }^{12} \mathrm{C}$ between different phases is proportional to the distribution of ${ }^{14} \mathrm{C}$ between the same phases.

8. Silicate weathering and precipitation reactions do not significantly affect carbonate chemistry. 
9. Calcium concentrations and the partial pressure of carbon dioxide are the only measured values that control carbonate concentrations at equilibrium.

\subsubsection{Modeling Approach Using PHREEQE}

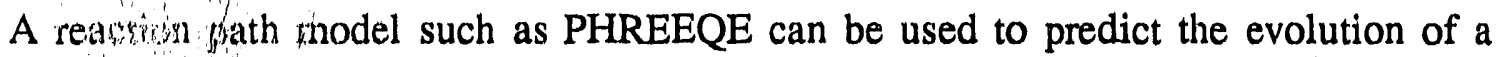
water if initial chemical concentrations and reactions are defined. The PHREEQE model allows the user several options to adjust for analyses that have a charge imbalance. A complex series of reactions including equilibria with mineral phases, irreversible geochemical processes, mixing of waters, and changes in the temperature of a system can be simulated.

Because available chemical data often are consistent with more than one set of reactions and mineral phases that could plausibly describe the geochemical system, reaction path models are frequently used to generate a series of reaction products for each of the hypothetical systems. Given an incomplete soil water analysis, PHREEQE can generate missing data if the system is constrained to be in equilibrium with specific mineral phases (Plummer et al., 1983). This capability is very useful because very few data defining the soil-water chemistry at Yucca Mountain are available.

To obtain a range of values of total dissolved carbon that can be used to calculate the retardation factor $B$, available data and basic assumptions about the geologic and geochemical environment were combined in a two-step procedure. Both steps employed PHREEQE. The first step used the model to predict missing parameters at ambient temperatures. Concentrations of carbonate species that would be in equilibrium with observed mineral phases at the measured partial pressure of carbon dioxide were generated. The second step used the output generated in the first step as input to simulate changes in speciation after the temperature has been raised following emplacement of the repository.

This approach is not meant to yield a unique geochemical model of the unsaturated zone, but only to give an order of magnitude estimate of chemical concentrations and speciation that may be expected. It should be emphasized that the procedure was developed in response to the lack of available data and is intended only to provide approximate values of the equilibrium concentrations of total dissolved carbon so that a carbon-14 retardation factor $B(T)$ as a function of temperature could be calculated. 
Comparison of results predicted from the first step with data from similar geologic areas, as well as with data obtained in the future, is the only way to determine the accuracy of the predictions.

Figure 5-1 is a flowchart detailing the two-step procedure used to solve the problem.

Step 1. Ambient carbonate concentrations were calculated. Two different approaches, based on different judgments about the accuracy of the data, were used.

Method 1 - Assume that endpoints of measured calcium concentrations bracket the range expected in soil water concentrations at Yucca Mountain. Assume a reasonable value of $\mathrm{pH}$ and, for each endmember of the calcium concentration range, allow PHREEQE to calculate carbonate values by setting this hypothetical system in equilibrium with solid calcite and crystobalite and measured partial pressures of carbon dioxide.

In this approach, the charge imbalance of the analysis is maintained throughout all calculations. If all of the chemical analyses are equally suspect, a reasonable assumption in this case, this option maintains whatever error exists in the data as a result of inaccurate or incomplete analyses. PHREEQE recalculates the $\mathrm{pH}$ of the sample at equilibrium with calcite and measured $\mathrm{pCO}_{2}$. In all simulations where this was done, the sample $\mathrm{pH}$ turned out to be highly buffered, with the final $\mathrm{pH}$ varying only few tenths of a unit regardless of the starting $\mathrm{pH}$.

Method 2 - Adjust concentrations thought to be highly suspect to account for charge inec-dalities. Because of difficulties in extracting a soil water sample from highly unsaturated media, all of the chemical analy ses are suspect; however, total carbon and calcium concentrations were selected to be adjusted.

At pH 7.66 and calcium of $110 \mathrm{mg} / \mathrm{L}$, PHREEQE increased the bicarbonate concentration to approximately $272 \mathrm{mg} / \mathrm{L}$ to account for the charge imbalance. It equilibrium this concentration was reduced to approximately $80 \mathrm{mg} / \mathrm{L}$, hypothetically depositing large quantities of calcite and degassing the soil water. Because the range of calcium concentrations is wide ( 30 to $110 \mathrm{mg} / \mathrm{L}$ ), it was necessary to adjust $\mathrm{pH}$ and the calcium concentrations using an iterative procedure until they showed little change after equilibration with the gas and mineral phases. 


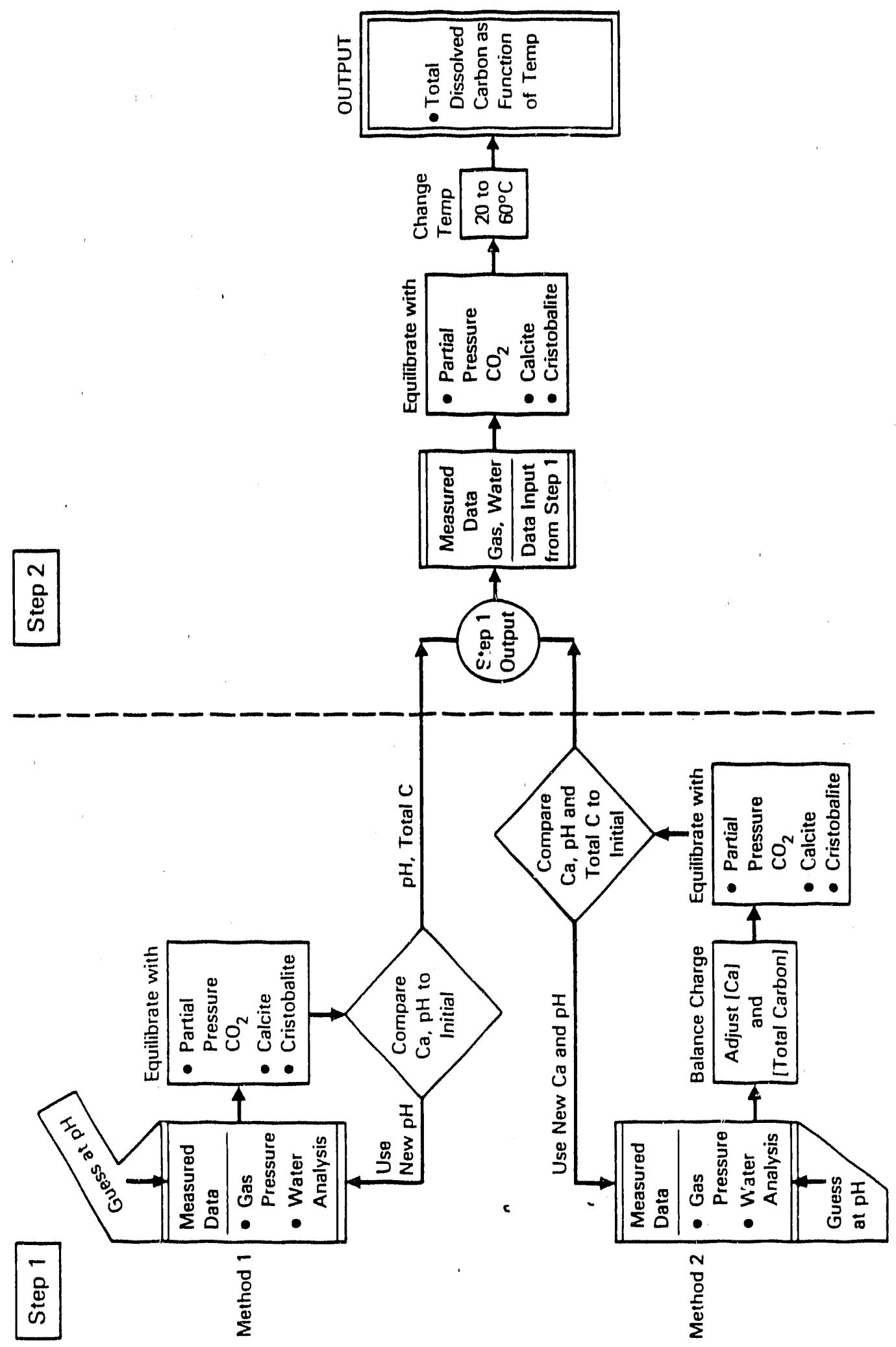

Figure 5-1. Flow chart of the procedure used with the PHREEQE chemical model. 
$\underline{\text { Step } 2}$ - Concentrations at increased temperatures were calculated. For each hypothetical system, the generated values of total carbon were substituted back into the original data set and retested to see if the syster $r_{i}$ remains at equilibrium. Next, the temperature of the system was increased, and corresponding changes in the concentration of dissolved species and saturation indices were noted for each hypothetical system. This method allowed a relationship between temperature and carbonate speciation to be defined.

The relative concentrations of carbonate species in liquid and gas phases at equilibrium were used to calculate a retardation factor for carbon-14 transport in the gas phase. The concentration calculated by the above procedure reflects a variety of chemical interactions, including ion exchange, mineral precipitation, and sorption. However, the retardation factor itself reflects only the distribution of carbon-14 between the gaseous and dissolved phases.

\subsection{Input Data}

Each simulation used the same aqueous chemical concentrations (with the exception of calcium concentrations), gas partial pressure, and temperature. Values of $\mathrm{pH}$ are required input to PHREEQE, but were unavailable and had to be solved for iteratively as discussed in section 5.2. Initial guesses of $\mathrm{pH}$ were based on analyses of unsaturated zone water analyzed at Rainier Mesa (nearby Yucca Mountain) that ranged from 7 to 8 .

\subsubsection{Soil Water}

Little chemical data exists for unsaturated zone water at Yucca Mountain. The data that have been published are ranges of concentrations reported by Yang (1987). Two different techniques were used to obtain water samples: pressure squeezing and ultracentrifuge. A range of calcium concentrations from 30 to $110 \mathrm{mg} / \mathrm{L}$ was obtained. In this report it is assumed that these data are representative of the generalized unsaturated zone water quality. 


\subsubsection{Gas}

Yang et al. (1986) measured the partial pressure of carbon dioxide in gas samples collected at intervals to a depth of 1200 feet in Yucca Mountain. A characteristic value of $0.11 \%$ was used in all simulations.

\subsubsection{Porosity}

Values of porosity of the three hydrologic units defined in the unsaturated zune at Yucca Mountain are given in Montazer and Wilson (1985). The data are based on laboratory analyses of core samples.

$\begin{array}{lrc}\text { UNIT } & \text { total porosity } & \text { drained porosity } \\ \text { Tiva Canyon } & 0.12 & 0.04 \\ \text { Paintbrush } & 0.46 & 0.18 \\ \text { Topopah Spring } & 0.14 & 0.05\end{array}$

\subsection{Results}

Three sets of initial conditions were modeled using the procedure described in section 5.2.3. Method 1 was used to generate a hypothetical range of dissclved carbon concentrations and $\mathrm{pH}$, using the endpoints of the range of measured calcium concentrations (110 and $30 \mathrm{mg} / \mathrm{L}$ ). A third set of simulations employed method 2, which changed calcium and bicarbonate concentration to achieve a charge balance.

Concentrations calculated in each set of simulations were used to compute retardation factors. Retardation factors calculated by the charge-balance methods were roughly in the center of the range calculated by the other method, so they were adopted for use in travel-time calculations.

\subsubsection{Step 1}

PHREEQE generated total dissolved carbon concentrations by dissolution of calcite and carbon dinxide to achieve equilibrium with calcite, cristobalite, and measured partial pressures of carbon dioxide. Calculated values are listed in Table 5-1 and used as input in 
Step 2, below. The $\mathrm{pH}$ of the water at equilibrium was found to be a fairly robust parameter, as equilibrium $\mathrm{pH}$ was little changed for a wide range of input $\mathrm{pH}$. The $\mathrm{pHs}$ calculated for the Yucca Mountain analysis (7.69 to 7.97) are in the same range as those measured in unsaturated zone samples at Rainier Mesa (6.8 to 8.3). The mean generated $\mathrm{pH}$ falls within one standard deviation about the mean of $51 \mathrm{pH}$ measurements taken at Rainier Mesa.

Table 5-1. Values of $\mathrm{pH}$ and Total Carbon Generated from Step 1

\begin{tabular}{|c|c|c|c|c|c|}
\hline $\begin{array}{l}{[\mathrm{Ca}]} \\
\mathrm{mg} / \mathrm{L}\end{array}$ & $\mathrm{pH}$ & $\begin{array}{l}{[\mathrm{TIC}]} \\
\mathrm{mmol} / \mathrm{L}\end{array}$ & $\begin{array}{l}{\left[\mathrm{HCO}_{3}\right]} \\
\mathrm{mmol} / \mathrm{L}\end{array}$ & $\begin{array}{l}{\left[\mathrm{CO}_{3}\right]} \\
\mathrm{mmol} / \mathrm{L}\end{array}$ & $\begin{array}{l}{\left[\mathrm{H}_{2} \mathrm{CO}_{3}\right]} \\
\mathrm{mmol} / \mathrm{L}\end{array}$ \\
\hline $\begin{array}{c}30^{*} \\
110^{*} \\
44\end{array}$ & $\begin{array}{l}7.97 \\
7.69 \\
7.88\end{array}$ & $\begin{array}{l}1.5176 \\
0.83116 \\
1.26374\end{array}$ & $\begin{array}{l}1.453 \\
0.7737 \\
1.203\end{array}$ & $\begin{array}{l}8.84 \times 10^{-3} \\
2.57 \times 10^{-3} \\
6.09 \times 10^{-3}\end{array}$ & $\begin{array}{l}30.90 \times 10^{-3} \\
30.90 \times 10^{-3} \\
30.88 \times 10^{-3}\end{array}$ \\
\hline
\end{tabular}

*values input, not generated

As expected, bicarbonate ion is the predominant carbonate species in the generated data, varying from 0.77 to $1.45 \mathrm{mmol} / \mathrm{L}$ (47 to $89 \mathrm{mg} / \mathrm{L}$ ). Bicarbonate concentrations of unsaturated zone water from Rainier Mesa ranged from 0.37 to $3.62 \mathrm{mmol} / \mathrm{L}$. All calculated bicarbonate concentrations fall within one standard deviation about the mean of 55 bicarbonate concentrations measured at Rainier Mesa.

Using the charge balance approach, a calcium concentration of $43 \mathrm{mg} / \mathrm{L}(1.097$ $\mathrm{mmol} / \mathrm{L}$ ) was calculated, which is within the range of measured calcium concentrations at Yucca mountain ( 30 to $120 \mathrm{mg} / \mathrm{L}$ ). In all cases saturation indices indicate the water is initially slightly undersaturated with respect to carbonate minerals, and supersaturated with respect to silicate minerals.

\subsubsection{Step 2}

Using the values generated in step 1 as input, the effect on speciation given a change in temperature from ambient conditions was simulated. The same three simulations were run as described in Step 1. 
As temperature increases, the concentration of dissolved inorganic carbon decreases and both precipitation of calcium carbonate and degassing of the water occur. Figure 5-2 shows total dissolved carbon concentration as a function of temperature for each of the three simulations.

\subsubsection{Retardation Factors}

Retardation factors were calculated using Equation (5-1). Values are dependent upon the concentration of dissolved inorganic carbon, the carbon concentration in the gas phase, physical characteristics of the unsaturated zone (porosity), and temperature. Retardation factors were calculated using measured porosities of each hydrologic unit, and the data generated in steps 1 and 2 above. Figure 5-3a-c shows retardation factors calculated for each of the three simulations. Within each hydrogeologic unit, retardation factors at a given temperature vary by approximately a factor of two among the thre; simulations. The results are fairly sensitive to input concentrations of aqueous species, with lower calcium concentration resulting in higher retardation factors. Thus, the accuracy of the retardation factors depends on the accuracy of the initial chemical analysis.

Although the calcium concentration predicted by the charge balance is in the lower range of observed calcium concentrations, retardation factors calculated for each hydrogeologic unit using these values are approximately in the middle of the range of retardation factors defined by calculations using extreme calcium concentrations. These values were therefore adopted for further use. Figure 5-4 shows the retardation factors in each hydrogeologic unit as calculated by the charge balance method.

To simplify calculations, linear approximations of the curves shown in Figure 5-3 were used to calculate travel times. These were generated by linear regression, and are as follows:

UNIT

Tiva Canyon welded

Paintbrush non-welded

Topopah Springs welded
RETARDATION EQUATION $\mathrm{r}^{2}$

$\mathrm{B}(\mathrm{T})=92.7-(0.948) \mathrm{T}$

$\mathrm{B}(\mathrm{T})=71.66-(0.7305) \mathrm{T}$

$B(T)=84.89-(0.8673) T$ 0.9985 

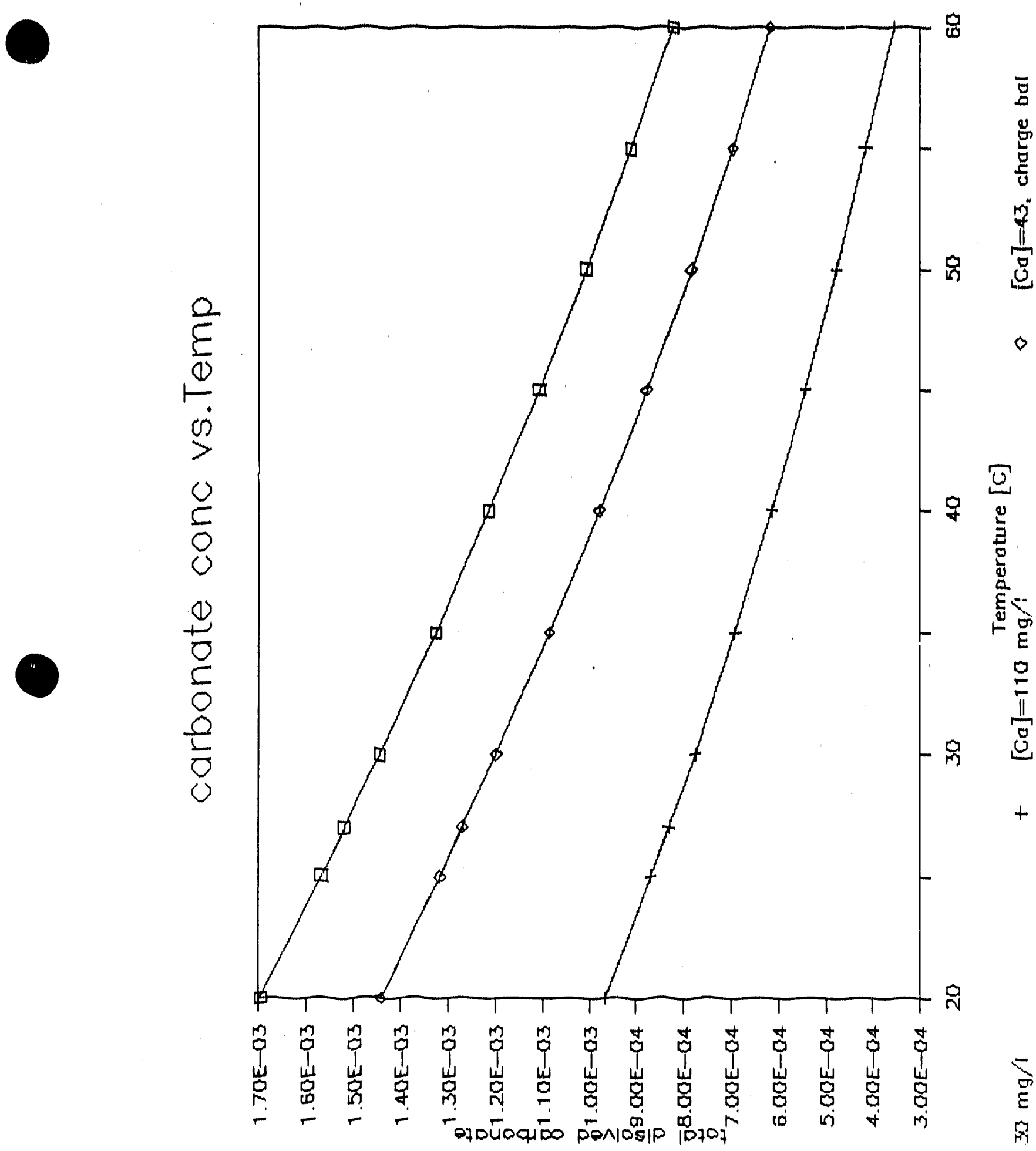

Figure 5-2. Predicted concentration of dissolved inorganic carbon as a function of temperature. 


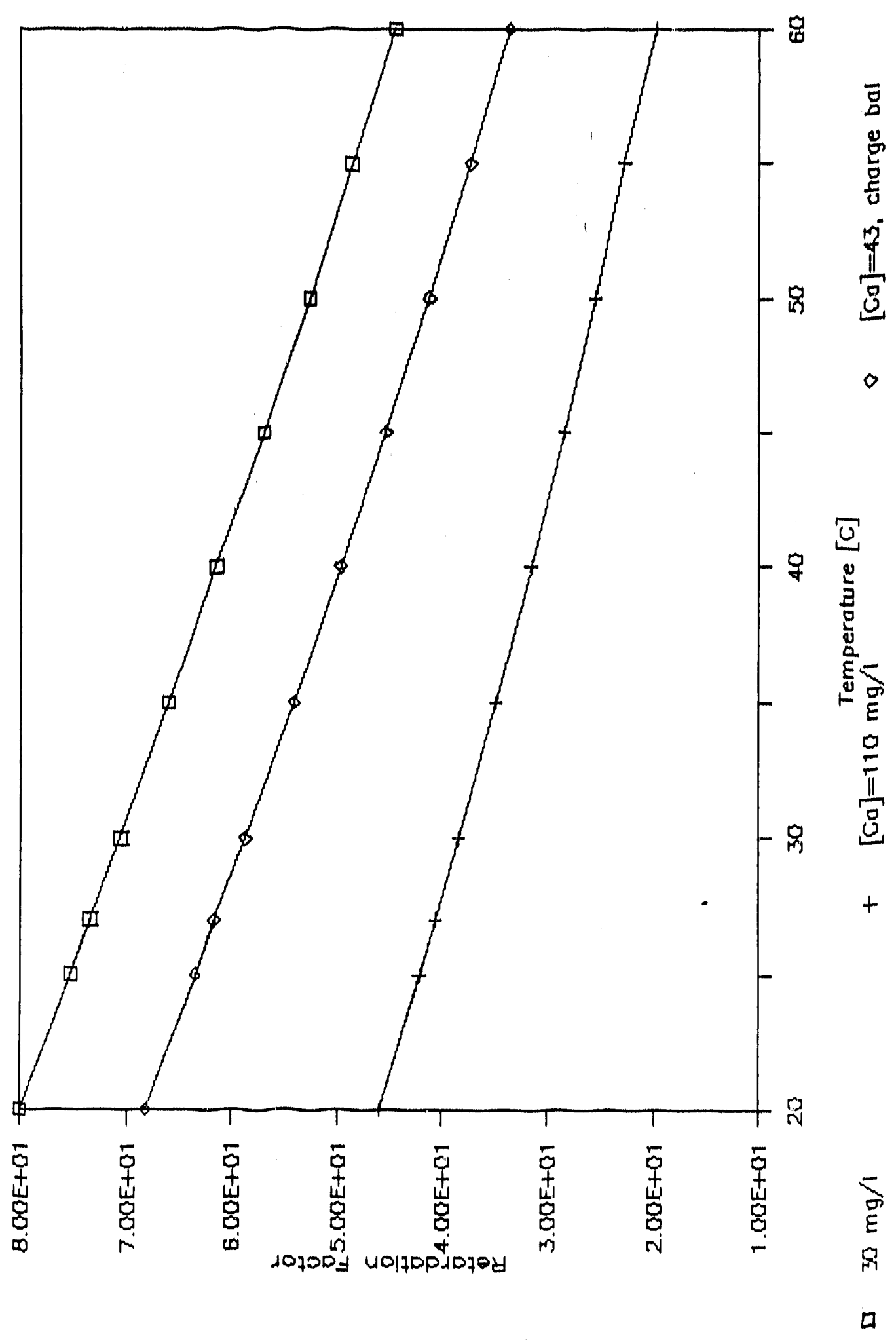

Figure 5-3a Retardation factor versus temperature in the Topopah Spring welded unit. 

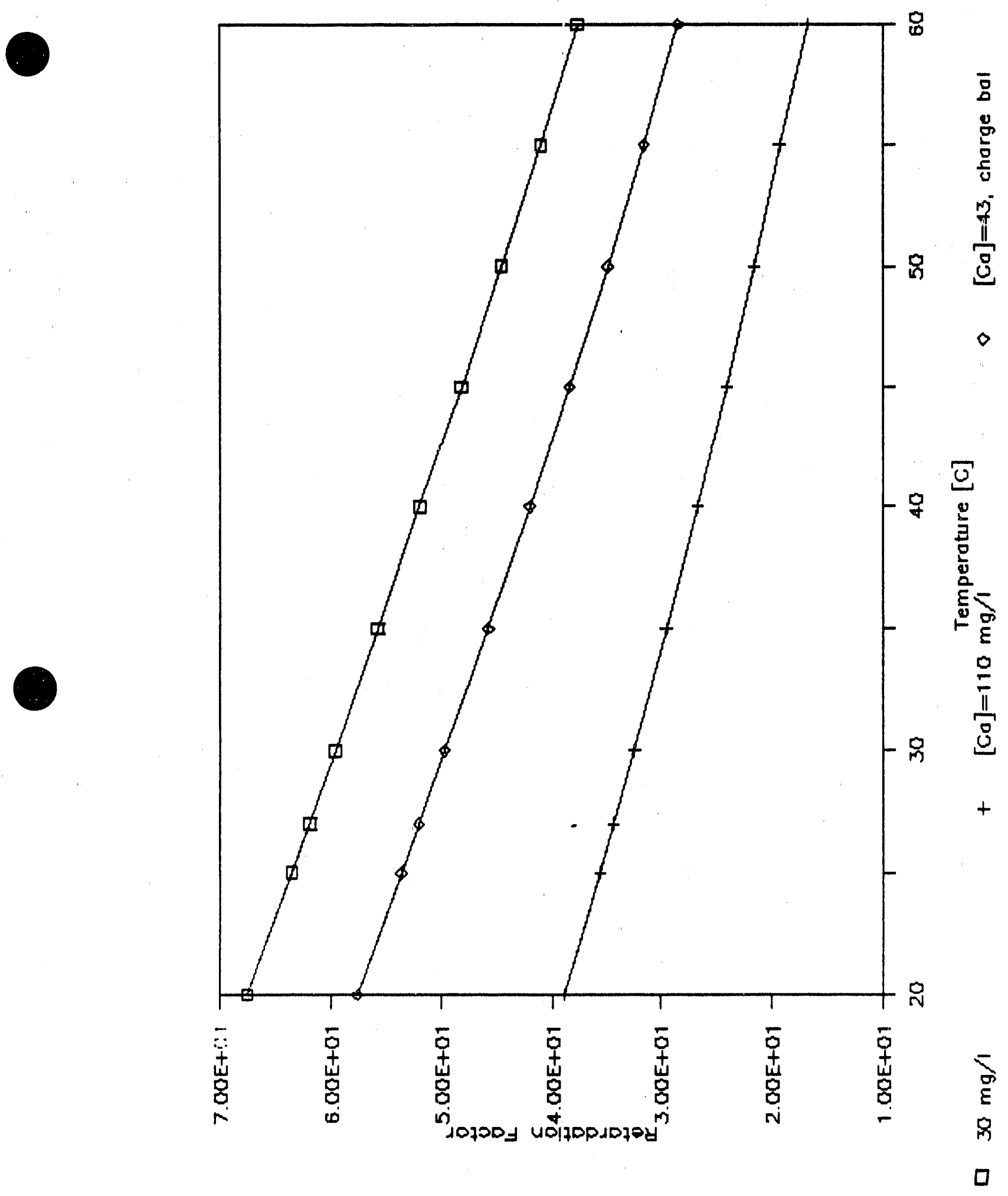

Figure 5-3b Retardation factor versus temperature in the Paintbrush nonwelded unit. 


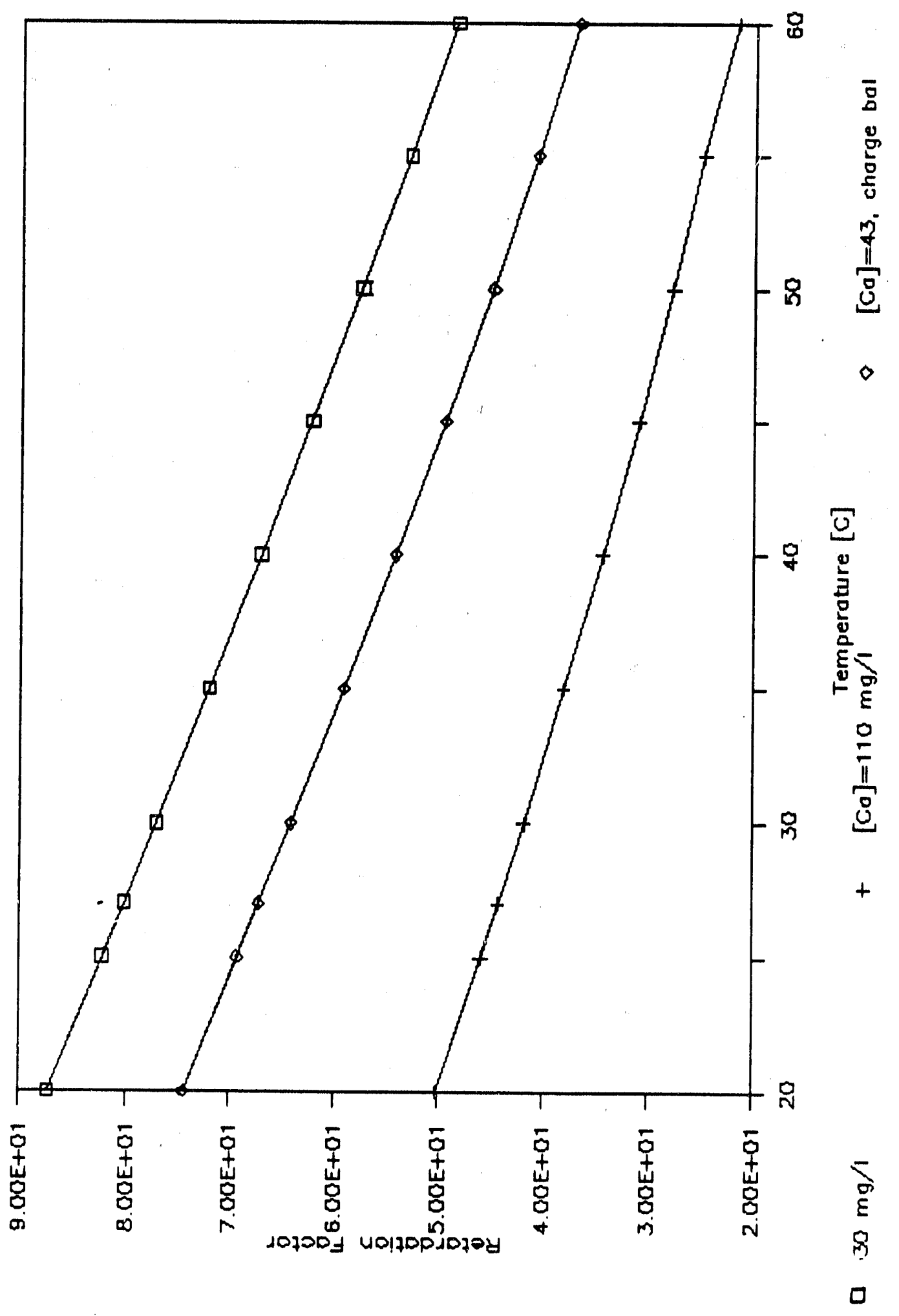

Figure 5-3c Retardation factor versus temperature in the Tiva Canyon unit. 


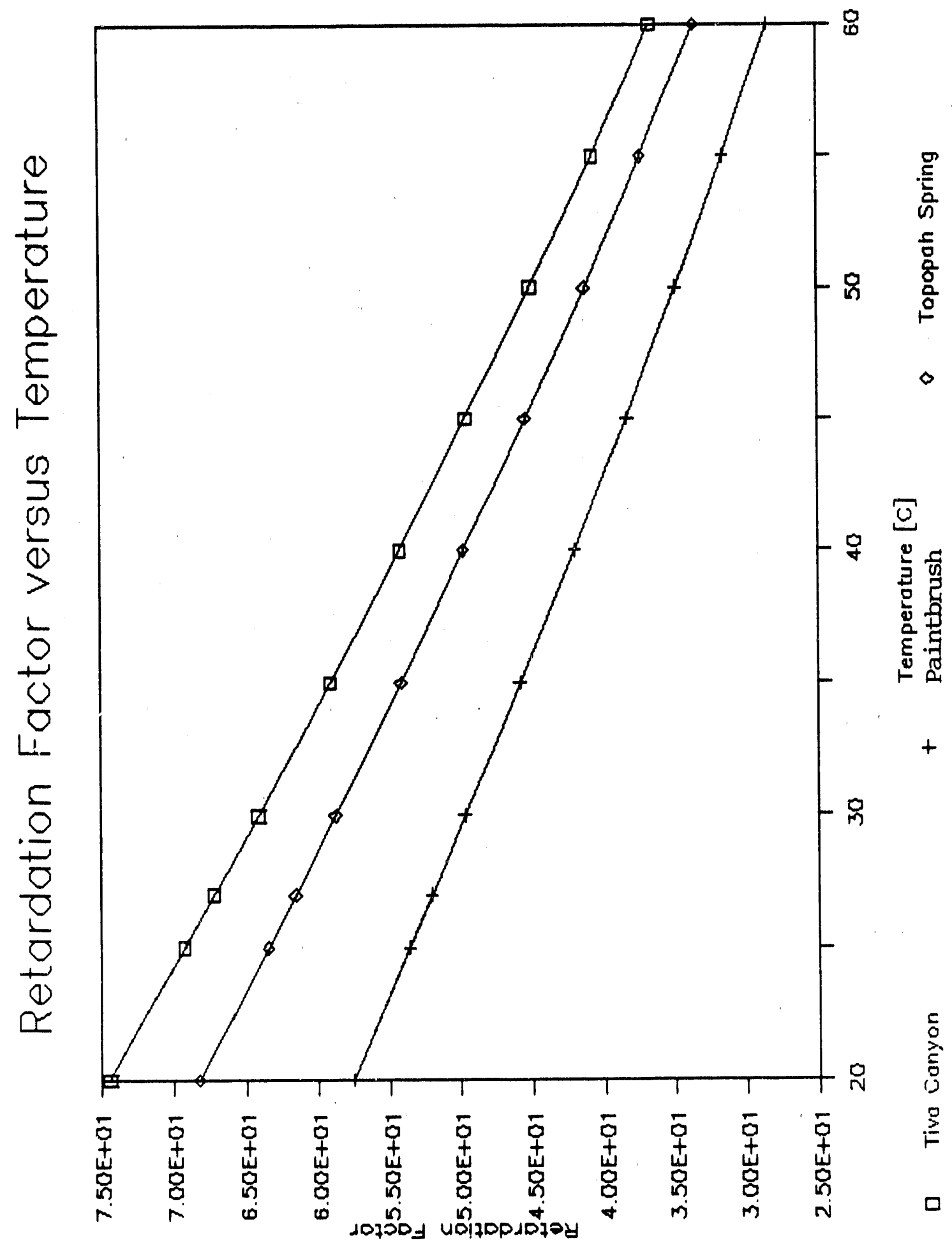

Figure 5-4. Retardation factor versus temperature for all units, using the charge balance method. 


\section{TRAVEL-TIME CALCULATIONS}

In this section, fluxes generated by the gas flow model (described in Section 4) and the retardation factors given in Section 5 are coupled to calculate the time required for ${ }^{14} \mathrm{CO}_{2}$ to travel from the repository to the surface.

\subsection{Method}

The average linear velocity $\mathbf{v}_{\mathbf{c}}$ of a species that is retarded by chemical interaction with an immobile phase is (Freeze and Cherry, 1979):

$$
\mathbf{v}_{\mathrm{c}}=\frac{\mathbf{d}}{t} b=\frac{\mathrm{q}}{\theta} b
$$

where $\quad \mathbf{d}$ is the distance traveled

$t$ is the time

$b$ is a retardation factor

$q$ is the Darcy flux

$\theta$ is the drained porosity of the matrix and fractures combined.

This equation can be solved for $t$ and put into finite difference form by setting the length of $\mathbf{d}$ equal to the model's node spacing $d$ and using node-specific values for the variables. As shown in Section 5, retardation factors are both unit and temperature dependent. The total travel time $t_{\mathrm{i}}$ trom the repository to the surface through column $\mathrm{i}$ will be:

$$
t_{\mathrm{i}}^{\mathrm{l}}=\sum_{\mathrm{j}=\mathrm{r}}^{\mathrm{s}} t_{\mathrm{ij}}=\sum_{\mathrm{j}=\mathrm{r}}^{s} \frac{d \theta_{\mathrm{ij}} b\left(T_{\mathrm{ij}}\right)}{q_{\mathrm{ij}}}
$$

where $\quad i, j \quad$ are the node indices

$s \quad$ is the $z$ coordinate index of the surface node

$r \quad$ is the $\mathrm{z}$ coordinate of the repository node

$T_{\mathrm{ij}} \quad$ is the temperature of the $i, j$ node

$t_{\mathrm{ij}}$ is the travel time through the region associated with the $i, j$ node. 
Two important approximations in this equation should be noted. The travel time is calculated along a straight line normal to the bedding, rather than along any actual travel path. The velocities used in the calculation are all calculated for the same instant of time, ignoring the passage of time as a particle travels.

\subsection{Results}

Travel times were calculated by solving Equation (6-2) for each $i^{\text {th }}$ column of nodes in the simulation. Figure 6.1 summarizes the travel-time calculation for ambient conditions, and 2,000,10,000, and 50,000 years after repository emplacement. The horizontal axis represents distance from the west end of the repository. The reader should note that topography strongly influences travel times. At the west end of the repository the distance to the surface is only half that from below the crest of the mountain. The lower permeability Paintbrush unit is thinnest above the west end of the repository. Travel times near the western edge of the repository are also reduced by large upward convective velocities that are an artifact of the sharp falloff of temperature that was assumed at the edge of the repository. 

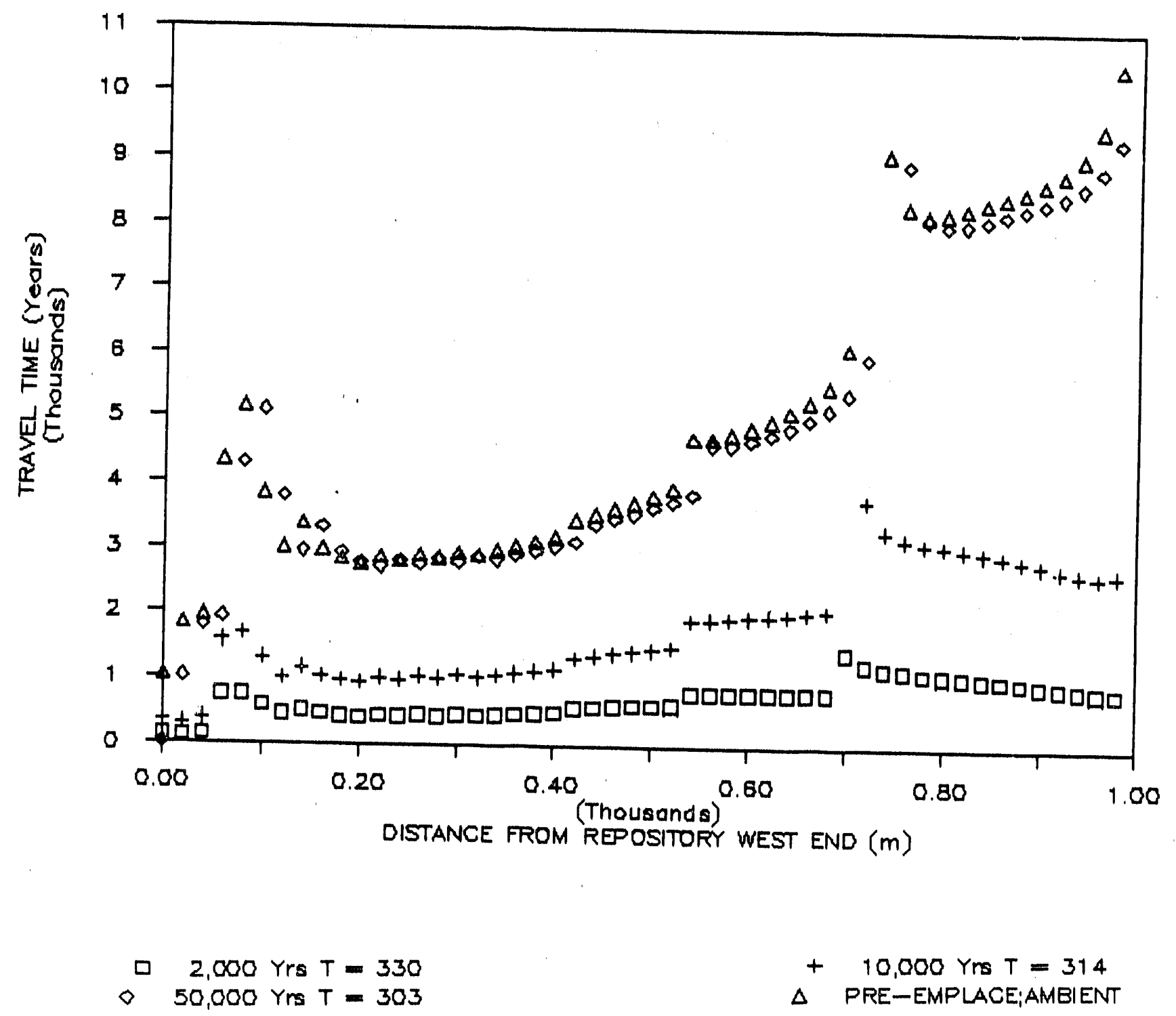

Figure 6.1 Carbon-14 travel time from the repository to the surface for ambient conditions, $2,000,10,0000$, and 50,000 years. 


\section{REFERENCES}

Broxton, D.E., D.L. Bish, and R.G. Warren, Distribution and chemistry of diagenetic minerals at Yucca Mountain, Nye County, Nevada, Clays and Clay Minerals, vol. 35, No. 2, pp. 89-110, 1987.

Faure, G., Principles of Isotorie Geology, Wiley, New York, 1986.

Fontes, J.C., and J.M. Garnier, Determination of the initial 14-carbon activity of the total dissolved carbon: a review of the existing models and a new approach, Water Resources Research, vol. 15, pp. 399-412 (1979).

Freeze, R.A. and J.A. Cherry, Grounc'water, Prentice-Hall, Englewood Cliffs, NJ, 1979.

Hem, J.D., Study and interpretation of the chemical characteristics of natural water, third edition, U.S. Geological Survey Water-Supply Paper 2254, 1985.

Jury, W.A., and J. Letey Jr., Water vapor movement in soil: reconciliation of theory and experiment, Soil Science Society of America Journal, vol. 43, pp. 823-827 (1987).

Kerrisk, J.F., Groundwater geochemistry at Yucca Mountain, Nevada, and vicinity, Los Alamos National Laboratory Report LA-10929-MS, 118 p., 1987.

Kipp, K.L., Jr., Effect of topographpy on gas flow in unsaturated fractured rock - numerical simulation, in Flow and Transport Through Unsaturated Fractured Rock, edited by D.D. Evans and T.J. Nicholson, Geophysical Monograph 42, American Geophysical Union, 1987, pp. 171-176.

Lusczynski, N.J., Head and flow of water of variable density, Journal of Geophysical Research, vol. 66, pp. 4247-4256, 1961.

Matuska, N.A., and J.W. Hess, Hydrology of the Yucca Mountain repository block and its relationship to the regional ground-water system: a geochemical and isotopic analysis, Geological Society of America Abstracts with Programs, 1987 Annual Meeting, Phoenix, AZ, p. 762, 1987.

Montazer, P., and W.E. Wilson, Hydrogeology of the unsaturated zone, Yucca Mountain, Nevada, Proceedings of the NWWA Conference on Characterization and Monitoring of the Vadose (Unsaturated) Zone, Denver, CO, Nov. 19-21, pp. 488-506, 1985.

Montazer, P., E.P. Weeks, F. Thamir, S.N. Yard, and P.B. Hofrichter, Monitoring the vadose zone in fractured tuff, Yucca Mountain, Nevada, in Proceedings of the NWWA Conference on Characterization and Monitoring of the Vadose (Unsaturated) Zone, Denver, November 19-21, 1985, pp. 439-469. 
Neretnieks, I., Age dating of groundwater in fissured rock: influence of water volume in micropores, Water Resour. Res., vol. 17, pp. 421-422 (1981).

Pluinmer, N.L., D.L. Parkhurst, and D.C. Thorstenson, Development of reaction path models for ground-water flow systems, Geochimica et Cosmochim Acta, Vol. 47, pp. $665-686,1983$.

Rasmuson, A., and I. Neretnieks, Migration of radionuclides in fissured rock: the influence of micropore diffusion and longitudinal dispersion, J. Geophys. Res., vol. 86, pp. 3749-58 (1981).

Ross, B., A Conceptual model of deep unsaturated zones with negligible recharge, Water Resources Research, vol. 20, pp. 1627-1629, 1984.

Sinnock, S., Geologic Information System product no. CAL0235, Sandia National Laboratories, 1988.

Thorstenson, D.C., E.P. Weeks, H. Haas, and D.W. Fisher, Distribution of gaseous ${ }^{12} \mathrm{CO}_{2}$, and ${ }^{14} \mathrm{CO}_{2}$ in the sub-soil unsaturated zone of the western U.S. Great Plains, Radiocarbon, vol. 25, pp. 315-346 (1983).

Tsang, Y.W. and K. Pruess, A study of thermally induced convection near a high-level nuclear waste repository in partially saturated fractured tuff, Water Resources Research, vol. 23, pp. 1958-1966, 1987.

Weeks, E.P., Effect of topography on gas flow in unsaturated fractured rock - concepts and observations, in Flow and Transport Through Unsaturated Fractured Rock, edited by D.C. Evans and T.J. Nicholson, Geophysical Monograph 42, American Geophysical Union, 1987, pp. 165-170.

White, A.F., and N.J. Chuma, Carbon and isotopic mass balance models of Oasis Valley-Fortymile Canyon groundwater basin, Southern Nevada, Water Resources Research, vol. 23, no. 4, pp. 571-582, 1987.

White, A.F., H.C. Classen, and L.V. Benson, The effect of dissolution of volcanic glass on the water chemistry in a tuffaceous aquifer, Rainier Mesa, Nevada, U.S. Geological Survey Water Supply Paper 1535-Q, 34 pp., 1980.

Yang, I.C., Chemical evidence of preferred water flow paths in unsaturated fractured tuffs, Yucca Mountain, Nevada, presented to American Geophysical Union, Spring Meeting, Baltimore, MD, May 20, 1987.

Yang, I.C., H.H. Weeks, E.P. Weeks, and D.C. Thorstensou, Analysis of gaseous-phase stable and radioactive isotopes in the unsaturated zune, Yucca Mountain, Nevada, Proceedings of the NWWA Conference on Characterization and Monitoring of the Vadose (Unsaturated) Zone, Denver, CO, Nov. 19-21, pp. 488-506, 1985. 


\section{DISTRIBUTION}

No. of

Copies

\section{OFFSITE}

2 DOE Office of Science and Technical Information

M. J. Apted

INTERA Science

3609 South Wadsworth Bivd.

5th Floor

Denver, CO 80235

J. A. Canepa

Los Alamos National Laboratory

P.0. Box 1663

Los Alamos, NM 87545

P. L. Cloke

Science Applications

International Corporation

101 Convention Center Bivd.

Suite 450

Las Vegas, NV 89109

2 Environmental Protection

Agency

J. Davidson, PM-221

E. Beh1

401 M Street S.W.

Washington, D.C. 20460

2 Golder Associates

D. Alexander

I. Miller

4104 184th Avenue N.E.

Redmond, WA 98052

B. Hastings

INTERA

2650 Park Tower Drive

Suite 800

Vienna, VA 22180
No. of

Copies

D. Hoxie

U.S. Geological Survey

P.0. Box 25046

Denver Federal Center

Denver, CO 80225

4 INTERA, Inc.

A. Brandstetter

R. W. Nelson

S. Pawah

A. E. Van Luik

101 Convention Center Drive

Phase II, Suite 540

Las Vegas, NV 89193

INTERA, Inc.

6850 Austin Center BTvd.

Suite 300

Austin, TX 78731

2 Lawrence Livermore National Laboratory

W. J. O'Connell

W. Halsey

University of California

P.0. Box 808

Livermore, CA 98052

T. H. Pigford

Department of Nuclear

Engineering

University of California

Berkeley, CA 94720

B. Ross

Disposal Safety, Inc. 1660 L Street N.W.

Suite 314

Washington, D.C. 20036 
No. of

Copies

2 Sandia National Laboratories

H. A. Dockery

M. A. Wilson

Division 6312

Albuquerque, NM 87185

2 Sandia National Laboratories

R. W. Barnard

T. E. Blejwas

Division 6313

Albuquerque, NM 87185

2 S.W. Research Institute

B. Sagar

J. Walton

622 Culebra Road

San Antonio, TX 78228

4 U.S. Department of Eneryy

J. M. Boak

J. R. Dyer

C. P. Gertz

J. J. Lorenz

Yucca Mountain Site Characterization Project Office

M/S 523

P.0. Box 98608

Las Vegas, NV 89193-8608

2 U.S. Nuclear Regulatory Commission

D. Code11

S. Coplan, NLS-260

Division of Engineering Safety Washington, D.C.
No. of

Copies

ONSITE

DOE Richland Field Office

D. C. Langstaff

2 Westinghouse Hanford Company

D. W. Langford

S. J. Ouderkirk

25 Pacific Northwest Laboratory

P. G. Doctor

K6-96

D. M. Elwood

D. W. Engel

P. W. Estinger (5)

M. D. Freshiey

J. M. Gephart

C. K. Hastings

C. T. Kincaid

M. R. Kreiter

K. M. Krupka

W. E. Nichols

D. L. Strenge

J. E. Tanner

R. E. Williford

Publishing Coordination

Technical Report Files

Routing

R. M. Ecker

J. W. Falco

M. J. Graham

R. L. Skaggs

P. C. Hays (1ast)
K7LAND

K7 -63

K6-96

$\mathrm{K} 6-77$

K6-86

$\mathrm{K} 6-96$

$K 6-77$

K7-90

K6-96

$\mathrm{K} 6-77$

K3-51

K3-70

K2-44 

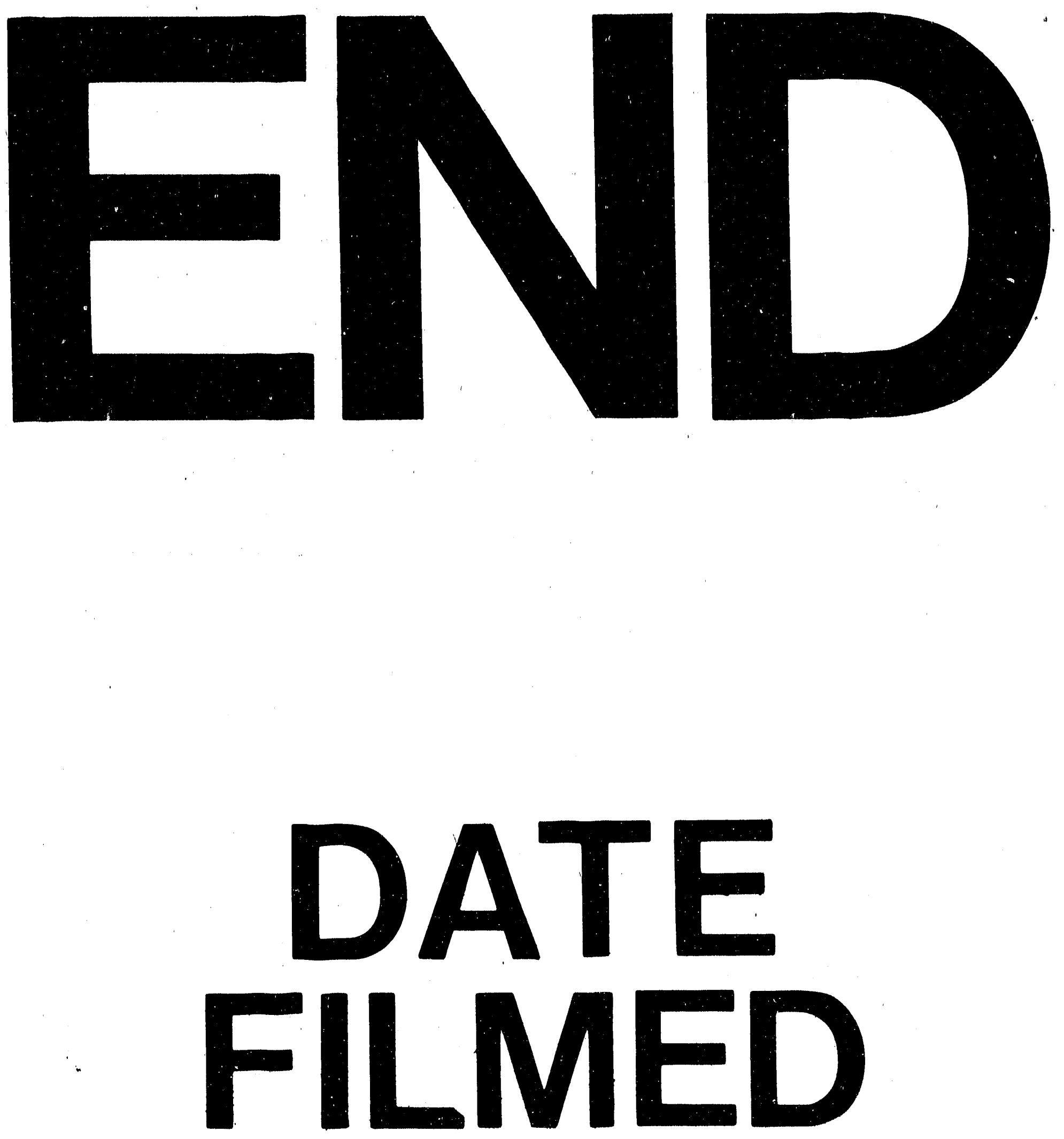

1

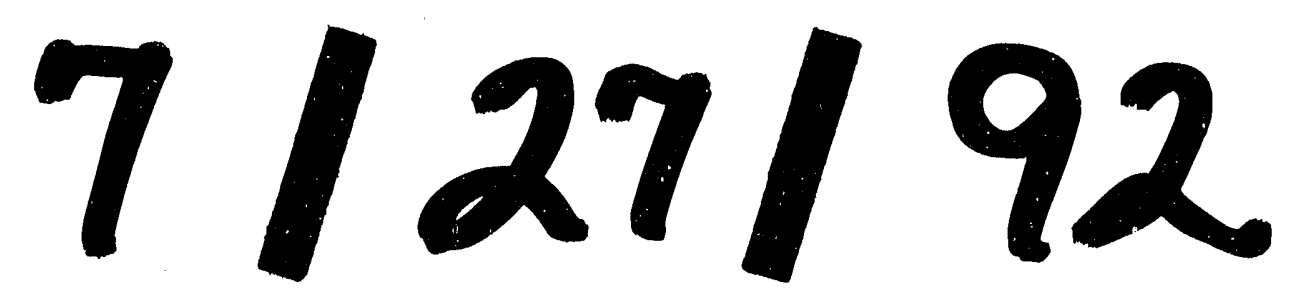




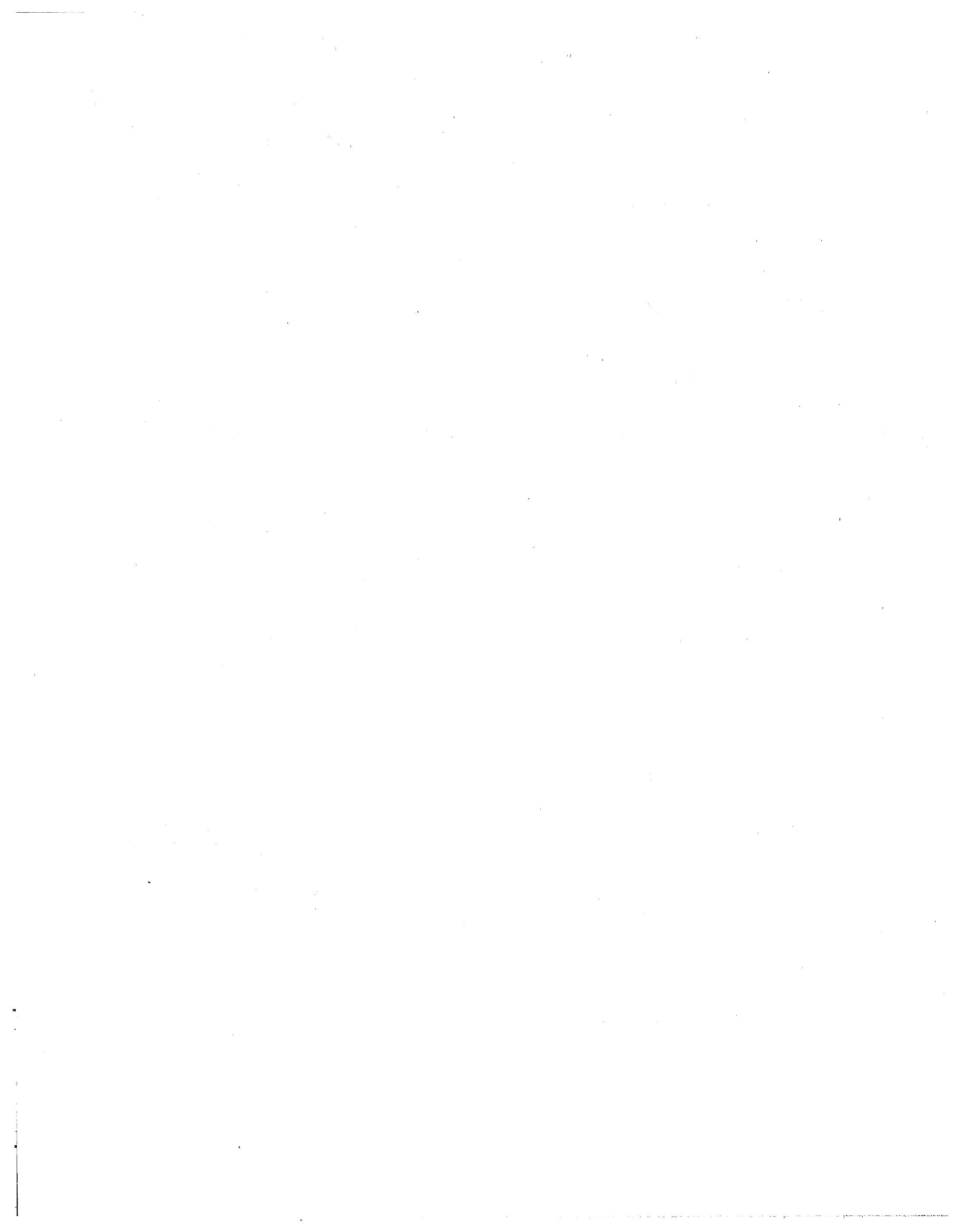

